JORGE ANDREY WILHELMS GUT

MODELAGEM MATEMÁTICA E VALIDAÇÃO EXPERIMENTAL DA PASTEURIZAÇÃO DE ALIMENTOS LÍQUIDOS EM TROCADORES DE CALOR A PLACAS 
JORGE ANDREY WILHELMS GUT

\section{MODELAGEM MATEMÁTICA E VALIDAÇÃO EXPERIMENTAL DA PASTEURIZAÇÃO DE ALIMENTOS LÍQUIDOS EM TROCADORES DE CALOR A PLACAS}

Tese apresentada à Escola Politécnica da Universidade de São Paulo para obtenção do título de Livre-Docente em Engenharia 


\section{FICHA CATALOGRÁFICA}

\section{Gut, Jorge Andrey Wilhelms}

Modelagem matemática e validação experimental da pasteurização de alimentos líquidos em trocadores de calor a placas $I$ J.A.W. Gut. -- São Paulo, 2012.

$119 \mathrm{p}$.

Tese (Livre-Docência) - Escola Politécnica da Universidade de São Paulo. Departamento de Engenharia Química.

1. Pasteurização 2. Alimentos líquidos 3. Trocadores de calor 4. Modelagem matemática 5. Processo térmico I. Universidade de São Paulo. Escola Politécnica. Departamento de Engenharia Química II. t. 


\section{AGRADECIMENTOS}

À Fundação de Amparo à Pesquisa do Estado de São Paulo (FAPESP) pelo Auxílio Pesquisa concedido para o financiamento deste projeto (Processo 2006/01628-0).

Ao Conselho nacional de Desenvolvimento Científico e Tecnológico (CNPq), à Coordenação de Aperfeiçoamento de Pessoal de Nível Superior (CAPES) e à Associação dos Engenheiros Politécnicos (AEP) pelas bolsas de mestrado e de iniciação científica concedidas aos participantes deste projeto.

Às alunas de mestrado Carola G.C.C. Gutierrez e Helena F. Aguiar e aos bolsistas de iniciação científica Eduardo F.T.S. Dias e André S. Yamashita pela dedicação no desenvolvimento deste projeto de pesquisa e no empenho para superar os obstáculos.

À Profa. Carmen C. Tadini pelo constante apoio e incentivo.

Aos funcionários do Laboratório de Engenharia de Alimentos da USP, José Ivan N. Leite e Vanessa Duarte pelo suporte.

Ao Departamento de Engenharia Química da Escola Politécnica da Universidade de São Paulo pelo apoio institucional.

A todos que, direta ou indiretamente, contribuíram com a execução deste trabalho. 


\section{RESUMO}

O processamento térmico de alimentos líquidos tem por objetivo inativar micro-organismos ou enzimas que comprometam a segurança ou a vida de prateleira do produto. $\mathrm{O}$ dimensionamento tradicional deste processo adota métodos simplificados com ampla margem de segurança, o que pode prejudicar atributos sensoriais ou nutricionais do produto. Pretendese neste trabalho desenvolver e validar um modelo matemático de natureza fenomenológica para simular um processo contínuo de pasteurização HTST (alta temperatura curto tempo) em trocadores de calor a placas visando determinar o histórico de temperatura do produto ao longo do processo, sobre o qual é avaliada a letalidade ou efeito letal. O modelo é baseado na determinação das temperaturas médias do produto em diversos pontos e nos tempos de residência médios de cada etapa. Um equipamento de escala laboratorial foi usado para aplicação e validação do modelo. Ensaios foram realizados para determinar a distribuição do tempo de residência (DTR) nos tubos de retenção em diferentes vazões e no trocador de calor a placas com diferentes arranjos de passes, assim como para determinar a distribuição de temperatura nas condições nominais de operação. O estudo da DTR permitiu diagnosticar o escoamento no equipamento e obter os tempos médios de residência. Foi necessário o desenvolvimento de uma metodologia para eliminar a distorção do sinal provocada pelo sistema de detecção do traçador, já que o volume interno do equipamento era pequeno. Indicadores enzimáticos foram desenvolvidos e testados para uso como integradores de tempo-temperatura na avaliação de processos HTST. A atividade residual após o processamento do indicador baseado em fosfatase alcalina em tampão fosfato foi determinada experimentalmente e comparada com a predição do modelo para diferentes temperaturas de processo com resultados satisfatórios. A distribuição de temperatura prevista pelo modelo teve excelentes resultados com desvios inferiores a $2{ }^{\circ} \mathrm{C}$. O modelo desenvolvido tem bom potencial para uso no dimensionamento, avaliação e otimização de processos contínuos de pasteurização.

Palavras chave: pasteurização, modelagem matemática, alimentos líquidos, trocador de calor, processo térmico. 


\begin{abstract}
The thermal processing of liquid foods aims the inactivation of micro-organisms or enzymes that compromise the safety or shelf life of the product. The traditional design adopts simplified methods that provide a wide safety margin, which can impair sensory or nutritional attributes of the product. The aim of this work was to develop and validate a phenomenological mathematical model to simulate the continuous HTST (high temperature short time) pasteurization in plate heat exchangers in order to determine the temperature history of the product throughout the process, over which the lethality or lethal effect is evaluated. The model is based on the determination of the average temperature of the product at various points and the average residence time of each step. A laboratory-scale equipment was used for application and validation of the model. Experiments were performed to determine residence time distribution (RTD) of the holding tubes at different flow rates and of the plate heat exchanger with different pass arrangements, as well as to determine the temperature distribution for the nominal operating conditions. The study of RTD enabled the diagnosis of the flow in the equipment and provided the average residence times. It was necessary to develop a method to eliminate the signal distortion caused by the detection system of the tracer, since the internal volume of the equipment was small. Enzymatic indicators were developed and tested for use as time-temperature integrators for HTST process assessment. The residual activity after processing the indicator based on alkaline phosphatase in phosphate buffer was experimentally determined and compared with the model prediction for different processing temperatures with satisfactory results. The temperature distribution predicted by the model had excellent results with errors below $2{ }^{\circ} \mathrm{C}$. The model has good potential for use in the design, evaluation and optimization of continuous processes of pasteurization.
\end{abstract}

Keywords: pasteurization, mathematical modeling, liquid foods, heat exchanger, continuous process 


\section{LISTA DE FIGURAS}

Figura 1.1.1. Esquema de uma unidade de pasteurização HTST destacando as seções do trocador a placas (Gut et al., 2005).

Figura 1.1.2. Esquema da linha de pasteurização HTST de leite com trocador de calor a placas com cinco seções (Alfa Laval, 2002).

Figura 3.1.1. Distribuições de temperatura e letalidade na pasteurização de gema de ovo determinadas por modelo matemático do processo (Gut et al., 2005).

Figura 3.1.2. Esquema de um trocador de calor a placas e principais dimensões da placa (Gut e Pinto, 2009).

Figura 3.1.3. Parâmetros de configuração do trocador de calor a placas e dois exemplos de configuração para um trocador com oito canais (Gut e Pinto, 2009).

Figura 3.3.1. Curvas adimensionais de DTR para o modelo de dispersão axial, mostrando o efeito do parâmetro do modelo (Gutierrez et al., 2010).

Figura 3.3.2. Curvas adimensionais de DTR para o modelo de tanques em série, mostrando o efeito do parâmetro do modelo (Gutierrez et al., 2010).

Figura 3.3.3. Curvas adimensionais de DTR para o modelo de convecção generalizado, mostrando o efeito do parâmetro do modelo (Gutierrez et al., 2010).

Figura 3.3.4. Curvas adimensionais de DTR para o modelo de associação PFR+CSTR, mostrando o efeito do parâmetro do modelo (Gutierrez et al., 2010).

Figura 4.1.1. Esquema do processo de pasteurização adotado para o desenvolvimento da modelagem matemática (Gut e Pinto, 2009).

Figura 4.3.1. Exemplo de histórico de temperatura do produto que pode ser obtido através da modelagem matemática do processo de pasteurização.

Figura 4.4.1. Exemplo de histórico de temperatura do produto com cálculo e integração da letalidade, incluindo o caso ideal de processamento isotérmico para comparação.

Figura 4.4.2. Exemplo de histórico de temperatura do produto com curva da letalidade integrada, incluindo o caso ideal de processamento isotérmico para comparação.

Figura 5.1.1. Pasteurizador FT-43A (Armfield, Reino Unido) com tanque de alimentação e bomba peristáltica à esquerda, tubo de retenção no centro, trocador de calor com três seções abaixo e rotâmetros no canto esquerdo superior (Aguiar, 2009).

Figura 5.1.2. Tubos de retenção T1 e T2 do pasteurizador FT-43A (Armfield, Reino Unido), indicando os volumes internos (o isolamento térmico do tubo T2 foi removido para melhor visualização) (Gutierrez et al., 2010).

Figura 5.1.3. Dimensões da gaxeta do trocador de calor do pasteurizador FT-43A (Armfield, Reino Unido), valores em milímetros (Gutierrez, 2008).

Figura 5.1.4. Determinação do volume interno do trocador de calor do pasteurizador FT-43A (Armfield, Reino Unido) com arranjo de passes em série $2 \times 1 / 2 \times 1$

(Galeazzo et al., 2006; Gutierrez, 2008). 
Figura 5.1.5. Determinação do volume interno do trocador de calor do pasteurizador

FT-43A (Armfield, Reino Unido) com arranjo de passes em paralelo $1 \times 2 / 1 \times 2$

(Galeazzo et al., 2006; Gutierrez, 2008).

Figura 5.2.1. Uso do sistema Reflectoquant ${ }^{\circledR}$ para determinação de atividade

enzimática: a) refletômetro e algumas tiras reacionais já usadas; b) reagentes e tiras antes e após uso.

Figura 5.2.2. a) Termômetro digital TH-060 (Instrutherm, Brasil), b) Sensor termopar de ponta exposta, c) embalagem de polietileno com amostra do indicador e sensor termopar (com cobertura plástica termo-retrátil).

Figura 5.2.3. Esquema do tratamento térmico descontínuo e exemplos de curvas de temperatura registradas (Aguiar et al., 2012).

Figura 5.3.1. Montagem experimental para ensaio de DTR nos tubos de retenção T1 e T2, indicando a injeção do traçador na alimentação e a detecção na saída do tubo.

Figura 5.3.2. Montagem experimental para ensaio de DTR no trocador de calor, indicando a injeção do traçador na alimentação e a detecção na saída do tubo (Gutierrez, 2008).

Figura 5.3.3. Montagem experimental para ensaio de DTR na célula do condutivímetro, indicando a injeção do traçador na entrada da célula (Gutierrez, 2008).

Figura 5.3.4. Representação dos sinais envolvidos em um ensaio de DTR indicando a distorção provocada pelo sistema de aquisição de dados, devido escoamento dentro da célula de condutividade elétrica (Gutierrez et al., 2010).

Figura 5.3.5. Representação das etapas para correção da distorção de sinal provocada pelo sistema de aquisição de dados usando a técnica de convolução matemática de sinais (Gutierrez et al., 2010).

Figura 5.3.6. Trocador de calor estudado, mostrando placas e gaxetas e representando o escoamento nos arranjos em paralelo e em série (Gutierrez et al., 2011).

Figura 5.4.1. Esquema do processo de pasteurização considerado na modelagem e identificação dos pontos correspondentes no equipamento estudado.

Figura 5.4.2. Sistema de aquisição de dados de temperatura CompactDAQ e sensores de temperatura inseridos nas conexões do pasteurizador a placas.

Figura 5.4.3. Telas principais do software de aquisição de temperaturas do processo, elaborado em ambiente LabView (National Instruments, EUA).

Figura 6.1.1. Resultados do ajuste do modelo cinético para representar a inativação enzimática dos indicadores POD (peroxidase), LPO (lactoperoxidase) e ALP (fosfatase alcalina) incluindo gráficos de paridade para a predição da atividade enzimática residual ( $A E R$ ) e curvas de inativação térmica em diferentes temperaturas de referência para o modelo ajustado (Aguiar et al., 2012).

Figura 6.1.2. Curvas de inativação térmica dos indicadores POD (peroxidase), LPO (lactoperoxidase) e ALP (fosfatase alcalina) de acordo com o modelo cinético ajustado para temperaturas de referência de 70 e $80^{\circ} \mathrm{C}$ (Aguiar et al., 2012). 
Figura 6.1.3. Históricos de temperatura do indicador ALP (fosfatase alcalina) nos ensaios de validação com aquecimento lento (Aguiar et al., 2012).

Figura 6.1.4. Resultados dos ensaios de validação para o ALP (fosfatase alcalina) com o gráfico de paridade para a predição da atividade enzimática residual e a distribuição do resíduo (experimental - predito) (Aguiar et al., 2012).

Figura 6.1.5. Resultados dos ensaios de validação para o indicador POD (peroxidase) com os gráficos de paridade para a predição da atividade enzimática residual em dois conjuntos de experimentos independentes (Aguiar et al., 2012).

Figura 6.2.1. Resultados do ajuste da equação de calibração do traçador, tendo a condutividade elétrica da solução em função da temperatura e da concentração de cloreto de sódio. Pontos são experimentais e linhas da equação ajustada.

Figura 6.2.2. Dados experimentais de DTR para estudo do sistema de aquisição de dados na vazão de $20 \mathrm{~L} / \mathrm{h}$ incluindo curva do modelo de dispersão axial $(P e=7,6)$ (Gutierrez et al., 2010).

Figura 6.2.3. Resultados dos ensaios de DTR do sistema de aquisição de dados de condutividade incluindo o tempo médio de residência e o número de Peclet ajustado em função da vazão volumétrica (Gutierrez et al., 2010).

Figura 6.2.4. Exemplos de ajustes de modelos de DTR usando dados coletados para os tubos de retenção T1 e T2 (Gutierrez et al., 2010).

Figura 6.2.5. Tempos médios de residência e tempos espaciais para os tubos de retenção T1 e T2 em função da vazão (Gutierrez et al., 2010).

Figura 6.2.6. Tempos mínimos de residência para os tubos de retenção T1 e T2 em função da vazão, de acordo com o modelo de convecção generalizado (Gutierrez et al., 2010).

Figura 6.2.7. Curvas de DTR dos tubos de retenção T1 e T2 de acordo com o modelo de convecção generalizado ajustado (Gutierrez et al., 2010).

Figura 6.2.8. Exemplos de ajustes de modelos de DTR usando dados coletados para o trocador de calor a placas, neste caso um arranjo em série com 10 passes na vazão de 20 L/h (Gutierrez et al., 2011).

Figura 6.2.9. Média do somatório do erro quadrático para ajustes de modelos de DTR, nos ensaios com o trocador de calor com arranjo em série, em função do número de passes (Gutierrez et al., 2011).

Figura 6.2.10. Parâmetros volumétricos do modelo de associação PFR+CSTR ajustados para o estudo de DTR no trocador de calor com arranjos em série (curvas $a, b$ e $c$ ) e paralelo (curvas $d$, $e$ e $f$ ) (Gutierrez et al., 2011).

Figura 6.2.11. Identificação dos parâmetros volumétricos envolvidos no modelo de associação PFR+CSTR para representação de curvas de DTR (Gutierrez et al., 2011).

Figura 6.2.12. Contribuição relativa dos parâmetros volumétricos do modelo de associação PFR+CSTR ajustados para o estudo de DTR no trocador de calor com arranjos em série (a) e em paralelo (b) (Gutierrez et al., 2011). 
Figura 6.2.13. Curvas $E(t)$ para o trocador de calor a placas, de acordo com o modelo de associação PFR+CSTR ajustado, com arranjo em série (a) ou arranjo em paralelo (b), na vazão de $20 \mathrm{~L} / \mathrm{h}$ (Gutierrez et al., 2011).

Figura 6.2.14. Volume ativo do trocador calor em função do número de passes para arranjo em série, de acordo com os modelos de DTR ajustados (Gutierrez et al., 2011).

Figura 6.2.15. Dados experimentais de DTR para o processo de pasteurização na vazão de $15 \mathrm{~L} / \mathrm{h}$ com o ajuste pelo modelo de dispersão axial (Gutierrez, 2008).

Figura 6.2.16. Dados experimentais de DTR para o processo de pasteurização na vazão de 20 L/h com o ajuste pelo modelo de dispersão axial (Gutierrez, 2008).

Figura 6.2.17. Dados experimentais de DTR para o processo de pasteurização na vazão de 25 L/h com o ajuste pelo modelo de dispersão axial (Gutierrez, 2008).

Figura 6.2.18. Tempo médio de residência no processo de pasteurização em função da vazão de processamento de acordo com o modelo de dispersão axial ajustado (Gutierrez, 2008).

Figura 6.2.19. Número de Peclet no processo de pasteurização em função da vazão de processamento de acordo com o modelo de dispersão axial ajustado (Gutierrez, 2008).

Figura 6.2.20. Tempo médio de residência no processo de pasteurização em função da vazão de processamento de acordo com o modelo de dispersão axial ajustado incluindo curvas de tempo espacial e de tempo médio obtido a partir do volume ativo.

Figura 6.3.1. Comparação entre os históricos de temperatura preditos pelos Modelos 2 e 3 e os pontos experimentais para o ensaio de pasteurização HTST.

Figura 6.3.2. Comparação entre os perfis de letalidade avaliados sobre os históricos de temperatura preditos pelos Modelos 1, 2 e 3 para as condições de pasteurização HTST.

Figura 6.3.3. Históricos de temperatura (linhas pontilhadas) e perfis de letalidade (linhas contínuas) preditos pela simulação do Modelo 2 nas condições de pasteurização HTST considerando: tempo espacial, tempo médios de residência e tempo mínimo de residência.

Figura 6.4.1. Históricos de temperatura experimentais e obtidos a partir do Modelo 2 para os ensaios de pasteurização do indicador POD em diferentes temperaturas de processo, incluindo o caso ideal de tubo isotérmico com aquecimento e resfriamento instantâneos.

Figura 6.4.2. Evolução da atividade enzimática residual do indicador POD predita para os ensaios de pasteurização em diferentes temperaturas de processamento, incluindo o valor experimental determinado na saída do processo.

Figura 6.4.3. Históricos de temperatura experimentais e obtidos a partir do Modelo 2 para o primeiro conjunto de ensaios de pasteurização do indicador ALP em diferentes temperaturas de processo, incluindo o caso ideal de tubo isotérmico com aquecimento e resfriamento instantâneos. 
Figura 6.4.4. Evolução da atividade enzimática residual do indicador ALP predita para o primeiro conjunto de ensaios de pasteurização em diferentes temperaturas de processamento, incluindo o valor experimental determinado na saída do processo.

Figura 6.4.5. Históricos de temperatura experimentais e obtidos a partir do Modelo 2 para o segundo conjunto de ensaios de pasteurização do indicador ALP em diferentes temperaturas de processo, incluindo o caso ideal de tubo isotérmico com aquecimento e resfriamento instantâneos.

Figura 6.4.6. Evolução da atividade enzimática residual do indicador ALP predita para o segundo conjunto de ensaios de pasteurização em diferentes temperaturas de 105 processamento, incluindo o valor experimental determinado na saída do processo. 


\section{LISTA DE TABELAS}

Tabela 4.3.1. Valores de temperatura e de tempo de residência médio para o exemplo ilustrativo de obtenção do histórico de temperatura do produto no processo de pasteurização.

Tabela 4.4.1. Contribuição de cada trecho sobre a letalidade integrada para o exemplo ilustrativo de avaliação de letalidade.

Tabela 5.1.1. Características das placas do trocador de calor do pasteurizador FT43A (Armfield, Reino Unido) (Gut et al., 2004).

Tabela 5.1.2. Parâmetros de configuração das seções de troca térmica do pasteurizador a placas FT-43A (Armfield, Reino Unido).

Tabela 5.1.3. Volumes internos parciais do trocador de calor a placas.

Tabela 5.1.4. Identificação e dimensões das conexões existentes na linha do produto do pasteurizador a placas FT-43A (Armfield, Reino Unido).

Tabela 5.3.1. Determinação numérica do sinal de saída através da convolução discreta do sinal de entrada com a curva $E$ do processo (Gutierrez et al., 2010).

Tabela 6.1.1. Parâmetros cinéticos ajustados para a inativação térmica dos indicadores POD (peroxidase), LPO (lactoperoxidase) e ALP (fosfatase alcalina) (Aguiar et al., 2012).

Tabela 6.2.1. Valores minimizados do somatório do erro quadrático $\left(S E Q \times 10^{3}, \mathrm{~s}^{-2}\right)$ para ajuste dos modelos de DTR aos dados coletados com os tubos de retenção T1 e T2 (Gutierrez et al., 2010).

Tabela 6.2.2. Valores minimizados do somatório do erro quadrático (SEQ $\left.\times 10^{3}, \mathrm{~s}^{-2}\right)$ para ajuste dos modelos de DTR aos dados coletados no processo de pasteurização.

Tabela 6.2.3. Volumes internos dos trechos que compõem o percurso do produto alimentício e tempo espacial calculado para vazão volumétrica de $20 \mathrm{~L} / \mathrm{h}$.

Tabela 6.2.4. Volumes ativos dos trechos que compõem o percurso do produto alimentício e tempo médio de residência para vazão volumétrica de $20 \mathrm{~L} / \mathrm{h}$.

Tabela 6.2.5. Tempo mínimo de residência dos trechos que compõem o percurso do produto alimentício para vazão volumétrica de $20 \mathrm{~L} / \mathrm{h}$.

Tabela 6.3.1. Temperaturas experimentais e preditas pelos modelos matemáticos para as condições de processamento HTST do equipamento.

Tabela 6.3.2. Verificação da conservação de energia nos trocadores de calor no ensaio de pasteurização HTST.

Tabela 6.3.3. Cargas térmicas experimentais e calculadas pelos modelos matemáticos para os trocadores de calor no ensaio de processamento HTST.

Tabela 6.3.4. Parâmetros do modelo calculados para a simulação do ensaio de pasteurização em condições HTST.

Tabela 6.3.5. Parâmetros do modelo calculados para os trocadores na simulação do ensaio de pasteurização em condições HTST. 
Tabela 6.3.6. Contribuição de cada trecho sobre a letalidade integrada para a simulação do Modelo 2 referente ao estudo de caso de pasteurização HTST.

Tabela 6.4.1. Atividade enzimática residual do indicador POD predita para os ensaios em diferentes temperaturas de processamento, incluindo o valor experimental.

Tabela 6.4.2. Atividade enzimática residual do indicador ALP predita para o primeiro conjunto de ensaios em diferentes temperaturas de processamento, incluindo o valor experimental.

Tabela 6.4.3. Atividade enzimática residual do indicador ALP predita para o segundo conjunto de ensaios em diferentes temperaturas de processamento, incluindo o valor experimental. 


\section{LISTA DE ABREVIATURAS E SIGLAS}

ALP indicador enzimático baseado em fosfatase alcalina em tampão fosfato

CFD Computational fluid dynamics (dinâmica dos fluidos computacional)

CSTR Continuous stirred-tank reactor (reator de tanque de mistura)

DMC Dynamic matrix control (controle de matriz dinâmica)

DTR Distribuição do tempo de residência

HTST High temperature short time (alta temperatura e curto tempo)

LPO indicador enzimático baseado em lactoperoxidase em tampão fosfato

MPC Model predictive control (controle de modelo preditivo)

PID Proportional-Integral-Derivative (proporcional-integral-derivativo)

PFR Plug flow reactor (reator de escoamento pistonado)

POD indicador enzimático baseado em peroxidase em tampão fosfato

TTI Time-temperature integrator (integrador de tempo-temperatura)

UHT Ultra high temperature (ultra alta temperatura) 


\section{LISTA DE SÍMBOLOS}

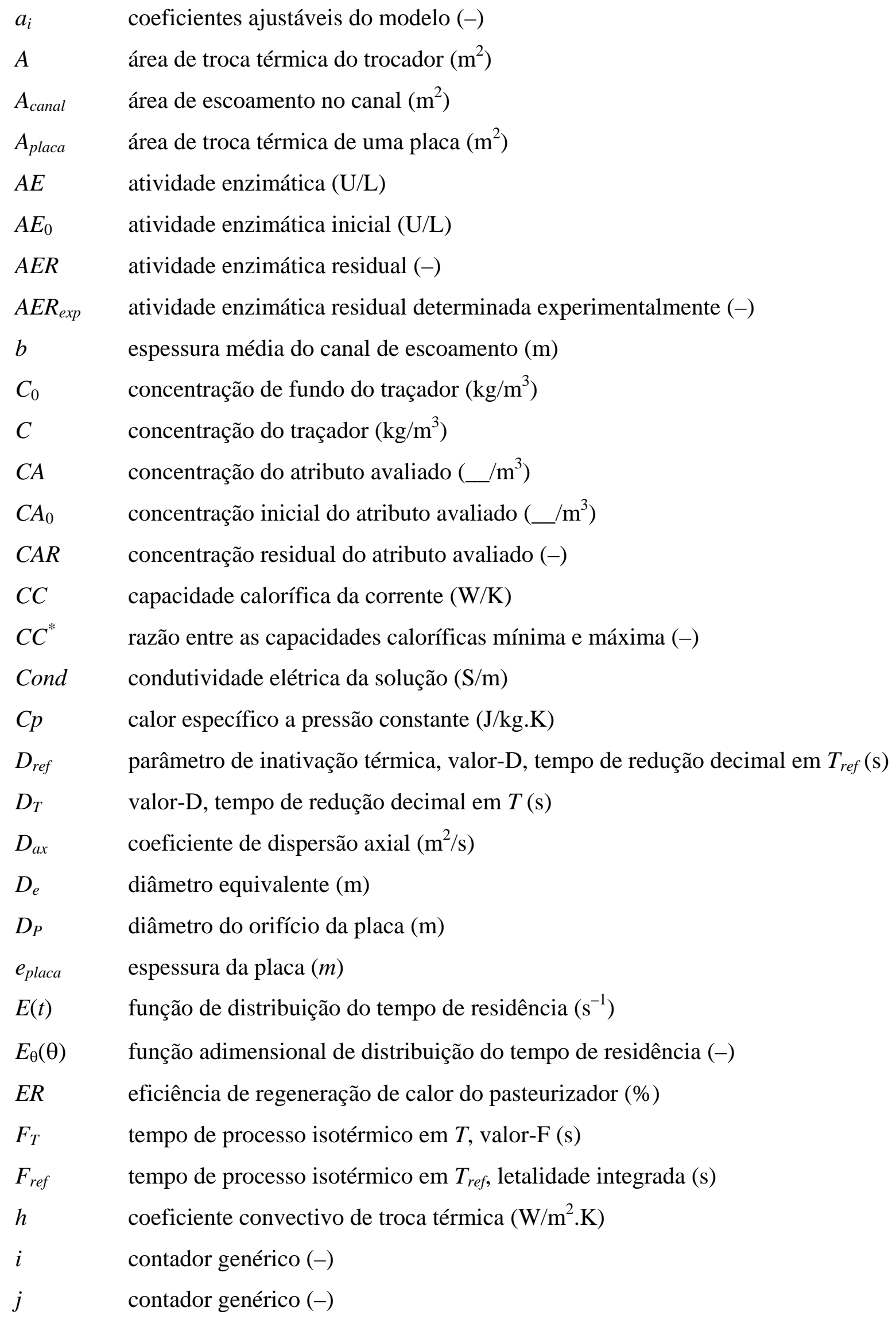




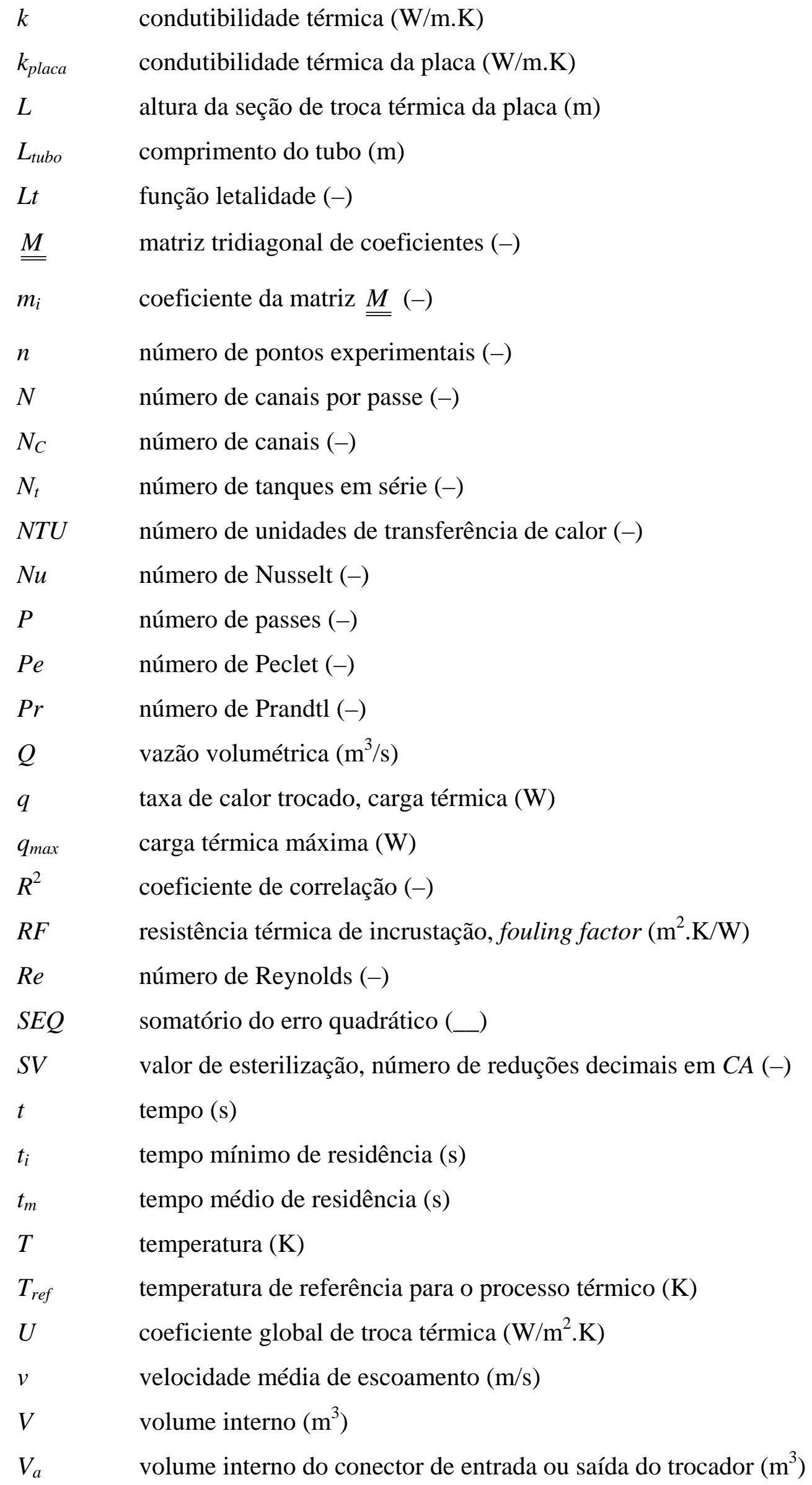




$\begin{array}{ll}V_{\text {ativo }} & \text { volume ativo }\left(\mathrm{m}^{3}\right) \\ V_{b} & \text { volume interno da passagem entre dois canais }\left(\mathrm{m}^{3}\right) \\ V_{c} & \text { volume interno do canal }\left(\mathrm{m}^{3}\right) \\ V_{d} & \text { volume interno } V_{b} \text { sem a espessura da placa }\left(\mathrm{m}^{3}\right) \\ V_{\text {mix }} & \text { volume do CSTR, volume de mistura }\left(\mathrm{m}^{3}\right) \\ V_{\text {morto }} & \text { volume morto }\left(\mathrm{m}^{3}\right) \\ V_{\text {plug }} & \text { volume do PFR, volume de escoamento pistonado }\left(\mathrm{m}^{3}\right) \\ W & \text { largura da placa medido entre as gaxetas }(\mathrm{m}) \\ W & \text { vazão mássica da corrente }(\mathrm{kg} / \mathrm{s}) \\ X & \text { direção tangencial ao escoamento nos canais }(\mathrm{m}) \\ Y_{f} & \text { parâmetro binário para tipo de fluxo nos canais }(-) \\ Y_{h} & \text { parâmetro binário para localização do fluido quente no trocador }(-) \\ z & \text { parâmetro de inativação térmica, valor-z }\left({ }^{\circ} \mathrm{C}\right)\end{array}$

\section{Símbolos Gregos}

$\alpha \quad$ fração inicial da isoenzima termorresistente (-)

$\alpha^{I} \quad$ coeficiente de troca térmica adimensional para o lado I (-)

$\alpha^{I I} \quad$ coeficiente de troca térmica adimensional para o lado II (-)

$\beta \quad$ ângulo de inclinação das ranhuras da corrugação $\left(\left(^{\circ}\right)\right.$

$\Gamma \quad$ função matemática gama (-)

$\Delta t \quad$ passo de tempo (s)

$\Delta T_{\text {tubo }} \quad$ queda de temperatura no tubo de retenção $(\mathrm{K})$

$\varepsilon \quad$ eficiência térmica do trocador (\%)

$\varepsilon_{\mathrm{cc}} \quad$ eficiência térmica do trocador puramente contracorrente (\%)

$\eta \quad$ direção tangencial ao escoamento nos canais, adimensional (-)

$\theta \quad$ tempo adimensional (-)

$\theta_{0} \quad$ tempo mínimo de residência adimensional (-)

$\theta_{P} \quad$ tempo de residência adimensional do PFR (-)

$\mu \quad$ viscosidade (Pa.s)

$\pi \quad$ constante pi, razão entre perímetro e diâmetro de um círculo $(\pi=3,1416)$

$\rho \quad$ densidade $\left(\mathrm{kg} / \mathrm{m}^{3}\right)$

$\tau \quad$ tempo espacial, tempo médio de residência teórico (s)

$\tau_{\text {mix }} \quad$ tempo espacial do CSTR (s) 


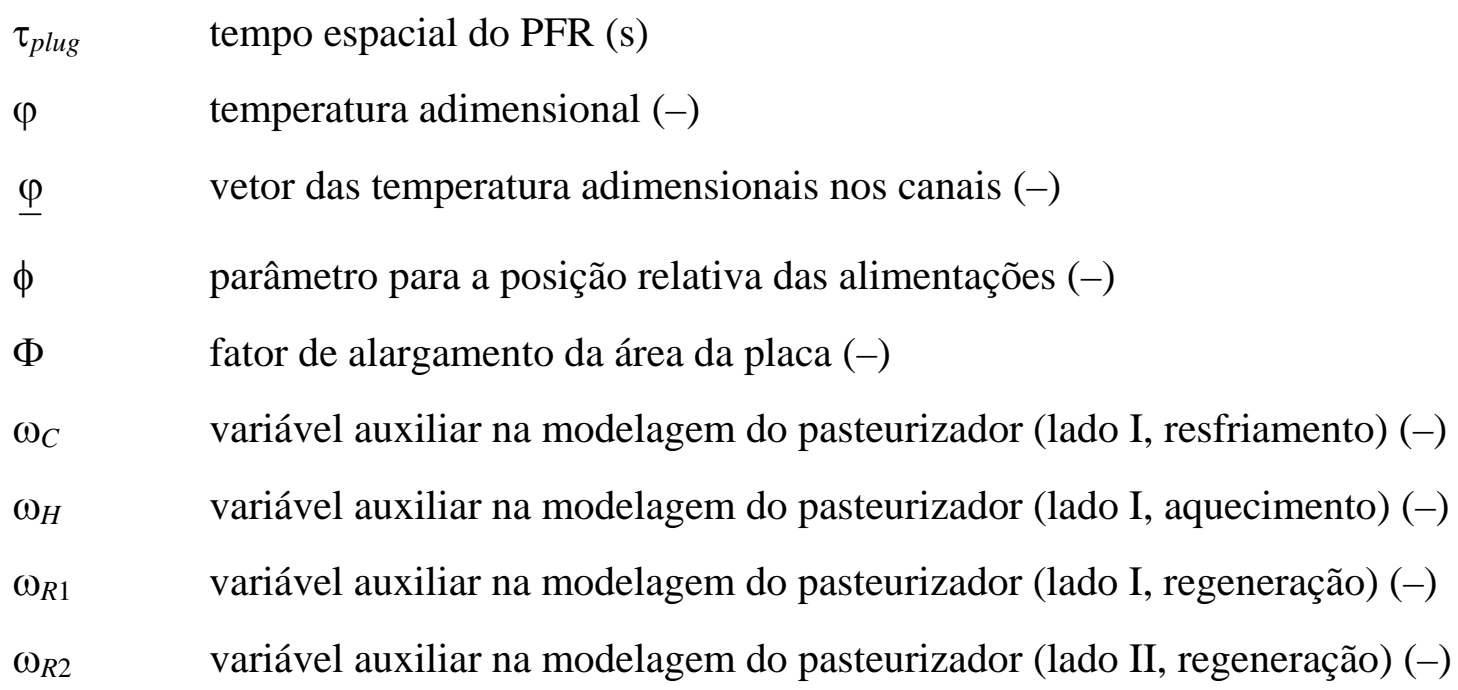

\section{Subscritos}

1 fração termorresistente da enzima

2 fração termolábil da enzima

$c^{*} \quad$ referente ao ponto * no diagrama do processo (linha de resfriamento)

$c 1-2$ referente ao trecho $\mathrm{c} 1 \rightarrow \mathrm{c} 2$ no diagrama do processo (linha de resfriamento)

$h^{*} \quad$ referente ao ponto * no diagrama do processo (linha de aquecimento)

h1-2 referente ao trecho $\mathrm{h} 1 \rightarrow \mathrm{h} 2$ no diagrama do processo (linha de aquecimento)

$i \quad$ elemento genérico $i$

ent entrada

$j \quad$ elemento genérico $j$

sai saída

$p^{*} \quad$ referente ao ponto $\mathrm{p}^{*}$ no diagrama do processo (linha do produto)

$p^{* \_*} \quad$ referente ao trecho $\mathrm{p}^{*} \rightarrow \mathrm{p}^{*}$ no diagrama do processo (linha do produto)

ref na temperatura de referência

\section{Sobrescritos}

C seção de resfriamento do pasteurizador

frio fluido frio ou lado frio do trocador

H seção de aquecimento do pasteurizador

I lado I do trocador (conjunto dos canais ímpares)

II lado II do trocador (conjunto dos canais pares)

quente fluido quente ou lado quente do trocador

$R$ seção de regeneração do pasteurizador 


\section{SUMÁRIO}

1. INTRODUÇÃO

1.1 Motivação do trabalho 1

2. OBJETIVOS 6

3. REVISÃO BIBLIOGRÁFICA

$\begin{array}{ll}3.1 \text { Modelagem matemática de processos térmicos contínuos } & 7\end{array}$

$\begin{array}{ll}3.1 .1 \text { Trocadores de calor a placas } & 10\end{array}$

$\begin{array}{ll}3.2 & \text { Integradores de tempo-temperatura } \\ \end{array}$

3.3 Distribuição do tempo de residência 14

3.3.1 Teoria da distribuição do tempo de residência 15

$\begin{array}{ll}\text { 3.3.2 Modelos de distribuição do tempo de residência } & 17\end{array}$

4. MODELAGEM MATEMÁTICA 23

$\begin{array}{ll}\text { 4.1 Modelagem do processo de pasteurização } & 23\end{array}$

$\begin{array}{ll}\text { 4.2 Modelagem da troca de calor } & 25\end{array}$

4.2.1 Modelo térmico de um trocador de calor a placas 29

4.3 Modelagem do escoamento 31

$\begin{array}{ll}\text { 4.4 Modelagem da letalidade } & 33\end{array}$

5. MATERIAIS E MÉTODOS 38

$\begin{array}{ll}\text { 5.1 Equipamento de processamento térmico } 38 & 38\end{array}$

5.2 Desenvolvimento dos indicadores enzimáticos 44

5.2.1 Preparação dos indicadores enzimáticos 44

5.2.2 Determinação da atividade enzimática $\quad 45$

5.2.3 Tratamento térmico descontínuo $\quad 47$

5.2.4 Modelo cinético 49

5.2.5 Tratamento térmico descontínuo para validação 51

5.3 Determinação da distribuição do tempo de residência 51

5.3.1 Distribuição do tempo de residência na célula de condutividade $\quad 54$

5.3.2 Correção para detecção não-ideal do traçador 55 
5.3.3 Distribuição do tempo de residência no processo

5.4 Ensaios de validação do modelo

5.4.1 Distribuição de temperatura 59

5.4.2 Uso dos indicadores enzimáticos

6. RESULTADOS E DISCUSSÃO

6.1 Desenvolvimento dos indicadores enzimáticos 64

6.1.1 Ajuste do modelo cinético $\quad 64$

6.1.2 Validação do modelo cinético $\quad 67$

6.2 Determinação da distribuição do tempo de residência 71

$\begin{array}{ll}\text { 6.2.1 Calibração do traçador } & 71\end{array}$

6.2.2 Distribuição do tempo de residência na célula de condutividade 72

6.2.3 Distribuição do tempo de residência nos tubos de retenção 74

6.2.4 Distribuição do tempo de residência no trocador de calor 80

6.2.5 Distribuição do tempo de residência no processo 88

6.2.6 Tempos médios de residência nas etapas do processo 92

6.3 Determinação da distribuição de temperatura e validação dos modelos 94

6.4 Uso dos indicadores enzimáticos e validação do modelo matemático $\quad 100$

7. CONCLUSÕES 106

8. REFERÊNCIAS BIBLIOGRÁFICAS 108

APÊNDICE A: Instruções para medição da atividade enzimática 117 


\section{INTRODUÇÃO}

\subsection{Motivação do trabalho}

O processo contínuo de pasteurização HTST (high temperature short time) destina-se ao tratamento térmico de produtos alimentícios líquidos para a inativação de micro-organismos patogênicos, micro-organismos deterioradores e/ou enzimas indesejáveis. A pasteurização busca garantir a segurança e a qualidade microbiológica do alimento e aumentar a sua vida de prateleira, mas com mínimo impacto sobre características sensoriais e valor nutricional do alimento (Lewis e Heppell, 2000). Em comparação com a esterilização, a pasteurização é um tratamento térmico leve no qual há um compromisso entre a segurança e a qualidade do produto final. Quando se deseja um tratamento mais severo para prolongar a vida de prateleira ou inativar esporos termoresistentes, opta-se pelo processo de esterilização UHT (ultra high temperature). O processamento UHT é também conhecido por “esterilização comercial”, pois o produto final não fica totalmente livre de micro-organismos. Mesmo assim, aqueles que sobrevivem dificilmente se desenvolvem nas condições de armazenamento do produto.

Nos processos de pasteurização HTST de alimentos de baixa viscosidade e sem material particulado é difundido o uso de trocadores de calor a placas para o aquecimento e o resfriamento indireto. Este tipo de trocador de calor oferece grandes vantagens como fácil higiene interna, alta eficiência térmica, turbulência induzida no escoamento em baixa velocidade, viabilidade econômica para fabricação em aço inoxidável, boa distribuição de temperatura e construção compacta e modular que permite acomodar várias seções de troca térmica em um mesmo pedestal (Kakaç e Liu, 2002).

A função do trocador de calor é de aquecer o alimento até a temperatura de pasteurização especificada para o processo e resfriá-lo até a temperatura de armazenamento ou embalagem. Para fazer isso de forma eficiente, a entalpia do produto quente é recuperada no pré-aquecimento do produto bruto em uma seção de regeneração térmica. A Figura 1.1.1 mostra como exemplo o esquema simplificado de uma unidade de pasteurização HTST com um trocador de calor a placas de três seções e os circuitos de aquecimento e resfriamento. A Figura 1.1.2 apresenta de forma esquemática um processo industrial de pasteurização de leite com um trocador de calor com cinco seções. 

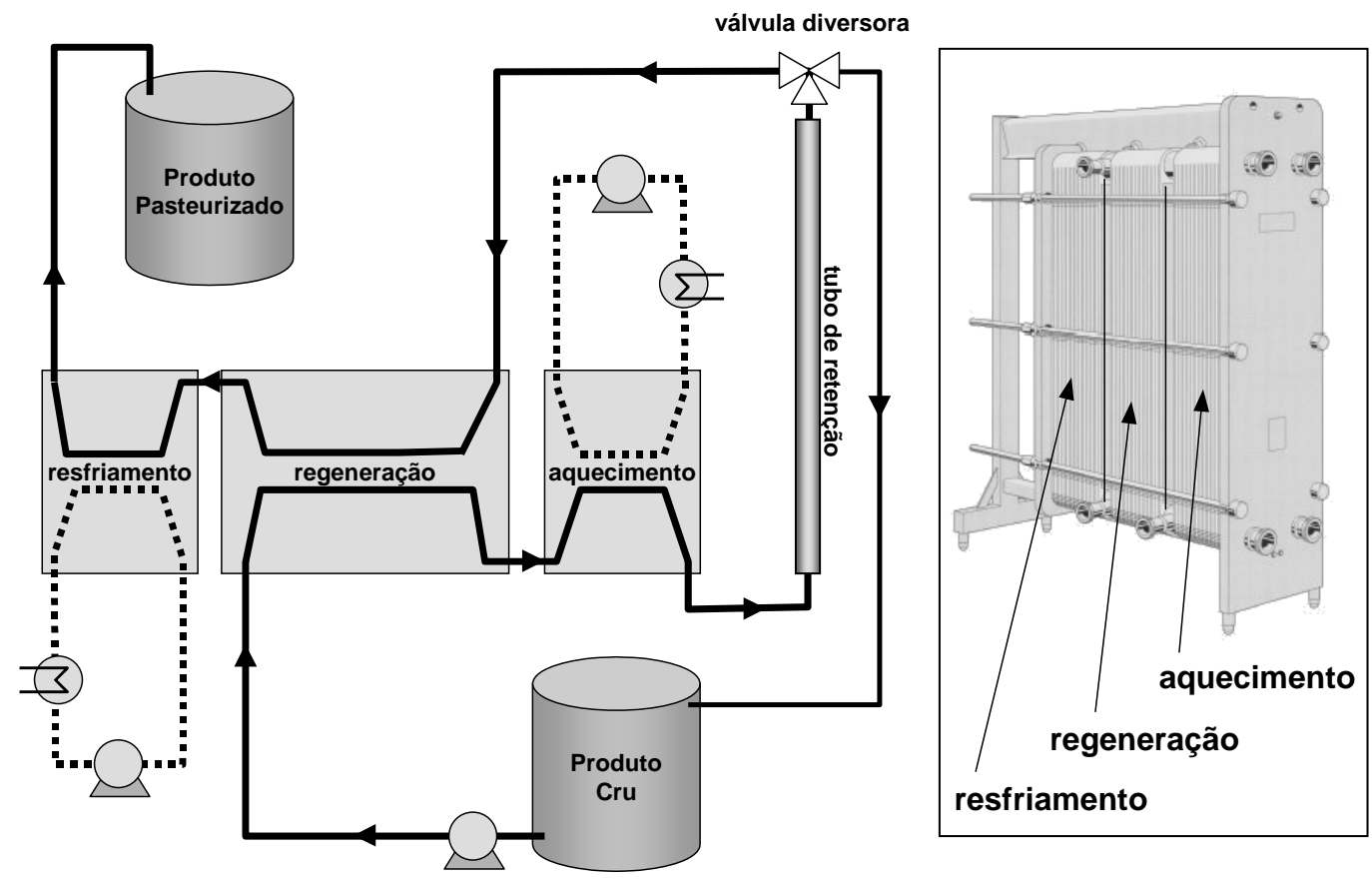

Figura 1.1.1. Esquema de uma unidade de pasteurização HTST destacando as seções do trocador a placas (Gut et al., 2005).

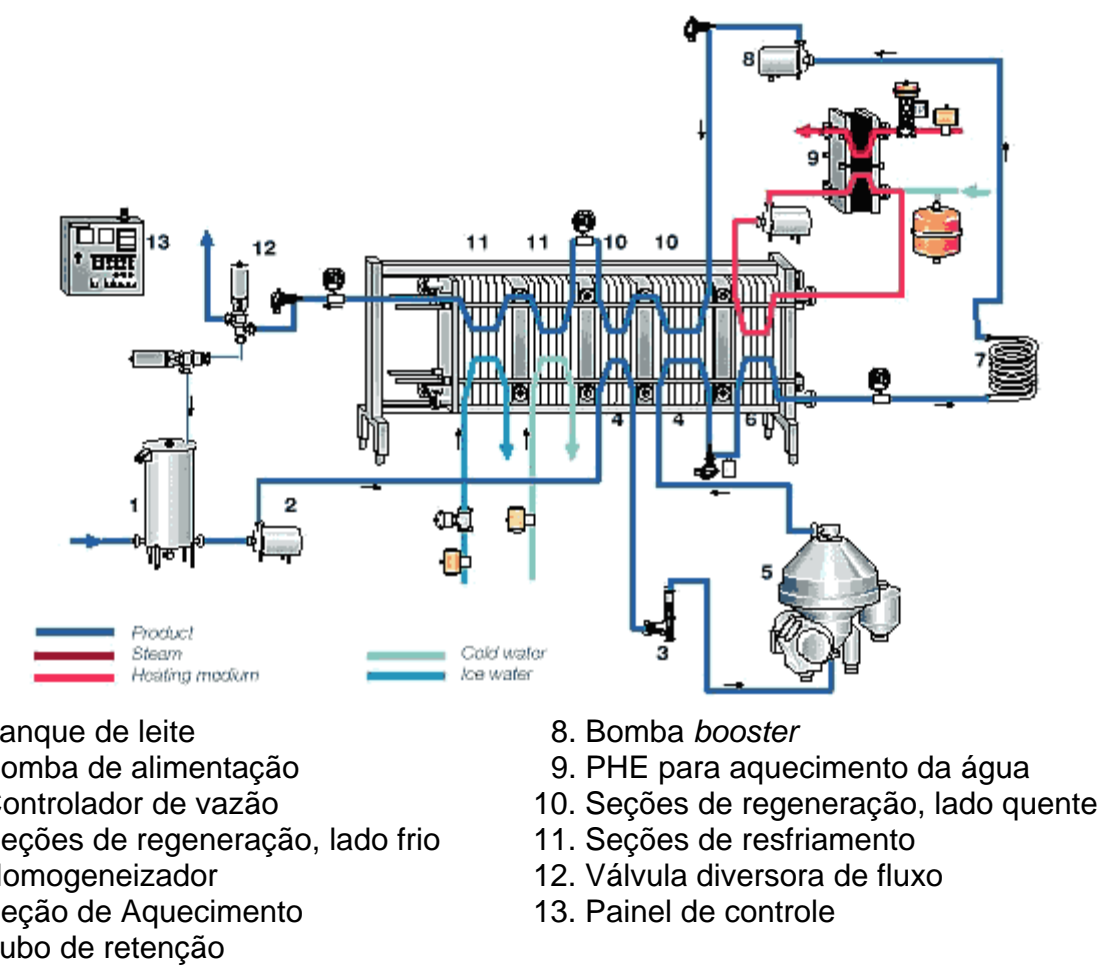

Figura 1.1.2. Esquema da linha de pasteurização HTST de leite com trocador de calor a placas com cinco seções (Alfa Laval, 2002).

As condições de temperatura e de tempo do tratamento térmico nos processos HTST são geralmente definidas tendo como base o micro-organismo patogênico mais termoresistente presente no alimento, como por exemplo, Mycobacterium tuberculosis ou Coxiella burnetti 
para o leite bovino, Salmonella senftenberg para o ovo líquido ou Escherichia coli para sucos de frutas ácidas (Lewis e Heppell, 2000). As condições são definidas de forma a atingir um número desejado de reduções decimais para a população do micro-organismo alvo. Por exemplo, para assegurar 12 reduções decimais na população de Mycobacterium tuberculosis no leite de vaca, realiza-se a sua pasteurização a $72{ }^{\circ} \mathrm{C}$ com um tempo de retenção de $15 \mathrm{~s}$ (Lewis, 1999).

O tubo de retenção do pasteurizador (ver Figuras 1.1.1 e 1.1.2) é dimensionado para atender ao tempo de retenção na temperatura de pasteurização desejada. Como a temperatura na saída do tubo deve ter uma variação muito pequena para evitar que o produto tenha de retornar ao tanque de alimentação (válvula diversora de fluxo) ou que ele seja sobreprocessado, o projeto e o controle do processo são fundamentais (Ibarrola et al., 2002).

A avaliação do grau do tratamento térmico ou do efeito letal de uma unidade de processamento térmico pode ser feita de duas formas: 1) teoricamente através da análise do perfil de temperatura vs. distribuição de tempo de residência, ou 2) experimentalmente utilizando integradores de tempo-temperatura (Lewis e Heppell, 2000).

Um integrador de tempo-temperatura (TTI, time-temperature integrator) é um componente termicamente sensível, intrínseco ou extrínseco ao alimento, que permite quantificar o impacto do processo térmico sobre um atributo de segurança ou de qualidade, sem conhecimento do histórico de temperatura. As alterações que o processo provoca no TTI devem ser irreversíveis e de dinâmica similar ao atributo que é estudado. Por exemplo, na pasteurização HTST do leite bovino, objetiva-se a destruição da bactéria Mycobacterium tuberculosis. A avaliação da eficiência do processo através de contagens microbiológicas na entrada e na saída da linha de processo seria custosa e demorada. Por este motivo utilizam-se como TTI a enzima fosfatase alcalina, natural do leite e inativada pelo processo térmico nas mesmas condições que a bactéria alvo.

Para o projeto e dimensionamento de uma unidade de pasteurização contínua, assume-se que a inativação térmica ocorre apenas dentro do tubo de retenção a uma temperatura constante e no tempo mínimo de residência (velocidade máxima no centro do tubo). Embora irreais, estas hipóteses simplificam muito o dimensionamento e favorecem a segurança do processo já que desprezam o tratamento térmico que ocorre dentro dos trocadores de calores e aquele associado às condições não isotérmicas do tubo de retenção e sua distribuição do tempo de residência. Na prática, tem-se um produto sobre-processado de menor qualidade sensorial e nutricional e com um gasto adicional de energia para aquecimento e resfriamento. Grijspeerdt et al. (2004), por exemplo, analisaram três sistemas de esterilização UHT de leite 
e verificaram que todos estavam super-dimensionados com respeito à inativação bacteriana. Já Landfeld et al. (2002) analisaram uma unidade pasteurizadora de gema de ovo e constataram que o tempo de retenção estava $48 \%$ acima do valor requerido pela regulamentação local para pasteurização da gema.

Com a recente valorização de hábitos saudáveis, há uma preocupação crescente com o valor nutricional dos alimentos e com a presença de compostos que melhorem a saúde. Como consequência, valorizaram-se os produtos alimentícios minimamente processados que conservam as características e propriedades do produto in natura. Segundo Gould (1996) e Nott e Hall (1999), esta é a uma forte tendência de desenvolvimento na área de preservação de produtos alimentícios. De acordo com Awuah et al. (2007), a demanda por produtos alimentícios de alta qualidade tem inspirado os pesquisadores e produtores a rever os métodos de processamento tradicionais. A indústria de processamento tem sido compelida a adotar tecnologias de alta eficiência energética e a oferecer produtos seguros e de qualidade. Entretanto, novos sistemas de controle e monitoramento precisam de forte validação e verificação para que possam ser adotados.

Diversos estudos têm sido realizados para quantificar o impacto do processamento industrial sobre as características “saudáveis” dos alimentos, por exemplo, Efigênia et al. (1997) analisaram a perda de qualidade nutricional do leite pasteurizado no Brasil. Pátkai et al. (1997) reportam que durante a pasteurização de sucos de frutas ocorre a decomposição de cerca de $40 \%$ do agente anti-cancerígeno betamina presente na fruta “in natura”. Van Boekel e Jongen (1997) ressaltam a necessidade de métodos para medir a atividade biológica de vitaminas, enzimas e outros compostos presentes em alimentos, para otimizar as etapas do processo produtivo visando a melhoria da qualidade do produto.

Trabalhos para quantificar a perda de qualidade sensorial também têm sido desenvolvidos, como por exemplo os estudos de Lee e Coates (2003) e Jordán et al. (2003) sobre mudanças de cor e perda do aroma, respectivamente, no suco de laranja processado. Já Valero et al. (2000) estudaram o efeito da pasteurização convencional e por microondas sobre as qualidades sensoriais do leite.

De acordo com Grijspeerdt et al. (2003), uma modelagem rigorosa do processo é necessária para que se possa simular e otimizar o tratamento térmico que ocorre no pasteurizador visando determinar condições ótimas de operação para minimizar os efeitos indesejáveis do aquecimento, garantir a qualidade microbiológica do alimento e reduzir os custos operacionais. Para a correta modelagem, são fundamentais modelos térmico e 
hidráulico rigorosos do equipamento e dados de cinética de inativação térmica e de propriedades termo-físicas confiáveis.

Ávila e Silva (1999), em sua revisão sobre a otimização de processamento térmico de alimentos, constatam que trabalhos de modelagem e otimização para processos de pasteurização de alimentos líquidos são relativamente escassos, enquanto que muitos trabalhos enfocam a simulação do processamento de alimentos sólidos por condução. O desenvolvimento de modelos para simular a troca térmica e o escoamento juntamente com as cinéticas de inativação e degradação resultaria em uma excelente ferramenta para otimização destes processos térmicos. Os autores recomendam o uso da teoria da distribuição de tempo de residência (DTR) para representar o processamento de alimentos líquidos, que tem características complexas de escoamento. É também enfatizada a importância da obtenção de dados cinéticos confiáveis para o processamento térmico e da validação experimental das condições ótimas determinadas matematicamente, que é raramente praticada. 


\section{OBJETIVOS}

Baseado no contexto apresentado no capítulo anterior, o presente trabalho de pesquisa tem os seguintes objetivos:

- Desenvolver uma modelagem matemática para simulação da operação de um processo contínuo de pasteurização HTST em trocador de calor a placas visando a determinação do histórico de temperatura do produto e a avaliação da letalidade do processo.

- Desenvolver e testar indicadores enzimáticos para serem usados como integradores tempo-temperatura (TTIs) para a avaliação do impacto de processos contínuos de pasteurização sobre produtos líquidos de baixa viscosidade como sucos, cerveja e leite.

- Determinar experimentalmente e caracterizar a distribuição do tempo de residência em tubos de retenção e trocadores de calor a placas usados no processamento térmico contínuo de alimentos líquidos.

- Validar o modelo matemático desenvolvido através da comparação entre resultados de simulação e dados experimentais em um caso de avaliação de um processo contínuo de pasteurização. 


\section{REVISÃO BIBLIOGRÁFICA}

\subsection{Modelagem matemática de processos térmicos contínuos}

Como mencionado no capítulo introdutório, a ferramenta de modelagem matemática é fundamental para realizar o dimensionamento ou a avaliação de um processo contínuo de pasteurização, visando avaliar o impacto do processo sobre atributos de segurança e de qualidade do produto (Awuah et al., 2007). Jung e Fryer (1999), por exemplo, simularam a esterilização de um alimento líquido viscoso não-Newtoniano (lei de potência) em trocador duplo-tubo através da modelagem da troca térmica e do perfil de velocidades dentro do tubo do início ao fim do processo. O modelo formulado foi resolvido por técnicas de CFD (computational fluid dynamics). A análise dos resultados mostrou que grande parte da inativação térmica ocorre fora do tubo de retenção e que a margem de segurança usada no projeto destes processos promove significativa perda de qualidade devido ao sobreprocessamento desnecessário do produto.

Gut et al. (2005) simularam a pasteurização contínua de gema de ovo líquida (escoamento de fluido não-Newtoniano) em um trocador de calor a placas com 58 canais, no qual avaliou-se o sobre-processamento do produto. Foram testados três tipos de modelos matemáticos, mas apenas uma validação experimental poderia indicar se algum deles fornece uma boa predição do processo real. Em todos os casos foi assumido escoamento pistonado para simplificação. A Figura 3.1.1 apresenta os resultados de temperatura (T) e letalidade (Lt) preditos pelo modelo e a letalidade integrada desejada (retângulo cinza).

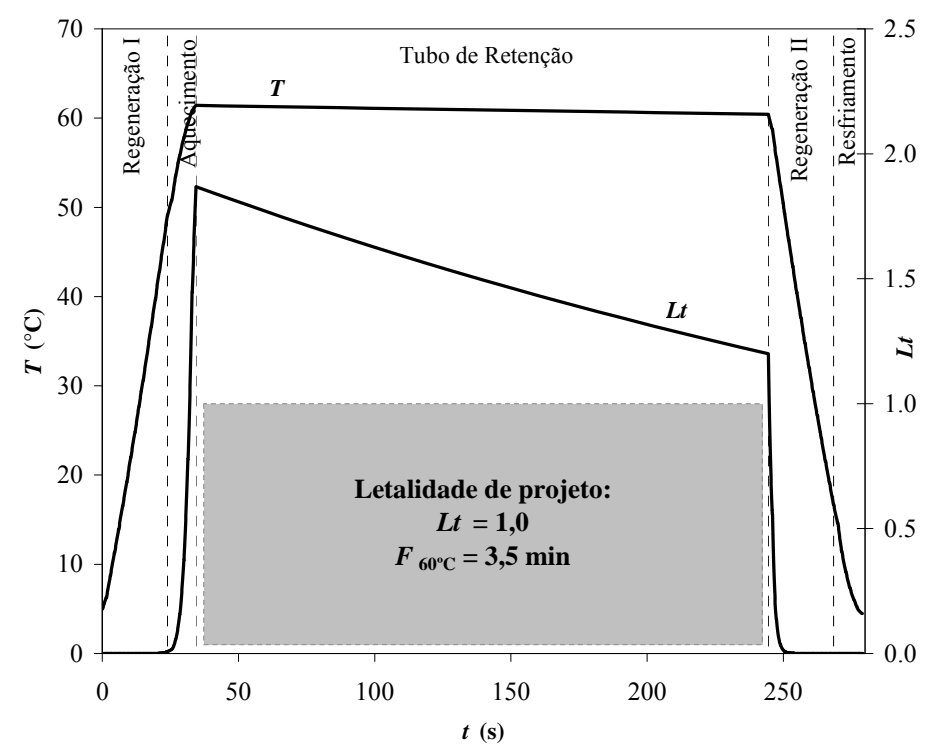

Figura 3.1.1. Distribuições de temperatura e letalidade na pasteurização de gema de ovo determinadas por modelo matemático do processo (Gut et al., 2005). 
Fernandes et al. (2006) utilizaram ferramentas de CFD para simular o escoamento e a troca térmica de iogurte em um canal de um trocador de calor a placas. A viscosidade do iogurte foi descrita pelo modelo de Herschel-Bulkley e a geometria ondulada das placas foi incorporada ao modelo. Em uma visão mais global, Cheng e Friis (2007) modelaram uma linha de produção de leite pasteurizado, semelhante àquela apresentada na Figura 1.1.2, como um fluxograma de operações unitárias interconectadas. As simulações permitiram um estudo da flexibilidade de operação da linha.

A incrustação é um fator crítico na pasteurização de alimentos. A incrustação de material particulado em trocadores a placas foi tema do trabalho de Grandegeorge (1998) e a incrustação por cristalização neste tipo de trocador foi estudada por Bansal et al. (2001). Entretanto, no processamento de alimentos, o calor favorece a formação de um tipo mais complexo de incrustação: a desnaturação de proteínas e sua adesão à superfície das placas simultaneamente ao depósito de minerais (Bennett, 2007). A modelagem da formação deste tipo de incrustação no processamento de leite foi estudada por De Jong (1997), por Georgiadis e Macchietto (2000) para pasteurização HTST e por Grijspeerdt et al. (2004) para esterilização UHT, sendo um desafio incorporar à modelagem dinâmica do processo a cinética de formação da incrustação.

Georgiadis e Macchietto (2000) desenvolveram a modelagem matemática da operação transiente de um trocador de calor a placas sujeito à incrustação de leite. Ao modelo dinâmico do trocador foi atrelado o modelo cinético de desnaturação de proteínas do leite e formação da incrustação. O sistema de equações diferenciais resultante foi resolvido pelo método de diferenças finitas. Resultados experimentais foram comparados aos de simulação indicando um bom desempenho do modelo em prever a redução no coeficiente global de troca térmica com o tempo de operação. Na mesma linha de trabalho, Narataruksaa et al. (2008) desenvolveram um modelo dinâmico de operação de um trocador de calor a placas sujeito à incrustação de leite de coco e compararam resultados experimentais e de simulação para validação do modelo.

Segundo De Jong (1997), o principal problema da incrustação é o aumento nos custos operacionais do processo (aquecimento e bombeamento). Foi sugerido o uso da modelagem proposta pelo autor para otimizar o processo, tendo como objetivo a determinação do par temperatura/tempo e da vazão que minimizem a formação da incrustação. Como resultado pode-se obter uma redução de até $50 \%$ nos custos operacionais. 
Grijspeerdt et al. (2004) também otimizaram a modelagem da incrustação para minimizar custos operacionais. Verificou-se que apenas otimizando o par temperatura/tempo do processo, uma redução pouco significativa na formação de incrustação foi obtida. Entretanto, assim como De Jong (1997) havia observado, a utilização de uma seção de préretenção no equipamento reduz de forma eficiente a incrustação no trocador após a retenção com pouca influência na qualidade final do produto. Esta seção, posicionada logo após ao aquecimento, recebe a maior parte da incrustação formada.

No processamento de alimentos, a segurança do produto é a principal preocupação. Com o desenvolvimento de sistemas de controle para garantir a segurança, a redução de custos e a melhora da qualidade do produto se tornaram o foco do aprimoramento dos sistemas de controle (Negiz et al., 1996). Vários trabalhos têm explorado novas técnicas de controle para processos de pasteurização. Negiz et al. (1996) demonstraram as vantagens do controle multivariável em cascata sobre o tradicional controle feedback em malha fechada na pasteurização HTST. A aplicação deste controlador PID em um processo foi bem sucedida e analisada em detalhes por Negiz et al. (1998a, 1998b, 1998c). O uso de um controlador preditivo DMC (dynamic matrix control) em um processo de pasteurização HTST foi analisado por Ibarrola et al. $(1998,2002)$ e a substituição do controle analógico PID (proportional-integral-derivative) pelo controle digital MPC (model predictive control) na pasteurização do leite foi estudada por Khadir e Ringwood (2003), que verificaram que o controle MPC reduz significativamente a variação da temperatura do leite pasteurizado, economizando energia e preservando a qualidade do produto. Entretanto, a aplicação de um controlador MPC requer o desenvolvimento de um modelo preditivo do processo, o que necessitou a aplicação da técnica de redes neurais para sua obtenção, em vez de elaborar um modelo de base fenomenológica.

Para a pasteurização de alimentos viscosos, não é seguro assumir que o escoamento seja pistonado (plug flow) ao longo do pasteurizador e que, portanto, todas as partículas tenham o mesmo tempo de residência (Lewis e Heppell, 2000). O perfil de velocidades dentro do tubo de retenção é parabólico no escoamento laminar, sendo que a máxima velocidade ocorre no centro do tubo, e há uma distribuição de tempo de residência. É possível dimensionar o tubo de retenção levando em conta apenas a velocidade máxima, mas neste caso o tubo será certamente super-dimensionado (Jung e Fryer, 1999). Através da determinação do perfil de velocidades no escoamento pode-se determinar com maior segurança o grau de inativação no tubo e, portanto, as suas dimensões (Toledo, 2007). 
Skoglund e Dejmek (2008) modelaram a inativação microbiana no escoamento turbulento de acordo com o modelo de fluxo pistonado com dispersão axial, tratando o tubo de retenção como um reator químico. Analogamente, Kechichian et al. (2012) modelaram o processamento térmico em sistema tubular não isotérmico como um reator de fluxo laminar com dispersão radial para avaliação da letalidade do processo. $\mathrm{O}$ modelo desenvolvido foi resolvido pela técnica de diferenças finitas.

\subsubsection{Trocadores de calor a placas}

Os trocadores de calor a placas são amplamente usados no processamento contínuo de alimentos líquidos de baixa viscosidade e sem material particulado, como leite, sucos ou cerveja. Suas maiores vantagens são a facilidade de higienização e alta eficiência térmica. A corrugação das placas consegue induzir turbulência mesmo em baixas velocidades de escoamento. Para a modelagem da troca térmica neste equipamento é necessário o conhecimento de suas características geométricas e de configuração de escoamento (Gut e Pinto, 2003a). As principais dimensões da placa são identificadas na Figura 3.1.2: altura da seção de troca térmica $(L)$, largura entre as gaxetas $(w)$, diâmetro do orifício $\left(D_{P}\right)$, espessura média do canal de escoamento $(b)$, espessura da placa $\left(e_{\text {placa }}\right)$ e ângulo da corrugação $(\beta)$.
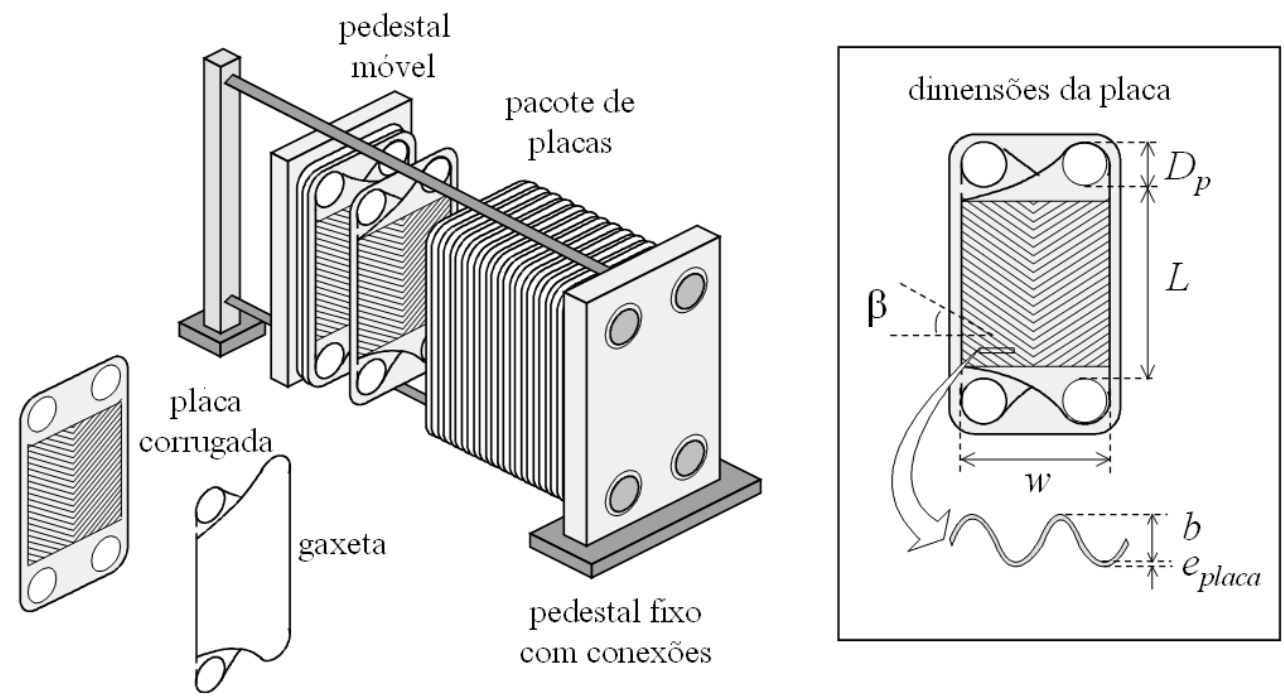

Figura 3.1.2. Esquema de um trocador de calor a placas e principais dimensões da placa (Gut e Pinto, 2009).

A área de troca térmica de uma placa é dada pela Equação (3.1.1), em que $\Phi \geq 1$ é o fator de alargamento da placa (razão entre a área efetiva de troca térmica e sua área projetada), que depende do tipo de corrugação. A área de escoamento no canal entre placas é 
dada pela Equação (3.1.2) e o diâmetro equivalente do canal é definido na Equação (3.1.3) como quatro vezes a razão entre a área de escoamento e o perímetro molhado do canal, sendo a aproximação indicada válida para $b<<w$ (Kakaç e Liu, 2002).

$$
\begin{aligned}
& A_{\text {placa }}=\Phi \cdot w \cdot L \\
& A_{\text {canal }}=b \cdot w \\
& D_{e}=4 \cdot \frac{b \cdot w}{2 \cdot(b+\Phi \cdot w)} \cong \frac{2 \cdot b}{\Phi}
\end{aligned}
$$

A configuração de um trocador de calor a placas define o escoamento dos fluidos quente e frio através do pacote de placas. Segundo Gut e Pinto (2003a), a configuração de um trocador de calor a placas pode ser representada através de seis parâmetros discretos: número de canais $\left(N_{C}\right)$, número de passes no lado I $\left(P^{I}\right)$, número de passes no lado II $\left(P^{I I}\right)$, localização relativa das alimentações $(\phi)$, localização do fluido quente $\left(Y_{h}\right)$ e tipo de escoamento nos canais $\left(Y_{f}\right)$. Os canais de escoamento são numerados e os canais ímpares constituem o lado I, enquanto os canais pares constituem o lado II.
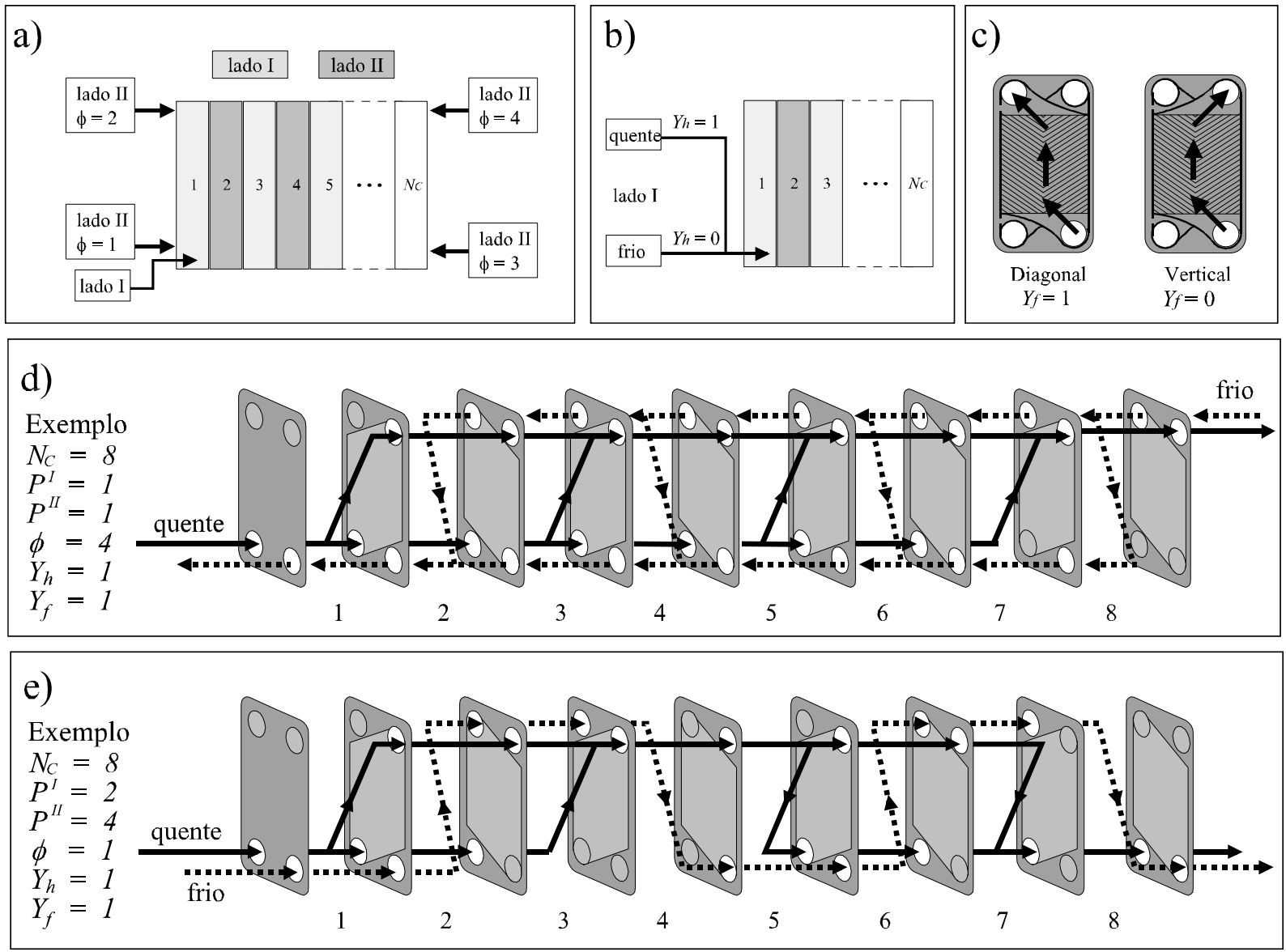

Figura 3.1.3. Parâmetros de configuração do trocador de calor a placas e dois exemplos de configuração para um trocador com oito canais (Gut e Pinto, 2009). 
Os canais de um lado do trocador são divididos em certo número de passes $(P)$, sendo que cada passe deve ter o mesmo número de canais $(N)$. O arranjo de passes do trocador, que deve satisfazer a Equação (3.1.4), pode ser representado como $P^{I} \times N^{I} / P^{I I} \times N^{I I}$ ou como $P^{\text {quente }} \times N^{\text {quente }} / P^{\text {frio }} \times N^{\text {frio }}$, considerando os lados quente e frio do trocador.

$N_{C}=P^{I} \cdot N^{I}+P^{I I} \cdot N^{I I}$

O fluido quente é associado aos lados do trocador através do parâmetro binário $Y_{h}$. Se $Y_{h}$ $=1$, então o fluido quente ocupa o lado I. Se $Y_{h}=0$, então o fluido frio ocupa o lado I. O parâmetro binário $Y_{f}$ indica se o escoamento nos canais é diagonal $\left(Y_{f}=1\right)$ ou vertical $\left(Y_{f}=0\right)$. O último parâmetro, $\phi$, fornece a posição relativa entre as conexões de alimentação dos lados I e II do trocador, conforme esquema (a) na Figura 3.1.3, mantendo fixa a posição da alimentação do lado I. Esta figura também ilustra a definição dos parâmetros binários $Y_{h} \mathrm{e} Y_{f} \mathrm{e}$ apresenta dois exemplos ilustrativos de configurações para um trocador com oito canais (sete placas térmicas).

O número de configurações possíveis para um trocador de calor a placas é elevado e seu desempenho tem forte dependência na configuração, especialmente no arranjo de passes. $\mathrm{O}$ número de canais por passe $(N)$, por exemplo, está diretamente ligado à velocidade de escoamento no canal. Alta velocidade fornece melhores coeficientes de troca térmica, mas eleva a perda de carga.

\subsection{Integradores de tempo-temperatura}

A avaliação do impacto de um processo térmico contínuo sobre atributos de segurança e de qualidade do alimento é fundamental para a avaliação ou o projeto de um processo. A avaliação in situ de contagem de micro-organismos ou conteúdo de vitaminas é usualmente demorado e caro. De forma alternativa, esse impacto pode ser avaliado de duas formas: 1) análise do histórico de temperatura do produto, ou das distribuições de temperatura e de tempo de residência, agregando a cinética de degradação térmica; 2) usando um integrador de tempo-temperatura (TTI, time-temperature-integrator) como indicador indireto de qualidade e segurança (Lewis e Heppell, 2000; Van Loey et al., 1996).

A primeira opção requer o conhecimento do histórico de temperatura, que pode ser registrado no processo usando técnicas e equipamentos adequados para determinação da distribuição de temperatura e de tempo de residência. Os resultados, combinados com o conhecimento da cinética de degradação térmica, permitem o cálculo do impacto do processo térmico. Alternativamente, o histórico de temperatura pode ser determinado pela simulação 
matemática do processo, envolvendo o equacionamento da troca térmica e escoamento, desde que o modelo represente com confiança as condições do processo (Jung e Fryer, 1999; Georgiadis e Macchietto, 2000; Grijspeerdt et al., 2003; Gut et al., 2005; Gut e Pinto, 2009).

Por outro lado, um TTI pode ser usado para avaliar o impacto do processo térmico. O TTI pode ser um componente intrínseco ou extrínseco ao alimento, deve ser termicamente sensível e permitir a quantificação do impacto do processo térmico em atributos de segurança e qualidade. As mudanças que ocorrem durante o processo térmico devem ser irreversíveis e de dinâmica similar ao atributo estudado. A letalidade calculada através do histórico de temperatura deve estar de acordo com a letalidade fornecida pelo TTI (Hendrickx et al., 1995; Van Loey et al., 1996).

TTIs baseados em enzimas têm sido muito utilizados para avaliação da letalidade de processos térmicos de alimentos enlatados ou sólidos. Por exemplo, as enzimas fosfatase alcalina e lactoperoxidase, intrínsecas ao leite bovino, são amplamente utilizadas como TTIs para avaliar sub-processamento e sobre-procesamento na pasteurização HTST do leite, respectivamente (Claeys et al., 2002). Hendrickx et al. (1992) desenvolveram um TTI elaborado com a fração termorresistente da peroxidase de raiz-forte, imobilizada covalentemente sobre esferas porosas de vidro em dodecano, para indicar a intensidade de um processo de pasteurização. Guiavarc'h et al. (2002a, 2002b) estudaram a inativação térmica de $\alpha$-amilase de Bacillus licheniformis para desenvolver um TTI que consiste de esferas de silicone ocas contendo a enzima. Este TTI foi usado para investigar o impacto do processo térmico no interior de partículas sólidas em um meio heterogêneo em latas processados em autoclave rotativa. Tucker et al. (2009) desenvolveram um TTI enzimático que consiste de $\alpha$ amilase em tampão acetato $10 \mathrm{nM}$ para avaliar processos brandos de pasteurização de alimentos embalados. Pequenas amostras do TTI $(20 \mu \mathrm{L})$ foram encapsuladas em tubos de silicone que foram posicionados no interior da embalagem.

Alguns TTIs foram desenvolvidos para avaliação de processos térmicos contínuos de alimentos contendo partículas em suspensão. Por exemplo, Tucker et al. (2002) inseriram um TTI enzimático em pequenas partículas de silicone que foram incorporadas aleatoriamente em preparados com pedaços de cassis, abacaxi ou morango que foram processados em um trocador de calor bitubular. Para avaliar o processamento térmico contínuo de um alimento líquido usando um TTI extrínseco, este precisa ser introduzido em um lote do produto ou em algum meio fluido que mimetize o produto alimentício (alimento modelo). Miles e Swartzel (1995a), por exemplo, usaram corante Azul \#2 em tampão carbonato-bicarbonato para avaliar 
a letalidade de um processo contínuo constituído por dois trocadores de calor bitubulares (aquecimento e resfriamento) e um tubo de retenção (temperatura de processo entre 75 e 140 $\left.{ }^{\circ} \mathrm{C}\right)$. Ellborg and Trägårdh (1994) desenvolveram um método para determinar a distribuição da letalidade em escoamento não-isotérmico em trocadores de calor bitubulares usando a hidrólise ácida da dextrana.

Miles e Swartzel (1995b) determinaram parâmetros cinéticos da hidrólise ácida da sacarose para uso na avaliação da letalidade em processos contínuos não-isotérmicos. Torres e Oliveira (1999) usaram a mesma reação para avaliação de processos contínuos de pasteurização com o objetivo de predizer a temperatura de retenção. Os resultados tiveram desvios inferiores a $4{ }^{\circ} \mathrm{C}$ em relação à temperatura medida com termopares para conversões entre 0,4 e 0,7 na reação de hidrólise.

Gentry e Roberts (2004) determinaram parâmetros cinéticos da formação de 5hidroximetilfurfural, uma substância que se forma da degradação térmica de monossacarídeos, na pasteurização de cidra de maçã em processo contínuo com aquecimento por micro-ondas. A concentração de 5-hidroximetilfurfural foi medida na entrada e na saída do processo usando cromatografia gasosa e o aumento de concentração foi usado para avaliar a letalidade do processo. Os valores obtidos tiveram boa correlação com aqueles preditos a partir do histórico de temperatura do produto.

\subsection{Distribuição do tempo de residência}

Para a avaliação de processos térmicos contínuos de alimentos líquidos, o conhecimento da distribuição do tempo de residência (DTR) no processo é tão importante quando o conhecimento da distribuição de temperatura, especialmente na etapa de retenção (Rao e Loncin, 1974a; Rao e Loncin, 1974b; Torres et al., 1998; Ibarrola et al., 2002, Gut et al., 2005).

Torres e Oliveira (1998a, 1998b) e Torres et al. (1998) apresentam uma extensa revisão sobre a análise de DTR no processamento de alimentos líquidos e destacam a sua importância para a otimização de processos. A otimização não pode ser alcançada apenas escolhendo o par temperatura/tempo mais adequando, mas também pelo controle das características do escoamento no tubo de retenção.

Estudos recentes têm determinado experimentalmente a DTR em pasteurizadores. Landfeld et al. (2002) realizou um estudo de DTR para a pasteurização da gema de ovo em um trocador a placas de três seções. Foi utilizada a técnica de adição de sal e acompanhamento da condutividade elétrica do produto na saída do processo. A técnica 
condutimétrica foi também utilizada por Ditchfield et al. (2004) para estudar a DTR no tratamento térmico de purê de banana em trocador de calor duplo-tubo, e por Tomasula e Kozempel (2004) para analisar o processo de pasteurização HTST de leite em trocador a placas através da determinação das curvas de DTR.

Uma ferramenta que vem sendo usada para o estudo do escoamento dentro de trocadores a placas é a simulação fluido-dinâmica em CFD (computational fluid dynamics), como por Kho e Muller-Steinhagen (1999) para placas lisas. Um trabalho semelhante foi realizado por Grijspeerdt et al. (2003) para um trocador com placas corrugadas espinha-depeixe. Este tipo de simulação ainda é um desafio devido à geometria complexa do canal de um trocador a placas, mas os resultados são úteis no desenho de corrugações que reduzam a incrustação. A simulação em CFD de um trocador a placas com quatro canais e placas lisas foi realizada por Galeazzo et al. (2006) e obteve-se uma boa predição dos comportamento real.

\subsubsection{Teoria da distribuição do tempo de residência}

Cada elemento de fluido percorre um equipamento com determinado tempo de escoamento. A distribuição destes tempos, avaliada na saída do equipamento para operação em estado estacionário, caracteriza a DTR do processo ou a curva $E(t)$. A forma mais simples de obter a curva $E(t)$ é através de experimentos de perturbações em pulso, nos quais uma pequena quantidade de um traçador não reativo e miscível no meio é instantaneamente injetada na entrada do equipamento, proporcionalmente à velocidade, e sua concentração $C$ é continuamente registrada na saída. A curva $E(t)$ é então obtida através da Equação 3.3.1, em que $C_{0}$ é a concentração de fundo do traçador, caso existente. Consequentemente, a área abaixo da curva $E$ é unitária, conforme Equação 3.3.2 (Levenspiel, 1999).

$$
\begin{aligned}
& E(t)=\frac{C(t)-C_{0}}{\int_{0}^{\infty} C(t)-C_{0} d t} \\
& \int_{0}^{\infty} E(t) d t=1
\end{aligned}
$$

O tempo médio de residência $t_{m}$ pode ser calculado através da Equação (3.3.3) e a curva $E(t)$ adimensional, denominada $E_{\theta}(\theta)$, pode ser obtida a partir da Equação (3.3.4), em que $\theta=$ $t / t_{m}$ é o tempo adimensional (Levenspiel, 1999).

$$
t_{m}=\int_{0}^{\infty} t \cdot E(t) d t
$$




$$
E_{\theta}(\theta)=t_{m} \cdot E(t)
$$

A análise dos dados de DTR de uma operação unitária ou processo é útil para avaliar o padrão de escoamento, determinar o grau de mistura e diagnosticar problemas de escoamento, como recirculação, formação de canais preferenciais, curto-circuito e estagnação. Esta técnica é muito difundida para estudo de reatores químicos e leitos de preenchimento (Levenspiel, 1989). No processamento de alimentos, a análise da DTR tem sido aplicada para avaliar os efeitos de variáveis de processo sobre as características do escoamento, principalmente em linhas assépticas (Torres e Oliveira, 1998a).

Para o escoamento em tubos, a DTR está associada ao perfil de velocidades, à difusão e à turbulência. Os casos ideais de perfil parabólico de velocidades em escoamento laminar e de perfil pistonado de escoamento em escoamento turbulento raramente representam bem a DTR de sistemas reais. No caso do processamento térmico de alimentos líquidos, o escoamento é normalmente laminar no tubo de retenção, o que promove uma considerável dispersão na DTR. Em uma abordagem conservadora, utiliza-se o tempo de retenção mínimo (elemento de fluido no centro do tubo) para cálculos de letalidade e dimensionamento do tubo de retenção, simplificando muito a análise. Para uma abordagem mais rigorosa, um modelo que represente a DTR deve ser introduzido nos cálculos de avaliação ou projeto de processo.

Em um processo térmico contínuo, a maior parte da letalidade ocorre no tubo de retenção, mas há um impacto térmico associado ao escoamento dentro dos trocadores de calor, especialmente na etapa de aquecimento. Para que seja possível avaliar o impacto da alta temperatura sobre atributos de segurança e qualidade do alimento, é necessário conhecer as distribuições de temperatura e de tempo de residência dentro dos trocadores (Lewis e Heppell, 2000). O acoplamento entre escoamento, troca térmica e cinética de degradação térmica permite a elaboração de um modelo matemático abrangente do processo que pode ser usado para problemas de projeto, análise ou otimização (Georgiadis et al., 1998; Jung e Fryer, 1999; Gut e Pinto, 2003b; Gut et al., 2005; Skoglund e Dejmek, 2008).

A determinação da DTR em trocadores de calor usados no processamento térmico de alimentos líquidos, com ou sem partículas, tem sido investigada, especialmente para produtos de maior viscosidade ou comportamento reológico não-Newtoniano. Por exemplo, Ditchfield et al. (2006) determinaram a DTR de purê de banana em um trocador de calor bitubular, Mabit et al. (2008) estudaram a DTR de fluidos viscosos em um trocador de calor de superfície raspada e Landfeld et al. (2002) determinaram a DTR de ovo líquido em um trocador de calor a placas. Além disso, Roetzel e Balzereit (1997) determinaram o coeficiente 
de dispersão axial em trocadores de calor a placas através de experimentos de DTR. Os resultados indicaram considerável desvio em relação ao escoamento pistonado e confirmaram a necessidade de um modelo de dispersão para melhor descrever o comportamento transiente de trocadores a placas.

\subsubsection{Modelos de distribuição do tempo de residência}

Modelos ideais de escoamento como escoamento pistonado, tanque de mistura perfeita e escoamento laminar dificilmente representam de forma satisfatória a DTR de sistemas reais. Modelos não-ideais são derivados de modelos ideais para contemplar desvios implícitos em sistema reais (Torres e Oliveira, 1998a). Modelos com um parâmetro livre são muito adequados para representar sistemas tubulares (Levenspiel e Bischoff, 1963). Nesta seção, são apresentados alguns modelos de DTR com um parâmetro ajustável, além do tempo médio de residência $t_{m}$, e suas correspondentes equações de $E(t)$. O tempo médio de residência experimental pode diferir do tempo médio de residência teórico, denominado tempo espacial $(\tau)$ e definido na Equação (3.3.5) como a relação entre volume interno $V$ e vazão volumétrica $Q$ para o escoamento monofásico sem mudanças de densidade.

$$
\tau=\frac{V}{Q}
$$

Devido à formação de zonas de estagnação ou de recirculação dentro do equipamento, o seu volume "útil" para escoamento torna-se inferior ao volume interno, resultado em $t_{m}<\tau$. Desta forma, defini-se o volume ativo do equipamento através da Equação (3.3.6a). Consequentemente tem-se o volume morto através da Equação (3.3.6b).

$$
\begin{aligned}
& t_{m}=\frac{V_{\text {ativo }}}{Q} \\
& V_{\text {morto }}=V-V_{\text {ativo }}
\end{aligned}
$$

- Modelo de dispersão axial

O modelo de dispersão axial é útil para representar pequenos desvios do escoamento pistonado e outros escoamentos não-ideais em sistemas tubulares. Tem sido amplamente aplicado para descrever o escoamento em tubos e é a escolha mais usual para modelar a DTR em tubos de retenção de linhas assépticas em regime turbulento de escoamento (Torres et al., 1998). O parâmetro do modelo é o número de Peclet, que é definido conforme Equação 
(3.3.7), em que $L_{\text {tubo }}$ é o comprimento do tubo, $v$ é a velocidade média e $D_{a x}$ é o coeficiente de dispersão axial (Levenspiel, 1999).

$$
P e=\frac{L_{t u b o} \cdot v}{D_{a x}}
$$

Este adimensional representa a relação entre advecção (escoamento) e difusão. Quando $P e$ tende ao infinito, tem-se o escoamento pistonado com dispersão desprezível. Já quando $P e$ tende a zero, tem-se intensa mistura como em um tanque de mistura perfeita. A solução da equação transiente de conservação do traçador atravessando um tubo fornece a curva $E(t)$ associada a este modelo; entretanto, o resultado depende das condições de contorno adotadas e em geral a equação não tem solução analítica simples. Neste trabalho, é adotada a Equação (3.3.8) que é uma aproximação da solução analítica do problema considerando condições de contorno de sistema fechado (Gouvêa et al., 1990). A Equação (3.3.8) é uma adaptação do trabalho de Nauman (1985) e é válida para $P e>16$.

$$
E_{\theta}(\theta)=\sqrt{\frac{P e+1}{4 \cdot \pi \cdot \theta^{3}}} \exp \left(\frac{-(P e+1) \cdot(1-\theta)^{2}}{4 \cdot \theta}\right)
$$

A Figura 3.3.8 apresenta as curvas de DTR para diversos valores de Pe. Pode-se notar que para $P e$ tendendo ao infinito a curva aproxima-se do delta de Dirac. Para $P e<16$ as curvas são características de DTR, mas o significado do número de Peclet na Equação (3.3.7) não é mais válido.

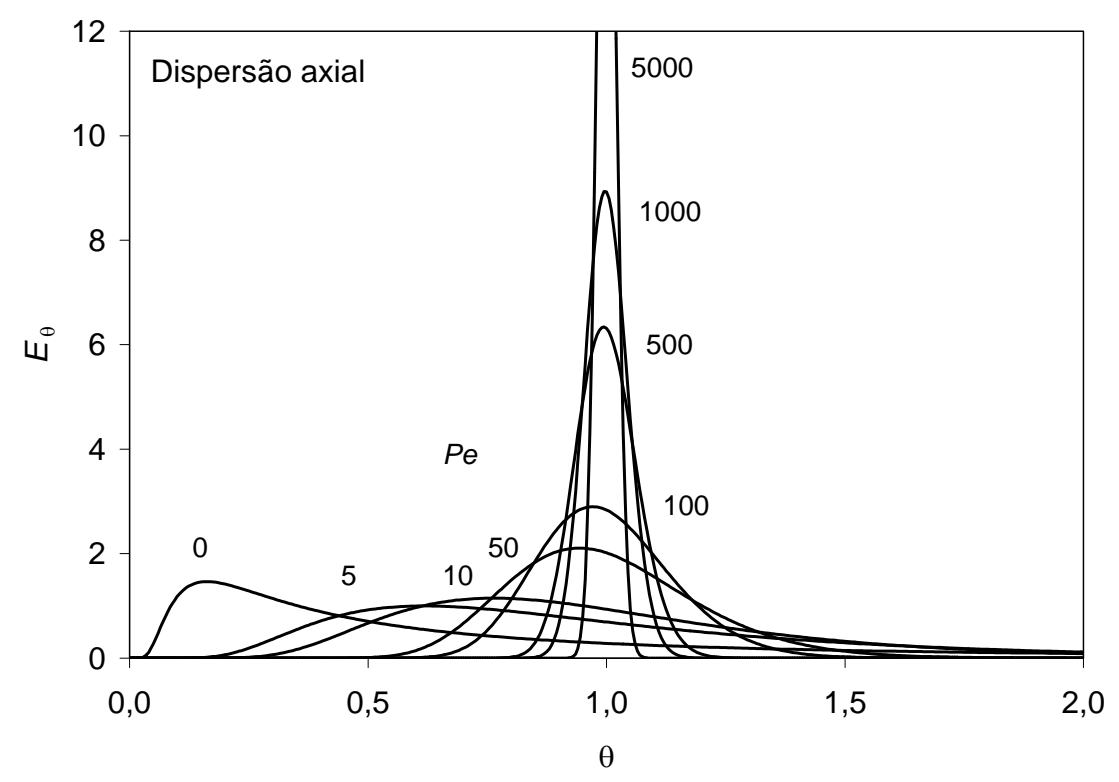

Figura 3.3.1. Curvas adimensionais de DTR para o modelo de dispersão axial, mostrando o efeito do parâmetro do modelo (Gutierrez et al., 2010). 
- Modelo de tanques em série estendido

O modelo de tanques em série é baseado no escoamento através de uma série de tanques de mistura perfeita iguais e pode ser usado para representar desvios do escoamento pistonado em tubos e tanques de mistura reais (Levenspiel, 1999). A curva $E(t)$ em formato adimensional para este modelo é apresentada na Equação (3.3.9), na qual o parâmetro livre é o número de tanques $N_{t}$.

$$
E_{\theta}(\theta)=\frac{N_{t} \cdot\left(N_{t} \cdot \theta\right)^{N_{t}-1}}{\left(N_{t}-1\right) !} \exp \left(-N_{t} \cdot \theta\right)
$$

$\mathrm{Na}$ forma "estendida" desde modelo, o número de tanques pode assumir valores não inteiros (Martin, 2000). Para avaliar o fatorial de um número não inteiro na Equação (3.3.9), utiliza-se a função matemática $\Gamma$, conforme Equações (3.3.10) e (3.3.11).

$$
\begin{aligned}
& \Gamma\left(N_{t}\right)=\int_{0}^{\infty} x^{N_{t}-1} \cdot e^{-x} d x \\
& N_{t} !=\Gamma\left(N_{t}+1\right)=N_{t} \cdot \Gamma\left(N_{t}\right)=N_{t} \cdot\left(N_{t}-1\right) \cdot \Gamma\left(N_{t}-1\right)=\cdots \\
& =\left[\prod_{i=0}^{\operatorname{piso}\left(N_{t}-1\right)}\left(N_{t}-i\right)\right] \cdot \Gamma\left[N_{t}-\operatorname{piso}\left(N_{t}-1\right)\right]
\end{aligned}
$$

Neste trabalho, a função $\Gamma$ foi aproximada por um polinômio de grau cinco para o intervalo $1,0 \leq N_{t} \leq 2,0$ usando 1001 pontos gerados com o software MatLab (MathWorks, EUA) com precisão $10^{-14}$. Os coeficientes do polinômio ajustado são $a_{5}=-0,095280563, a_{4}=$ $+0,881949260, a_{3}=-3,253059648, a_{2}=+6,361011447, a_{1}=-6,587129421$ e $a_{0}=$ $+3,692414299$. Ajuste realizado com o software Excel (Microsoft, EUA). Segue um exemplo de uso da função $\Gamma$ para determinação de um fatorial não inteiro: $4,65 !=\Gamma(5,65)=(4,65$. $3,65 \cdot 2,65) \cdot \Gamma(1,65)=(74,2) \cdot 0,90=66,8$.

A Figura 3.3.2 apresenta as curvas adimensionais para o modelo de tanques em série, de acordo com a Equação (3.3.9). Nota-se grande semelhança com as curvas do modelo de dispersão axial na Figura 3.3.1. Para $N_{t}=1$ tem-se o caso de tanque de mistura perfeita, que corresponde a $P e=0$. É perceptível o desvio em comparação com a curva na Figura 3.3.1, pois a Equação (3.3.8) só é válida para $P e>16$. Para valores elevados de $N_{t}$ é preferível usar o modelo de dispersão axial para representar a DTR, evitando erros numéricos na avaliação da Equação (3.3.9). 


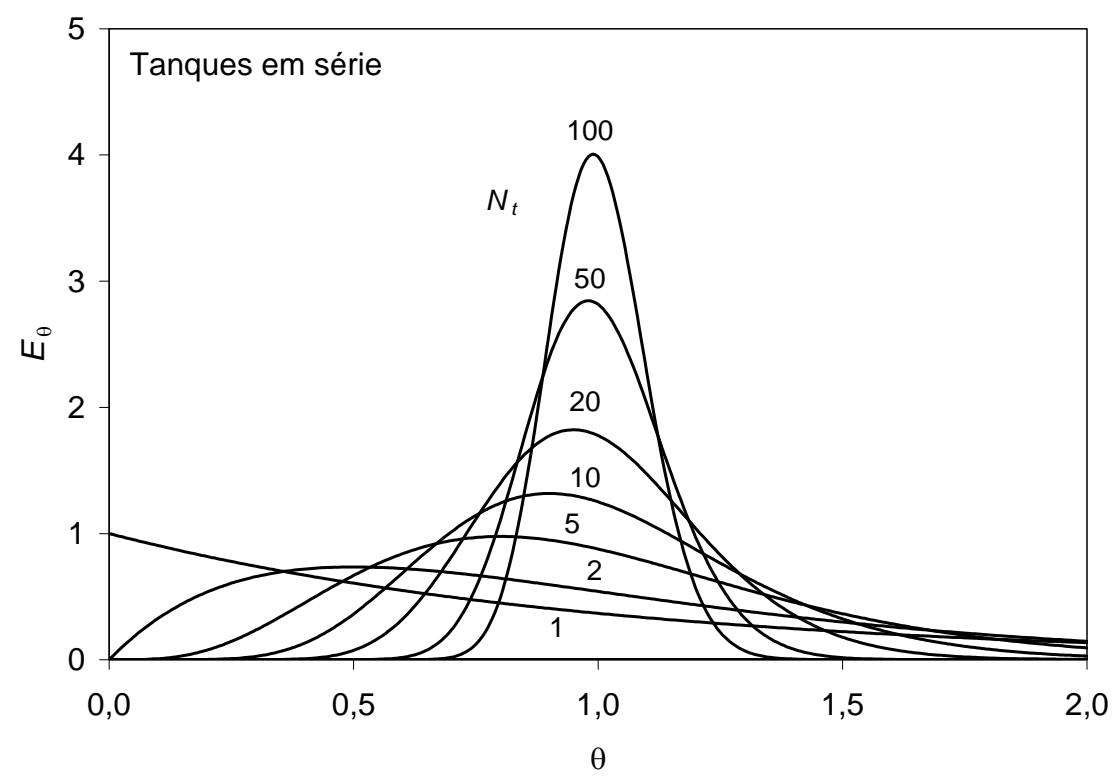

Figura 3.3.2. Curvas adimensionais de DTR para o modelo de tanques em série, mostrando o efeito do parâmetro do modelo (Gutierrez et al., 2010).

- Modelo de convecção generalizado

O modelo de convecção considera o escoamento laminar ideal de um líquido Newtoniano em um tubo de seção circular. Como não há difusão, o espalhamento na DTR é causado pelo perfil de velocidade parabólico no tubo. Neste caso, a resposta ao pulso de traçador pode ser determinada analiticamente através da equação de conservação de massa, tendo como resultado a Equação (3.3.12), que não tem parâmetros (Levenspiel, 1989).

$$
E_{\theta}(\theta)=\frac{1}{2} \frac{1}{\theta^{3}} \quad \theta \geq 0,5
$$

Uma forma generalizada da Equação (3.3.12) pode ser obtida transformando o tempo mínimo de residência adimensional $\left(\theta_{0}=0,5\right)$ em um parâmetro livre. Neste caso, a Equação (3.3.12) toma a forma da Equação (3.3.13) para satisfazer as Equações (3.3.2) e (3.3.3) (Levenspiel, 1989; Gutierrez et al., 2010). Para $\theta_{0}=0,5$, a Equação (3.3.12) é obtida.

$$
E_{\theta}(\theta)=\frac{1}{1-\theta_{0}} \frac{1}{\theta}\left(\frac{\theta_{0}}{\theta}\right)^{\frac{1}{1-\theta_{0}}} \quad \theta \geq \theta_{0}
$$

A Figura 3.3.3 apresenta as curvas do modelo de convecção generalizado obtidas a partir da Equação (3.3.13) para diferentes valores do parâmetro $\theta_{0}$. O formato das curvas é típico de escoamento laminar, com um pico inicial pronunciado e uma longa cauda, diferente das curvas geradas pelos modelos de dispersão axial e de tanques em série (Figuras 3.3.1 e 3.3.2). 


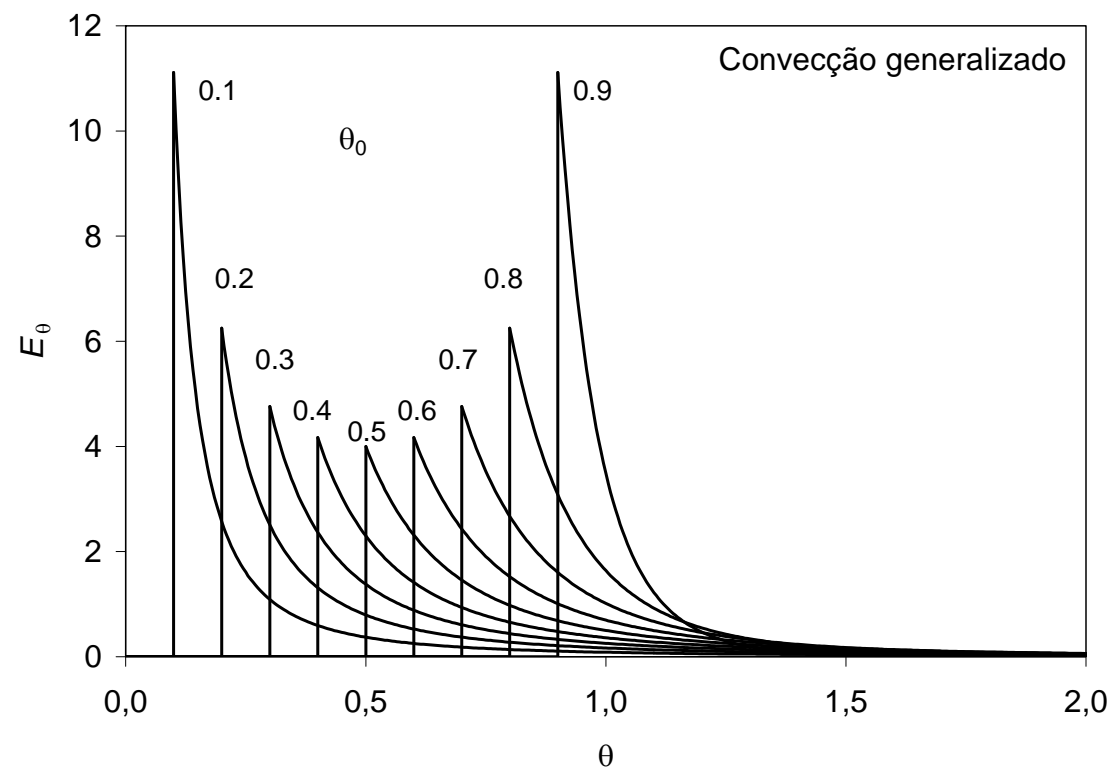

Figura 3.3.3. Curvas adimensionais de DTR para o modelo de convecção generalizado, mostrando o efeito do parâmetro do modelo (Gutierrez et al., 2010).

Modificações análogas do modelo de convecção foram adotadas anteriormente por Ruthven (1971), Trivedi e Vasudeva (1974) e Nauman (1977), para representar o escoamento laminar em tubos helicoidais, e também por Levien e Levenspiel (1999), Heibel et al. (2005) e Garcia-Serna et al. (2007) para representar o escoamento em reatores químicos.

- Modelo de associação PFR+CSTR

Modelos combinados ou de associação são baseados na associação em série e/ou em paralelo de dois os mais reatores ideais, que podem ser o reator de escoamento pistonado (PFR, plug flow reactor) ou o reator de tanque de mistura perfeita (CSTR, continuous stirredtank reactor). As características dos reatores ideais são ajustadas para que a DTR da associação seja próxima da DTR que se quer representar (Levenspiel e Bischoff, 1963; Levenspiel, 1999). Fillaudeau et al. (2009) usaram com sucesso uma associação em série de um PFR e dois CSTRs para representar o escoamento através de um aquecedor de efeito Joule usado para tratamento térmico de alimentos líquidos. No presente trabalho, uma associação em série de um PFR e um CSTR é considerada, por ter apenas um parâmetro ajustável, além do tempo médio de residência.

A curva $E(t)$ do modelo de associação PFR+CSTR pode ser expressa em função do tempo de residência mínimo adimensional referente ao $\operatorname{PFR}\left(\theta_{P}\right)$, conforme Equação (3.3.14). Esta equação representa a DTR de um tanque de mistura com um atraso provocado pela 
passagem do PFR, como pode-se notar pelo formato das curvas na Figura 3.3.4. No limite de $\theta_{P}=0$ tem-se a DTR de um tanque de mistura conforme Equação (3.3.9) e Figura 3.3.2.

$$
E_{\theta}(\theta)=\frac{1}{1-\theta_{P}} \exp \left(-\frac{\theta-\theta_{P}}{1-\theta_{P}}\right) \quad \theta \geq \theta_{P}
$$

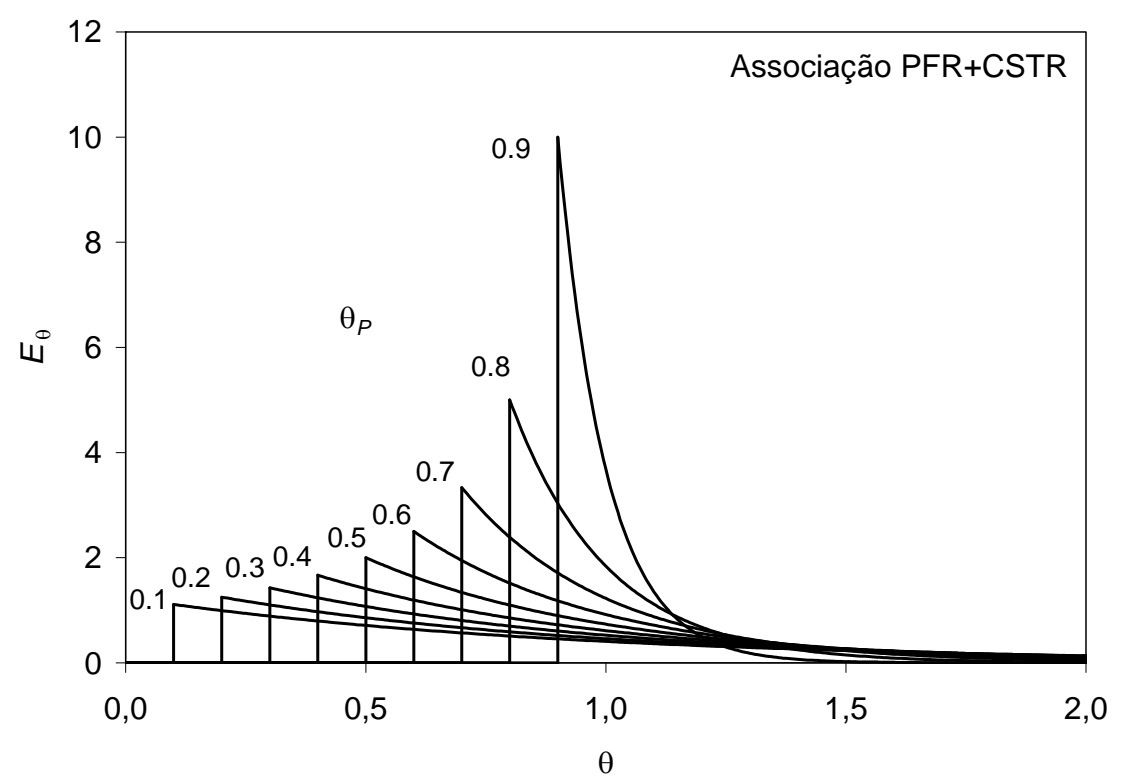

Figura 3.3.4. Curvas adimensionais de DTR para o modelo de associação PFR+CSTR, mostrando o efeito do parâmetro do modelo (Gutierrez et al., 2010).

Os verdadeiros parâmetros deste modelo são os volumes dos reatores ideais: $V_{\text {plug }}$ (volume do PFR) e $V_{\text {mix }}$ (volume do CSTR). Os tempos espaciais nestes dois reatores são $\tau_{\text {plug }}$ $=V_{\text {plug }} / Q$ e $\tau_{\text {mix }}=V_{\text {mix }} / Q$. Consequentemente, o tempo médio de residência da associação de reatores é calculado como $t_{m}=\tau_{\text {plug }}+\tau_{\text {mix. }}$ O volume ativo do sistema é $V_{\text {ativo }}=V_{\text {plug }}+V_{\text {mix }}$ e o volume morto é obtido através da Equação (3.3.6b). O tempo mínimo de residência é obtido através da Equação (3.3.15).

$$
\theta_{P}=\frac{\tau_{\text {plug }}}{\tau_{\text {plug }}+\tau_{\text {mix }}}=\frac{V_{\text {plug }}}{V_{\text {plug }}+V_{\text {mix }}}
$$

No formato dimensional, a equação correspondente à curva $E(t)$ deste modelo pode ser expressa em função de $\tau_{p l u g}$ e $\tau_{m i x}$, conforme Equação (3.3.16).

$$
E(t)=\frac{1}{\tau_{\text {mix }}} \exp \left(-\frac{t-\tau_{\text {plug }}}{\tau_{\text {mix }}}\right) \quad t \geq \tau_{\text {plug }}
$$




\section{MODELAGEM MATEMÁTICA}

Neste capítulo é desenvolvido um modelo matemático de base fenomenológica para simular um processo contínuo de pasteurização em tocador de calor a placas. O objetivo do modelo é predizer a distribuição de temperatura dos fluidos envolvidos (produto e utilidades) e a distribuição de letalidade do atributo de segurança do produto alimentício.

\subsection{Modelagem do processo de pasteurização}

A Figura 4.1.1 apresenta um esquema do processo de pasteurização considerado neste trabalho. Um trocador de calor a placas é dividido em três seções de troca térmica usando grades conectoras, que pode ser consideradas como trocadores de calor independentes: aquecimento, regeneração e resfriamento. A seção de regeneração é utilizada para recuperação de calor do produto pasteurizado que deixa o tubo de retenção.
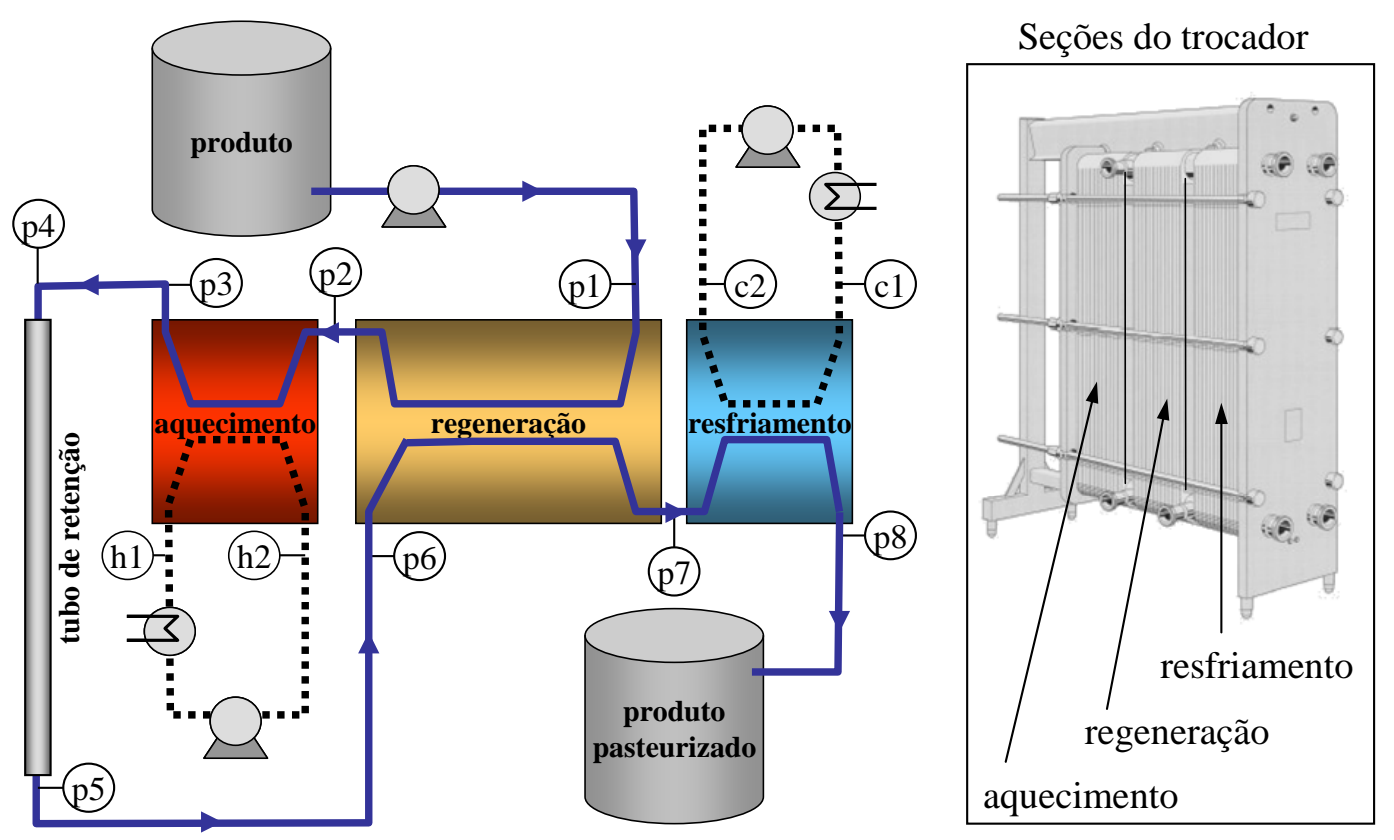

Figura 4.1.1. Esquema do processo de pasteurização adotado para o desenvolvimento da modelagem matemática (Gut e Pinto, 2009).

Seguindo o trajeto indicado na Figura 4.1.1, o produto bombeado é pré-aquecido na seção de regeneração $(\mathrm{p} 1 \rightarrow \mathrm{p} 2)$ e depois é aquecido até a temperatura desejada na seção de aquecimento $(\mathrm{p} 2 \rightarrow \mathrm{p} 3)$. Após o aquecimento, o produto percorre o tubo de retenção $(\mathrm{p} 4 \rightarrow \mathrm{p} 5)$, cujo tempo de residência deve proporcionar o efeito letal desejado. No modelo são consideradas as conexões tubulares de entrada $(\mathrm{p} 3 \rightarrow \mathrm{p} 4)$ e de saída $(\mathrm{p} 5 \rightarrow \mathrm{p} 6)$ do tubo de retenção, pois a letalidade nestes trechos é importante devido à alta temperatura. Na posição 
p5 a temperatura deve ser controlada para ser mantida na temperatura de processamento escolhida. Geralmente manipula-se a temperatura do fluido de aquecimento (posição h1) para controlar a temperatura do produto em p5. Caso a temperatura neste ponto seja inferior à escolhida, o produto é considerado sub-processado e automaticamente desviado para o tanque de alimentação através da válvula diversora de fluxo.

Já na seção de regeneração, o produto é resfriado para recuperação de calor (p6 $\rightarrow$ p7) e depois é novamente resfriado na seção de resfriamento $(\mathrm{p} 7 \rightarrow \mathrm{p} 8)$ antes da embalagem ou estoque. O meio de aquecimento $(\mathrm{h} 1 \rightarrow \mathrm{h} 2)$ é usualmente água quente pressurizada (aquecida diretamente ou indiretamente com vapor) e o meio de resfriamento (c1 $\rightarrow$ c2) é normalmente água gelada ou uma mistura de água e etileno glicol. Alternativamente o trocador de calor a placas pode ter uma segunda seção de resfriamento para baixar ainda mais a temperatura do produto usando um fluido adequado para operação próximo de $0{ }^{\circ} \mathrm{C}$. Além disso, há casos em que a seção de regeneração é dividida em duas seções através de uma grade conectora (Figura 1.1.2), cujo objetivo é desviar o produto para uma etapa de homogeneização antes de prosseguir com o aquecimento (Lewis e Heppell, 2000).

Para o desenvolvimento da modelagem matemática do processo representado na Figura 4.1.1, foram adotadas as seguintes hipóteses:

- Operação em regime permanente.

- Escoamento pistonado (perfil chato de velocidade, sem dispersão axial).

- Há troca de calor com o ambiente apenas no tubo de retenção, ocasionando uma queda de temperatura.

- Fluidos homogêneos, monofásicos e com propriedades termo-físicas avaliadas na temperatura média do trecho.

A influência de algumas hipóteses será explorada através de testes de três modelos matemáticos:

- Modelo 1: variação linear de temperatura entre os pontos p1 a p8. Trocadores de calor com eficiência térmica de arranjo puramente contracorrente.

- Modelo 2: semelhante ao Modelo 1, mas calculando a eficiência térmica dos trocadores com base no arranjo de passes.

- Modelo 3: semelhante ao Modelo 2, mas com variação não-linear de temperatura dentro dos trocadores de calor. 
Nas seções a seguir são desenvolvidas as modelagens referentes à transferência de calor e à distribuição de temperatura, ao escoamento e tempo de residência e à distribuição de letalidade.

\subsection{Modelagem da troca de calor}

As cargas térmicas das seções de regeneração, aquecimento e resfriamento $\left(q^{R}, q^{H}\right.$ e $q^{C}$, respetivamente) podem ser avaliadas através das Equações (4.2.1a), (4.2.1b) e (4.2.1c), considerando a variação entálpica dos fluidos que entram e saem dos trocadores e a eficiência de troca térmica (Gut e Pinto, 2009). Nestas equações, $C C=W \cdot C p$ é a capacidade calorífica do fluido, em que $W$ é a vazão mássica e $C p$ é o calor específico médio do fluido no trecho. A variável $\varepsilon$ é a eficiência térmica do trocador de calor, definida como $\varepsilon=q / q_{\max }$, em que $q_{\max }$ é a carga térmica máxima que pode ser atingida no trocador (área infinita com máxima variação de temperatura pelo fluido com menor capacidade calorífica). Os subscritos das variáveis identificam o trecho a que se referem, por exemplo, $C C_{p 1-2}$ é a capacidade calorífica do produto no trecho $\mathrm{p} 1 \rightarrow \mathrm{p} 2$ (Figura 4.1.1).

$$
\begin{aligned}
q^{R}= & C C_{p 1-2} \cdot\left(T_{p 2}-T_{p 1}\right)=C C_{p 6-7} \cdot\left(T_{p 6}-T_{p 7}\right)= \\
& =\varepsilon^{R} \cdot \min \left(C C_{p 1-2}, C C_{p 6-7}\right) \cdot\left(T_{p 6}-T_{p 1}\right) \\
q^{H}= & C C_{p 2-3} \cdot\left(T_{p 3}-T_{p 2}\right)=C C_{h 1-2} \cdot\left(T_{h 1}-T_{h 2}\right)= \\
& =\varepsilon^{H} \cdot \min \left(C C_{p 2-3}, C C_{h 1-2}\right) \cdot\left(T_{h 1}-T_{p 2}\right) \\
q^{C}= & C C_{p 7-8} \cdot\left(T_{p 7}-T_{p 8}\right)=C C_{c 1-2} \cdot\left(T_{c 2}-T_{c 1}\right)= \\
& =\varepsilon^{C} \cdot \min \left(C C_{p 7-8}, C C_{c 1-2}\right) \cdot\left(T_{p 7}-T_{c 1}\right)
\end{aligned}
$$

Geralmente as temperaturas de alimentação $T_{p 1}, T_{h 1}$ e $T_{c 1}$ são conhecidas ou especificadas, assim como as capacidades caloríficas médias dos fluidos. Para que seja possível resolver o sistema de equações definido pelas Equações (4.2.1a), (4.2.1b) e (4.2.1c) para determinar as outras temperaturas, devem ser conhecidas as eficiências térmicas das três seções de troca $\left(\varepsilon^{R}, \varepsilon^{H}\right.$ e $\left.\varepsilon^{C}\right)$ e a queda de temperatura no tubo de retenção $\left(\Delta T_{\text {tubo }}\right)$ para que seja possível calcular $T_{p 6}$ a partir de $T_{p 4}$, conforme Equações (4.2.2a), (4.2.2b) e (4.2.2c), assumindo conexões isotérmicas de entrada e saída do tubo de retenção.

$$
\begin{aligned}
& T_{p 4}=T_{p 3} \\
& T_{p 5}=T_{p 4}-\Delta T_{\text {tubo }} \\
& T_{p 6}=T_{p 5}
\end{aligned}
$$


Como a eficiência térmica de um trocador depende de seu arranjo de escoamento, a sua determinação não é trivial. A hipótese de arranjo puramente contracorrente (Modelo 1) simplifica muito a determinação da eficiência térmica. A eficiência térmica para arranjo contracorrente $\left(\varepsilon_{c c}\right)$ pode ser determinada através da Equação (4.2.3a), em que $C C^{*}$ é a razão entre as capacidades caloríficas mínima e máxima $\left(0<C C^{*} \leq 1\right)$, definida na Equação (4.2.3b), em que os sobrescritos quente e frio se referem aos lados do trocador. Sabe-se que $\varepsilon$ $<\varepsilon_{c c}$ para outros arranjos de escoamento (Hewitt et al., 1994; Shah e Sekulik, 1998).

$$
\begin{array}{ll}
\varepsilon_{c c}= \begin{cases}\frac{1-\exp \left[-N T U \cdot\left(1-C C^{*}\right)\right]}{1-C C^{*} \cdot \exp \left[-N T U \cdot\left(1-C C^{*}\right)\right]} & \text { se } 0<C C^{*}<1 \\
\frac{N T U}{N T U+1} & \text { se } C C^{*}=1\end{cases} \\
C C^{*}=\frac{\min \left(C C^{\text {quente }}, C C^{\text {frio }}\right)}{\max \left(C C^{\text {quente }}, C C^{\text {frio }}\right)}
\end{array}
$$

Na Equação (4.2.3a), NTU é o número de unidades de transferência de calor. Esta variável adimensional é definida na Equação (4.2.4) como uma função do coeficiente global de troca térmica do trocador $(U)$ e da área de troca térmica $(A)$. No caso de um trocador de calor a placas, tem-se que $A=\left(N_{C}-1\right) \cdot A_{\text {placa }}$, em que $N_{C}$ é o número de canais e $A_{\text {placa }}$ é a área de troca térmica de uma placa.

$$
N T U=\frac{U \cdot A}{\min \left(C C^{\text {quente }}, C C^{\text {frio }}\right)}
$$

O coeficiente global de troca térmica pode ser calculado através da Equação (4.2.5) considerando uma associação em série de resistências térmicas, incluindo os termos de resistência convectiva dos fluidos $(1 / h)$, resistência condutiva da placa metálica $\left(e_{\text {placa }} / k_{\text {placa }}\right)$ e resistência da camada de incrustação $(R F)$. Nesta equação, $h$ é o coeficiente de convecção do fluido sobre a placa, $k_{\text {placa }}$ é a condutividade térmica do material da placa, $e_{\text {placa }}$ é a espessura da placa e $R F$ é o fator de incrustação (fouling factor) (Hewitt et al., 1994; Shah e Sekulik, 1998). Fatores de incrustação típicos para trocadores de calor a placas são reportados por Marriott (1971).

$$
\frac{1}{U}=\frac{1}{h^{\text {quente }}}+\frac{1}{h^{\text {frio }}}+\frac{e_{\text {placa }}}{k_{\text {placa }}}+R F^{\text {quente }}+R F^{\text {frio }}
$$

O coeficiente de convecção do fluido depende da velocidade do fluido no canal. Assumindo distribuição uniforme do fluxo entre os canais que compõem um passe do trocador, a velocidade média ( $v$ ) pode ser calculada pela Equação (4.2.6), em que $N$ é o número canais por passe, $\rho$ é a densidade do fluido e $A_{\text {canal }}$ é a área da seção transversal ao 
escoamento no canal (Equação (3.1.2)), considerando as dimensões $b$ (espessura) e $w$ (largura) (Figura 3.1.2).

$$
v=\frac{W}{\rho \cdot N \cdot A_{\text {canal }}}
$$

Correlações empíricas entre os adimensionais número de Nusselt, número de Reynolds e número de Prandtl são a forma mais comum de obtenção do coeficiente de convecção do fluido; entretanto, para trocadores de calor a placas, estas correlações são dependentes do tipo de corrugação da placa e do ângulo de inclinação das ranhuras (Raju e Bansal, 1983; Shah e Focke, 1988; Kakaç e Liu, 2002, Ibarz e Barbosa-Cánovas, 2003). Os três adimensionais mencionados são definidos nas Equações (4.2.7a), (4.2.7b) e (4.2.7c), em que $k$ é a condutividade térmica do fluido, $\mu$ é a viscosidade Newtoniana do fluido e $D_{e}$ é o diâmetro equivalente do canal do trocador (Equação 3.1.3). As propriedades termo-físicas são avaliadas na temperatura média do fluido. No caso de fluidos não-Newtonianos do tipo lei de potência, adota-se o conceito de viscosidade generalizada apresentado por Carezzato et al. (2007).

$$
\begin{aligned}
& N u=\frac{h \cdot D_{e}}{k} \\
& \operatorname{Re}=\frac{D_{e} \cdot v \cdot \rho}{\mu} \\
& \operatorname{Pr}=\frac{C p \cdot \mu}{k}
\end{aligned}
$$

A hipótese de escoamento puramente contracorrente $\left(\varepsilon \cong \varepsilon_{c c}\right)$ é viável para trocadores de calor a placas com arranjo simétrico (mesmo número de passes e canais por passe nos dois lados do trocador, ou seja, $P^{I}=P^{I I}$ e $\left.N^{I}=N^{I I}\right)$, elevado número de canais por passe $\left(P^{I}\right.$ e $\left.P^{I I}\right)$ e entradas em lados opostos do pacote de placas com $\phi=3$ para número ímpar de passes ou $\phi=$ 4 para número par de passes (Figura 3.1.3). Neste caso, o fluxo é contracorrente na maioria dos canais do pacote de placas (Pignotti e Tamborenea, 1988; Kandlikar e Shah, 1989; Gut et al., 2004).

Para a correta determinação da eficiência térmica do trocador de calor com um arranjo de escoamento que seja diferente do puro contracorrente, o balanço diferencial de energia deve ser aplicado ao longo do percurso dos fluidos no trocador. Para um trocador de calor a placas, assumindo escoamento pistonado unidimensional na altura da placa, sem difusão axial de calor no canal, distribuição uniforme de fluxo no passe, o modelo térmico pode ser formulado como um sistema linear de equações diferenciais ordinárias de valor de contorno (Zaleski, 1984; Georgiadis e Macchietto, 2000; Strelow, 2000; Gut e Pinto, 2003a). 
A solução deste sistema de equações, usando condições de contorno de ligação entre os passes, fornece a distribuição axial de temperatura ao longo de todos os canais e, consequentemente, as temperaturas de saída e a eficiência térmica do trocador. A determinação da eficiência térmica por este caminho é descrita na Seção 4.2.1. Modelos que consideram o escoamento bi- ou tridimensional dentro dos canais do trocador são de grande complexidade e requerem o uso de ferramentas de CFD (computational fluid dynamics) para resolução (Grijspeerdt et al., 2003; Fernandes et al., 2005; Galeazzo et al., 2006).

Retomando a discussão inicial, para que seja possível a resolução do sistema de equações definido pelas Equações (4.2.1a), (4.2.1b) e (4.2.1c), incluindo as Equações (4.2.2a), (4.2.2b) e (4.2.2c), são necessárias as eficiências térmicas das três seções de troca térmica $\left(\varepsilon^{R}\right.$, $\varepsilon^{H}$ e $\left.\varepsilon^{C}\right)$, sejam elas calculadas assumindo escoamento puramente contracorrente ou modelando termicamente o trocador. Este sistema de equações pode ser reordenado para que seja possível calcular sequencialmente as temperaturas ao longo do trajeto do produto alimentício ( $T_{p 2}$ a $T_{p 8}$ na Figura 4.1.1), conforme Equações (4.2.8a) a (4.2.8g) (Gut e Pinto, 2009). As variáveis auxiliares $\omega_{R 1}, \omega_{R 2}, \omega_{H}$ e $\omega_{C}$ são definidas nas Equações (4.2.9a), (4.2.9b), (4.2.9c) e (4.2.9d).

$$
\begin{aligned}
& T_{p 2}=\frac{\omega_{R 1} \cdot\left(\omega_{H} \cdot T_{h 1}-\Delta T_{\text {tubo }}\right)+\left(1-\omega_{R 1}\right) \cdot T_{p 1}}{1-\omega_{R 1} \cdot\left(1-\omega_{H}\right)} \\
& T_{p 3}=\omega_{H} \cdot T_{h 1}+\left(1-\omega_{H}\right) \cdot T_{p 2} \\
& T_{p 4}=T_{p 3} \\
& T_{p 5}=T_{p 4}-\Delta T_{\text {tubo }} \\
& T_{p 6}=T_{p 5} \\
& T_{p 7}=\omega_{R 2} \cdot T_{p 1}+\left(1-\omega_{R 2}\right) \cdot T_{p 6} \\
& T_{p 8}=\omega_{C} \cdot T_{c 1}+\left(1-\omega_{C}\right) \cdot T_{p 7} \\
& \omega_{R 1}=\varepsilon^{R} \cdot \frac{\min \left(C_{p 1-2}, C_{p 6-7}\right)}{C_{p 1-2}} \\
& \omega_{R 2}=\varepsilon^{R} \cdot \frac{\min \left(C_{p 1-2}, C_{p 6-7}\right)}{C_{p 6-7}} \\
& \omega_{H}=\varepsilon^{H} \cdot \frac{\min \left(C_{h 1-2}, C_{p 2-3}\right)}{C_{p 2-3}}
\end{aligned}
$$




$$
\omega_{C}=\varepsilon^{C} \cdot \frac{\min \left(C_{c 1-2}, C_{p 7-8}\right)}{C_{p 7-8}}
$$

Para a resolução do modelo, considera-se que as temperaturas de alimentação $T_{p 1}, T_{h 1}$ e $T_{c 1}$ sejam conhecidas. Alternativamente, pode-se especificar a temperatura de processamento $T_{p 5}$, que é uma variável controlada, deixando livre a temperatura de alimentação do produto $T_{p 1}$ ou a temperatura de alimentação da água quente $T_{h 1}$, que normalmente é a variável de processo controlada. Neste caso, a sequência de resolução das Equações (4.2.8a) a (4.2.8g) deve ser alterada de acordo.

Nos Modelos 1 e 2, assume-se variação linear de temperaturas entre os pontos do trajeto do produto alimentício ( $T_{p 1}$ a $T_{p 8}$ na Figura 4.1.1), tendo como diferença a forma de obtenção das eficiências térmicas $\varepsilon^{R}$, $\varepsilon^{H}$ e $\varepsilon^{C}$. Para o Modelo 1 utilizou-se a Equação (4.2.3a), assumindo escoamento contracorrente e para o Modelo 2 foi solucionado o modelo térmico de cada trocador levando em conta a real configuração de escoamento. O Modelo 3 é similar ao Modelo 2, na medida em que é usado o modelo térmico do trocador; entretanto, não é adotada a hipótese de variação linear de temperatura ao longo dos trocadores. Em vez disso, são usados os perfis de temperatura nos canais do trocador originados na resolução do modelo térmico. Este modelo é descrito na Seção 4.2.1.

\subsubsection{Modelo térmico de um trocador de calor a placas}

A carga térmica de um trocador de calor a placas (q), para operação em estado estacionário, sem mudanças de fases ou trocas de calor com o ambiente, pode ser obtida através das Equações (4.2.10a), (4.2.10b) e (4.2.10c), em que os sobrescritos I e II referem-se aos lados I (canas ímpares) e II (canais pares) do trocador e os subscritos sai e ent referem-se à saída e à entrada do trocador.

$$
\begin{aligned}
& q=C C^{I} \cdot\left|T^{I}{ }_{\text {sai }}-T^{I}{ }_{\text {ent }}\right| \\
& q=C C^{I I} \cdot\left|T^{I I}{ }_{\text {sai }}-T^{I I}{ }_{\text {ent }}\right| \\
& q=\varepsilon \cdot q^{\text {max }}=\varepsilon \cdot \min \left(C C^{I}, C C^{I I}\right) \cdot\left|T^{I}{ }_{\text {ent }}-T^{I I}{ }_{\text {ent }}\right|
\end{aligned}
$$

As correntes quente e fria são associadas aos lados I e II do trocador através do parâmetro binário $Y_{h}$ (Figura 3.1.3). Para que seja possível resolver estas três equações e determinar a carga térmica e as duas temperaturas de saída, a eficiência térmica $(\varepsilon)$ deve ser conhecida. Para obtê-la é necessário modelar termicamente o trocador de calor, aplicando balanços diferenciais de energia ao longo dos canais de escoamento. 
Assumindo escoamento pistonado unidimensional dentro dos canais do trocador, distribuição uniforme de fluxo nos canais do passe, desprezando a difusão axial de calor e adotando valores médios para as propriedades termo-físicas dos fluidos quente e frio, o modelo térmico do trocador de calor a placas pode ser expresso através do sistema linear de equações diferenciais ordinárias apresentado nas Equações (4.2.11) e (4.2.12). A dedução deste modelo é apresentada por Gut e Pinto (2003a) e Gut e Pinto (2009).

$$
\begin{aligned}
& \frac{d \underline{\underline{\varphi}}}{d \eta}=\underline{\underline{M}} \cdot \underline{\varphi} \\
& \underline{\underline{M}}=\left[\begin{array}{cccccc}
-m_{1} & +m_{1} & 0 & 0 & \ldots & 0 \\
+m_{2} & -2 . m_{2} & +m_{2} & 0 & \cdots & 0 \\
0 & +m_{3} & -2 . m_{3} & +m_{3} & & \vdots \\
\vdots & & & & & 0 \\
0 & \ldots & 0 & +m_{N_{C}-1} & -2 m_{N_{C}-1} & +m_{N_{C}-1} \\
0 & \ldots & 0 & 0 & +m_{N_{C}} & -m_{N_{C}}
\end{array}\right]_{N_{C} \times N_{C}}
\end{aligned}
$$

Cada equação do sistema corresponde ao balanço diferencial de energia aplicado a um dos canais do trocador, levando em conta a troca térmica com os canais vizinhos através das placas. A temperatura no canal é expressa na forma adimensional definida pela Equação (4.2.13) $(0 \leq \varphi \leq 1)$ e o comprimento do canal é adimensionalizado usando a Equação (4.2.14) $(0 \leq \eta \leq 1)$.

$$
\begin{aligned}
& \varphi(\eta)=\frac{T(\eta)-T_{\text {ent }}^{\text {frio }}}{T_{\text {ent }}^{\text {quente }}-T_{\text {ent }}^{\text {frio }}} \\
& \eta=\frac{x}{L}
\end{aligned}
$$

Os coeficientes da matriz tridiagonal na Equação (4.2.12) são dados pela Equação (4.2.15), sendo que o sinal é positivo para canal com escoamento na direção crescente de $x$ e negativo para canal com escoamento na direção decrescente de $x$. As variáveis $\alpha^{I}$ e $\alpha^{I I}$ são os coeficientes adimensionais de transferência de calor para os lados I e II do trocador, conforme definição nas Equações (4.2.16a) e (4.2.16b), em que $U$ é coeficiente global de troca térmica do trocador (Equação (4.2.5)).

$$
\begin{aligned}
& m_{i}= \begin{cases} \pm \alpha^{I} & \text { se i é ímpar } \\
\pm \alpha^{I I} & \text { se } i \text { é par }\end{cases} \\
& \alpha^{I}=\frac{A_{\text {placa }} \cdot U \cdot N^{I}}{C C^{I}}
\end{aligned}
$$




$$
\alpha^{I I}=\frac{A_{\text {placa }} \cdot U \cdot N^{I I}}{C C^{I I}}
$$

Para resolver a Equação (4.2.11), um conjunto de $N_{C}$ condições de contorno é necessário. Estas condições de contorno devem fornecer a temperatura na entrada de cada canal $i$ (posições $\eta=0$ ou $\eta=1$, dependendo do sentido do escoamento). Para isso, assume-se que a temperatura de entrada no canal é aquela da mistura perfeita ao fim do passe anterior, conforme Equação (4.2.17).

$$
\varphi_{e n t, i}=\frac{\sum_{j=1}^{N} \varphi_{s a i, j}}{N}, \quad \text { canais } i \text { e } j \text { pertencem a passes subsequentes }
$$

A temperatura de entrada para os canais do primeiro passe é uma variável especificada $\left(\varphi_{\text {ent }}^{I}\right.$ e $\left.\varphi_{\text {ent }}^{I I}\right)$. Já a temperatura de saída do trocador é calculada após a resolução do sistema de equações diferenciais através da Equação (4.2.18), considerando o fim do último passe.

$$
\varphi_{\text {sai }}=\frac{\sum_{j=1}^{N} \varphi_{s a i, j}}{N} \quad, \quad \text { canais } j \text { pertencem ao último passe }
$$

O sistema de equações diferenciais na Equação (4.2.11) pode ser resolvido analiticamente (Zaleski, 1984; Zaleski e Klepacka, 1992; Strelow, 2000) ou numericamente (Jackson e Troupe, 1966; Georgiadis e Macchietto, 2000; Gut e Pinto, 2003a). Como solução tem-se as distribuições da temperatura adimensional ao longo dos canais do trocador, $\varphi_{i}(\eta)(1$ $\leq i \leq N_{C}$ ), e as temperaturas adimensionais de saída nos dois lados do trocador, $\varphi_{\text {sai }}{ }^{I}$ e $\varphi_{\text {sai }}{ }^{I I}$. Para finalizar, a eficiência térmica do trocador pode ser calculada através da Equação (4.2.19).

$$
\varepsilon=\frac{N^{I}}{\alpha^{I}} \cdot \max \left(\frac{\alpha^{I}}{N^{I}}, \frac{\alpha^{I I}}{N^{I I}}\right) \cdot\left|\varphi_{\text {sai }}{ }^{I}-\varphi_{\text {ent }}{ }^{I}\right|=\frac{N^{I I}}{\alpha^{I I}} \cdot \max \left(\frac{\alpha^{I}}{N^{I}}, \frac{\alpha^{I I}}{N^{I I}}\right) \cdot\left|\varphi_{\text {sai }}{ }^{I I}-\varphi_{\text {ent }}{ }^{I I}\right|
$$

\subsection{Modelagem do escoamento}

Para determinar a letalidade através do modelo do processo são necessárias as distribuição de temperatura e de tempo de residência ao longo do percurso do produto alimentício. A distribuição de temperatura pode ser determinada através do equacionamento apresentado na Seção 4.2, que fornece a temperatura do produto nos pontos p1 a p8 na Figura 4.1.1. Seguindo a hipótese de escoamento pistonado sem dispersão axial adotada no modelo térmico, a distribuição do tempo de residência será contemplada apenas pelo tempo de residência médio ou pelo tempo espacial em cada trecho do percurso. 
O tempo espacial foi definido na Equação (3.3.5) como a razão entre o volume interno do equipamento e a vazão volumétrica que o atravessa. O tempo médio de residência é inferior ao tempo espacial, pois o volume ativo no interior do equipamento é menor do que o volume total, já que este pode conter zonas de recirculação ou estagnação (Equações (3.3.6a) e (3.3.6b)).

Caso esteja disponível o valor do tempo médio de residência $\left(t_{m}\right)$ correspondente a cada trecho do percurso p1 a p8 na Figura 4.1.1, nas condições do processo, este valor é adotado como tempo de residência. Caso contrário, é utilizado o tempo espacial ( $\tau$ ) (Equação (3.3.5)). Para os Modelos 1 e 2, considera-se que a temperatura do produto varie linearmente de um ponto a outro (p1 a p8 na Figura 4.1.1) ao longo do tempo de residência. No Modelo 3 tem-se a distribuição não-linear de temperatura nos canais do trocador de calor determinada conforme o modelo térmico da Seção 4.2.1.

Pontos adicionais podem ser incluídos no trajeto do produto na Figura 4.1.1 para contemplar outras conexões, por exemplo. Estas conexões podem ser isotérmicas ou ter uma queda de temperatura conhecida. Pode-se considerar, por exemplo, a passagem da seção de regeneração para a seção de aquecimento através da grade conectora do trocador de calor a placas.

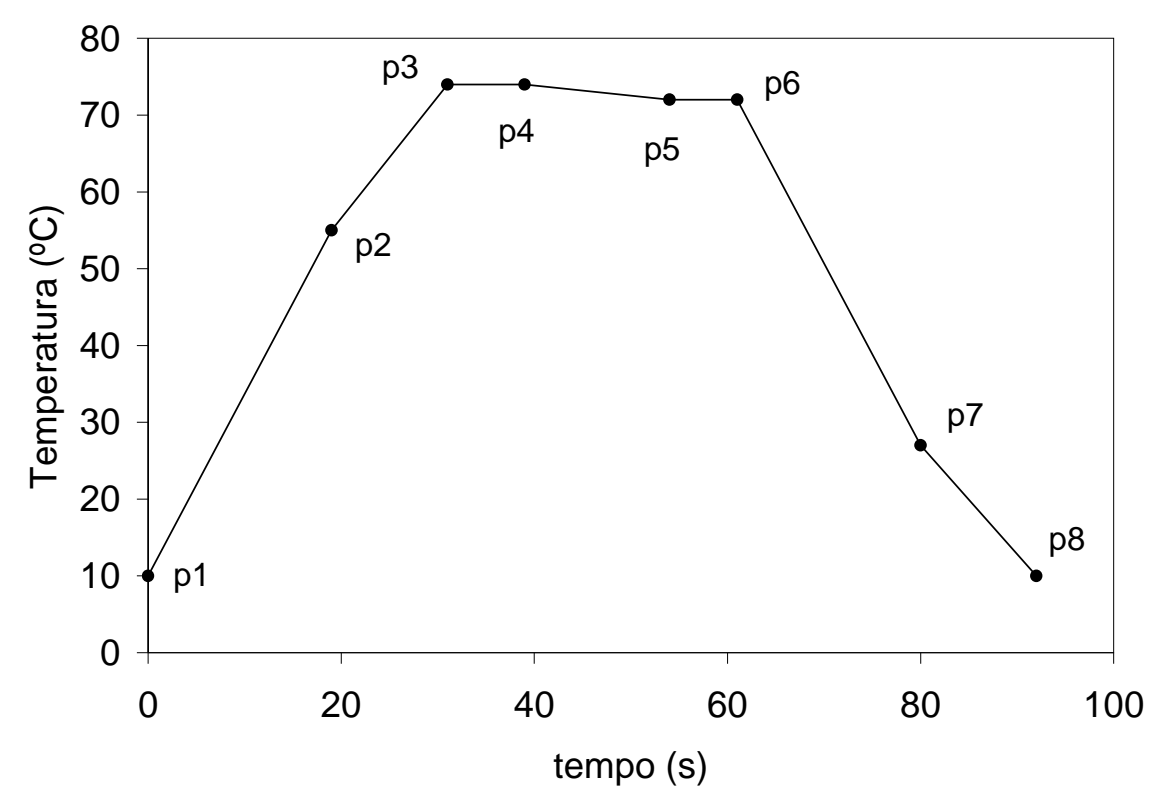

Figura 4.3.1. Exemplo de histórico de temperatura do produto que pode ser obtido através da modelagem matemática do processo de pasteurização.

A combinação da distribuição de temperatura com os valores dos tempos de residência em cada trecho do processo fornece o histórico de temperatura média $T(t)$ do produto no 
processo de pasteurização, como mostra o exemplo ilustrativo na Figura 4.3.1 para um caso de pasteurização HTST a $72{ }^{\circ} \mathrm{C}\left(T_{p 5}\right)$ com 15 s de retenção $(\mathrm{p} 4 \rightarrow \mathrm{p} 5)$. Os dados de temperatura e de tempo de residência usados para este exemplo ilustrativo são apresentados na Tabela 4.3.1. Foi considerada a hipótese de variação linear de temperatura entre pontos.

Tabela 4.3.1. Valores de temperatura e de tempo de residência médio para o exemplo ilustrativo de obtenção do histórico de temperatura do produto no processo de pasteurização.

\begin{tabular}{cccc}
\hline Ponto & $T\left({ }^{\circ} \mathrm{C}\right)$ & $t_{m}(\mathrm{~s})$ & $t(\mathrm{~s})$ \\
\hline p1 & 10 & - & 0 \\
p2 & 55 & 19 & 19 \\
p3 & 74 & 12 & 31 \\
p4 & 74 & 8 & 39 \\
p5 & 72 & 15 & 54 \\
p6 & 72 & 7 & 61 \\
p7 & 27 & 19 & 80 \\
p8 & 10 & 12 & 92 \\
\hline
\end{tabular}

\subsection{Modelagem da letalidade}

A partir do histórico de temperatura obtido através da distribuição de temperatura e da determinação do tempo de residência médio de cada trecho, pode-se avaliar a letalidade sobre algum atributo de segurança, como a população de um micro-organismo patogênico, ou mesmo a degradação de algum atributo de qualidade, com a atividade de alguma enzima ou concentração de um nutriente termolábil. Esta avaliação é realizada através do conceito de letalidade integrada.

Geralmente a cinética de degradação térmica no processamento de alimentos é expressa pela cinética de $1^{\text {a }}$ ordem com parâmetros cinéticos $D_{\text {ref }}$ e $z$ válidos para uma determinada faixa de temperatura e condições de processamento. O parâmetro $D_{\text {ref }}$ representa o tempo na temperatura de referência para ter uma redução de $90 \%$ na concentração do atributo, enquanto que $z$ representa o aumento de temperatura necessário para ter uma redução de $90 \%$ no valor de $D_{T}$. Considerando o processamento térmico a uma temperatura constante $T$, é possível determinar o valor de $D_{T}$ nesta temperatura através da Equação (4.4.1), valor este que corresponde ao intervalo de tempo necessário para ter uma redução de 90\% (uma decada logarítmica ou redução decimal) sobre a concentração de um atributo (CA). Nesta equação, 
$D_{\text {ref }}$ corresponde ao parâmetro cinético $D_{T}$ válido para a temperatura de referência $T_{\text {ref }}$ (Toledo, 2007).

$$
D_{T}=D_{r e f} \cdot \operatorname{alog}\left(\frac{T_{r e f}-T}{Z}\right)
$$

Considerando uma concentração inicial $C A_{0}$ e um tempo de processo isotérmico $F_{T}$ na temperatura $T$, também denominado Valor-F, a concentração final do atributo pode ser determinada através da Equação (4.4.2a). De forma, análoga, a concentração em um instante $t$ pode ser determinada através da Equação (4.4.2b).

$$
\begin{aligned}
& \log \left(\frac{C A}{C A_{0}}\right)=-\frac{F_{T}}{D_{T}} \\
& \log \left(\frac{C A(t)}{C A_{0}}\right)=-\frac{t}{D_{T}}
\end{aligned}
$$

Um histórico de temperatura não isotérmico, como o exemplificado na Figura 4.3.1 pode ser aproximado por uma sequência de processos isotérmicos de duração infinitesimal dt. Cada um destes processos provoca uma alteração no atributo que é equivalente a de um processo isotérmico realizado na temperatura de referência e com duração $\mathrm{d} F_{\text {ref. }}$ Partindo das Equações (4.4.2a) e (4.4.1), tem-se $\mathrm{d} F_{r e f}$ na Equação (4.4.3a). A função letalidade $L t$ na Equação (4.4.3b) é definida a partir da segunda expressão na Equação (4.4.3a).

$$
\begin{array}{lll}
\frac{\mathrm{d} F_{r e f}}{D_{\text {ref }}}=\frac{\mathrm{d} t}{D_{T}} & \rightarrow & \mathrm{d} F_{\text {ref }}=\frac{\mathrm{d} t}{\operatorname{alog}\left(\frac{T_{r e f}-T}{Z}\right)} \\
\mathrm{d} F_{r e f}=L t \cdot \mathrm{d} t & \rightarrow & L t=\operatorname{alog}\left(\frac{T-T_{r e f}}{Z}\right)
\end{array}
$$

A integração de $\mathrm{d} F_{\text {ref }}$ no tempo de processamento fornece $F_{\text {ref }}$ ou "letalidade integrada" (Equação (4.4.4)), que representa o tempo de processo isotérmico que é equivalente ao processo não isotérmico para o impacto sobre o atributo avaliado.

$$
F_{r e f}=\int_{0}^{t} \mathrm{~d} F_{r e f}=\int_{0}^{t} L t \cdot \mathrm{d} t=\int_{0}^{t} \mathrm{alog}\left(\frac{T(t)-T_{r e f}}{Z}\right) \mathrm{d} t
$$

A variável $F_{\text {ref }}$ é muito usada para avaliação da letalidade de processos não isotérmicos, pois pode ser comparada com o tempo de processo desejado assumindo condições ideais de processamento na temperatura de referência (aquecimento e resfriamento instantâneos e retenção isotérmica). Outra variável muito utilizada para este propósito é o valor de 
esterilização (SV) que representa o número de reduções decimais na concentração de um atributo de segurança ou qualidade microbiológica, conforme Equação (4.4.5).

$$
S V=\log \left(\frac{C A_{0}}{C A}\right)=\frac{F_{r e f}}{D_{r e f}}=\frac{\int_{0}^{t} \operatorname{alog}\left(\frac{T(t)-T_{r e f}}{Z}\right) d t}{D_{r e f}}
$$

No caso do atributo ser uma concentração de nutriente, é mais usual a avaliação através da variável $C A R$ que representa a concentração residual do atributo em porcentagem ou fração (Equação (4.4.6a)). Analogamente, tem-se a variável $A E R$ na Equação (4.4.6b) para representar a atividade residual de uma enzima, em relação à atividade inicial $A E_{0}(\mathrm{U} / \mathrm{L})$.

$$
\begin{gathered}
C A R=\frac{C A}{C A_{0}}=\operatorname{alog}\left(-\frac{F_{r e f}}{D_{\text {ref }}}\right)=\operatorname{alog}\left(-\frac{\int_{0}^{t} \operatorname{alog}\left(\frac{T(t)-T_{r e f}}{Z}\right) \mathrm{d} t}{D_{\text {ref }}}\right) \\
A E R=\frac{A E}{A E_{0}}=\operatorname{alog}\left(-\frac{F_{r e f}}{D_{r e f}}\right)=\operatorname{alog}\left(-\frac{\int_{0}^{t} \operatorname{alog}\left(\frac{T(t)-T_{r e f}}{z}\right) d t}{D_{r e f}}\right)
\end{gathered}
$$

A resolução da Equação (4.4.4) é normalmente feita por integração numérica da função letalidade, calculada ao longo do histórico de temperatura (Toledo, 2007). Como no caso dos Modelos 1 e 2 testados neste trabalho o perfil de temperatura é considerado linear, é possível resolver analiticamente a Equação (4.4.4) substituindo a Equação (4.4.7) que representa um trecho do processo com temperaturas de entrada e saída $T_{\text {ent }}$ e $T_{\text {sai }}$, respectivamente, e tempo de residência $t_{m}$. Como solução tem-se o valor de $F_{\text {ref }}$ referente a este trecho através da Equação (4.4.8a) (Gut e Pinto, 2009), válida quando $T_{\text {sai }} \neq T_{\text {ent. }}$ Para o caso de $T_{\text {sai }}=T_{\text {ent }}$ (isotérmico), a solução da integral na Equação (4.4.4) é simples, conforme Equação (4.4.8b). O valor de $F_{\text {ref }}$ do processo é obtido pelo somatório de $F_{\text {ref }}$ dos trechos individuais do histórico de temperatura.

$$
\begin{aligned}
& T(t)=T_{\text {ent }}+\frac{\left(T_{\text {sai }}-T_{\text {ent }}\right)}{t_{m}} \cdot t \\
& F_{\text {ref }}=\frac{Z \cdot t_{m}}{\left(T_{\text {sai }}-T_{\text {ent }}\right) \cdot \ln (10)}\left[\operatorname{alog}\left(\frac{T_{\text {sai }}-T_{\text {ref }}}{Z}\right)-\operatorname{alog}\left(\frac{T_{\text {ent }}-T_{\text {ref }}}{Z}\right)\right] \\
& F_{\text {ref }}=\operatorname{alog}\left(\frac{T(t)-T_{\text {ref }}}{Z}\right) \cdot t \quad \text { se } T_{\text {sai }}=T_{\text {ent }}
\end{aligned}
$$


Para ilustrar o cálculo da letalidade integrada, a função letalidade foi calculada sobre o histórico de temperatura exemplificado na Figura 4.3.1 e também integrada, tendo como temperatura de referência $T_{\text {ref }}=72{ }^{\circ} \mathrm{C}$. O parâmetro cinético adotado foi $z=4,4{ }^{\circ} \mathrm{C}$ referente à inativação térmica da bactéria Coxiella burnetti (Cerf e Condron, 2006), de grande importância na pasteurização do leite. O resultado é apresentado na Figura 4.4.1, na qual se verifica a distribuição de temperatura e a função letalidade correspondente ( $L t$, via Equação (4.4.3b). A Figura 4.4.1 também apresenta na função letalidade correspondente ao histórico de temperatura ideal (15 s a $72{ }^{\circ} \mathrm{C}$, isotérmico) para comparação.

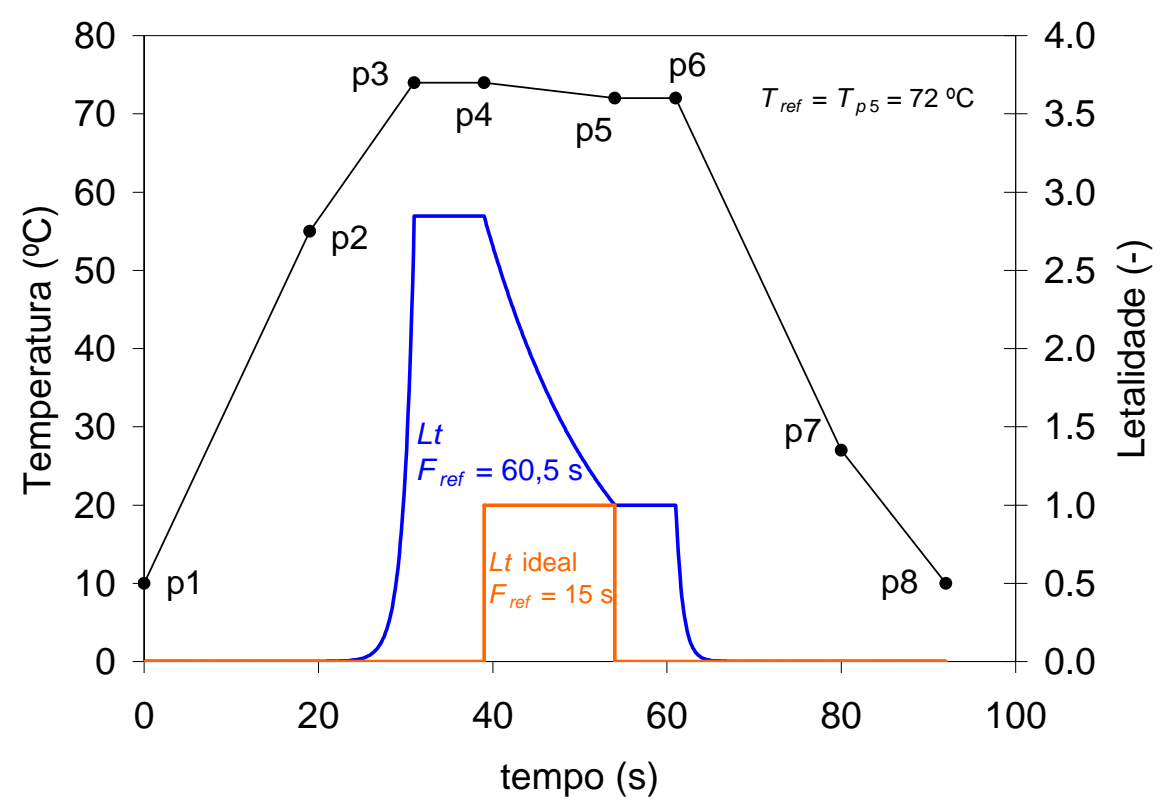

Figura 4.4.1. Exemplo de histórico de temperatura do produto com cálculo e integração da letalidade, incluindo o caso ideal de processamento isotérmico para comparação.

Tabela 4.4.1. Contribuição de cada trecho sobre a letalidade integrada para o exemplo ilustrativo de avaliação de letalidade.

\begin{tabular}{ccccc}
\hline Trecho & $F_{\text {ref }}$ do trecho (s) & $\begin{array}{c}\text { Contribuição } \\
(\%)\end{array}$ & $\begin{array}{c}F_{\text {ref }} \text { ideal no } \\
\text { trecho (s) }\end{array}$ & $\begin{array}{c}\text { Contribuição no } \\
\text { caso ideal (\%) }\end{array}$ \\
\hline $\mathrm{p} 1 \rightarrow \mathrm{p} 2$ & 0,0 & 0,0 & 0 & 0 \\
$\mathrm{p} 2 \rightarrow \mathrm{p} 3$ & 3,4 & 5,7 & 0 & 0 \\
$\mathrm{p} 3 \rightarrow \mathrm{p} 4$ & 22,8 & 37,7 & 0 & 0 \\
$\mathrm{p} 4 \rightarrow \mathrm{p} 5$ & 26,5 & 43,8 & 15 & 100 \\
$\mathrm{p} 5 \rightarrow \mathrm{p} 6$ & 7,0 & 11,6 & 0 & 0 \\
$\mathrm{p} 6 \rightarrow \mathrm{p} 7$ & 0,8 & 1,3 & 0 & 0 \\
$\mathrm{p} 7 \rightarrow \mathrm{p} 8$ & 0,0 & 0,0 & 0 & 0 \\
\hline Total & 60,5 & 100 & 15 & 100 \\
\hline
\end{tabular}


Na Figura 4.4.1 é possível avaliar o sobre-processamento pelo aumento no valor de $F_{\text {ref }}$ em relação ao valor desejado de 15 s. Este desvio está ligado principalmente às conexões de entrada e saída do tubo de retenção $(\mathrm{p} 3 \rightarrow \mathrm{p} 4 \mathrm{e} \mathrm{p} 5 \rightarrow \mathrm{p} 6)$ e à queda de temperatura de $2,0{ }^{\circ} \mathrm{C}$ no tubo de retenção $(\mathrm{p} 4 \rightarrow \mathrm{p} 5)$ que exige a elevação da temperatura na saída da seção de aquecimento (p3). A área sob a curva de letalidade na Figura 4.4.1 pode ser subdividida para avaliação das contribuições de cada trecho no valor de $F_{\text {ref }}$, como apresentado na Tabela 4.4.1. Alternativamente, pode-se avaliar a curva de letalidade integrada, obtida numericamente a partir da Equação (4.4.4), como pode-se verificar na Figura 4.4.2.

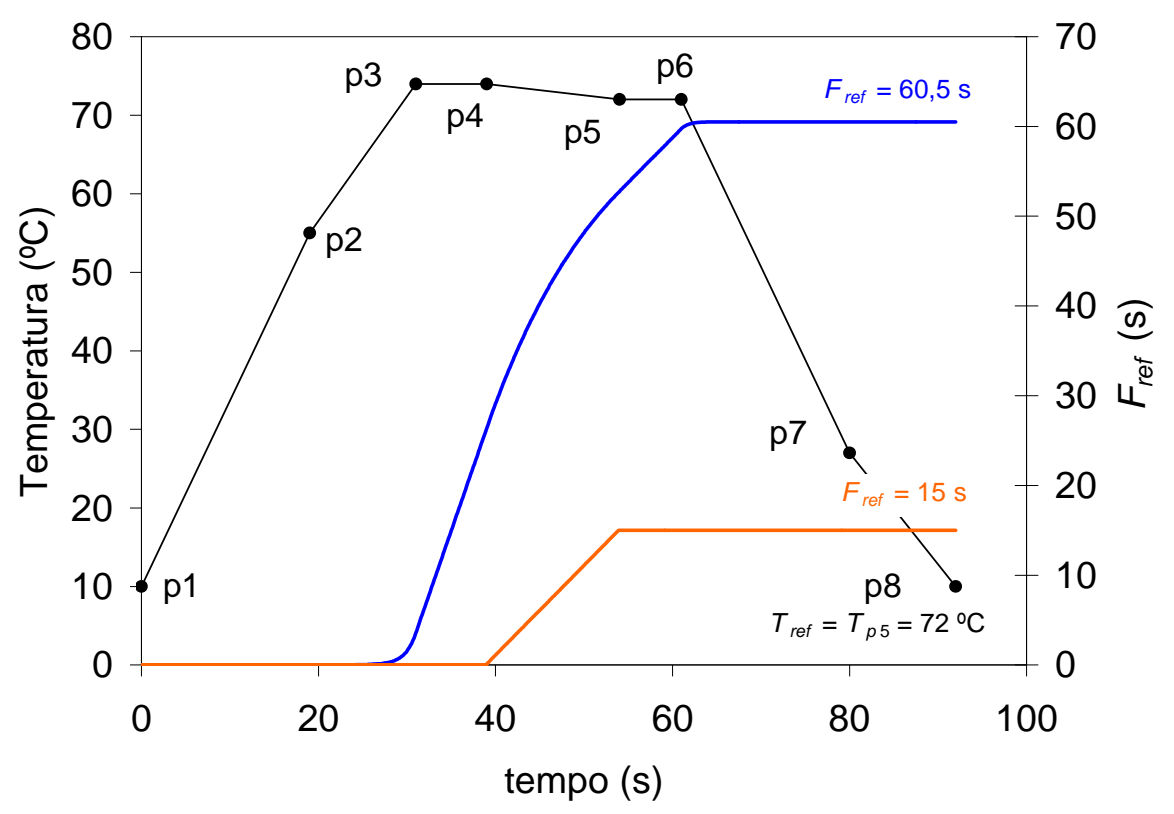

Figura 4.4.2. Exemplo de histórico de temperatura do produto com curva da letalidade integrada, incluindo o caso ideal de processamento isotérmico para comparação.

No caso do Modelo 3, os perfis de temperatura não-lineares fornecidos pelo modelo térmico dos trocadores de calor a placas são adotados para o cálculo da letalidade. Atenção deve ser dada para o caso de arranjos com mais de um canal por passe $(N>1)$. Neste caso, haverá escoamento paralelo seguido de mistura ao final de cada passe e um conjunto de condições de contorno deverá ser aplicada para avaliação da evolução da letalidade utilizando a variável $C A$ na Equação (4.4.6a) para representar a concentração de micro-organismos viáveis. 


\section{MATERIAIS E MÉTODOS}

Neste capítulo é apresentado o equipamento usado para o estudo de caso e são descritos os procedimentos experimentais dos ensaios de distribuição de temperatura e de tempo de residência. É também apresentado o procedimento usado para desenvolvimento dos indicadores enzimáticos e o uso destes indicadores como integradores de tempo-temperatura. Resultados de simulação do processo obtidos dos modelos matemáticos apresentados no Capítulo 4 são reportados e comparados com os resultados experimentais para validação.

\subsection{Equipamento de processamento térmico}

Para aplicar e validar a modelagem matemática do processamento térmico contínuo foi adotado um equipamento de escala laboratorial. Trata-se do pasteurizador a placas FT-43A (Armfield, Reino Unido), desenvolvido para pasteurização de leite a $72{ }^{\circ} \mathrm{C}$ com capacidade nominal de $20 \mathrm{~L} / \mathrm{h}$ (Figura 5.1.1). O alimento líquido armazenado em um tanque de $4 \mathrm{~L}$ é bombeado usando uma bomba peristáltica 7017-20 (Masterflex, EUA) para o trocador de calor a placas. Este trocador é dividido em três seções de troca térmica: aquecimento, regeneração e resfriamento. As placas do trocador são chapas lisas de aço inox (12 x 8 cm) e as gaxetas são de silicone. A Tabela 5.1.1 apresenta as principais características das placas.

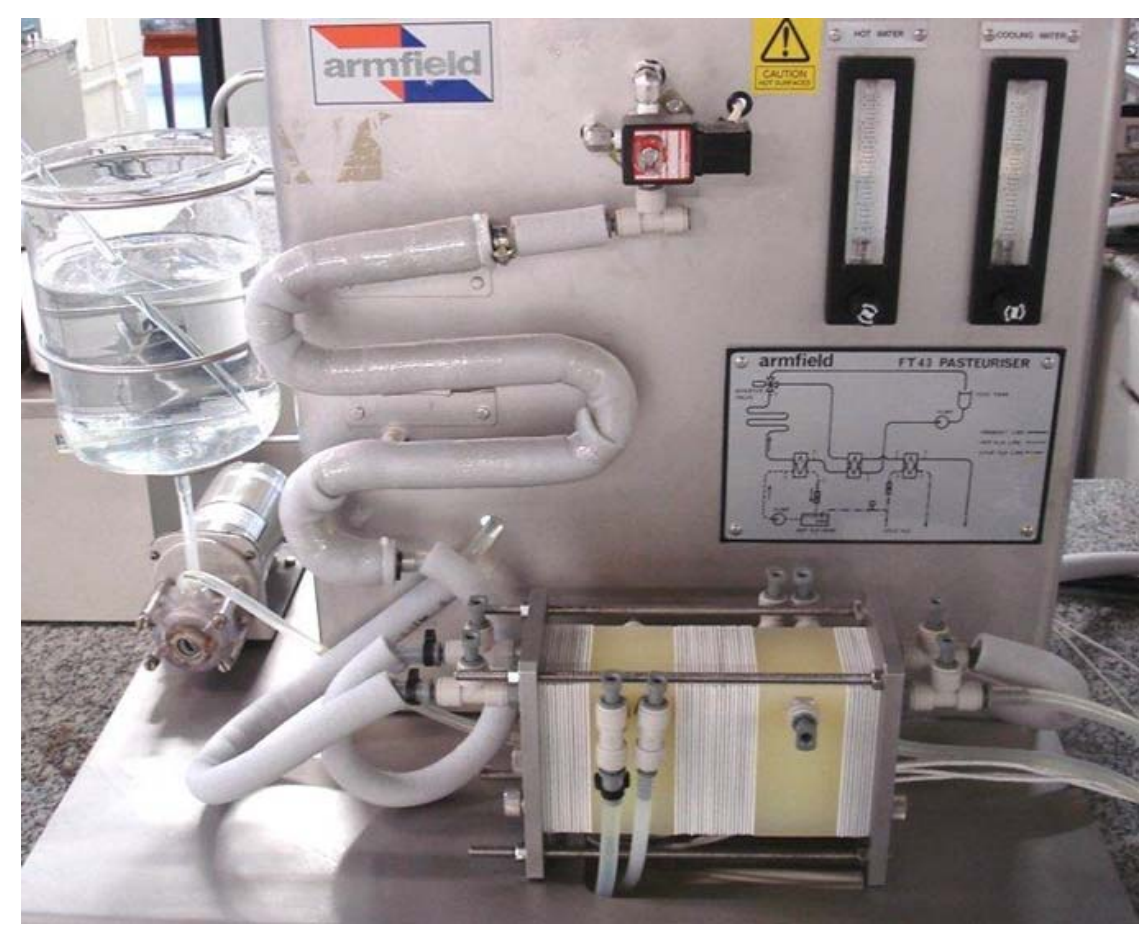

Figura 5.1.1. Pasteurizador FT-43A (Armfield, Reino Unido) com tanque de alimentação e bomba peristáltica à esquerda, tubo de retenção no centro, trocador de calor com três seções abaixo e rotâmetros no canto esquerdo superior (Aguiar, 2009). 
Tabela 5.1.1. Características das placas do trocador de calor do pasteurizador FT-43A (Armfield, Reino Unido) (Gut et al., 2004).

\begin{tabular}{lc}
\hline \multicolumn{1}{c}{ Característica } & Valor \\
\hline Comprimento da parte úmida, $L$ & $8,35 \mathrm{~cm}$ \\
Largura da parte úmida, $w$ & $6,00 \mathrm{~cm}$ \\
Espessura do canal, $b$ & $1,5 \mathrm{~mm}$ \\
Diâmetro do orifício, $D_{p}$ & $8,0 \mathrm{~mm}$ \\
Espessura da placa, $e_{\text {placa }}$ & $1,0 \mathrm{~mm}$ \\
Fator de alargamento, $\Phi$ & 1,00 \\
Área de troca térmica, $A_{\text {placa }}=L \cdot w$ & $0,00501 \mathrm{~m}^{2} /$ placa \\
Condutividade térmica do metal, $k_{\text {placa }}$ & $13,4 \mathrm{~W} / \mathrm{K} \cdot \mathrm{m}$ \\
\hline
\end{tabular}

O pasteurizador FT-43A possuiu dois tubos de retenção (Figura 5.1.2): T1, tubo padrão para processamento de leite $\left(15 \mathrm{~s}\right.$ a $72{ }^{\circ} \mathrm{C}$ ) com volume interno de $75 \mathrm{~mL}$; e T2, tubo helicoidal com volume interno de $200 \mathrm{~mL}$ para atender tempos de retenção mais longos. Os volumes foram determinados através de medidas de peso do tubo vazio e do tubo cheio de água, dada a densidade da água na temperatura ambiente. Os diâmetros interno e externo de T1 são 1,07 cm e 1,27 cm, respectivamente. Os diâmetros interno e externo de T2 são 0,93 cm e $1,27 \mathrm{~cm}$, respectivamente.

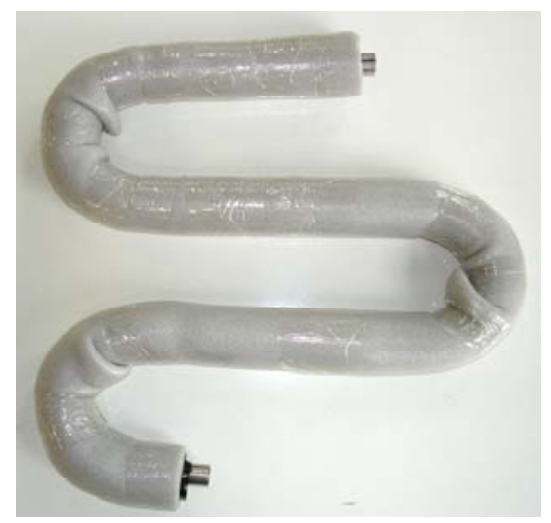

Tubo de retenção $\mathrm{T} 1$ $75 \mathrm{~mL}$

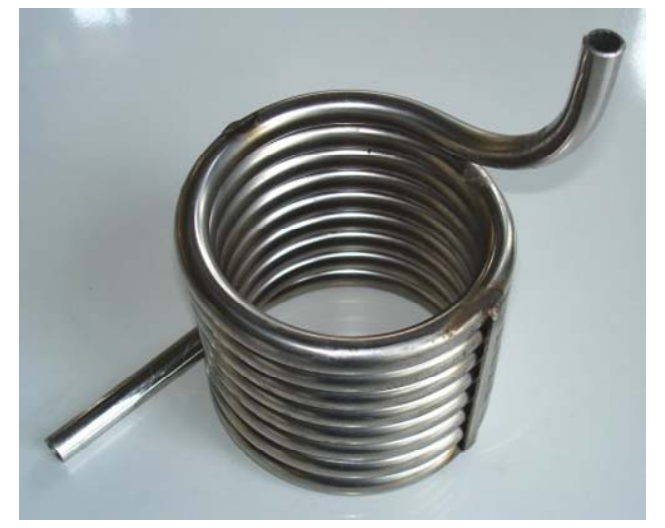

Tubo de retenção T2 $200 \mathrm{~mL}$

Figura 5.1.2. Tubos de retenção T1 e T2 do pasteurizador FT-43A (Armfield, Reino Unido), indicando os volumes internos (o isolamento térmico do tubo T2 foi removido para melhor visualização) (Gutierrez et al., 2010). 
Os três trocadores de calor possuem arranjos de passes simétricos em série e em contracorrente; isso significa que cada passe é constituído por apenas um canal, que os fluidos entram em lados opostos do pacote de placas e que os lados quente e frio possuem o mesmo número de passes. Os arranjos de passes padrões para os trocadores são: $6 \times 1 / 6 \times 1$ na seção de aquecimento, $10 \times 1 / 10 \times 1$ na seção de regeneração e $4 \times 1 / 4 \times 1$ na seção de resfriamento. Os três trocadores estão agrupados em um mesmo pedestal, como se pode notar na Figura 5.1.1 e são separados por grades conectoras confeccionados em material polimérico. As entradas e saídas dos trocadores estão localizados na parte superior dos pacotes de placas. Os parâmetros de configuração das três seções de troca térmica são apresentados na Tabela 5.1.2, de acordo com a descrição apresentada na Seção 3.1.1.

Tabela 5.1.2. Parâmetros de configuração das seções de troca térmica do pasteurizador a placas FT-43A (Armfield, Reino Unido).

\begin{tabular}{cccc}
\hline Parâmetro & Aquecimento & Regeneração & Resfriamento \\
\hline$N_{C}$ & 12 & 20 & 8 \\
$P^{I}$ & 6 & 10 & 4 \\
$P^{I I}$ & 6 & 10 & 4 \\
$\phi$ & 3 & 3 & 3 \\
$Y_{h}$ & 0 & 0 & 1 \\
$Y_{f}$ & 1 & 1 & 1 \\
\hline
\end{tabular}

Nos ensaios, o circuito de aquecimento foi mantido com uma bomba centrífuga e um banho aquecido com resistência elétrica de $1,5 \mathrm{~kW}$ ligada ao controlador de temperatura do equipamento. O circuito de água gelada foi mantido com um gerador de água gelada FT-61 (Armfield, Reino Unido) com bomba centrífuga interna e temperatura mínima de operação de $4{ }^{\circ} \mathrm{C}$. Para os dois circuitos de utilidade, o fluido utilizado foi água destilada e a vazão foi mantida no valor nominal de 1,0 L/min, ajustada através de rotâmetros e válvulas agulha.

Para o cálculo de letalidade, os volumes internos das seções são importantes, por estarem ligados ao tempo de residência médio ou tempo espacial (Equação (3.3.5)). Os volumes internos dos tubos de retenção são fornecidos na Figura 5.1.2. Os volumes internos dos trocadores de calor dependem da geometria do canal, do arranjo de passes e do número de placas. A Figura 5.1.3 apresenta as dimensões da gaxeta que forma o canal do trocador e a Figura 5.1.4 representa o cálculo do volume interno de um lado do trocador com arranjo de 
dois passes de um canal $(2 \times 1 / 2 \times 1)$. Analogamente, a Figura 5.1 .5 representa o cálculo do volume interno de um lado do trocador com arranjo de um passe de dois canais $(2 \times 1 / 2 \times 1)$.

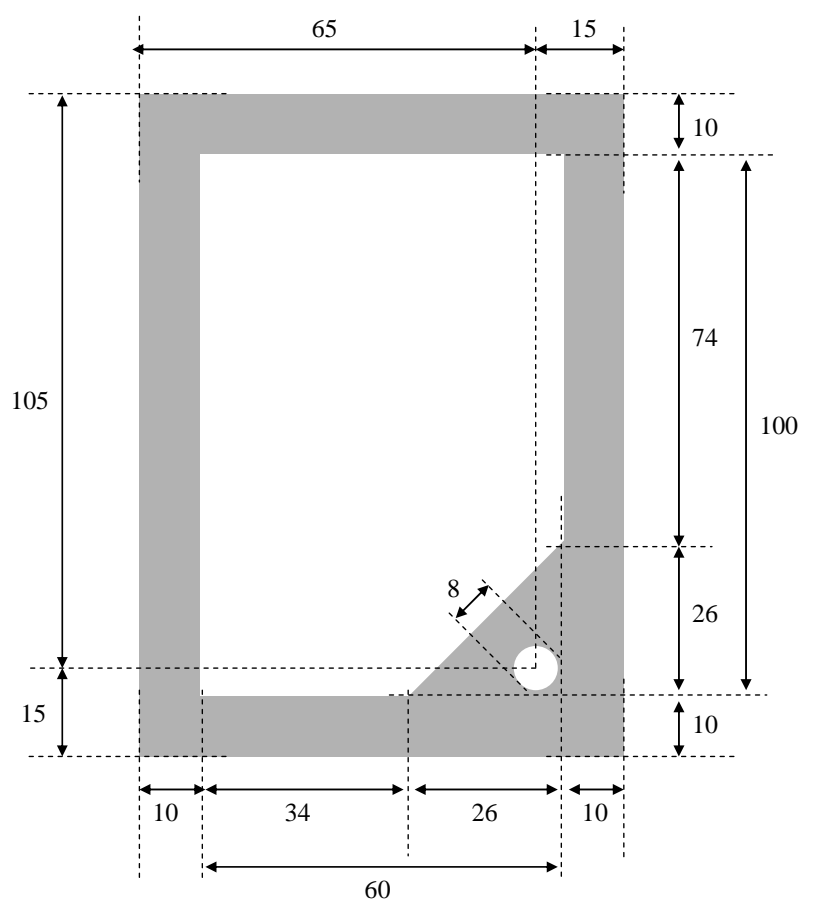

Figura 5.1.3. Dimensões da gaxeta do trocador de calor do pasteurizador FT-43A (Armfield, Reino Unido), valores em milímetros (Gutierrez, 2008).

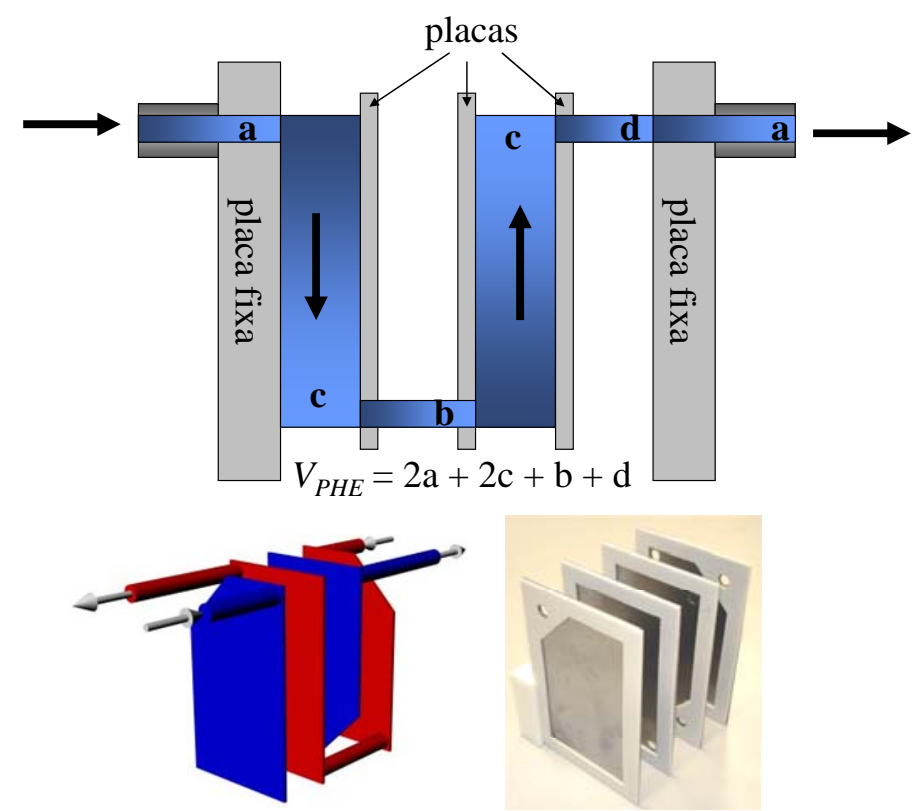

Figura 5.1.4. Determinação do volume interno do trocador de calor do pasteurizador FT-43A (Armfield, Reino Unido) com arranjo de passes em série 2×1/2×1 (Galeazzo et al., 2006; Gutierrez, 2008). 


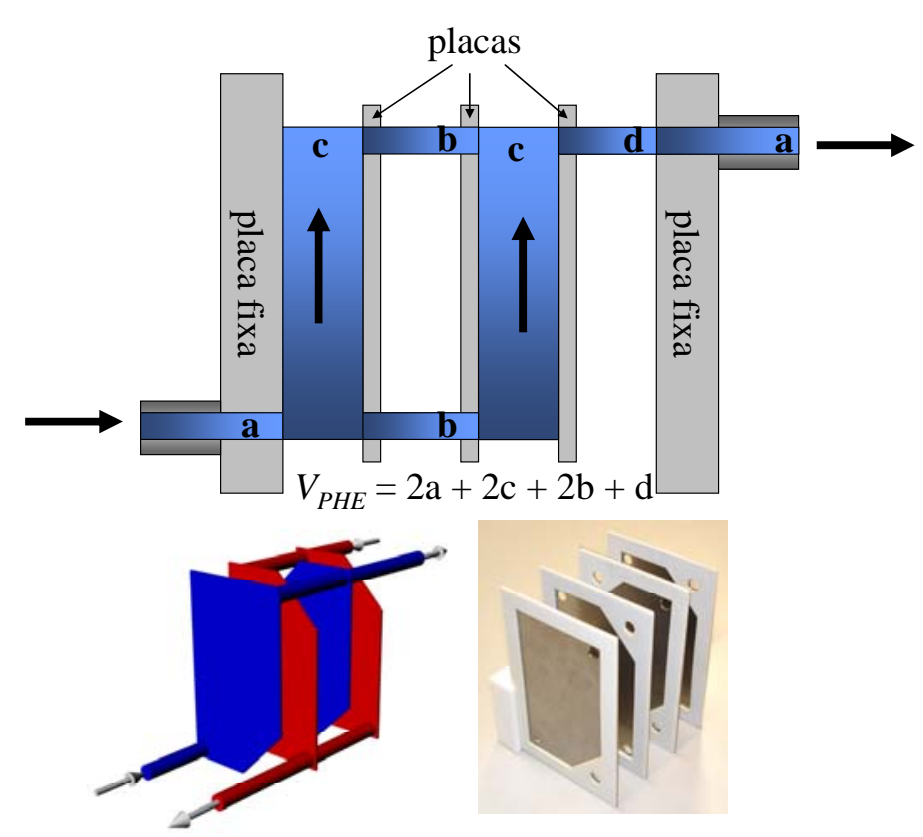

Figura 5.1.5. Determinação do volume interno do trocador de calor do pasteurizador FT-43A (Armfield, Reino Unido) com arranjo de passes em paralelo 1×2/1×2 (Galeazzo et al., 2006;

Gutierrez, 2008).

Os volumes internos indicados nas Figuras 5.1.4 e 5.1.5 podem ser determinados a partir das dimensões dos dutos e da gaxeta (Tabela 5.1.1 e Figura 5.1.3) e os valores obtidos são apresentados na Tabela 5.1.3. O cálculo do volume interno do trocador pode ser generalizado, usando estes volumes, para arranjos em série com $P$ passes na Equação (5.1.1a) ou arranjos em paralelo com $N$ canais na Equação (5.1.1b). A Equação (5.1.1c) apresenta o caso geral de $P$ passes com $N$ canais.

$$
\begin{aligned}
& V=2 \cdot V_{a}+(P-1) \cdot V_{b}+P \cdot V_{c}+V_{d} \\
& V(\mathrm{~mL})=9,20 \cdot P+2,85 \\
& V=2 \cdot V_{a}+2 \cdot(N-1) \cdot V_{b}+N \cdot V_{c}+V_{d} \\
& V(\mathrm{~mL})=9,40 \cdot N+2,65 \\
& V=2 \cdot V_{a}+P \cdot\left[(2 N-1) \cdot V_{b}+N \cdot V_{c}\right]+V_{d}-V_{b}
\end{aligned}
$$

Tabela 5.1.3. Volumes internos parciais do trocador de calor a placas.

\begin{tabular}{ccl}
\hline Volume & Valor (mL) & \multicolumn{1}{c}{ Identificação } \\
\hline$V_{a}$ & 1,46 & Conector de entrada ou saída \\
$V_{b}$ & 0,201 & Passagem entre dois canais \\
$V_{c}$ & 8,99 & Canal de escoamento \\
$V_{d}$ & 0,126 & $V_{b}$ sem a espessura de uma placa \\
\hline
\end{tabular}


O volume interno das conexões de entrada e de saída do tubo de retenção são importantes para a letalidade do processo, pois a temperatura é alta nestes trechos. A conexão de entrada do tubo de retenção é uma mangueira de silicone com diâmetro interno de 9,5 mm e diâmetro externo de 14,6 mm (padrão \#208), com isolamento térmico em espuma (Elumaflex, Brasil). O comprimento total entre a saída do aquecimento e o início do tubo é de 48 cm. Já a ligação entre a saída do tubo de retenção e a entrada do lado quente da regeneração possui dois trechos em mangueira de silicone. O primeiro tem os mesmos diâmetros da conexão anterior, mas com comprimento de $10 \mathrm{~cm}$ e também isolado termicamente. O segundo trecho tem diâmetro interno de 6,0 mm e diâmetro externo de 10,0 mm (padrão \#203), tendo como comprimento total $107 \mathrm{~cm}$ e sem isolamento térmico (inclui a passagem pela válvula diversora). Entre estes dois trechos localiza-se o ponto de medida de temperatura na saída do tubo de retenção. A Tabela 5.1.4 apresenta os volumes internos destas duas conexões, baseados nas dimensões apresentadas, e os respectivos temos espaciais para vazão volumétrica de operação de 20 L/h (Equação (3.3.5)).

Tabela 5.1.4. Identificação e dimensões das conexões existentes na linha do produto do pasteurizador a placas FT-43A (Armfield, Reino Unido).

\begin{tabular}{lcc}
\hline Conexão & $V(\mathrm{~mL})$ & $\tau(\mathrm{s}), Q=20 \mathrm{~L} / \mathrm{h}$ \\
\hline 1) Mangueira de entrada do tubo de retenção & 34,0 & 6,1 \\
2) Mangueira de saída do tubo de retenção & 37,3 & 6,7
\end{tabular}

O desempenho térmico deste trocador de calor foi estudado por Miura (2006) que ajustou a Equação (5.1.2) como correlação para determinação do coeficiente de convecção nos canais do trocador para arranjo de passes em série $(N=1)$. A correlação é válida para água com $120 \leq R e \leq 1950$. Os adimensionais número de Nusselt, número de Reynolds e número de Prandtl são definidos nas equações (4.2.7a), (4.2.7b) e (4.2.7c), respectivamente.

$$
N u=0,0263 \cdot \operatorname{Re}^{0,867} \cdot \operatorname{Pr}^{1 / 3}
$$

Para incluir no modelo a queda de temperatura que ocorre no tubo de retenção devido à troca térmica entre o produto e o ar ambiente, utilizou-se como parâmetro a variação $\Delta T_{\text {tubo }}=$ $2{ }^{\circ} \mathrm{C}$, valor baseado em resultados de ensaios preliminares realizados na vazão nominal de 20 L/h com água. 


\subsection{Desenvolvimento dos indicadores enzimáticos}

Para avaliar o impacto do processo térmico contínuo, optou-se por desenvolver indicadores enzimáticos que tenham sensibilidade para detectar o sobre-processamento em condições de pasteurização (temperaturas entre 70 e $85{ }^{\circ} \mathrm{C}$ e tempos entre 10 e 60 s). A atividade enzimática deve ser de fácil quantificação e de boa reprodutibilidade; desta forma optou-se por adaptar o uso de um aparelho reflectométrico comercial portátil.

Para padronizar os indicadores e simplificar suas aplicações, estes foram desenvolvidos a partir da dissolução de enzimas comerciais em solução tampão. Esta decisão limita o uso dos indicadores para avaliação do processamento de líquidos com viscosidade próxima da água, como leite ou alguns sucos não concentrados. O processamento térmico do indicador enzimático deve provocar uma queda na atividade da enzima, que está associada ao impacto do processo sobre um dado atributo do produto. Neste trabalho, os indicadores enzimáticos foram utilizados para validar a modelagem matemática do processo (Capítulo 4) através da comparação entre a letalidade prevista pelo modelo e aquela avaliada experimentalmente através do indicador.

\subsubsection{Preparação dos indicadores enzimáticos}

Três enzimas foram testadas para atuarem como indicadores enzimáticos de um processo térmico, ou seja, integradores de tempo-temperatura (TTI). Cada indicador consiste da enzima comercializada sob a forma de pó liofilizado (Sigma-Aldrich, EUA) dissolvida em tampão fosfato (pH 6,6 e força iônica de $50 \mathrm{nM}$ ). O tampão foi preparado através da dissolução de fosfato de sódio monobásico $\left(\mathrm{NaH}_{2} \mathrm{PO}_{4} \cdot 1 \mathrm{H}_{2} \mathrm{O}\right)$ e fosfato de sódio dibásico $\left(\mathrm{Na}_{2} \mathrm{HPO}_{4} \cdot 7 \mathrm{H}_{2} \mathrm{O}\right)$ na forma de sais sólidos hidratados (Synth, Brasil) em água destilada. Para preparar um litro de solução foram diluídos 4,471 g de $\mathrm{NaH}_{2} \mathrm{PO}_{4} \cdot 1 \mathrm{H}_{2} \mathrm{O}$ e 4,791 g de $\mathrm{Na}_{2} \mathrm{HPO}_{4} \cdot 7 \mathrm{H}_{2} \mathrm{O}$ em $1,00 \mathrm{~L}$ de água destilada. $\mathrm{O} \mathrm{pH}$ foi determinado usando pHStat (Radiometer Copenhagen, Dinamarca) e foi corrigido, quando necessário, gotejando solução de ácido fosfórico 1,0 N ou solução de hidróxido de sódio 1,0 N sob agitação.

A escolha do tampão fosfato foi baseada nos trabalhos de Saraiva et al. (1996) e Machado e Saraiva (2002). O valor de $\mathrm{pH}$ 6,6 foi escolhido por ser próximo ao $\mathrm{pH}$ do leite bovino, já que o método reflectométrico adotado foi desenvolvido originalmente para avaliação de leite. As concentrações das enzimas foram escolhidas de forma a obter um valor de atividade próximo ao limite superior da escala do método de determinação (Seção 5.2.2), para que seja possível avaliar a sua queda. 
O indicador POD consiste na enzima peroxidase de raiz-forte (EC 1.11.1.7, SigmaAldrich P6782) dissolvida no tampão fosfato. Para preparação da solução estoque, o pó liofilizado foi dissolvido em água destilada para obter uma concentração de $100 \mathrm{mg} / \mathrm{L}$ e depois mantido congelado a $-30{ }^{\circ} \mathrm{C}$ em alíquotas de $1,0 \mathrm{~mL}$, por até três meses. Para o uso, alíquotas foram descongeladas e diluídas em tampão fosfato para obter uma concentração de 1,0 mg/L (uma alíquota para $100 \mathrm{~mL}$ de tampão). A solução foi conservada a $5{ }^{\circ} \mathrm{C}$ por até cinco dias (testes preliminares verificaram a manutenção da atividade enzimática nestas condições). Após preparação, a atividade enzimática foi determinada em triplicata e ajustes de concentração foram realizados, quando necessários, para ter uma leitura na faixa de 120 a 180 U/L. O método de determinação da atividade enzimática é descrito na Secção 5.2.2.

O indicador LPO consiste na enzima lactoperoxidase de leite bovino (EC 232-668-6, Sigma-Aldrich L8257) dissolvida no tampão fosfato. Para preparação da solução estoque, o pó liofilizado foi dissolvido em água destilada para obter uma concentração de $833 \mathrm{mg} / \mathrm{L}$ (conteúdo de 5,0 mg em 6,0 mL) e depois mantido congelado a $-30^{\circ} \mathrm{C}$, em alíquotas de 1,0 mL, por até três meses. Para o uso, alíquotas foram descongeladas e diluídas em tampão fosfato para obter uma concentração de 20,8 mg/L (uma alíquota para $40 \mathrm{~mL}$ de tampão). A solução foi conservada a $5{ }^{\circ} \mathrm{C}$ por até cinco dias (testes preliminares verificaram a manutenção da atividade enzimática nestas condições). Após preparação, a atividade enzimática foi determinada em triplicata e ajustes de concentração foram realizados, quando necessários, para ter uma leitura na faixa de 120 a $180 \mathrm{U} / \mathrm{L}$.

O indicador ALP consiste na enzima fosfatase alcalina de mucosa intestinal bovina (EC 3.1.3.1, Sigma-Aldrich P7640) dissolvida no tampão fosfato. Para preparação da solução estoque, o pó liofilizado foi dissolvido em tampão fosfato para obter uma concentração de 250 $\mathrm{mg} / \mathrm{L}$ e a solução foi conservada a $5{ }^{\circ} \mathrm{C}$ por até cinco dias (testes preliminares indicaram perda de atividade de cerca de $80 \%$ no congelamento, portanto esta etapa não foi realizada). Para o uso, a solução estoque foi diluída em tampão fosfato para atingir uma concentração de 0,38 $\mathrm{mg} / \mathrm{L}$ e conservada a $5{ }^{\circ} \mathrm{C}$ por até cinco dias. Após preparação, a atividade enzimática foi determinada em triplicata e ajustes de concentração foram realizados, quando necessários, para ter uma leitura na faixa de 7,0 a 9,0 U/L.

\subsubsection{Determinação da atividade enzimática}

Para simplificar a aplicação prática dos indicadores enzimáticos propostos neste trabalho, um método rápido e simples para determinação de atividade enzimática foi 
necessário. Neste sentido, um sistema comercial portátil de avaliação reflectométrica foi adaptado.

As atividades enzimáticas dos indicadores POD, LPO e ALP foram determinadas usando o sistema Reflectoquant ${ }^{\circledR}$ (Merck, Alemanha) que consiste de um reflectômetro portátil (RQflex plus 10) e tiras analíticas de reação (Figura 5.2.1). O kit para determinação de atividade de peroxidase em leite (Merck 1.16121) foi usado para determinar a atividade enzimática dos indicadores POD e LPO. O kit para determinação de atividade de fosfatase alcalina em leite (Merck 1.16123) foi usado para determinar a atividade enzimática do indicador ALP.

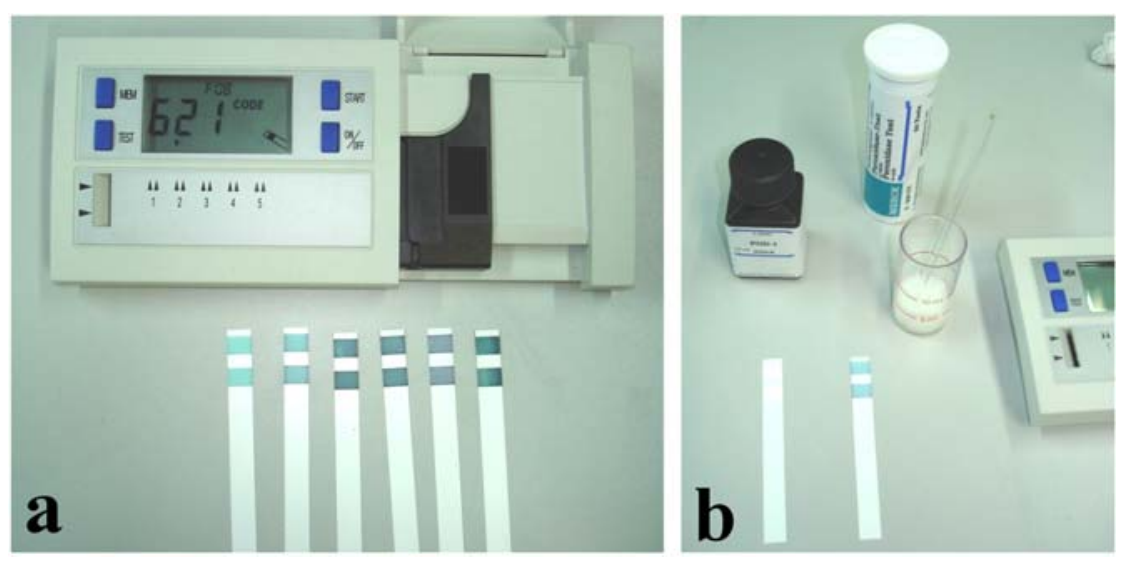

Figura 5.2.1. Uso do sistema Reflectoquant ${ }^{\circledR}$ para determinação de atividade enzimática: a) refletômetro e algumas tiras reacionais já usadas; b) reagentes e tiras antes e após uso.

Como os kits comerciais foram calibrados para leite (Martin et al., 2005; Sharma et al., 2003), os resultados absolutos de atividade enzimática expressos pelo reflectômetro para os indicadores propostos neste trabalho não podem ser usados diretamente. Para contornar esta limitação, a atividade residual expressa de forma relativa na Equação (5.2.1) foi adotada como variável de estudo. Nesta equação, $A E R_{\text {exp }}$ é a atividade enzimática residual determinada experimentalmente, $A E_{0}$ é a atividade enzimática inicial e $A E$ é a atividade enzimática medida após o tratamento térmico.

$$
A E R_{\text {exp }}=\frac{A E}{A E_{0}}
$$

O teste de peroxidase foi realizado de acordo com as instruções do fabricante (Merck, 2008) usando uma amostra de $1,0 \mathrm{~mL}, 4,0 \mathrm{~mL}$ de água destilada e cinco gotas do reagente POD-1. O tempo de reação foi de 180 s a $23^{\circ} \mathrm{C}$. Após a reação, a tira reacional era inserida no reflectômetro para aferição da atividade, sendo que a faixa de leitura é de 5 a 200 U/L. O procedimento experimental é apresentado no Apêndice A. 
Para o teste de fosfatase foi utilizada amostra de 2,0 $\mathrm{mL}$ e quatro gotas do reagente ALP-3. Originalmente utiliza-se 5,0 mL de amostra e 10 gotas do reagente ALP-3, mas os ensaios descontínuos de tratamento térmico foram realizados com apenas $3 \mathrm{~mL}$ do indicador. O tempo reacional foi de 20 min a $37^{\circ} \mathrm{C}$ (Merck, 2005) e a faixa de leitura de atividade é de 0,8 a 12,0 U/L. O procedimento experimental é apresentado no Apêndice A.

Para ambos os testes, a tira reacional foi mantida dentro de uma cubeta semi-micro (semi-microcell, fornecida nos kits) parcialmente imersa em um banho termostático Q215-1 (Quimis, Brasil) com controle de temperatura. No caso do teste de fosfatase, a cubeta continha previamente 15 gotas do reagente ALP-1.

\subsubsection{Tratamento térmico descontínuo}

Para determinar os parâmetros cinéticos da inativação enzimática dos indicadores POD, LPO e ALP, foram realizados ensaios descontínuos de tratamento térmico em diferentes condições de temperatura e de tempo de retenção. Inicialmente as condições de tempo e temperatura escolhidas foram baseadas nos estudos cinéticos de Claeys et al. (2002) para fosfatase alcalina em leite $\left(D_{60^{\circ} \mathrm{C}}=24,6 \mathrm{~min}, \mathrm{z}=5,3^{\circ} \mathrm{C}\right)$ e lactoperoxidase $\left(D_{71^{\circ} \mathrm{C}}=38,6 \mathrm{~min}, \mathrm{z}\right.$ $=4,3{ }^{\circ} \mathrm{C}$ ) para obter reduções de atividade entre $10 \%$ e $90 \%$ com tempos de imersão entre $5 \mathrm{~s}$ e 20 min. A partir dos resultados obtidos nos ensaios, o planejamento foi sendo reformulado para melhor explorar a faixa de inativação dos indicadores testados.

Em cada ensaio térmico, uma amostra do indicador (2,0 mL de POD, 2,0 mL de LPO ou 3,0 $\mathrm{mL}$ de ALP) foi acondicionada no fundo de uma embalagem de polietileno (2,5 $\mathrm{cm} \times 30$ cm com bordas seladas com calor e espessura de filme de 0,06 mm). O filme de polietileno foi usado no lugar do vidro para acomodar a amostra, devido sua baixa resistência térmica que facilita o aquecimento e o resfriamento da amostra. Um termopar tipo K de junta exposta foi introduzido na embalagem de forma que a junta do termopar ficasse no centro da amostra líquida (Figura 5.2.2). A temperatura foi coletada a cada segundo usando um termômetro digital portátil TH-060 com data-logger (Instrutherm, Brasil), previamente calibrado. 


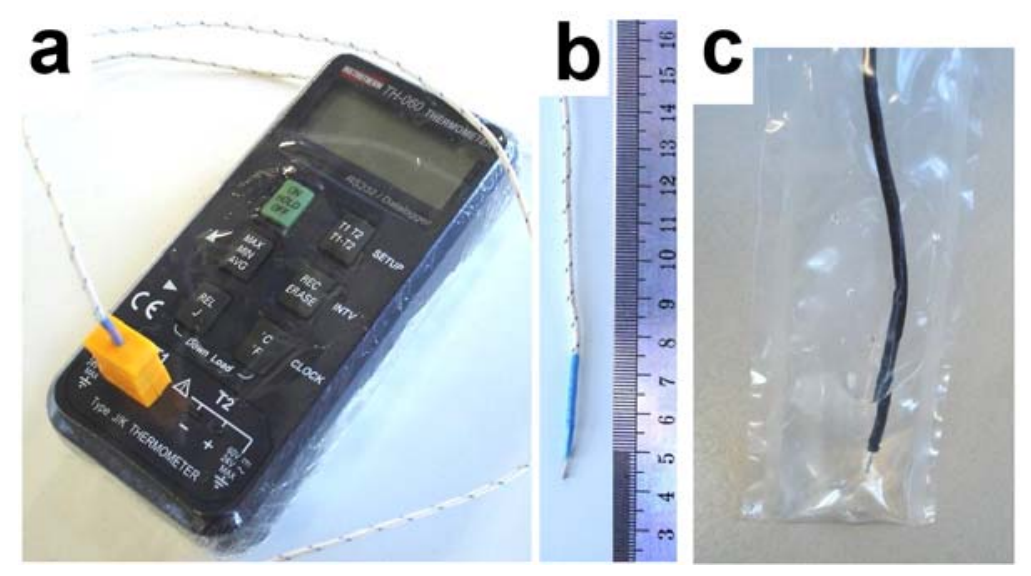

Figura 5.2.2. a) Termômetro digital TH-060 (Instrutherm, Brasil), b) Sensor termopar de ponta exposta, c) embalagem de polietileno com amostra do indicador e sensor termopar (com cobertura plástica termo-retrátil).

Para o tratamento térmico, a embalagem contendo a amostra foi imersa em banho termostático com controle de temperatura e agitação por um período definido de tempo, seguido de rápida imersão em banho de água com gelo sob agitação até que a temperatura registrada estivesse abaixo de $10{ }^{\circ} \mathrm{C}$. Em vez de assumir condições isotérmicas de processamento, o histórico de temperatura foi registrado para cada ensaio. As amostras tratadas termicamente foram mantidas em banho de gelo por até $90 \mathrm{~min}$ antes da determinação da atividade enzimática. A Figura 5.2.3 mostra um esquema do tratamento térmico descontínuo e alguns exemplos de históricos de temperatura registrados para diferentes tempos de imersão.
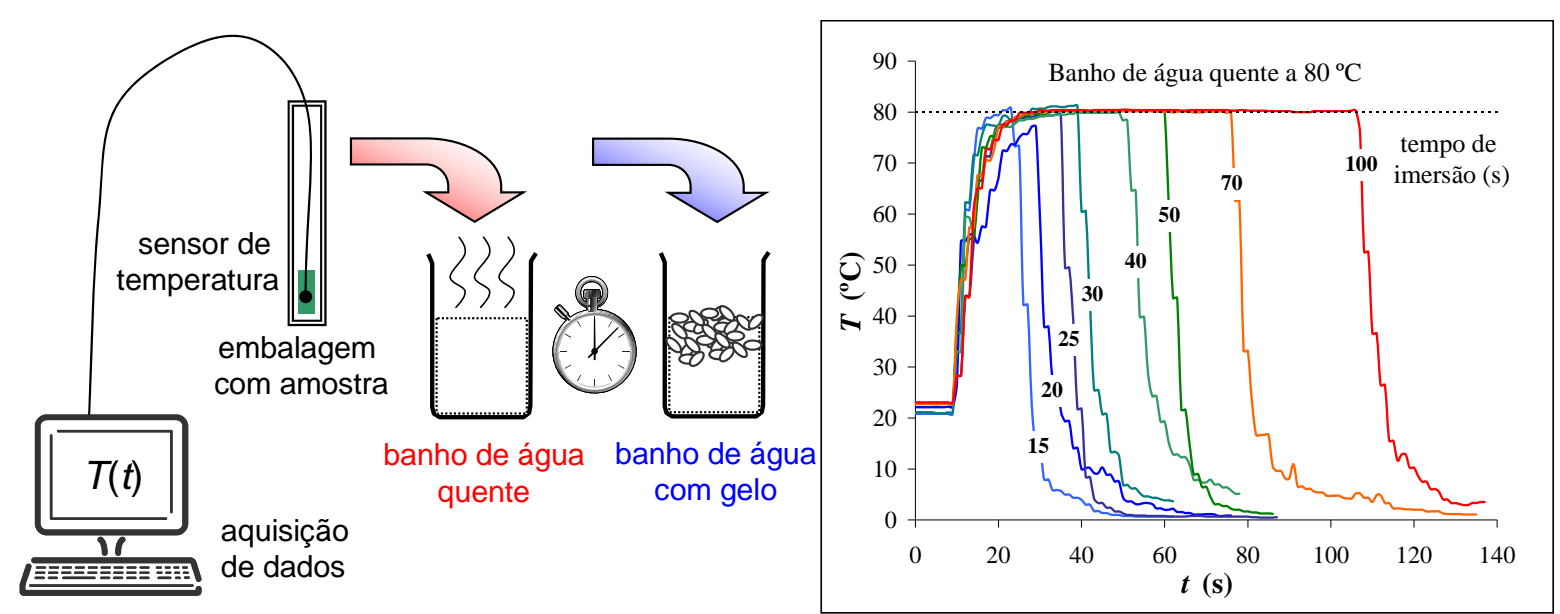

Figura 5.2.3. Esquema do tratamento térmico descontínuo e exemplos de curvas de temperatura registradas (Aguiar et al., 2012).

Devido ao pequeno volume de indicador usado em cada ensaio, não foi possível realizar medições de atividade enzimática em duplicata ou triplicata para cada condição de tempo- 
temperatura. Algumas condições foram repetidas, mas como o histórico de temperatura registrado é particular para cada ensaio, as repetições não foram tratadas como duplicatas. A avaliação do erro na medição da atividade enzimática foi realizada através das repetições na determinação de $A E_{0}$.

Diversas combinações de tempo de imersão (de $15 \mathrm{~s}$ a $10 \mathrm{~min}$ ) e temperatura de banho (de 60 a $95{ }^{\circ} \mathrm{C}$ ) foram testadas para explorar a faixa de trabalho que fornece atividade enzimática residual entre 5 e 95\%. As temperaturas ensaiadas para o indicador POD foram 60,0, 65,0, 70,0, 75,0, 80,0, 85,0, 90,0 e 95,0 ${ }^{\circ} \mathrm{C}$. Já para o indicador LPO, as temperaturas testadas foram 60,0, 62,5, 65,0, 67,5, 70,0, 72,5, 75,0, 77,5 e 80,0 ${ }^{\circ} \mathrm{C}$. Para o indicador ALP, as temperaturas testadas foram $60,0,65,0,70,0,75,0,80,0$ e $85,0^{\circ} \mathrm{C}$.

\subsubsection{Modelo cinético}

Segundo Claeys et al. (2002), as enzimas fosfatase alcalina e lactoperoxidase em leite bovino tem cinética de inativação térmica de primeira ordem, modelo bastante comum para este tipo de transformação. Fadiloglu et al. (2006) reportam cinética de primeira ordem para fosfatase alcalina em leite cru, leite pasteurizado e tampão. Olszewski e Reuter (1992) propõem cinética de ordem fracionária 1,5 para inativação de lactoperoxidase em leite.

Neste trabalho, o modelo cinético adotado para representar a inativação térmica dos indicadores POD, LPO e ALP é o modelo de cinética de primeira ordem para sistema de dois componentes (Chen e Wu, 1998; Fujikawa e Itoh, 1996; Murasaki-Aliberti et al., 2009; Tribess e Tadini, 2006), pois o modelo clássico usando parâmetros $D_{\text {ref }}$ e $z$ não teve bons resultados no ajuste dos dados. De acordo com o modelo de dois componentes, duas isoenzimas com diferentes resistências térmicas contribuem para a atividade enzimática. O parâmetro $\alpha$ representa a fração da atividade enzimática inicial associada à isoenzima termorresistente e (1- $\alpha$ ) representa a contribuição da isoenzima termolábil. A inativação térmica de cada enzima segue cinética de primeira ordem que é caracterizada pelos parâmetros $D_{\text {ref }}$ e $z$, sendo que o primeiro representa o tempo de redução decimal em uma temperatura de referência $T_{\text {ref }}$ e o segundo representa o acréscimo de temperatura que promove uma redução decimal no valor de $D_{\text {ref }}$.

O tempo de redução decimal das isoenzimas termorresistente (subscrito 1) e termolábil (subscrito 2) está relacionado com a temperatura do processo $T$ através das Equações (5.2.2a) e (5.2.2b) (vide Equação (4.4.1)). Para um dado tempo de processo isotérmico na temperatura $T\left(F_{T}\right)$, a atividade enzimática residual pode ser avaliada através da Equação (5.2.3). 


$$
\begin{aligned}
& D_{1}=D_{1, r e f} \cdot \operatorname{alog}\left(\frac{T_{r e f}-T}{z_{1}}\right) \\
& D_{2}=D_{2, r e f} \cdot \operatorname{alog}\left(\frac{T_{r e f}-T}{z_{2}}\right) \\
& A E R=\alpha \cdot \operatorname{alog}\left(-\frac{F_{T}}{D_{1}}\right)+(1-\alpha) \cdot \operatorname{alog}\left(-\frac{F_{T}}{D_{2}}\right)
\end{aligned}
$$

Para um processo não-isotérmico com histórico de temperatura $T(t)$ conhecido, o tempo de processo isotérmico equivalente na temperatura de referência pode ser calculado através das Equações (5.2.4a) e (5.2.4b) para cada isoenzima (vide Equação (4.4.4)).

$$
\begin{aligned}
& F_{1, \text { ref }}=\int_{0}^{t} \operatorname{alog}\left(\frac{T(t)-T_{r e f}}{z_{1}}\right) \mathrm{d} t \\
& F_{2, \text { ref }}=\int_{0}^{t} \operatorname{alog}\left(\frac{T(t)-T_{r e f}}{z_{2}}\right) \mathrm{d} t
\end{aligned}
$$

Combinando as Equações (5.2.3), (5.2.4a) e (5.2.4b), tem-se o modelo cinético de primeira ordem para sistema de dois componentes expresso na Equação (5.2.5). A dedução detalhada desta equação é apresentada por Murasaki-Aliberti et al. (2009). Este modelo cinético tem cinco parâmetros: $\alpha$ (fração inicial do componente termorresistente), $D_{1, \text { ref, }} D_{2, \text { ref }}$ (tempo de redução decimal na temperatura de referência das suas isoenzimas), $z_{1}$ e $z_{2}$ (parâmetros $z$ das duas isoenzimas).

$$
A E R=\alpha \cdot \operatorname{alog}\left(-\frac{\int_{0}^{t} \operatorname{alog}\left(\frac{T(t)-T_{r e f}}{z_{1}}\right) d t}{D_{1, \text { ref }}}\right)+(1-\alpha) \cdot \operatorname{alog}\left(-\frac{\int_{0}^{t} \operatorname{alog}\left(\frac{T(t)-T_{r e f}}{z_{2}}\right) d t}{D_{2, \text { ref }}}\right)
$$

Dado o histórico de temperatura experimental $T(t)$, as integrais na Equação (5.2.5) foram avaliadas numericamente através do método dos trapézios. Estimativas iniciais dos parâmetros cinéticos foram usadas para ser possível calcular o valor predito de AER. Para cada indicador enzimático foi calculado o somatório do erro quadrático na predição da atividade residual através da Equação (5.2.6), considerando um conjunto de $n$ ensaios experimentais.

$$
S E Q=\sum_{i=1}^{n}\left(A E R_{\text {calculado }, i}-A E R_{\text {experimental }, i}\right)^{2}
$$

O somatório do erro quadrático foi minimizado utilizando a função Solver do software Excel (Microsoft, EUA), que adota um algoritmo de otimização GRG2 (programação 
matemática com gradiente reduzido generalizado), tendo como variáveis os cinco parâmetros cinéticos do modelo. Antes de usar o Solver, uma exploração manual sobre os valores dos parâmetros foi realizada para melhorar a estimativa inicial e detectar ensaios com erros grosseiros. Gráficos de paridade foram usados para avaliar a distribuição do erro de predição e a qualidade do ajuste do modelo.

\subsubsection{Tratamento térmico descontínuo para validação}

Para validar o modelo cinético ajustado para a inativação térmica dos indicadores POD, LPO e ALP, ensaios descontínuos com aquecimento lento foram realizados para comparar a atividade residual experimental com aquela predita através da Equação (5.2.5) usando os parâmetros ajustados. Para estes ensaios, amostras de 3,0 mL do indicador foram colocadas em pequenos tubos de vidro (espessura de parede: 1,2 $\mathrm{mm}$ ) que foram imersos em banho de água quente por 1,0 ou 2,0 min antes do resfriamento em banho de água com gelo. O histórico

de temperatura da amostra foi registrado da mesma forma descrita no item 5.2.3. As temperaturas testadas foram $65,0,70,0,75,0,80,0$ e $85,0^{\circ} \mathrm{C}$.

\subsection{Determinação da distribuição do tempo de residência}

Foram realizados ensaios para determinar a distribuição do tempo de residência (DTR) do produto nas etapas do processo térmico estudado no pasteurizador FT-43A (Armfield, Reino Unido). Visando um estudo mais abrangente, a DTR foi determinada para os dois tubos de retenção disponíveis em diferentes vazões de escoamento e para o trocador de calor a placas com diferentes arranjos de passes e diferentes vazões.

A técnica utilizada para os ensaios de DTR foi de introdução de uma perturbação instantânea do tipo pulso na entrada da seção estudada com registro da concentração do traçador na saída da seção. Todos os ensaios foram realizados usando água destilada como fluido produto, já que as propriedades de escoamento da água não diferem muito daquelas do leite, principal alimento processado neste equipamento (Tomasula e Kozempel, 2004). As vazões estudadas foram de 10, 15, 20, 25, 30 e $35 \mathrm{~L} / \mathrm{h}$ para os tubos de retenção e de 15, 20 e $35 \mathrm{~L} / \mathrm{h}$ para o trocador de calor, lembrando que a vazão nominal de operação do equipamento é de $20 \mathrm{~L} / \mathrm{h}$. O escoamento foi mantido através da bomba peristáltica de alimentação, que introduz uma leve pulsação ao escoamento, e os ensaios foram realizados em condições isotérmicas (temperatura ambiente).

O traçador utilizado foi uma solução saturada de cloreto de sódio (concentração de 359 $\mathrm{g} / \mathrm{L})$. Um volume de $0,05 \mathrm{~mL}$ do traçador era injetado rapidamente através de uma mangueira 
de silicone, na entrada da seção de estudo, usando uma seringa de 1,0 mL (seringa de insulina). A detecção da passagem do traçador na saída da seção foi realizada através de um condutivímetro YSI3200 com uma célula de escoamento YSI3445 e adaptador YSI3232 (YSI, EUA) conectado a um computador pessoal por cabo RS232. A célula do condutivímetro é constituída por um recipiente de anular de vidro (volume interno: $15 \mathrm{~mL}$ ) e dois eletrodos de platina-irídio com conectores elétricos externos. A temperatura no interior da célula foi adquirida através de um termopar tipo K com junta exposta inserido no tubo interno do ânulo de vidro e conectado a um termômetro digital TH-1200C (Instrutherm, Brasil).

Uma concentração de fundo de cloreto de sódio entre 0,5 e 1,0 g/L teve que ser mantida na água destilada para reduzir o ruído nas leituras de condutividade elétrica, que era realizadas com intervalos entre 1 e 5 s, dependendo a vazão. A Figura 5.3 .1 mostra o arranjo experimental dos ensaios de DTR nos tubos de retenção e a Figura 5.3.2 mostra o arranjo experimental para um ensaio de determinação de DTR no trocador de calor a placas.
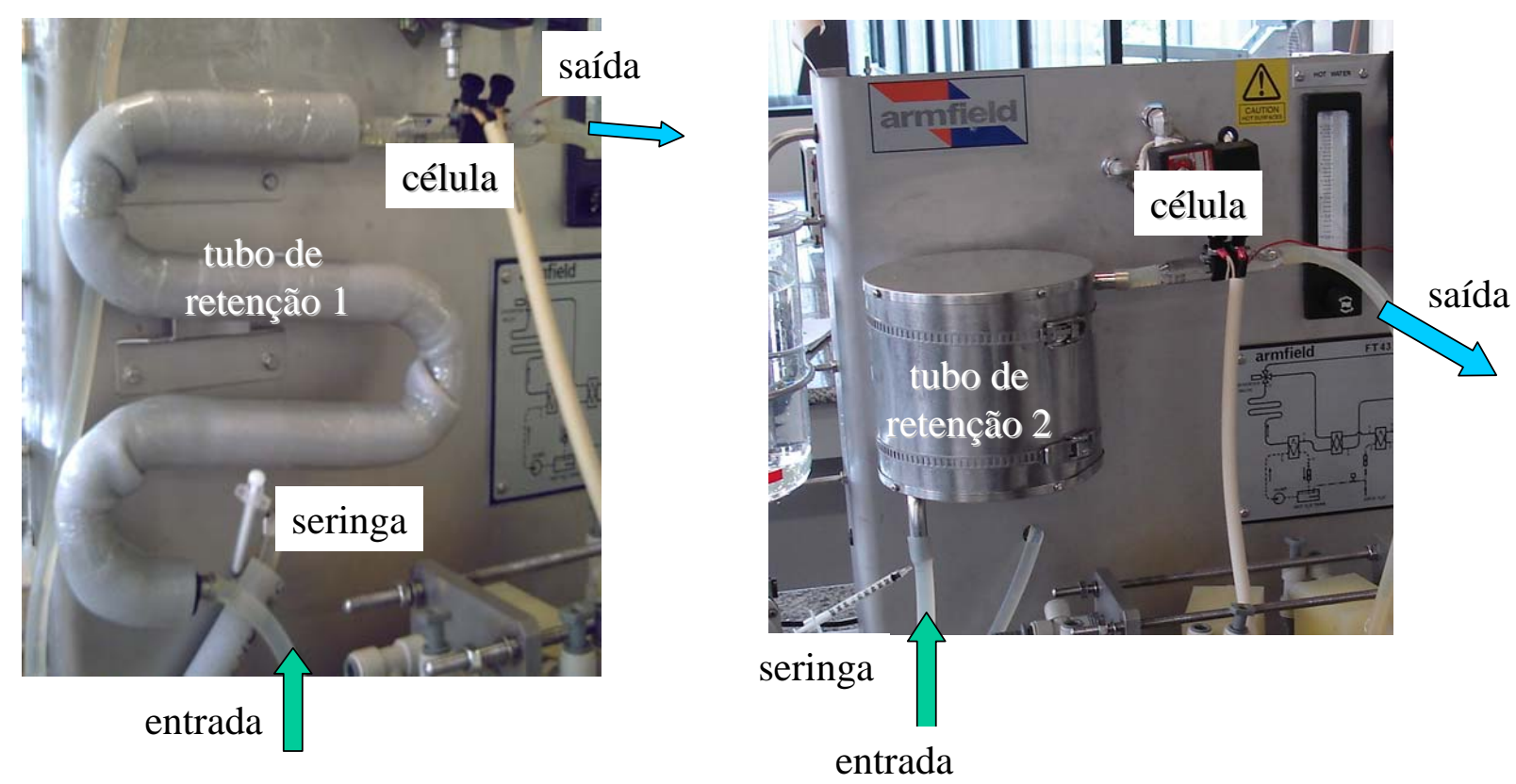

Figura 5.3.1. Montagem experimental para ensaio de DTR nos tubos de retenção T1 e T2, indicando a injeção do traçador na alimentação e a detecção na saída do tubo. 


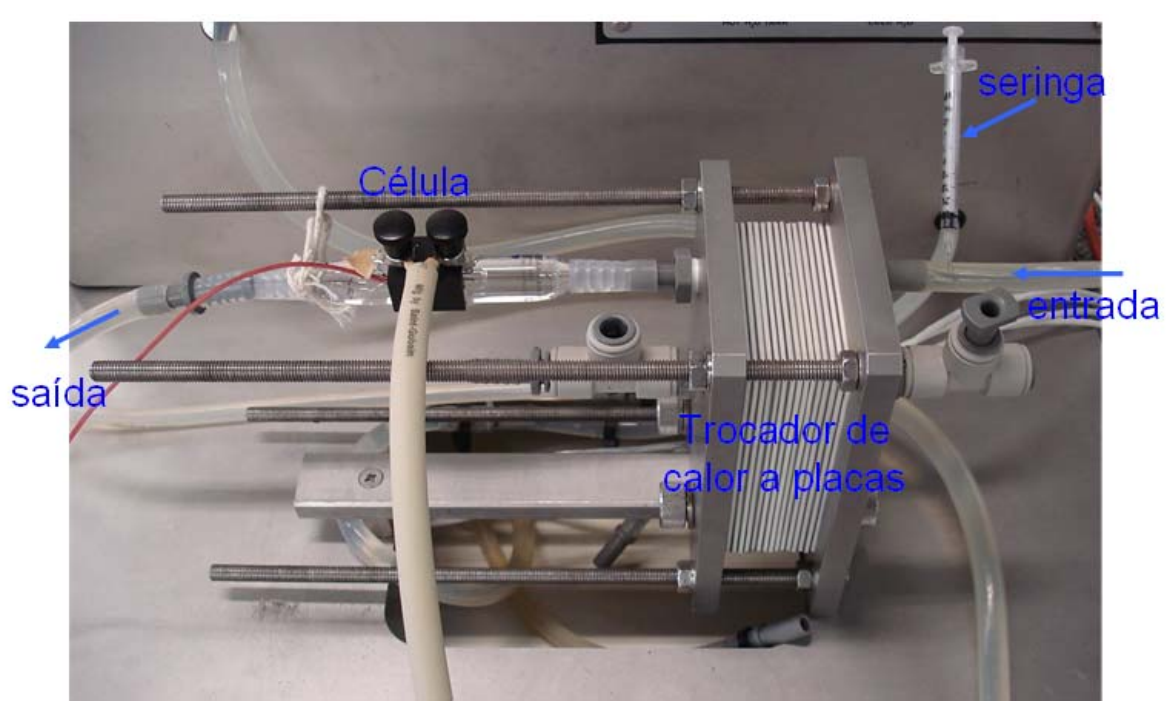

Figura 5.3.2. Montagem experimental para ensaio de DTR no trocador de calor, indicando a injeção do traçador na alimentação e a detecção na saída do tubo (Gutierrez, 2008).

Antes da realização dos ensaios, foi feita a calibração do traçador através da correlação entre a condutividade elétrica da solução de cloreto de sódico, a concentração do sal e a temperatura. Soluções com concentração de 0,25, 0,50, 0,75, 1,00, 1,25, 1,50 e 1,75 g/L tiveram a condutividade elétrica aferida para 35 temperaturas entre 17 e $31{ }^{\circ} \mathrm{C}$ (passo de 0,5 $\left.{ }^{\circ} \mathrm{C}\right)$. Devido a pequena quantidade de traçador injetado, a concentração de saída foi inferior à 1,75 g/L em todos os ensaios de DTR. Esta faixa de temperatura foi escolhida, pois a temperatura ambiente média era de $25{ }^{\circ} \mathrm{C}$. Nas medições, a temperatura da célula foi mantida por imersão da célula em banho termostatizado (Unitemp, Brasil).

Para cada concentração, a condutividade elétrica Cond foi linearmente correlacionada com a temperatura $T$ no formato da Equação (5.3.1), através do ajuste dos parâmetros $a_{1}$ e $a_{2}$.

$$
\text { Cond }=a_{1}+a_{2} \cdot T
$$

Os parâmetros $a_{1}$ e $a_{2}$ foram correlacionados com a concentração nos formatos das Equações (5.3.2a) e (5.3.2b) através dos ajustes dos parâmetros $a_{3}, a_{4}, a_{5}$ e $a_{6}$. Consequentemente a equação de calibração possui quatro parâmetros empírcos e pode ser representada no formato da Equação (5.3.3). Os ajustes de parâmetros foram realizados através da minimização do erro quadrático com o auxílio da ferramenta Solver do software Excel (Microsoft, EUA). Esta correlação foi reordenada no formato da Equação (5.3.4) para calcular a concentração de traçador a partir dos dados experimentais de Cond e $T$.

$$
\begin{aligned}
& a_{1}=a_{3} \cdot C+a_{4} \cdot C^{2} \\
& a_{2}=a_{5} \cdot C+a_{6} \cdot C^{2} \\
& \text { Cond }=\left(a_{3} \cdot C+a_{4} \cdot C^{2}\right)+\left(a_{5} \cdot C+a_{6} \cdot C^{2}\right) \cdot T
\end{aligned}
$$




$$
C=\frac{-\left(a_{3}+a_{5} \cdot T\right)+\sqrt{\left(a_{3}+a_{5} \cdot T\right)^{2}+4 \cdot\left(a_{4}+a_{6} \cdot T\right) \cdot \text { Cond }}}{2 \cdot\left(a_{4}+a_{6} \cdot T\right)}
$$

Para cada ensaio de DTR era obtida uma curva de concentração do traçador em função do tempo de injeção, com o auxílio da Equação (5.3.4). Através da Equação (3.3.1) eram determinados os pontos da curva $E(t)$, sendo que a integral era avaliada numericamente através do método de trapézios usando o software Excel (Microsoft, EUA). Da mesma forma foi avaliada, para verificação, a Equação (3.3.2) e a também a Equação (3.3.3) para cálculo do tempo médio de residência $\left(t_{m}\right)$. A curva adimensional $E_{\theta}(\theta)$ foi determinada através da Equação (3.3.4) $\operatorname{com} \theta=t / t_{m}$.

\subsubsection{Distribuição do tempo de residência na célula de condutividade}

Como o volume interno da célula de condutividade $(15 \mathrm{~mL})$ tinha a mesma ordem de grandeza dos volumes das seções que seriam avaliadas, foi necessário verificar a eficiência do sistema de aquisição em detectar a passagem do traçador. Isso foi realizado através da determinação da DTR da célula de condutividade, injetando o pulso de traçador diretamente na mangueira de alimentação da célula, como mostra Figura 5.3.3.

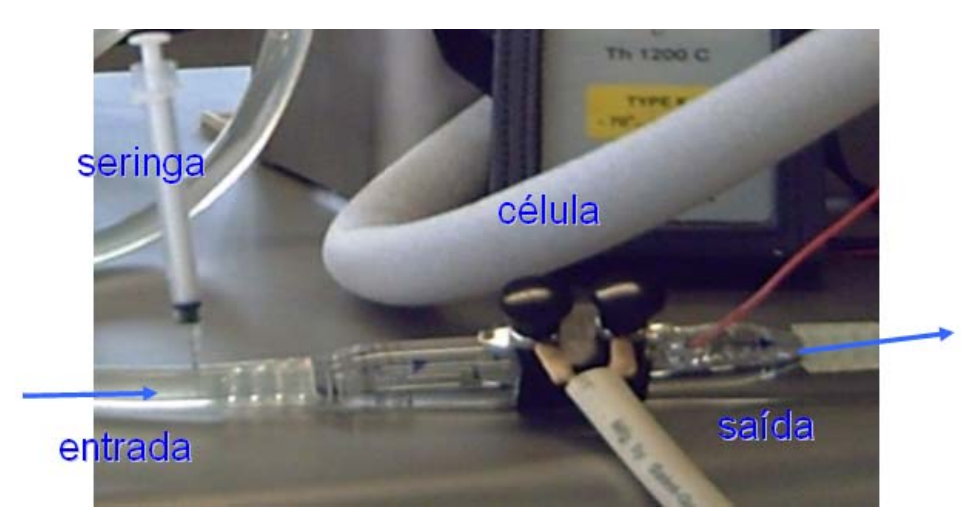

Figura 5.3.3. Montagem experimental para ensaio de DTR na célula do condutivímetro, indicando a injeção do traçador na entrada da célula (Gutierrez, 2008).

Assumindo que a injeção de traçador foi ideal e formou um sinal próximo ao delta de Dirac, o sistema de aquisição de dados de condutividade elétrica deveria representar a passagem do traçador adequadamente. Entretanto, há um pequeno tempo morto entre a injeção e a detecção e também ocorre recirculação de fluxo no interior da célula, retardando a saída do traçador e criando uma cauda na curva $E(t)$. Estas características poderiam ser desprezadas se o volume do sistema analisado fosse consideravelmente superior ao volume da célula, mas neste trabalho este efeito de distorção de sinal teve que ser levado em conta. Para 
isso, foi determinada a DTR da célula de condutividade para vazões de 10, 15, 20, 25, 30 e 35 L/h. Como o tempo de residência na célula é curto, foram realizadas pelo menos seis repetições para cada condição.

Aos dados obtidos de $E_{\theta}(\theta)$ foram ajustados os modelos de dispersão axial (Equação (3.3.8)) e tanques em série estendido (Equação (3.3.9)). Os parâmetros ajustados dos modelos e o tempo médio de residência foram correlacionados com a vazão. O modelo ajustado para a célula de condutividade foi incorporado como uma distorção de sinal a ser compensada no tratamento de dados dos ensaios de DTR realizados nos tubos de retenção e no trocador de calor a placas, conforme descrito na Seção 5.3.2.

\subsubsection{Correção para detecção não-ideal do traçador}

Conforme discutido na seção anterior, é necessário corrigir a não-idealidade na detecção do sinal gerado pela passagem do traçador pelo sistema de aquisição de dados de condutividade. A Figura 5.3.4 ilustra a teoria: a injeção de traçador é assumida como ideal (delta de Dirac) e na saída do processo tem-se a curva $E(t)$ do processo, que difere da curva $E(t)$ fornecida pelo sistema de aquisição. Considera-se que a curva $E(t)$ fornecida é na verdade a convolução da curva $E(t)$ do processo com a curva $E(t)$ do sistema de aquisição de dados.

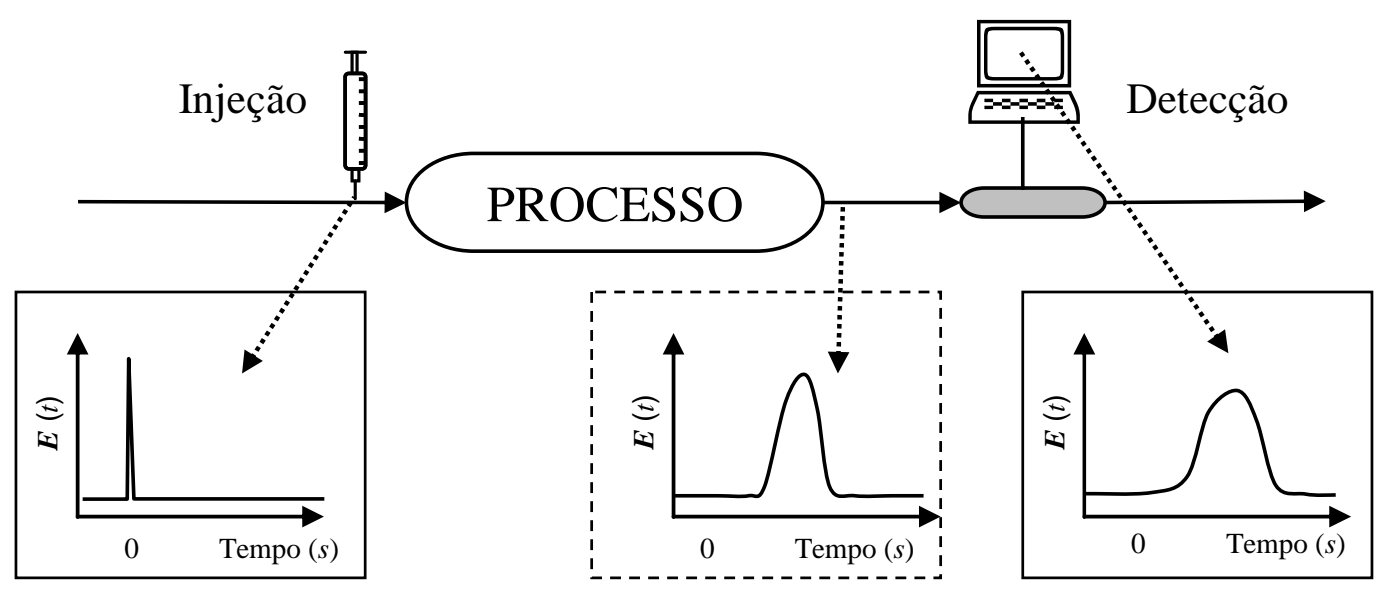

Figura 5.3.4. Representação dos sinais envolvidos em um ensaio de DTR indicando a distorção provocada pelo sistema de aquisição de dados, devido escoamento dentro da célula de condutividade elétrica (Gutierrez et al., 2010).

O procedimento proposto para corrigir a distorção provocada pela detecção não-ideal do traçador é ilustrado na Figura 5.3.5. Primeiro obtém-se os dados de DTR do processo. Em seguida caracteriza-se a DTR do sistema de aquisição de dados nas mesmas condições do ensaios do processo (fluido, vazão, temperatura etc.), ajustando um modelo à curva $E(t)$. 
Propõem-se então um modelo para representar a DTR do processo, escolhendo valores estimados para o tempo médio de residência e o parâmetro do modelo. Faz-se a convolução matemática entre a curva $E(t)$ do processo e a curva $E(t)$ do sistema de aquisição. Compara-se a curva gerada na convolução com os dados experimentais de DTR do processo e calcula-se o somatório do erro quadrático em $E(t)$ através da Equação (5.3.5). O erro quadrático deve ser minimizado, variando o tempo médio de residência e o parâmetro do modelo atribuídos ao processo estudado.

$$
S E Q=\sum_{i=1}^{n}\left[E_{\text {convolução }}\left(t_{i}\right)-E_{\text {experimental }}\left(t_{i}\right)\right]^{2}
$$

1) Obter a DTR experimental RTD do processo

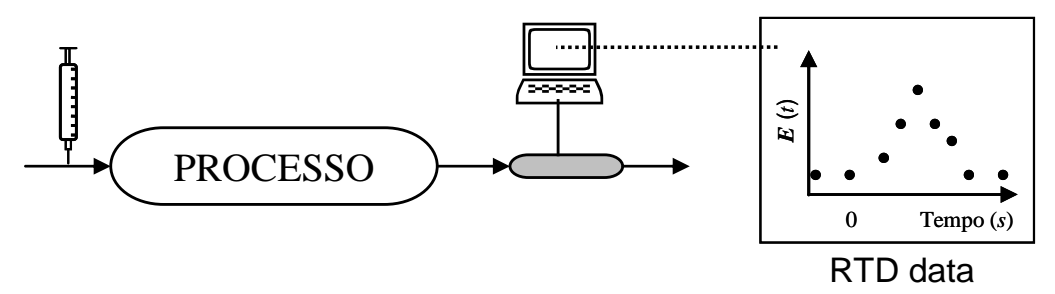

2) Determinar a DTR do sistema de detecção

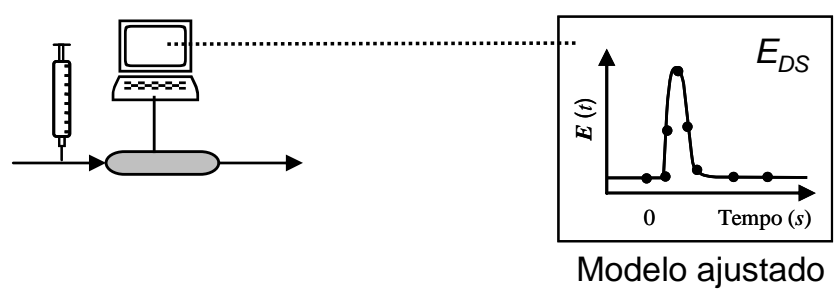

3) Ajustar modelo de DTR convolucionado

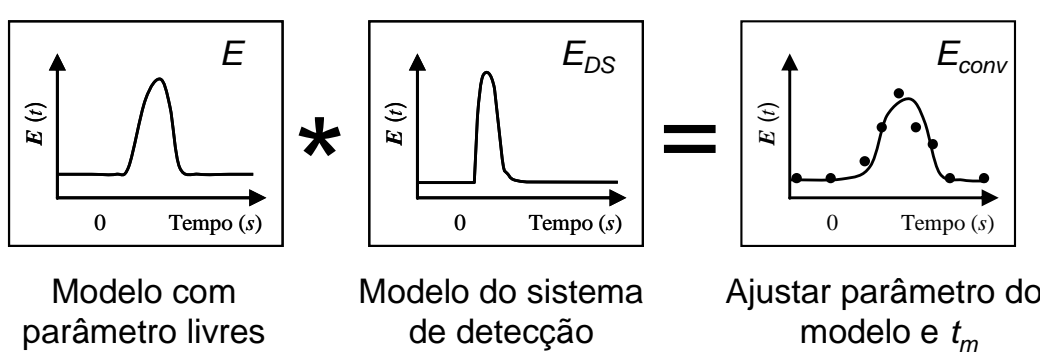

Figura 5.3.5. Representação das etapas para correção da distorção de sinal provocada pelo sistema de aquisição de dados usando a técnica de convolução matemática de sinais

(Gutierrez et al., 2010).

De uma forma geral, quando um sinal de entrada de DTR ( $C_{\text {ent }}$, concentração de traçador em função do tempo) passa por um equipamento, este é convertido em um sinal de saída $\left(C_{s a i}\right)$. A modificação do sinal está associada à curva $E(t)$ (resposta ao pulso) deste equipamento conforme a integral de convolução na Equação (5.3.6) (Levenspiel, 1999). 


$$
C_{\text {sai }}(t)=\int_{0}^{t} C_{e n t}\left(t-t^{\prime}\right) \cdot E\left(t^{\prime}\right) \mathrm{d} t^{\prime}
$$

Quando os sinais de entrada e de saída de um ensaio de DTR são conhecidos, é possível obter a curva $E(t)$ do processo através da Equação (5.3.6) usando um método de deconvolução que envolve transformadas de Fourier ou de Laplace. De forma alternativa, a integral de convolução pode ser discretizada no domínio temporal como na Equação (5.3.7) (Levenspiel, 1999). Nesta equação, $t_{i}$ e $t_{j}$ representam instantes discretos de tempo e $\Delta t$ é o passo de tempo.

$$
C_{\text {sai }}\left(t_{i}\right)=\Delta t \cdot \sum_{j=1}^{i-1} C_{e n t}\left(t_{i-j}\right) \cdot E\left(t_{j}\right)
$$

Se os dados de $C_{\text {ent }}(t)$ e a função $E(t)$ do processo são conhecidos, o sinal discreto de saída $C_{\text {sai }}(t)$ pode ser obtido através da implementação da Tabela 5.3.1, gerada a partir da Equação (5.3.7).

Tabela 5.3.1. Determinação numérica do sinal de saída através da convolução discreta do

\begin{tabular}{|c|c|c|c|c|c|}
\hline Saída & $j=1$ & $j=2$ & $j=3$ & $j=4$ & $j=5$ \\
\hline$C_{s a i}\left(\mathrm{t}_{1}\right) / \Delta t=$ & 0 & & & & \\
\hline$C_{\text {sai }}\left(\mathrm{t}_{2}\right) / \Delta t=$ & $C_{\text {ent }}\left(\mathrm{t}_{1}\right) \cdot E\left(\mathrm{t}_{1}\right)+$ & 0 & & & \\
\hline$C_{s a i}\left(\mathrm{t}_{3}\right) / \Delta t=$ & $C_{\text {ent }}\left(\mathrm{t}_{2}\right) \cdot E\left(\mathrm{t}_{1}\right)+$ & $C_{\text {ent }}\left(\mathrm{t}_{1}\right) \cdot E\left(\mathrm{t}_{2}\right)+$ & 0 & & \\
\hline$C_{s a i}\left(\mathrm{t}_{4}\right) / \Delta t=$ & $C_{\text {ent }}\left(\mathrm{t}_{3}\right) \cdot E\left(\mathrm{t}_{1}\right)+$ & $C_{\text {ent }}\left(\mathrm{t}_{2}\right) \cdot E\left(\mathrm{t}_{2}\right)+$ & $C_{\text {ent }}\left(\mathrm{t}_{1}\right) \cdot E\left(\mathrm{t}_{3}\right)+$ & 0 & \\
\hline$C_{s a i}\left(\mathrm{t}_{5}\right) / \Delta t=$ & $C_{\text {ent }}\left(\mathrm{t}_{4}\right) \cdot E\left(\mathrm{t}_{1}\right)+$ & $C_{\text {ent }}\left(\mathrm{t}_{3}\right) \cdot E\left(\mathrm{t}_{2}\right)+$ & $C_{\text {ent }}\left(\mathrm{t}_{2}\right) \cdot E\left(\mathrm{t}_{3}\right)+$ & $C_{\text {ent }}\left(\mathrm{t}_{1}\right) \cdot E\left(\mathrm{t}_{4}\right)+$ & 0 \\
\hline$C_{s a i}\left(\mathrm{t}_{6}\right) / \Delta t=$ & $C_{e n t}\left(\mathrm{t}_{5}\right) \cdot E\left(\mathrm{t}_{1}\right)+$ & $C_{e n t}\left(\mathrm{t}_{4}\right) \cdot E\left(\mathrm{t}_{2}\right)+$ & $C_{\text {ent }}\left(\mathrm{t}_{3}\right) \cdot E\left(\mathrm{t}_{3}\right)+$ & $\cdots$ & $\cdots$ \\
\hline$C_{s a i}\left(\mathrm{t}_{7}\right) / \Delta t=$ & $C_{\text {ent }}\left(\mathrm{t}_{6}\right) \cdot E\left(\mathrm{t}_{1}\right)+$ & $C_{\text {ent }}\left(\mathrm{t}_{5}\right) \cdot E\left(\mathrm{t}_{2}\right)+$ & $\cdots$ & $\cdots$ & $\cdots$ \\
\hline$C_{s a i}\left(\mathrm{t}_{8}\right) / \Delta t=$ & $C_{e n t}\left(\mathrm{t}_{7}\right) \cdot E\left(\mathrm{t}_{1}\right)+$ & $\cdots$ & $\cdots$ & $\cdots$ & $\cdots$ \\
\hline$\ldots$ & $\ldots$ & $\ldots$ & $\ldots$ & ... & ... \\
\hline
\end{tabular}
sinal de entrada com a curva $E$ do processo (Gutierrez et al., 2010).

Para implementar a Etapa 3 representada na Figura 5.3.5, utilizou-se a Tabela 5.3.1, sendo que $C_{e n t}\left(t_{i}\right)$ é a curva $E(t)$ proposta para representar a DTR do processo e $E\left(t_{j}\right)$ é a curva $E(t)$ do sistema de aquisição de dados ajustada na Etapa 2. O passo de tempo adotado foi $\Delta t=$ 0,5 s. O resultado, $C_{\text {sai }}\left(t_{i}\right)$ é a curva convolucionada que foi comparada aos dados experimentais para cálculo do somatório do erro quadrático. O erro quadrático na Equação (5.3.5) foi minimizado com o auxílio da ferramenta Solver do software Excel (Microsoft, 
EUA) para determinar os valores ótimos do tempo médio de residência do processo e do parâmetro do modelo. Antes de executar a ferramenta, boas estimativas das variáveis de otimização foram alcançadas por tentativa e erro. Esta estratégia foi importante para evitar problemas de divergência ou de localização de mínimos locais.

\subsubsection{Distribuição do tempo de residência no processo}

Conforme descrito no início da Seção 5.3, foram realizados ensaios de coleta de dados de DTR nos dois tubos de retenção do pasteurizador e no trocador de calor com diferentes arranjos de passes. Os dados coletados forneceram as curvas experimentais de DTR, que foram tratadas de acordo com o procedimento descrito na Seção 5.3.2 para ajuste do modelo de DTR. Os modelos ajustados foram: dispersão axial, tanques em série estendido, convecção generalizado e associação PFR+CSTR, apresentados na Seção 3.3.1. Dentre os modelos ajustados, foi eleito o que forneceu o melhor ajuste, levando em conta o valor minimizado do somatório do erro quadrático na Equação (5.3.5) para o conjunto de ensaios.

Para os tubos de retenção T1 e T2 (Figura 5.1.2), as vazões volumétricas ensaiadas foram de 10, 15, 20, 25, 30 e 35 L/h e os resultados foram correlacionados com a vazão. Já para o trocador de calor, as vazões testadas foram de 15, 20 e $35 \mathrm{~L} / \mathrm{h}$ e os resultados foram correlacionados com a configuração do trocador (número de passes e número de canais). Os ensaios foram realizados minimamente em triplicata.

Para os ensaios com o trocador de calor, as grades conectoras foram removidas e um único pacote de placas foi montado entre as placas fixa e móvel do pedestal, como mostra a Figura 5.3.2. Um dos lados do trocador foi ligado à bomba de alimentação enquanto o outro ficou seco. Foram testados arranjos em série com número par de passes: $2 \times 1,4 \times 1,6 \times 1,8 \times 1$, $10 \times 1,12 \times 1,14 \times 1,16 \times 1$ e $18 \times 1$, pois são os arranjos mais utilizados na operação do equipamento. Também foram testados arranjos em paralelo com passe único contendo $N=2$, 3, 4, 5, 6 ou 7 canais. A Figura 5.3.6 ajuda a diferenciar os dois tipos de arranjo. Nos ensaios com arranjos em paralelo, a alimentação foi realizada na parte inferior do pacote de placas, para evitar o acúmulo de bolhas de ar dentro do trocador. Em todos os ensaios, vazões elevadas de alimentação foram aplicadas no início para garantir total preenchimento dos canais. 


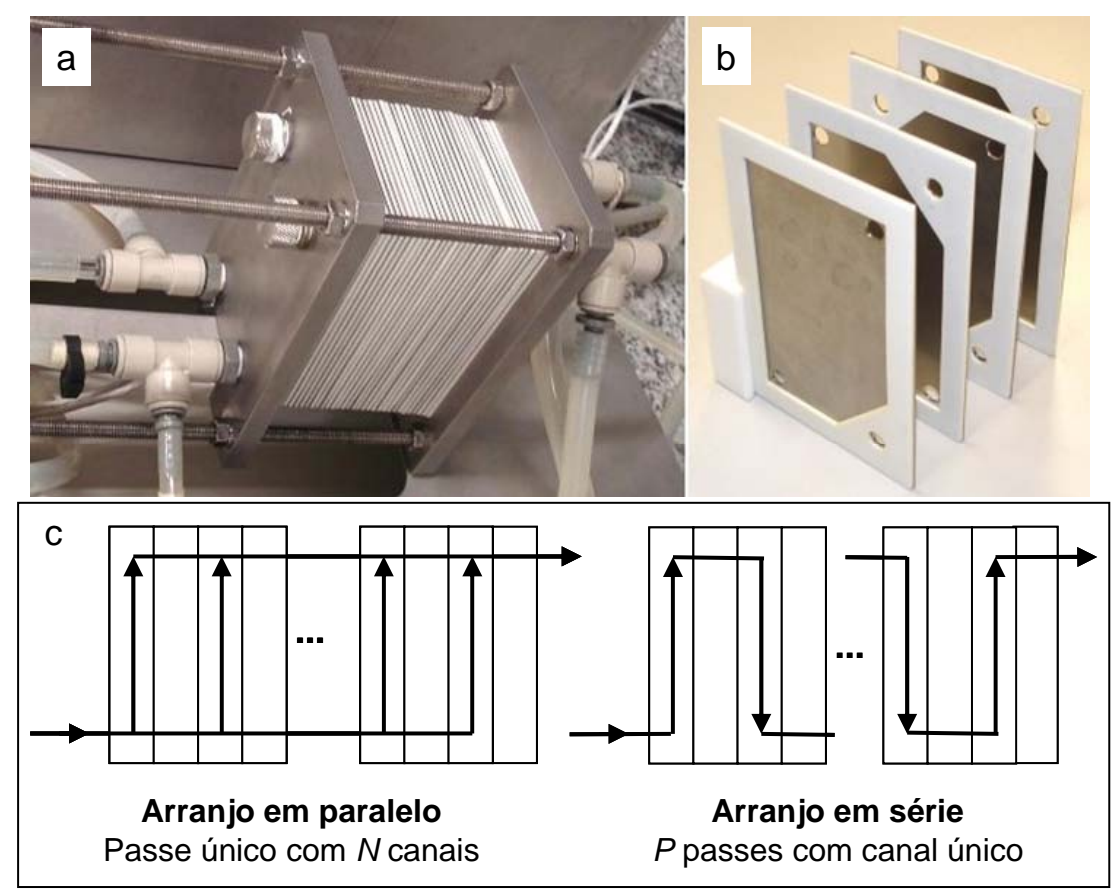

Figura 5.3.6. Trocador de calor estudado, mostrando placas e gaxetas e representando o escoamento nos arranjos em paralelo e em série (Gutierrez et al., 2011).

Os números de Reynolds nos canais do trocador para o arranjo em série foram de 1450, 1930 e 2410 para as vazões de 15, 20 e 35 L/h, respectivamente. No caso do arranjo em paralelo, o número de Reynolds variou entre 210 e 1210, dependendo de $N$. Para o tubo de retenção T1, o número de Reynolds variou entre 370 e 1290. Já para o tubo T2, o número de Reynolds variou entre 420 e 1490.

Para avaliar a dispersão no processo como um todo, ensaios de DTR foram realizados para escoamento do produto, em condições isotérmicas, ao longo de todo o percurso da pasteurização. As vazões volumétricas avaliadas foram 15, 20 e 25 L/h.

\subsection{Ensaios de validação do modelo}

\subsubsection{Distribuição de temperatura}

Para validar a distribuição de temperatura predita pelos modelos matemáticos de simulação para o processo de pasteurização HTST estudado, foi realizado um ensaio para obtenção das temperaturas no estado estacionário de operação do equipamento e os resultados foram comparados com aqueles preditos pelos Modelos 1, 2 e 3 apresentados no Capítulo 4. Retomando a Figura 4.1.1 que esquematiza o processo de pasteurização modelado, pode-se identificar os pontos correspondentes no equipamento estudado, conforme Figura 5.4.1. 


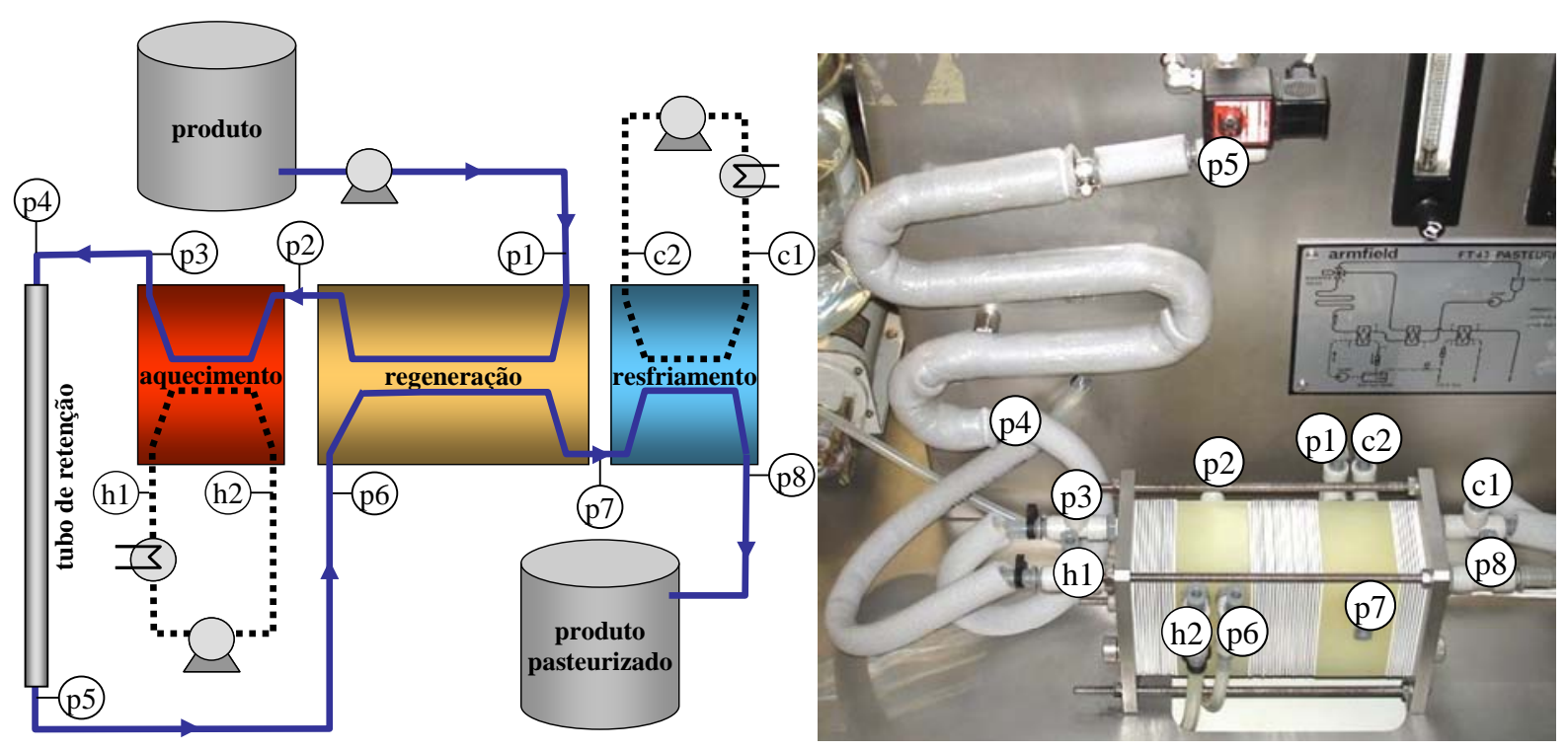

Figura 5.4.1. Esquema do processo de pasteurização considerado na modelagem e identificação dos pontos correspondentes no equipamento estudado.

Os ensaios foram realizados usando água mineral como fluido produto. Na posição p5 (Figura 5.4.1) foi inserido sensor de temperatura do controlador do processo, que manipula a taxa de aquecimento do circuito de água quente. O set-point definido foi de $72{ }^{\circ} \mathrm{C}$. Vazões de utilidades foram mantidas em 1,0 L/min. Os trocadores mantiveram a configuração padrão apresentada na Seção 5.1. O sistema de controle e aquisição de dados do equipamento IFD3FT (Armfield, Reino Unido), que possui seis termopares foi utilizado nos ensaios, com auxílio de um termômetro digital portátil TH-060 com data-logger (Instrutherm, Brasil). Uma vez identificado o estado estacionário de operação, as temperaturas foram adquiridas a cada segundo por no mínimo um minuto, para determinação de média e do desvio padrão.

Alternativamente foi utilizado um sistema de aquisição de dados cDAQ-9172 (National Instruments, EUA) com três módulos NI-9211 para termopares. Neste caso, foi utilizado um conjunto de 12 termopares tipo $\mathrm{T}$ de junta exposta com cabo 24AWG (IOPE, Brasil) adaptados a conectores PI0812S 3/8” (John Guest, Reino Unido) para inserção no equipamento (Figura 5.4.2). A Figura 5.4.3 mostra as principais telas do software de aquisição de dados de temperatura elaborado em ambiente LabView (National Instruments, EUA). Todos os termopares usados foram previamente calibrados para a faixa de 0 a $90{ }^{\circ} \mathrm{C}$. 

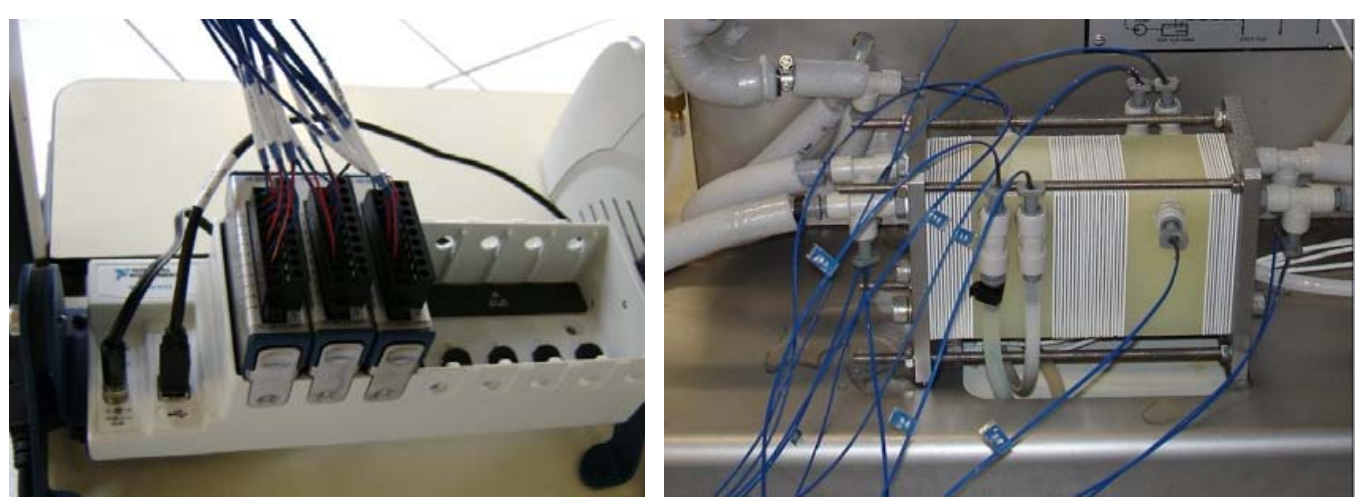

Figura 5.4.2. Sistema de aquisição de dados de temperatura CompactDAQ e sensores de temperatura inseridos nas conexões do pasteurizador a placas.
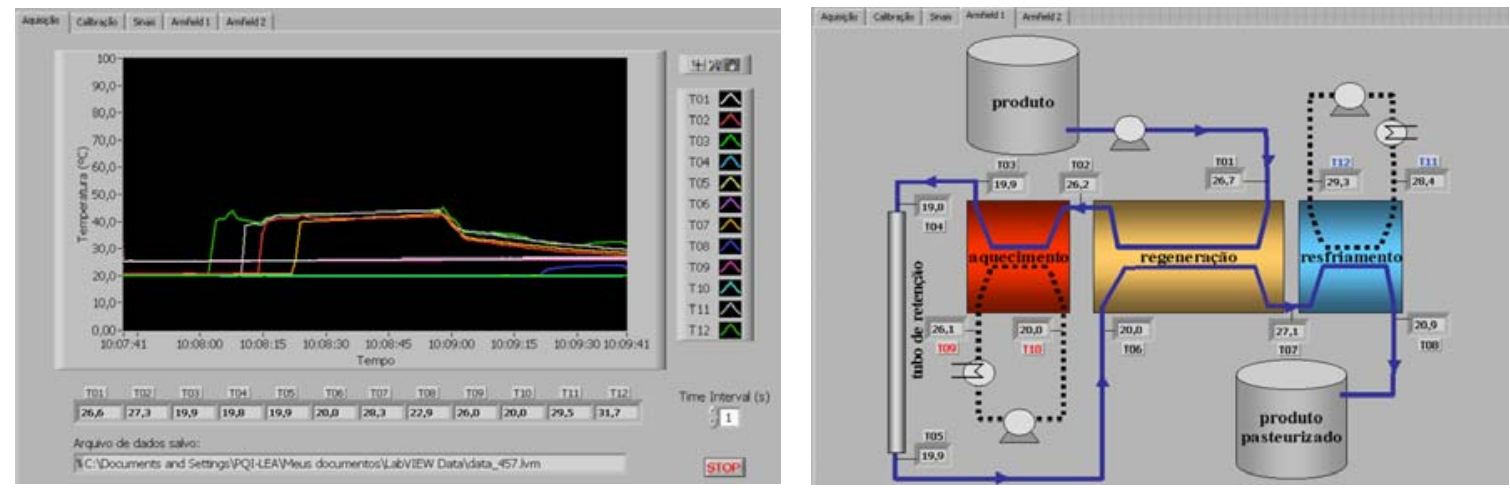

Figura 5.4.3. Telas principais do software de aquisição de temperaturas do processo, elaborado em ambiente LabView (National Instruments, EUA).

A modelagem matemática de troca térmica apresentada na Seção 4.2 foi aplicada para simulação do processo visado determinar a distribuição de temperatura do produto alimentício no percurso p2 $\rightarrow$ p8 (Figura 5.4.1). As características do equipamento descritas na Seção 5.1 (dimensões, configuração, arranjo, Equação (5.1.2), $\Delta T_{\text {tubo }}$ ) foram usadas como parâmetros do modelo. As propriedades termo-físicas da água foram calculadas nas temperaturas experimentais de entrada e de saída de cada trecho e valores médios foram adotadas para a modelagem. A Equação (5.4.1a) fornece a densidade da água em $\mathrm{kg} / \mathrm{m}^{3}$ para o intervalo $0 \leq T$ $\leq 90{ }^{\circ} \mathrm{C}$ (Schwier, 1992). A Equação (5.4.1b) fornece o calor específico em $\mathrm{J} / \mathrm{kg} \cdot \mathrm{K}$ para $0 \leq T$ $\leq 260{ }^{\circ} \mathrm{C}$ (Perry et al., 1997). A Equação (5.4.1c) fornece a viscosidade em Pa.s para $0 \leq T \leq$ $100{ }^{\circ} \mathrm{C}$ (Bennett e Myers, 1982). A Equação (5.4.1d) fornece a condutividade térmica em $\mathrm{W} / \mathrm{K} \cdot \mathrm{m}$ para $0 \leq \mathrm{T} \leq 90^{\circ} \mathrm{C}$ (Schwier, 1992).

$$
\begin{aligned}
& \rho=2,080 \cdot 10^{-5} \cdot T^{3}-6,668 \cdot 10^{-3} \cdot T^{2}+0,04675 \cdot T+999,9 \\
& C p=5,201 \cdot 10^{-7} \cdot T^{4}-2,153 \cdot 10^{-4} \cdot T^{3}+4,176 \cdot 10^{-2} \cdot T^{2}-2,617 \cdot T+4227
\end{aligned}
$$




$$
\begin{aligned}
& \frac{1}{\mu}=21,482\left[(T-8,435)+\sqrt{8078,4+(T-8,435)^{2}}\right]-1200 \\
& k=0,5692+\frac{T}{538}-\frac{T^{2}}{1,333 \cdot 10^{5}}
\end{aligned}
$$

Para a resolução dos modelos matemáticos, as temperaturas de alimentação $T_{p 1}, T_{h 1}$ e $T_{c 1}$ foram especificadas de acordo com os valores experimentais. Adotou-se $\Delta T_{\text {tubo }}=2{ }^{\circ} \mathrm{C}$, conforme Seção 5.1. O Modelo 1 foi implementado e resolvido usando o software Excel (Microsoft, EUA), pois envolve apenas equações algébricas. Para o Modelo 2, foi utilizada a mesma base do Modelo 1, mas substituindo a eficiência do arranjo contracorrente pela eficiência real do arranjo do trocador. Esta eficiência foi obtida através da resolução do modelo térmico apresentado na Seção 4.2.1 usando o método numérico de diferenças finitas centradas de segunda ordem com 20 pontos para discretização da temperatura adimensional nos canais (Equação (4.2.11)). Este método foi implementado em software gPROMS (Process Systems Enterprise, Reino Unido) de acordo com Gut e Pinto (2003a). Os perfis de temperatura nos canais adotados para o Modelo 3 foram obtidos desta resolução e concatenados em série para representar o percurso através do arranjo em série dos trocadores.

O software gPROMS é um simulador de processo orientado a equações, de forma que o modelo do processo é representado por um sistema de equações matemáticas, resolvido de forma unificada. Em contrapartida, um simulador modular resolve sequencialmente as operações unitárias modulares do fluxograma até obter a convergência da solução.

\subsubsection{Uso dos indicadores enzimáticos}

Na Seção 5.2 é descrito o procedimento adotado para o desenvolvimento de indicadores enzimáticos para serem usados como integradores de tempo-tempratura de um processo de pasteurização HTST. Os indicadores POD e ALP foram utilizados para o estudo da pasteurização no equipamento estudado (Seção 5.1). A configuração do equipamento e as vazões utilizadas são iguais às descritas na Seção 5.4.1 para estudo da distribuição de temperatura. O fluido processado foi o indicador elaborado conforme procedimento na Seção 5.2.1. As temperaturas de processamento (set-point do controlador para $T_{p 5}$ ) foram 70, 75, 80 e $85{ }^{\circ} \mathrm{C}$, para explorar a faixa de atuação dos indicadores. A atividade inicial do indicador foi avaliada em quadruplicada, seguindo o procedimento descrito na Seção 5.2.2. Os ensaios com o indicador ALP foram realizados em duas vezes independentes.

Uma vez constatado o estado estacionário de operação, as temperaturas foram registradas por $4 \mathrm{~min}$. Ao longo deste período foram coletadas cinco amostras de $5 \mathrm{~mL}$ na 
saída do processo. Estas amostras foram acondicionas em banho de água e gelo para cessar a degradação térmica. As atividades enzimáticas foram determinadas em seguida e o valor da atividade enzimática residual do indicador $\left(A E R_{\text {exp }}\right)$ foi calculada através da Equação (5.2.1).

Por sua complexidade intermediária, o Modelo 2 foi adotado para simular os ensaios realizados. As propriedades termo-físicas dos indicadores ALP e POD foram consideradas iguais às da água destilada, devido a pequena quantidade de solutos envolvidos. Para a resolução do modelo, as temperaturas de alimentação $T_{p 1}, T_{h 1}$ e $T_{c 1}$ foram especificadas de acordo com os valores experimentais. Adotou-se novamente $\Delta T_{\text {tubo }}=2{ }^{\circ} \mathrm{C}$. O resultado de simulação do Modelo 2 combinado com os tempos médios de residência obtidos do estudo da distribuição do tempo de residência forneceram o histórico de temperatura do produto. A Equação (5.2.5) da atividade residual enzimática do indicador foi avaliada sobre os históricos obtidos, usando os parâmetros cinéticos ajustados. A predição de atividade residual pelo modelo matemático foi comparada com o valor determinado experimentalmente. 


\section{RESULTADOS E DISCUSSÃO}

Neste capítulo são apresentados e discutidos os resultados obtidos de experimentos e de simulações de modelo. Primeiramente são discutidos o desenvolvimento e os testes dos indicadores enzimáticos que foram usados como integradores de tempo-temperatura. $\mathrm{Na}$ sequência seguem os resultados do estudo de distribuição de tempo de residência, identificando os tempos médios de residência de cada etapa da pasteurização. Os resultados de ensaios de distribuição de temperatura são comparados com os resultados obtidos através da simulação dos Modelos 1, 2 e 3. Finalizando, a letalidade prevista pelos modelos matemáticos é comparada com a letalidade obtida através dos indicadores enzimáticos.

\subsection{Desenvolvimento dos indicadores enzimáticos}

\subsubsection{Ajuste do modelo cinético}

Os históricos de temperatura e as atividades residuais obtidas para os ensaios térmicos descontínuos aplicados aos indicadores enzimáticos POD (peroxidase), LPO (lactoperoxidase) e ALP (fosfatase alcalina) foram analisados de acordo com o conteúdo da Seção 5.2 para ajuste dos parâmetros cinéticos do modelo na Equação (5.2.5). A Tabela 6.1.1 apresenta os parâmetros ajustados, o número de experimentos válidos $(n)$ e o valor minimizado do somatório do erro quadrático sobre a atividade residual (SEQ na Equação (5.2.6)). A Figura 6.1.1 apresenta os gráficos de paridade dos ajustes e as curvas de inativação térmica preditas para diferentes temperaturas de referência usando o modelo ajustado.

Tabela 6.1.1. Parâmetros cinéticos ajustados para a inativação térmica dos indicadores POD (peroxidase), LPO (lactoperoxidase) e ALP (fosfatase alcalina) (Aguiar et al., 2012).

\begin{tabular}{ccccccccc}
\hline Indicador & $n$ & $S E Q$ & $T_{\text {ref }}\left({ }^{\circ} \mathrm{C}\right)$ & $\alpha$ & $D_{1, \text { ref }}(\mathrm{s})$ & $D_{2, \text { ref }}(\mathrm{s})$ & $z_{1}\left({ }^{\circ} \mathrm{C}\right)$ & $z_{2}\left({ }^{\circ} \mathrm{C}\right)$ \\
\hline POD & 56 & 0,57 & 80 & 0,368 & 808 & 27,0 & 15,1 & 8,22 \\
LPO & 59 & 1,11 & 70 & 0,568 & 173 & 149 & 2,40 & 8,91 \\
ALP & 61 & 0,60 & 75 & 0,585 & 478 & 3,83 & 7,57 & 6,57 \\
\hline
\end{tabular}



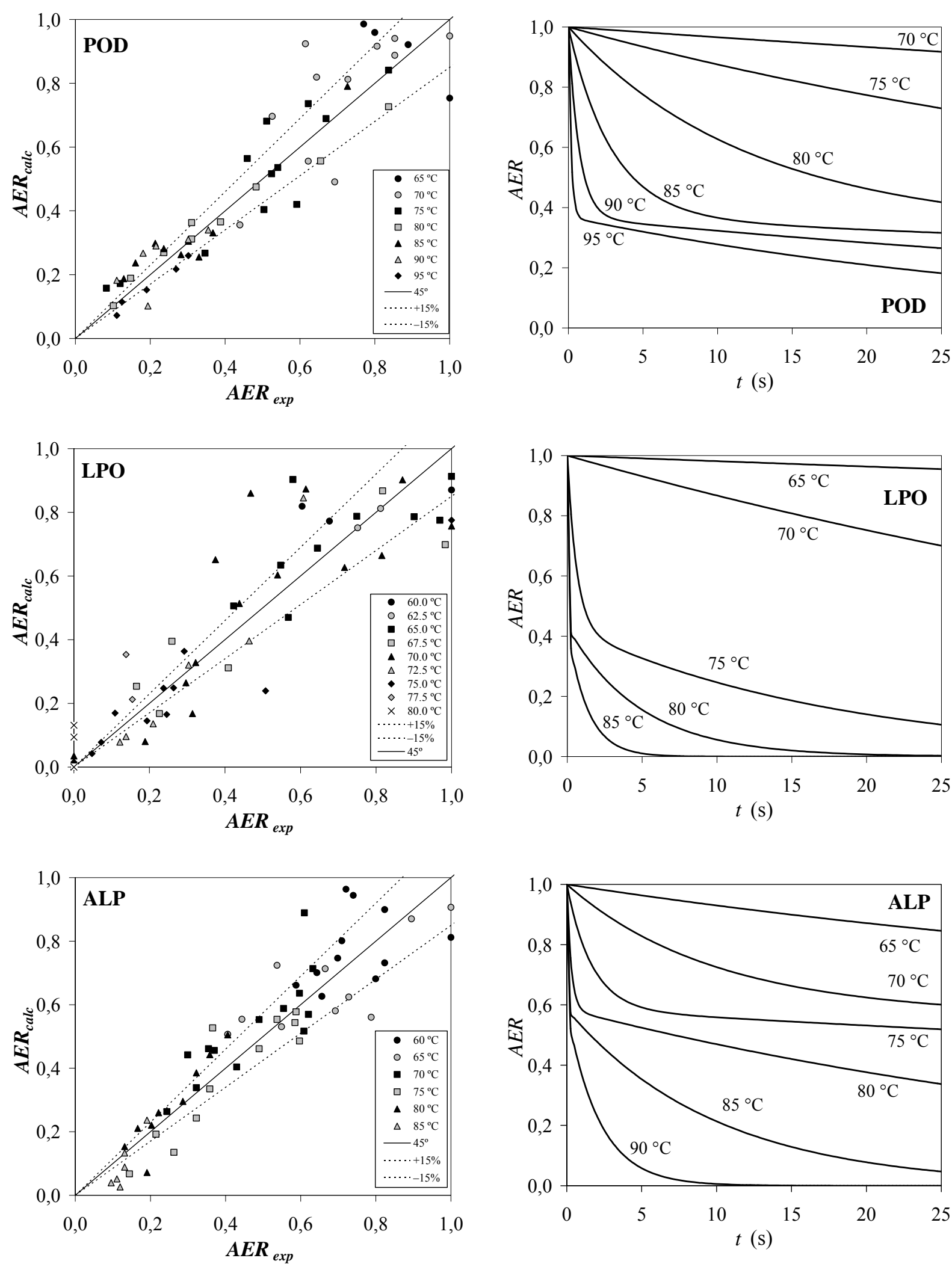

Figura 6.1.1. Resultados do ajuste do modelo cinético para representar a inativação enzimática dos indicadores POD (peroxidase), LPO (lactoperoxidase) e ALP (fosfatase alcalina) incluindo gráficos de paridade para a predição da atividade enzimática residual $(A E R) \mathrm{e}$ curvas de inativação térmica em diferentes temperaturas de referência para o modelo ajustado (Aguiar et al., 2012). 
Foi possível ajustar o modelo para os três indicadores testados; entretanto, os gráficos de paridade na Figura 6.1.1 apresentam considerável dispersão dos pontos, especialmente no caso do indicador LPO. Os desvios absolutos médios para predição da atividade enzimática residual foram 21\%, 27\% e 20\% para os indicadores POD, LPO e ALP, respectivamente. Estes desvios consideráveis estão associados ao erro experimental de determinação da atividade enzimática pelo método reflectométrico descrito na Seção 5.2.2 e ao erro do modelo proposto. Em comparação com estudos usando estas mesmas enzimas, a dispersão dos pontos está acima da esperada (Olszewski e Reuter, 1992; Machado e Saraiva, 2002; Wilińska et al., 2007).

Os resultados indicam a necessidade de múltiplas medidas (minimamente triplicatas) na aplicação prática dos indicadores para melhorar a precisão na determinação da atividade enzimática. Como cada ensaio tinha um histórico de temperatura particular e o volume da amostra permitia apenas uma medição de atividade, não foi possível realizar réplicas para avaliar a variância na atividade medida. Entretanto, baseado nas repetições realizadas para avaliar a atividade enzimática inicial $A E_{0}$, o desvio padrão médio para determinação da atividade pelo teste de peroxidase foi de $\pm 11 \mathrm{U} / \mathrm{L}$ (erro de $8,2 \%$ ) e desvio padrão médio para determinação da atividade pelo teste de fosfatase alcalina foi de $\pm 0,7 \mathrm{U} / \mathrm{L}$ (erro de 9,1\%).

A Figura 6.1.1 apresenta também as curvas de inativação térmicas preditas pelo modelo ajustado para diferentes temperaturas de referência e tempos de retenção de até $25 \mathrm{~s}$. Pode-se notar que a fração termorresistente do indicador POD permanece ativa mesmo a $95{ }^{\circ} \mathrm{C}$. Já a fração termolábil do indicador LPO é rapidamente inativada a $75^{\circ} \mathrm{C}$. Para temperaturas acima de $85^{\circ} \mathrm{C}$, o indicador POD é muito estável e perde sensibilidade para variações de tempo de residência e de temperatura, o que é desvantajoso para o seu uso. O indicador LPO se mostrou muito instável para uso em temperaturas acima de $80{ }^{\circ} \mathrm{C}$, sendo inativado em poucos segundos. Baseados nestas curvas, a fração termorresistente do indicador ALP parece ter potencial para avaliar o sobre-processamento em processos de pasteurização HTST, enquanto que sua fração termolábil pode avaliar bem o sub-processamento. Além disso, os valores de $z_{1}$ e $Z_{2}$ obtidos para o indicador ALP (Tabela 6.1.1) estão próximos aos valores de $z$ para inativação de alguns micro-organismos em alimentos líquidos, como o leite (Sung e Collins, 1998; Claeys et al., 2002). Para facilitar a comparação entre os indicadores, a Figura 6.1.2 apresenta os resultados para as temperaturas de 70 e $80^{\circ} \mathrm{C}$, considerando tempos mais longos.

Além dos parâmetros cinéticos, os custos dos indicadores devem ser levados em conta para avaliar sua aplicação prática. Baseado nas concentrações de pó liofilizado apresentadas na Seção 5.2.1, o custo específico para estes indicadores seria de, aproximadamente, 40 
US\$/L para POD, 2200 US\$/L para LPO e 0,25 US\$/L para ALP. A diferença entre os custos é evidente e inviabiliza a aplicação do indicador LPO, especialmente levando em conta a grande dispersão de pontos observada na Figura 6.1.1. Além disso, o reduzido valor de $z_{1}$ obtido para o indicador LPO (Tabela 6.1.1) o torna muito sensível a variações de temperatura para poder ser um bom integrador de tempo-temperatura (TTI).
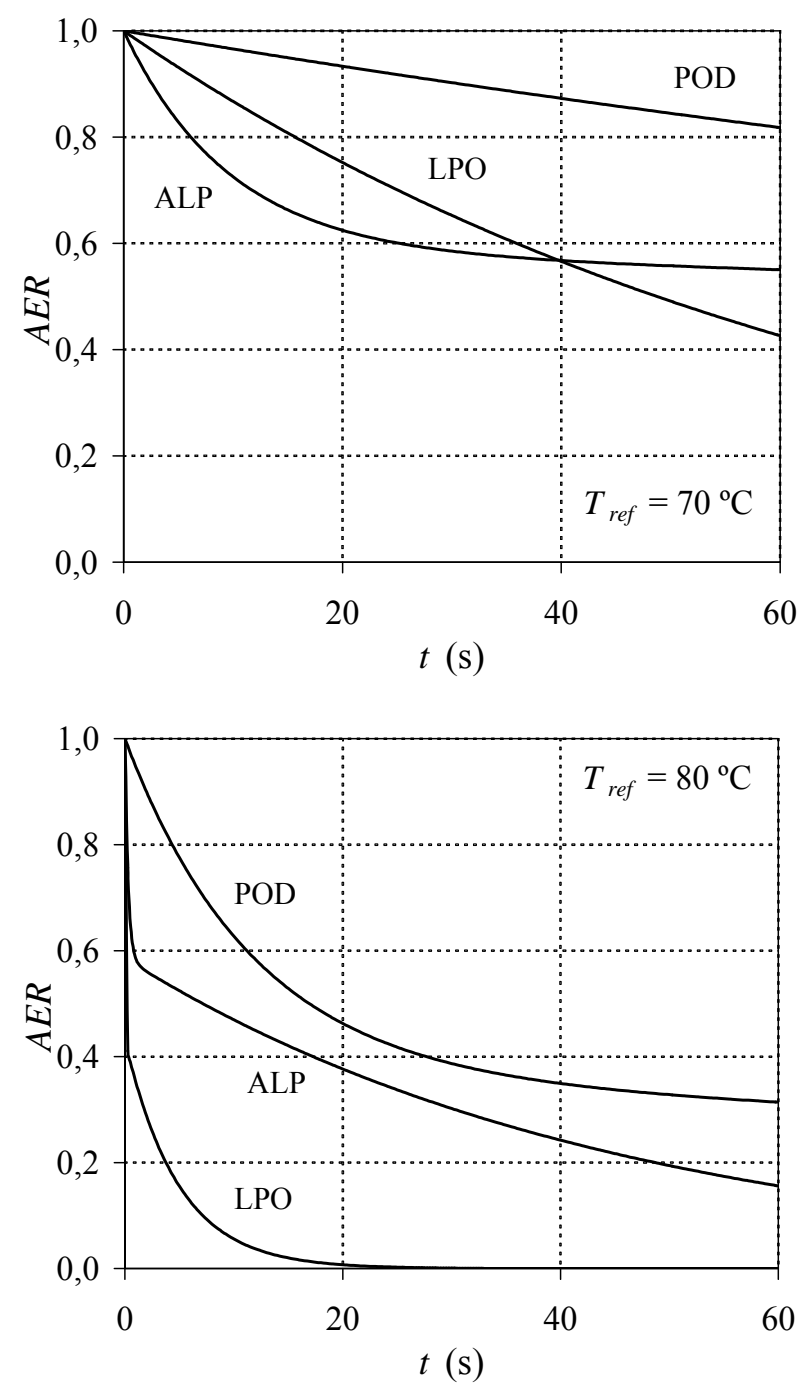

Figura 6.1.2. Curvas de inativação térmica dos indicadores POD (peroxidase), LPO (lactoperoxidase) e ALP (fosfatase alcalina) de acordo com o modelo cinético ajustado para temperaturas de referência de 70 e $80^{\circ} \mathrm{C}$ (Aguiar et al., 2012).

\subsubsection{Validação do modelo cinético}

Conforme descrito na Seção 5.2.5, os indicadores POD e ALP foram submetidos a ensaios de validação do modelo. O indicador LPO não foi testado, por ter sido considerado inviável economicamente para uso. A validação consistiu na comparação entre a atividade enzimática residual obtida em ensaios térmicos descontínuos com aquecimento lento e o valor 
predito pelo modelo ajustado, baseado no histórico de temperatura registrado. A Figura 6.1.3 traz, como exemplo, os históricos de temperatura obtidos para o indicador ALP em quatro temperaturas de banho quente e dois tempos de imersão.

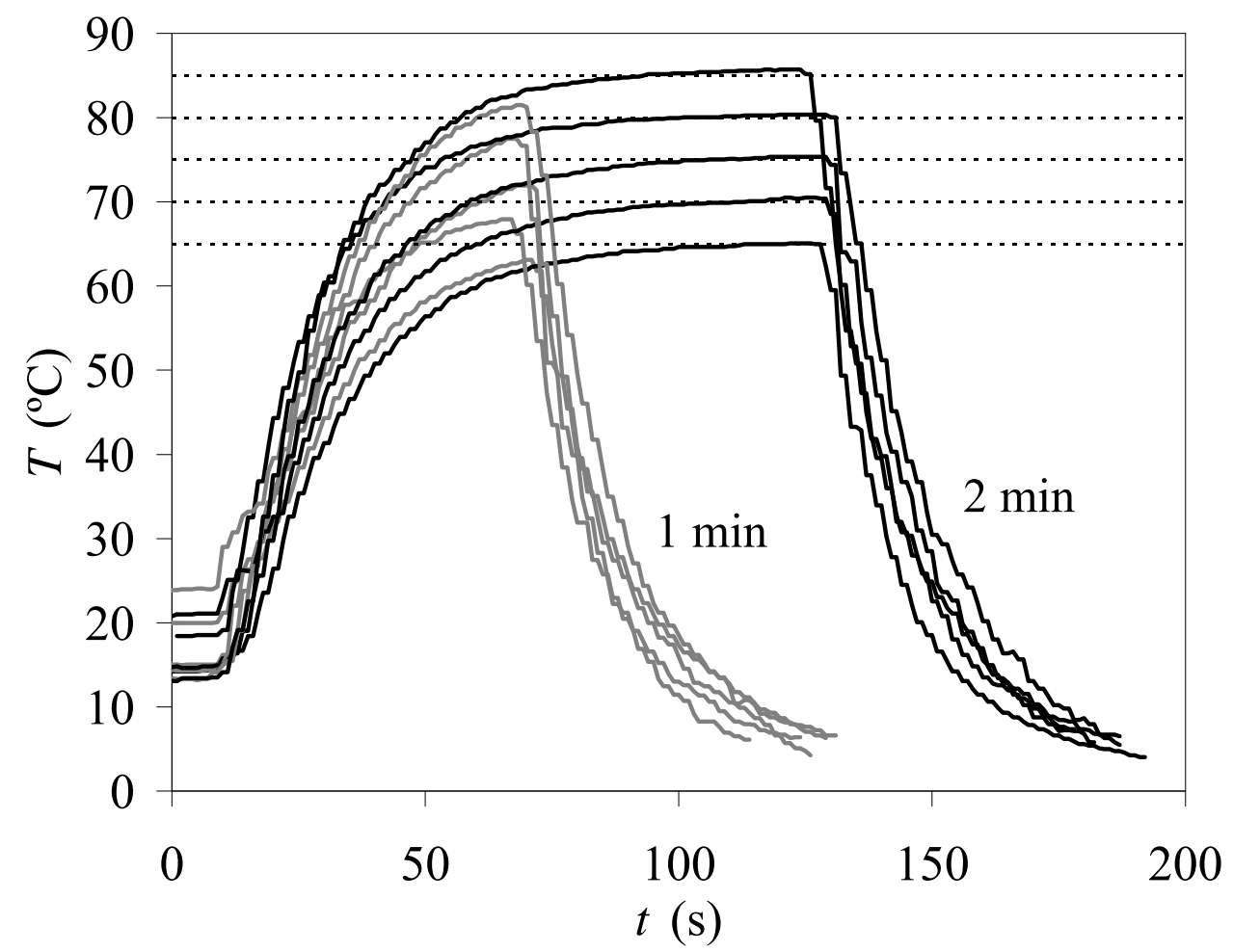

Figura 6.1.3. Históricos de temperatura do indicador ALP (fosfatase alcalina) nos ensaios de validação com aquecimento lento (Aguiar et al., 2012).

A Figura 6.1.4 compara a atividade residual experimental com a predita para a inativação do indicador ALP nos ensaios de validação. Como a distribuição dos pontos no gráfico de paridade é simular àquela na Figura 6.1.1 e a distribuição do resíduo não aparenta tendência significativa, pode-se considerar um bom resultado para o indicador ALP. Entretanto, em ambos os gráficos de paridade nota-se que para valores de $A E R_{\text {exp }}<0,2 \mathrm{o}$ resíduo relativo é geralmente positivo e relevante. 

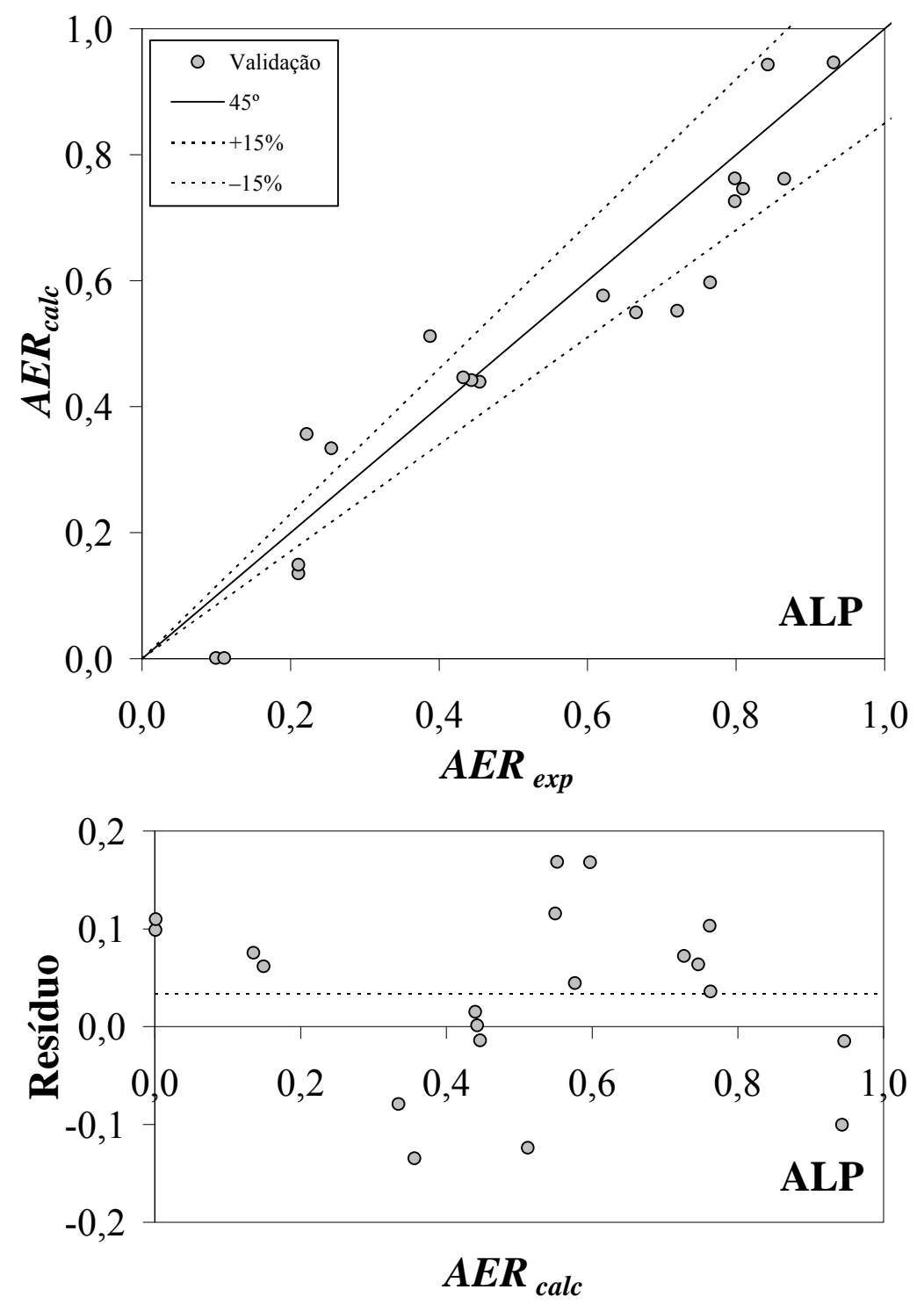

Figura 6.1.4. Resultados dos ensaios de validação para o ALP (fosfatase alcalina) com o gráfico de paridade para a predição da atividade enzimática residual e a distribuição do resíduo (experimental - predito) (Aguiar et al., 2012).

O indicador POD teve um desempenho insatisfatório nos ensaios de validação. A atividade residual experimental foi muito superior àquela predita pelo modelo ajustado. Para confirmar o resultado, um novo lote de indicador foi preparado e os ensaios de validação foram refeitos. Os resultados dos dois ensaios são apresentados na Figura 6.1.5. A inativação térmica do indicador POD apresentou cinética diferentes para ensaios com aquecimento rápido e ensaios com aquecimento lento. Isto indica que a enzima pode sofrer algum tipo de período de ativação ou sobre-ativação. Pesquisadores que estudaram a inativação térmica de peroxidades e outras enzimas já reportaram este tipo de comportamento (Polakovič e Vrábel, 1996; Martin et al., 2005). 

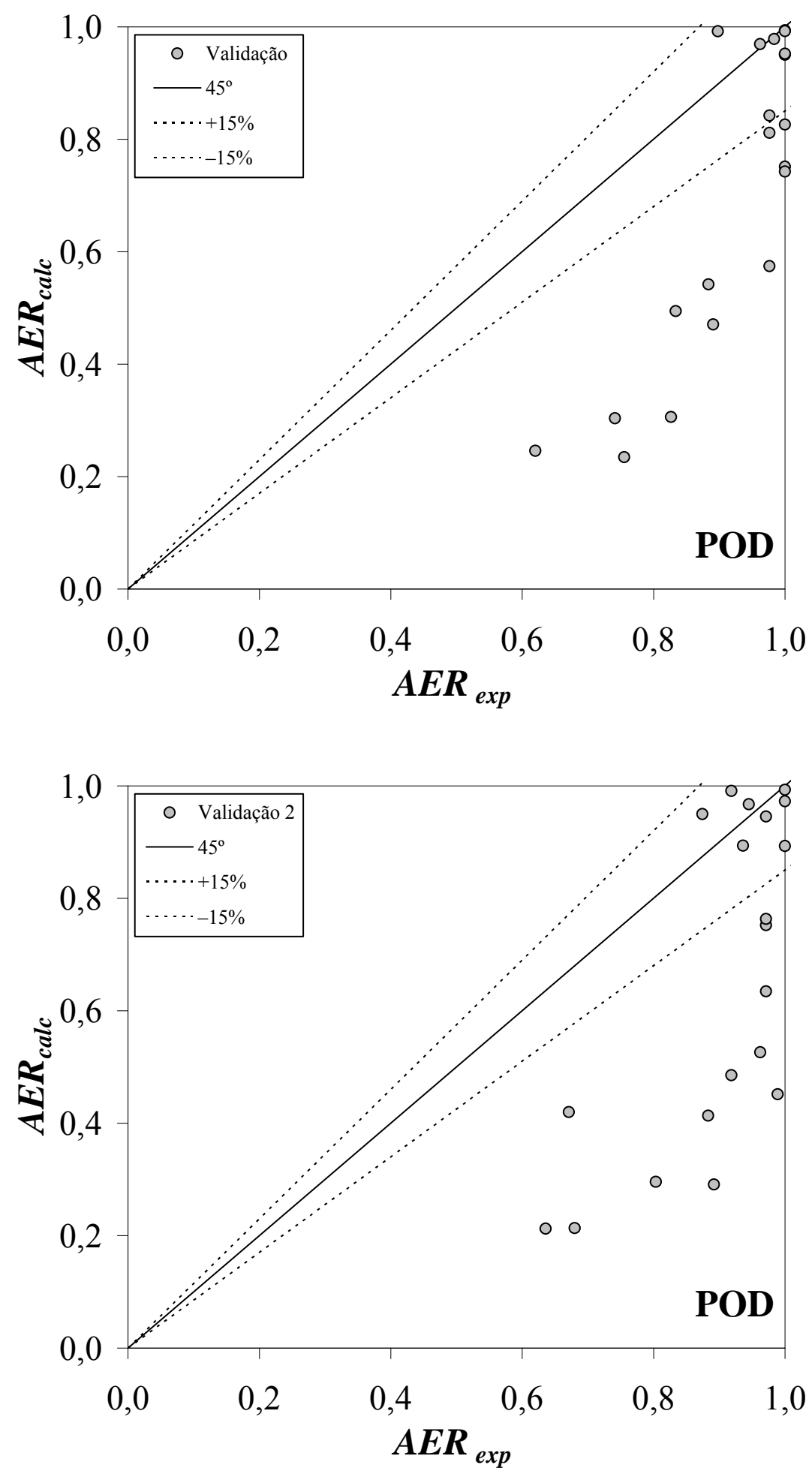

Figura 6.1.5. Resultados dos ensaios de validação para o indicador POD (peroxidase) com os gráficos de paridade para a predição da atividade enzimática residual em dois conjuntos de experimentos independentes (Aguiar et al., 2012). 
Devido ao comportamento observado para o indicador POD, a sua aplicação prática se torna inviável. Consequentemente, apenas o indicador ALP tem potencial para ser utilizado como integrador de tempo-temperatura (TTI) para avaliação de processos de pasteurização HTST (70 a $\left.80^{\circ} \mathrm{C}\right)$. As principais vantagens do indicador ALP como TTI são: 1) a atividade enzimática pode ser determinada facilmente através de kit comercial sem necessidade de equipamentos laboratoriais sofisticados; 2) o seu custo específico é baixo (0,25 US\$/L); 3) os valores de $z_{1}$ e $z_{2}$ são compatíveis com alguns micro-organismos presentes em alimentos líquidos; 4) seu uso abrange uma faixa de temperatura ampla devido à existência das frações termorresistente e termolábil. Para melhorar a precisão das medidas de atividade, réplicas são necessárias. Além do uso para avaliar processos contínuos HTST, este TTI pode ser encapsulado em pequenos recipientes inseridos em alimentos sólidos ou semi-sólidos para avaliar a letalidade durante processo descontínuo, desde que as condições sejam brandas $(T<$ $90{ }^{\circ} \mathrm{C}$ ) como nos trabalhos de Guiavarc'h et al. (2002a, 2002b) e Tucker et al. (2009).

\subsection{Determinação da distribuição do tempo de residência}

\subsubsection{Calibração do traçador}

Conforme descrito na Seção 5.3, a condutividade elétrica da solução de cloreto de sódio (Cond) foi correlacionada com a concentração de sal $(0,25 \leq C \leq 1,75 \mathrm{~g} / \mathrm{L})$ e com a temperatura $\left(17 \leq T \leq 35^{\circ} \mathrm{C}\right)$ através da Equação (5.3.3) que tem quatro parâmetros. Os parâmetros ajustados pela minimização do erro quadrático foram $a_{3}=923,3, a_{4}=-52,31, a_{5}=$ 42,82 e $a_{6}=-2,424\left(R^{2}=0,998\right)$. As unidades adotadas para a Equação (5.3.3) são: Cond $[\mu \mathrm{S} / \mathrm{cm}], T\left[{ }^{\circ} \mathrm{C}\right]$ e $C[\mathrm{~g} / \mathrm{L}]$. A Figura 6.2.1 apresenta resultados do ajuste realizado. Como era e se esperar, a condutividade elétrica da solução aumenta com a temperatura e com a concentração de eletrólito. A faixa de condutividade registrada foi de 440 a $3850 \mu \mathrm{S} / \mathrm{cm}$. 


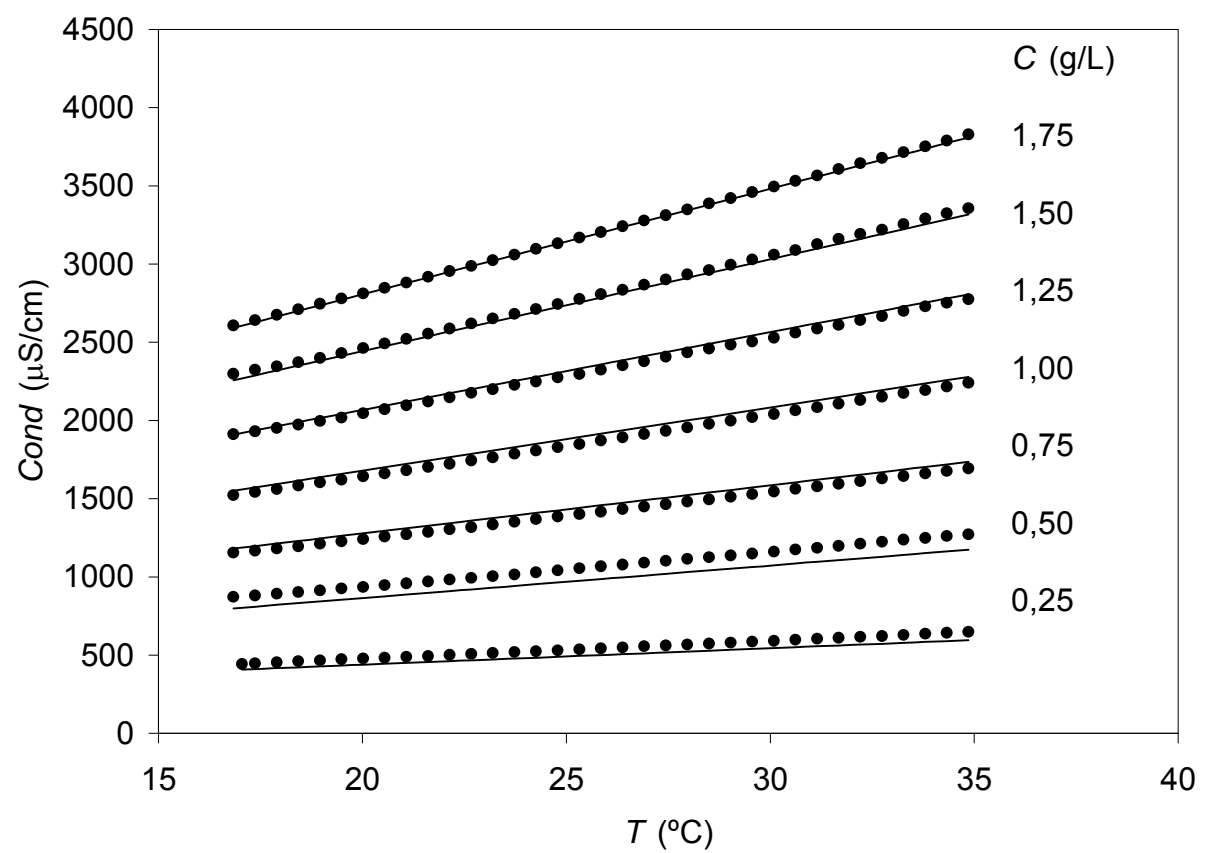

Figura 6.2.1. Resultados do ajuste da equação de calibração do traçador, tendo a condutividade elétrica da solução em função da temperatura e da concentração de cloreto de sódio. Pontos são experimentais e linhas da equação ajustada.

\subsubsection{Distribuição do tempo de residência na célula de condutividade}

Diversos ensaios de DTR foram realizados para estudar a resposta do sistema de aquisição de dados a um pulso de traçador aplicado na alimentação da célula de condutividade. As vazões testadas foram de 10, 15, 20, 25, 30 e $35 \mathrm{~L} / \mathrm{h}$. Como a passagem do traçador é tão rápida (tempo médio entre 2 e 5 s) quanto o intervalo de aquisições de dados (1 s), no mínimo seis repetições foram realizadas para melhor identificar o comportamento.

As curvas $E(t), E_{\theta}(\theta)$ e o tempo médio de residência foram obtidos através das Equações (3.3.1), (3.3.4) e (3.3.3), respectivamente. Os modelos de dispersão axial (Equação (3.3.8)) e de tanques em série estendido (Equação (3.3.9)) foram ajustados às curvas $E_{\theta}(\theta)$, sendo que o primeiro forneceu o melhor ajuste, baseado nos valores dos somatórios dos erros quadráticos em $E_{\theta}$. A Figura 6.2.2 apresenta um exemplo de comparação entre dados coletados de DTR e a curva predita pelo modelo ajustado. A curva na Figura 6.2.2 corresponde ao modelo de dispersão axial com $P e=7,6$, valor médio obtido para o conjunto de ensaios na vazão de $20 \mathrm{~L} / \mathrm{h}$. 


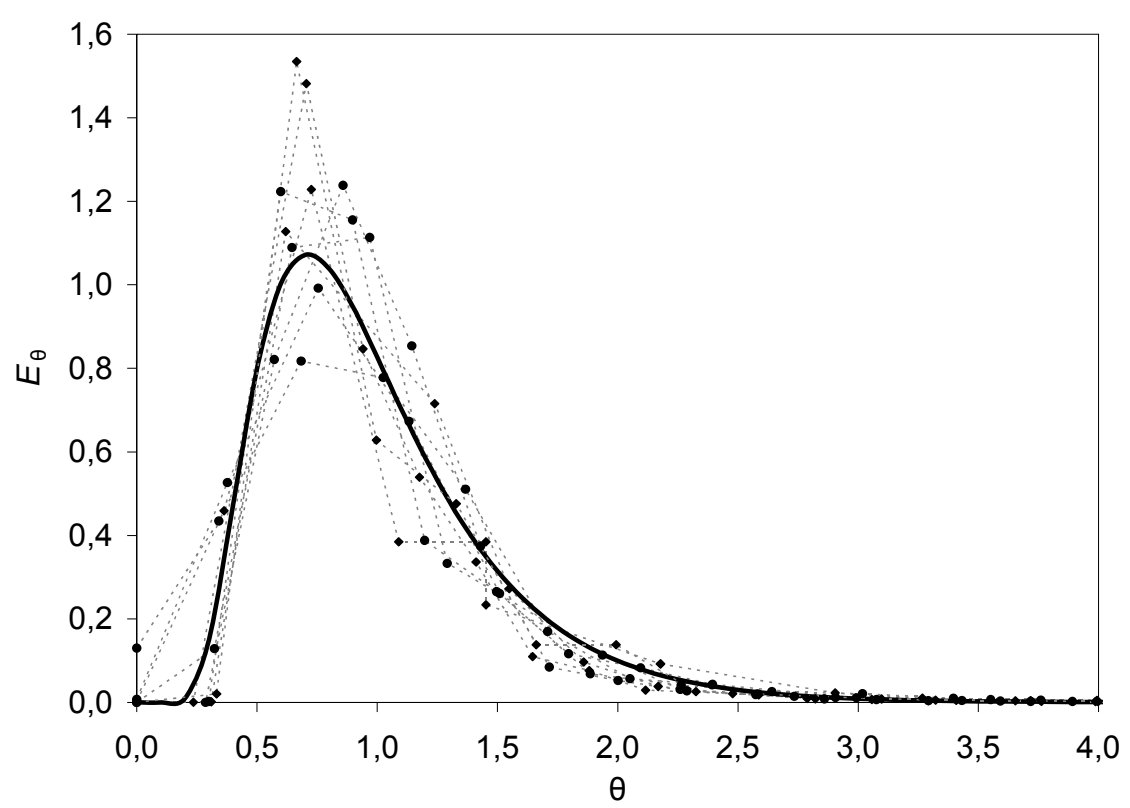

Figura 6.2.2. Dados experimentais de DTR para estudo do sistema de aquisição de dados na vazão de $20 \mathrm{~L} / \mathrm{h}$ incluindo curva do modelo de dispersão axial $(P e=7,6)($ Gutierrez et al., 2010).

A Figura 6.2.3 mostra a dependência do tempo médio de residência e do número de Peclet com a vazão volumétrica. Usualmente a relação entre o tempo médio de residência e a vazão é dada pela Equação (3.3.6a), na qual o parâmetro ajustável é o volume ativo. Neste caso, foi necessário incluir como parâmetro a potência na vazão volumétrica, conforme a Equação (6.2.1), ajustada pela minimização do erro quadrático. Este comportamento anormal é justificado pelo fato de o detector de condutividade estar inserido dentro do recipiente estudado e não após sua saída.

$$
t_{m}(\mathrm{~s})=\frac{10,4}{Q(\mathrm{~mL} / \mathrm{s})^{-2 / 3}}
$$

Como não foi possível identificar uma relação clara entre o número de Peclet e a vazão (Figura 6.2.3), o valor médio $P e=7,8 \pm 1,8$ foi adotado para a faixa de vazão estudada. Este valor está fora da faixa de validade da Equação (3.3.8) ( $P e>16)$, mas este fato não invalida o resultado, pois a equação ajustada continua sendo uma curva $E(t)$. Entretanto, o valor obtido de Peclet perde seu significado e não pode ser usado para cálculos de coeficiente de dispersão. Este valor médio e o tempo médio de residência na Equação (6.2.1) foram adotados para fornecer a curva $E(t)$ do sistema de aquisição de dados necessária para os cálculos de convolução de sinais, de acordo com o procedimento apresentado na Seção 5.3.2. 

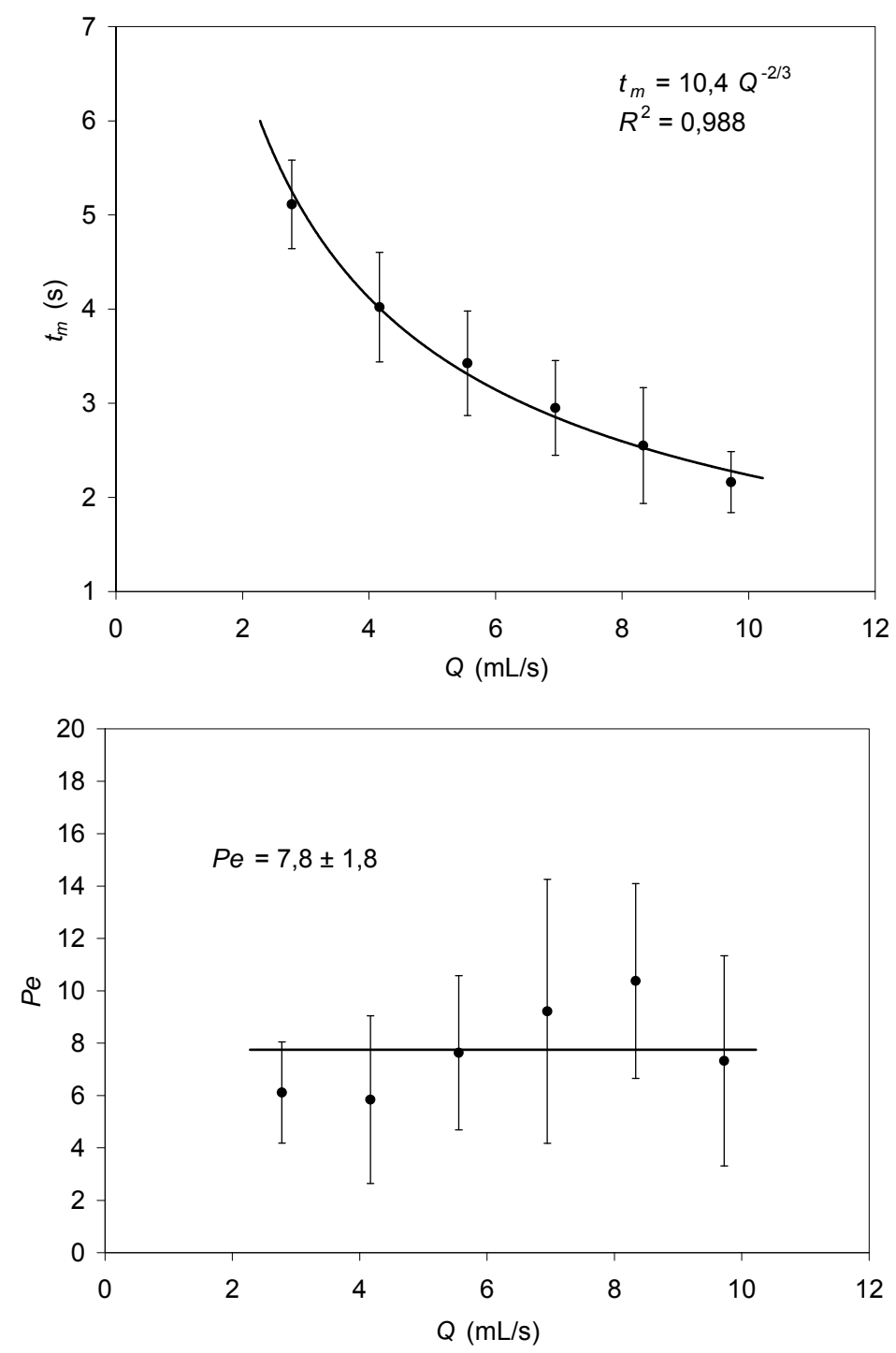

Figura 6.2.3. Resultados dos ensaios de DTR do sistema de aquisição de dados de condutividade incluindo o tempo médio de residência e o número de Peclet ajustado em função da vazão volumétrica (Gutierrez et al., 2010).

\subsubsection{Distribuição do tempo de residência nos tubos de retenção}

Os ensaios para estudo da DTR nos dois tubos de retenção (T1 e T2 na Figura 5.1.2) foram realizados de acordo com o procedimento descrito na Seção 5.3. Os modelos de DTR ajustados aos dados coletados foram de dispersão axial (Equação (3.3.8)), de tanques em série estendido (Equação (3.3.9)), de convecção generalizado (Equação (3.3.12)) e de associação PFR+CSTR (Equação (3.3.14)). Como exemplos, a Figura 6.2.4 apresenta ajustes de curva para dados experimentais coletados nos tubos $\mathrm{T} 1$ e T2. O modelo ajustado nestes exemplos é o de convecção generalizado. Nesta figura pode-se ver a curva $E(t)$ do modelo que representa o processo e a curva da convolução desde modelo com a curva $E(t)$ do sistema de aquisição. Esta curva convolucionada foi ajustada aos dados experimentais pela minimização do erro 
quadrático em $E(t)$, ajustando o parâmetro do modelo escolhido e o tempo médio de residência.
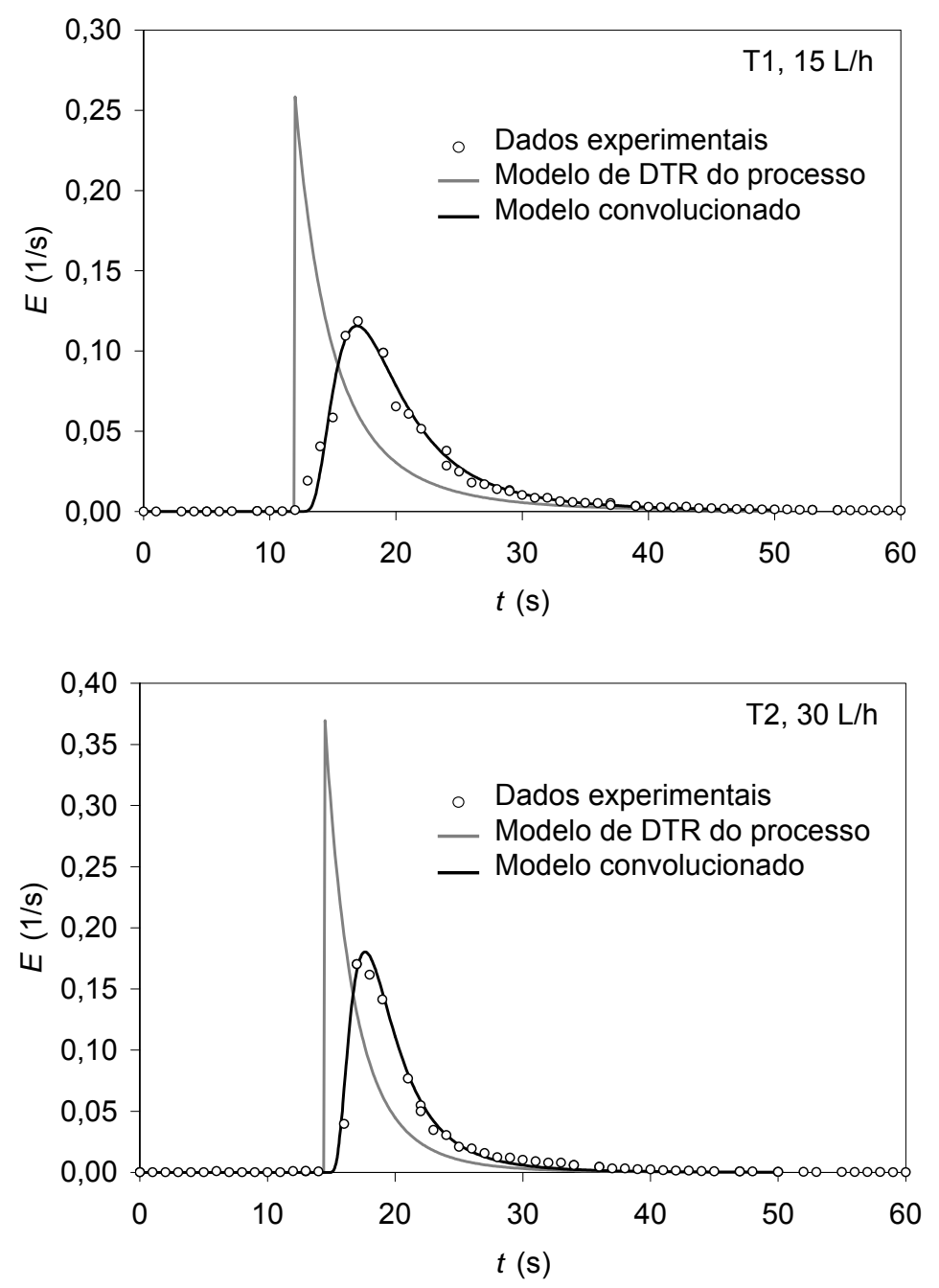

Figura 6.2.4. Exemplos de ajustes de modelos de DTR usando dados coletados para os tubos de retenção T1 e T2 (Gutierrez et al., 2010).

Na Figura 6.2.4 é nítida a distorção na curva $E(t)$ provocada pelo sistema de aquisição de dados de condutividade elétrica. Há um atraso ligado ao escoamento dentro da célula e um achatamento da curva, associado às recirculação interna do fluido. Fillaudeau et al. (2009) verificaram que a distorção de sinal pode ser desprezada se o tempo médio de residência na detecção não for superior a $1 \%$ do tempo médio de residência do processo avaliado. No presente trabalho, o tempo médio de residência do sistema de detecção (Figura 6.2.3) é maior que $22 \%$ do tempo médio do tubo T1 e $9 \%$ do tempo médio do tubo T2. Portanto, o procedimento de convolução é necessário para correta determinação da curva $E(t)$ do equipamento estudado. 
Para os dois tubos de retenção, o modelo que forneceu o melhor ajuste foi o de convecção generalizado, seguido pelo modelo de associação PFR+CSTR, como pode ser visto na Tabela 6.2.1, que traz os valores minimizados do somatório do erro quadrático. Os modelos de dispersão axial e de tanques em série estendido não tiveram sucesso em representar a cauda da curva $E(t)$, que pode ser vista nos exemplos da Figura 6.2.4.

Tabela 6.2.1. Valores minimizados do somatório do erro quadrático $\left(S E Q \times 10^{3}, \mathrm{~s}^{-2}\right)$ para ajuste dos modelos de DTR aos dados coletados com os tubos de retenção T1 e T2 (Gutierrez et al., 2010).

\begin{tabular}{clcccccc}
\hline \multirow{2}{*}{ Tubo } & \multirow{2}{*}{ Modelo } & \multicolumn{5}{c}{ Vazão volumétrica } \\
\cline { 3 - 8 } & & $10 \mathrm{~L} / \mathrm{h}$ & $15 \mathrm{~L} / \mathrm{h}$ & $20 \mathrm{~L} / \mathrm{h}$ & $25 \mathrm{~L} / \mathrm{h}$ & $30 \mathrm{~L} / \mathrm{h}$ & $35 \mathrm{~L} / \mathrm{h}$ \\
\hline T1 & Conv. generalizado & $0,6 \pm 0,2$ & $3,0 \pm 2,4$ & $2,3 \pm 1,6$ & $2,9 \pm 2,2$ & $10,5 \pm 1,8$ & $3,4 \pm 2,7$ \\
& Assoc. PFR+CSTR & $0,8 \pm 0,4$ & $3,5 \pm 2,9$ & $3,0 \pm 1,4$ & $2,7 \pm 1,9$ & $10,2 \pm 1,2$ & $3,0 \pm 2,4$ \\
& Dispersão axial & $3,4 \pm 0,8$ & $5,2 \pm 1,9$ & $5,9 \pm 1,5$ & $4,2 \pm 2,1$ & $8,8 \pm 1,2$ & $5,8 \pm 8,3$ \\
& Tanques em série & $4,2 \pm 0,6$ & $5,7 \pm 1,9$ & $6,5 \pm 1,5$ & $4,5 \pm 2,2$ & $13,0 \pm 5,5$ & $8,1 \pm 2,9$ \\
\hline T2 & Conv. generalizado & $0,8 \pm 0,2$ & $2,5 \pm 1,0$ & $2,4 \pm 1,4$ & $3,5 \pm 1,7$ & $3,5 \pm 2,4$ & $6,4 \pm 3,8$ \\
& Assoc. PFR+CSTR & $1,7 \pm 0,1$ & $3,1 \pm 1,2$ & $3,3 \pm 1,3$ & $4,5 \pm 2,5$ & $8,7 \pm 6,2$ & $6,7 \pm 3,5$ \\
& Dispersão axial & $5,7 \pm 0,3$ & $10,5 \pm 3,1$ & $11,4 \pm 1,7$ & $14,3 \pm 2,8$ & $14,4 \pm 7,7$ & $16,8 \pm 5,8$ \\
& Tanques em série & $6,1 \pm 0,3$ & $10,9 \pm 3,2$ & $11,9 \pm 1,6$ & $15,1 \pm 2,7$ & $14,9 \pm 7,8$ & $17,5 \pm 6,5$ \\
\hline
\end{tabular}

A Figura 6.2.5 apresenta os tempos médios de residência obtidos para os tubos T1 e T2, incluindo a curva do tempo espacial (Equação (3.3.5)). O valor do volume ativo dos tubos foi determinado através do ajuste da Equação (3.3.6a) aos dados na Figura 6.2.5. Os valores obtidos foram: $V_{\text {ativo }}=65,3 \mathrm{~mL}$ para $\mathrm{T} 1 \mathrm{e} V_{\text {ativo }}=154 \mathrm{~mL}$ para $\mathrm{T} 2$. Estes resultados indicam que o tubo $\mathrm{T} 1$ tem volume morto $V_{\text {morto }}=9,7 \mathrm{~mL}$, que corresponde a $13 \%$ do volume interno (Equação (3.3.6b)). Já o tubo T2 tem $V_{\text {morto }}=46 \mathrm{~mL}$, que corresponde a $23 \%$ do volume interno. O volume morto corresponde a regiões de estagnação e recirculação. O escoamento laminar está mais sujeito à formação de zonas de estagnação devido à menor turbulência e à baixa velocidade próxima às paredes. 

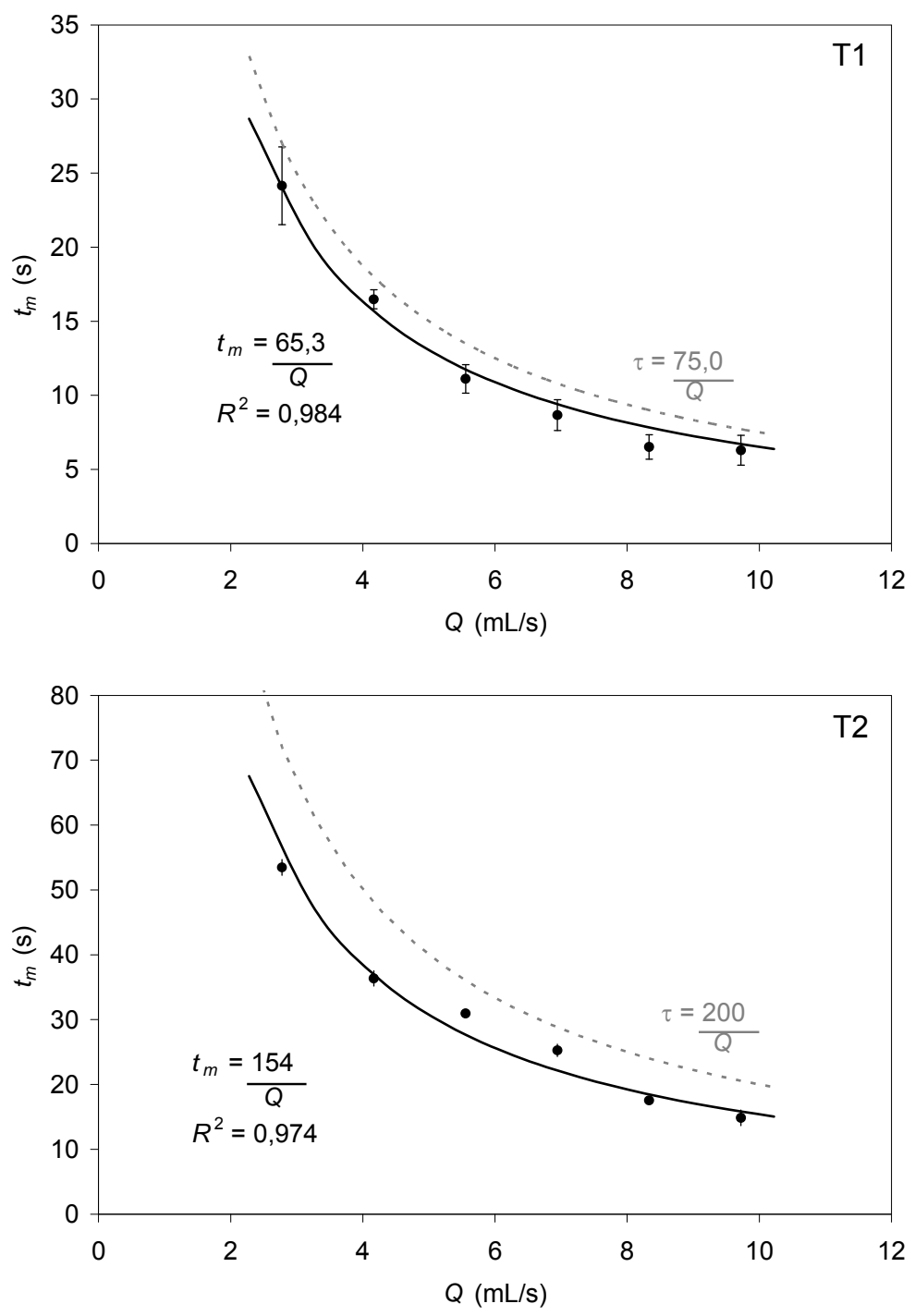

Figura 6.2.5. Tempos médios de residência e tempos espaciais para os tubos de retenção T1 e T2 em função da vazão (Gutierrez et al., 2010).

O parâmetro do modelo de convecção generalizado é o tempo mínimo de residência adimensional, $\theta_{0}$. A influência da vazão sobre os valores obtidos de $\theta_{0}$ para os tubos T1 e T2 é apresentada na Figura 6.2.6 e pelas correlações lineares ajustadas nas Equações (6.2.2a) (tubo T1) e (6.2.2b) (tubo T2).

$$
\begin{aligned}
& \theta_{0}=0.528+0.0326 \cdot Q(\mathrm{~mL} / \mathrm{s}) \\
& \theta_{0}=0.696+0.0165 \cdot Q(\mathrm{~mL} / \mathrm{s})
\end{aligned}
$$



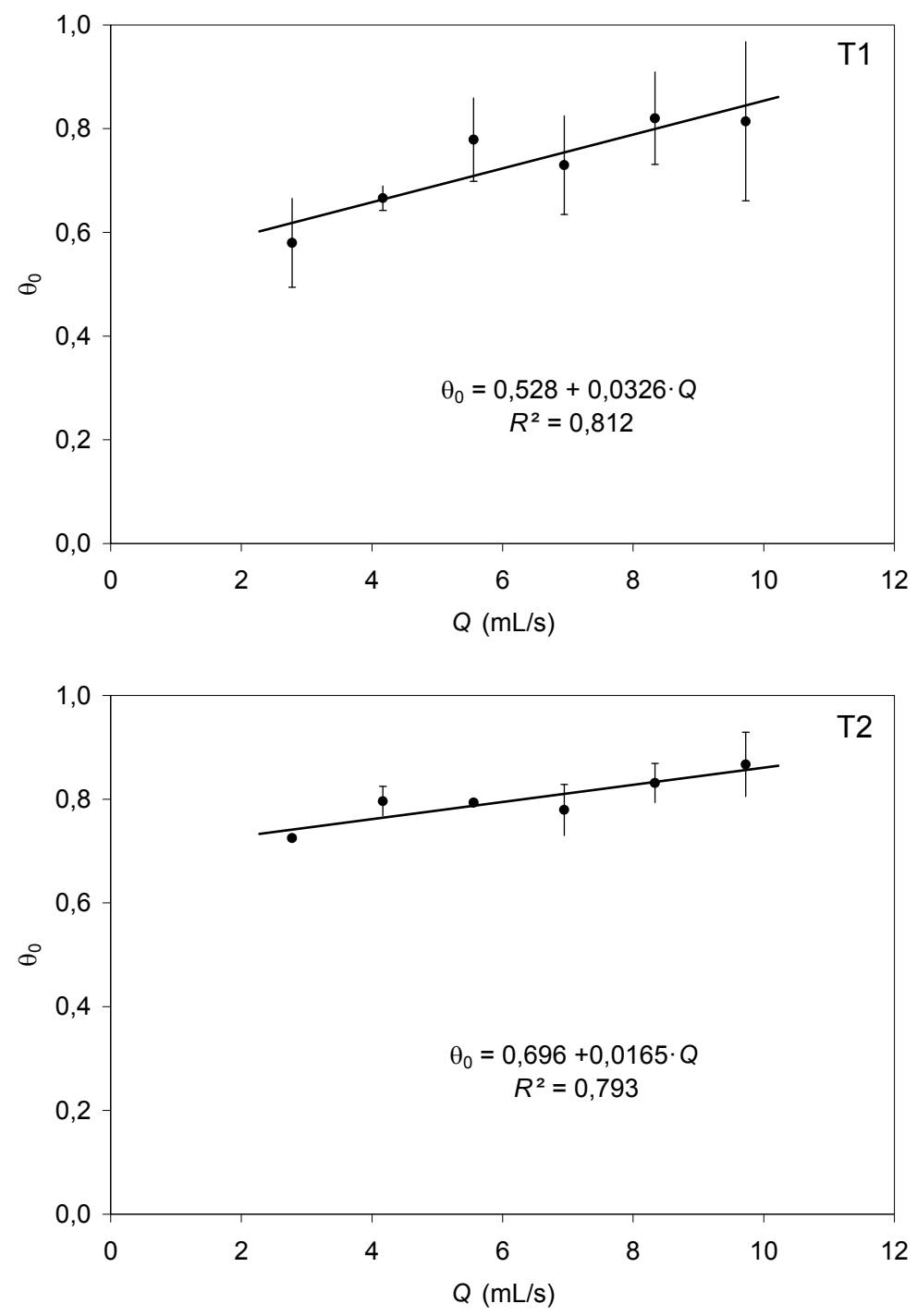

Figura 6.2.6. Tempos mínimos de residência para os tubos de retenção T1 e T2 em função da vazão, de acordo com o modelo de convecção generalizado (Gutierrez et al., 2010).

Para escoamento laminar ideal em um tubo reto, o valor teórico do tempo mínimo de residência é $\theta_{0}=0,5$. Os valores obtidos neste trabalho (Figura 6.2.6) são superiores ao valor teórico, indicando um perfil de velocidades no tubo mais achatado. No caso limite de $\theta_{0}=1,0$ tem-se o delta de Dirac associado ao perfil chato de velocidades do escoamento pistonado. Nos estudos de DTR em tubos helicoidais realizados por Ruthven (1971) e Trivedi e Vasudeva (1974), foram obtidos valores de $\theta_{0}$ entre 0,586 e 0,658. A circulação secundária induzida pelas curvas diminui o espalhamento do tempo de residência em escoamento laminar, o que é consistente com o aumento em $\theta_{0}$. Além disso, a bomba peristáltica usada neste trabalho induz uma leve pulsação ao escoamento e esta oscilação deve achatar o perfil de velocidade. 
Rao e Loncin (1974a) definiram a eficiência de um tubo de retenção como sendo a razão entre os tempos mínimo e médio de residência. Para o modelo de convecção generalizado, esta razão é o parâmetro $\theta_{0}$ expresso como porcentagem. Consequentemente, os casos ideais de escoamento pistonado e escoamento laminar em tubo têm eficiências de $100 \%$ e de $50 \%$, respectivamente. De forma geral, maiores números de Reynolds resultam em maiores eficiências de tubo (Torres e Oliveira, 1998b). O uso de tubos curvos e a pulsação no escoamento, como verificado, fornecem eficiências superiores a 50\% no escoamento laminar. Entretanto, os resultados indicam a existência de zonas de estagnação, o que é indesejado.
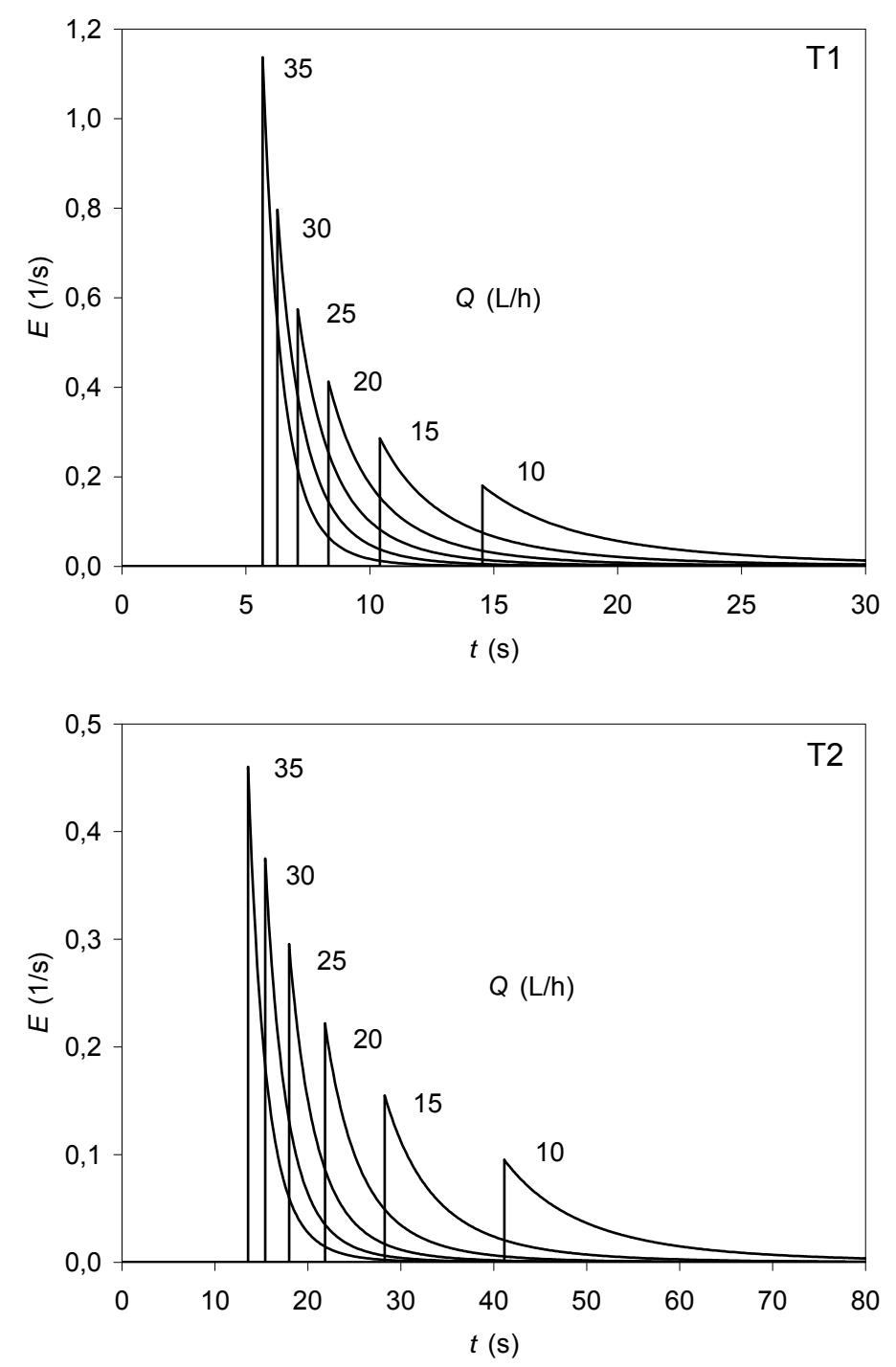

Figura 6.2.7. Curvas de DTR dos tubos de retenção T1 e T2 de acordo com o modelo de convecção generalizado ajustado (Gutierrez et al., 2010).

Finalizando, as curvas $E(t)$ para o escoamento de água nos tubos T1 e T2, na temperatura ambiente, são apresentadas na Figura 6.2.7 para diversas vazões, de acordo com o 
modelo de convecção generalizado ajustado. Como esperado, o espalhamento nas curvas é maior em baixas vazões e o tubo de retenção T1 tem um tempo de residência mais curto que $\mathrm{T} 2$.

\subsubsection{Distribuição do tempo de residência no trocador de calor}

Os ensaios para estudo da DTR no trocador de calor a placas com arranjos de passe em série ou paralelo (Figura 5.3.2) foram realizados de acordo com o procedimento descrito na Seção 5.3. Os modelos matemáticos de DTR ajustados aos dados coletados foram os modelos de dispersão axial (Equação (3.3.8)), de convecção generalizado (Equação (3.3.12)) e de associação PFR+CSTR (Equação (3.3.14)). A Figura 6.2.8 apresenta um exemplo de ajuste de modelos aos dados experimentais de um ensaio. Nesta figura pode-se ver a curva $E(t)$ do modelo que representa o processo e a curva da convolução desde modelo com a curva $E(t)$ do sistema de aquisição. A curva convolucionada foi ajustada aos dados experimentais pela minimização do erro quadrático em $E(t)$, ajustando o parâmetro do modelo e o tempo médio de residência do processo. Assim como no estudo da DTR dos tubos de retenção, é nítido o efeito de distorção da curva $E(t)$ provocado pelo sistema de aquisição de dados de condutividade.

Os dados experimentais coletados apresentaram curvas assimétricas com uma cauda de traçador que é típica de escoamento laminar ou da presença de zonas de estagnação (vide exemplo na Figura 6.2.8). Esta cauda foi mais pronunciada para baixas vazões de escoamento e para o arranjo de passes em paralelo com maior número de canais no passe. Como o número de Reynolds nos canais do trocador ficou entre 1450 e 2410 para os arranjos em série e entre 210 e 1210 para os arranjos em paralelo e as placas eram lisas (sem promotores de turbulência), esperava-se um comportamento próximo ao do regime laminar de escoamento.

Galeazzo et al. (2006) estudaram, através de modelo matemático em CFD (computational fluid dynamics), o escoamento dentro deste trocador de calor e identificaram zonas de baixa velocidade e de recirculação no interior dos canais ligadas à falta da corrugação, que é presente em trocadores de calor de placas industriais. Estas zonas devem contribuir para a maior dispersão do tempo de residência. Mesmo assim, arranjos em série com altas vazões e maior número de passes produziram curvas de DTR quase simétricas. Este resultado pode ser explicado para maior número de Reynolds que melhora a mistura nos canais e pela turbulência associada às expansões e contrações presentes nas mudanças de passes no pacote de placas. 

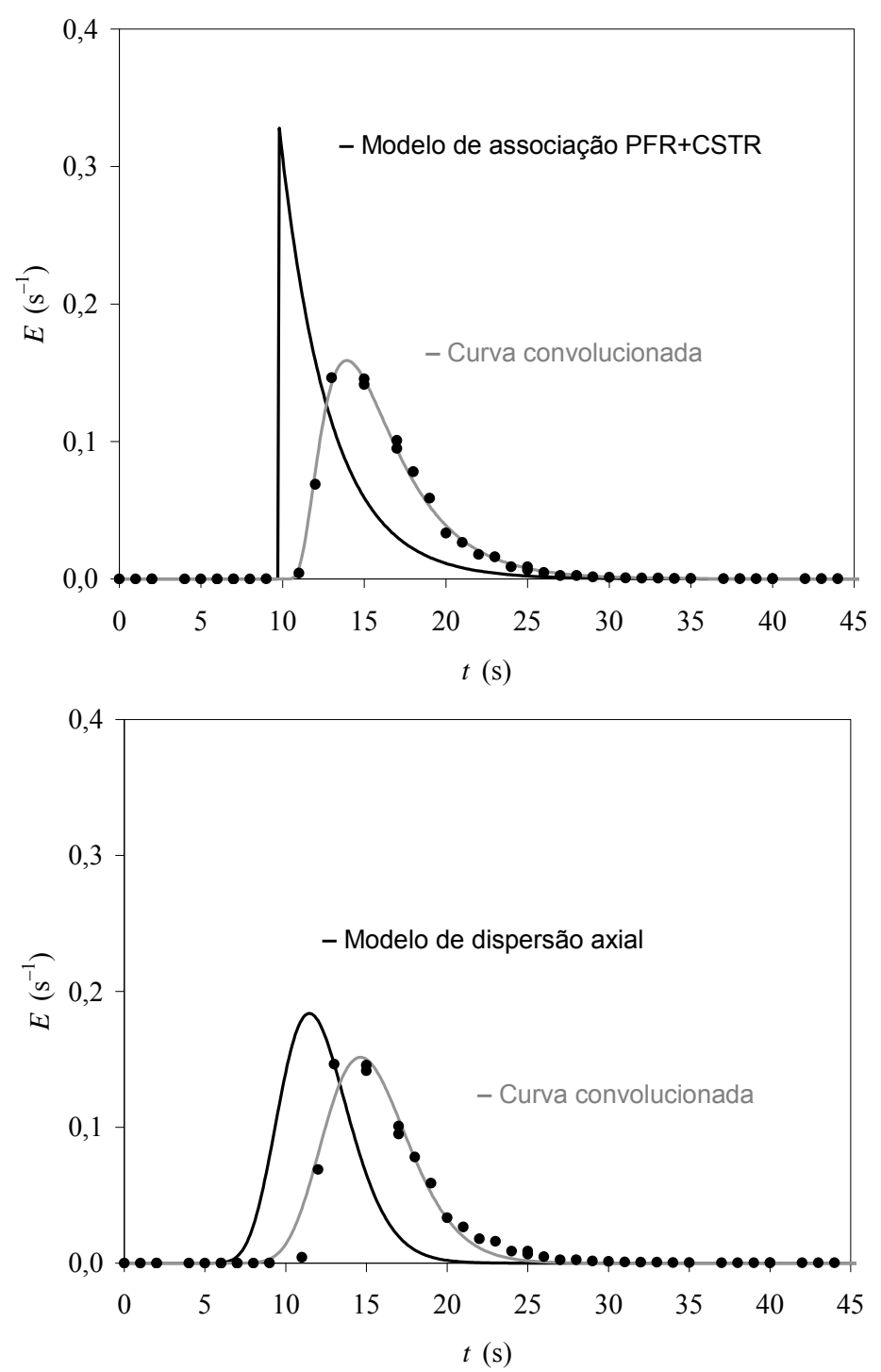

Figura 6.2.8. Exemplos de ajustes de modelos de DTR usando dados coletados para o trocador de calor a placas, neste caso um arranjo em série com 10 passes na vazão de $20 \mathrm{~L} / \mathrm{h}$ (Gutierrez et al., 2011).

A Figura 6.2.9 apresenta os valores médios do somatório do erro quadrático em função do número de passes para os arranjos em série do trocador, nas três vazões estudadas, considerando os três modelos matemáticos ajustados. De forma geral, os melhores ajustes tiveram $S E Q<2 \times 10^{-3} \mathrm{~s}^{-2}$. O modelo de associação PFR+CSTR teve o melhor resultado geral, enquanto que o modelo de dispersão axial teve resultados insatisfatórios. Entretanto, os resultados na Figura 2.6.9 sugerem que para maior número de passes essa situação deve se inverter. Com o aumento de $P$, aumenta a simetria da curva $E(t)$, que é melhor representada pelo modelo de dispersão, enquanto o modelo de associação é mais adequado para curvas assimétricas (Figuras 3.3.1 e 3.3.4). O maior erro para $P=2$ e $P=4$ está ligado à dificuldade 
em determinar DTRs com tempos de residência muito curtos, que fornecem poucos pontos experimentais e de menor confiabilidade.

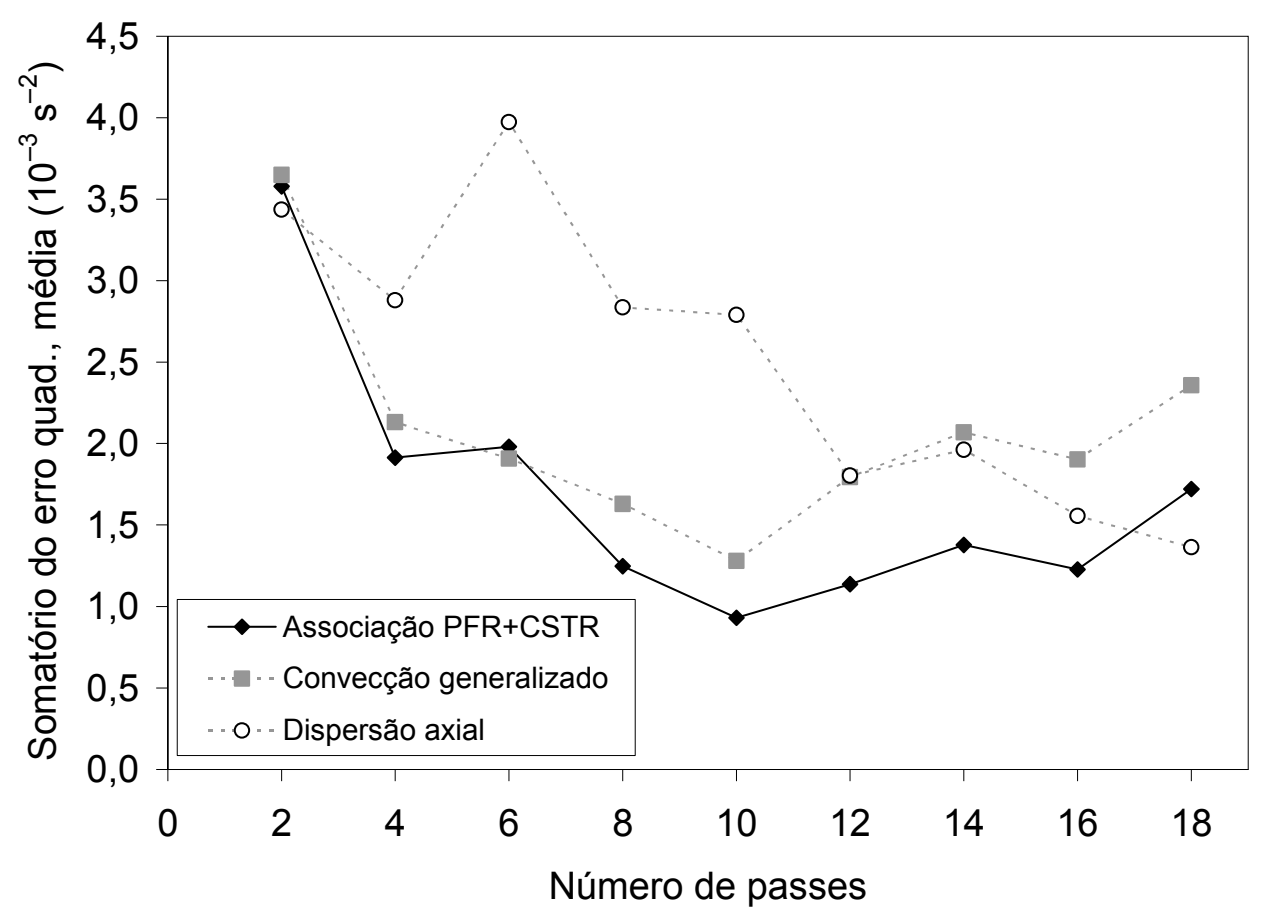

Figura 6.2.9. Média do somatório do erro quadrático para ajustes de modelos de DTR, nos ensaios com o trocador de calor com arranjo em série, em função do número de passes

(Gutierrez et al., 2011).

Curiosamente houve dificuldade em ajustar o modelo de convecção generalizada aos ensaios feitos com o trocador de calor em arranjo em paralelo com alto número de canais por passe. A longa cauda de traçador presente na curva $E(t)$ não permitiu um ajuste adequado, pois o parâmetro $\theta_{P}$ tendia a zero enquanto o tempo médio de residência tendia ao infinito no processo de minimização do erro, provendo diversos ótimos locais. Entretanto, este problema não foi observado para o arranjo em série do trocador. Neste caso o valor de $\theta_{P}$ se mostrou praticamente independente do número de passes e da vazão volumétrica, tendo um valor médio de $\theta_{P}=0,72 \pm 0,06$. Um valor de $\theta_{P}$ acima de 0,5 indicaria, para o escoamento em tubo, um perfil de velocidades mais achatado que o perfil laminar Newtoniano. Neste caso o atraso na saída do traçador (no tempo adimensional) pode estar ligado às zonas de recirculação internas nos canais do trocador.

Para a faixa de vazão estudada $(15,20$ e $25 \mathrm{~L} / \mathrm{h})$, a influência da vazão sobe os parâmetros volumétricos do modelo de associação PFR+CSTR ( $V_{\text {plug }}$ e $\left.V_{\text {mix }}\right)$ foi muito pequena, de forma que valores médios são aqui apresentados. Para a determinação destes 
volumes, o modelo de associação PFR+CSTR foi ajustado no formato da Equação (3.3.16), em vez da Equação (3.3.14), usando como parâmetros $\tau_{\text {plug }}$ e $\tau_{m i x}$, em vez de $\theta_{P}$ e $t_{m}$. O tempo médio de residência foi calculado posteriormente como $t_{m}=\tau_{p l u g}+\tau_{m i x}$ e $\theta_{P}$ foi obtido através da Equação (3.3.15). Os volumes dos reatores PFR e CSTR foram calculados como $V_{\text {plug }}=$ $\tau_{\text {plug }} \cdot Q$ e $V_{\text {mix }}=\tau_{m i x} \cdot Q$, em que $Q$ é a vazão volumétrica. $O$ volume ativo do trocador é a soma de $V_{\text {plug }}$ e $V_{\text {mix }}$, ou pode ser obtido através da Equação (3.3.6a). Como o volume interno do trocador é conhecido (Equações (5.1.1a) e (5.1.1b)), foi possível obter o volume morto usando a Equação (3.3.6b).

Os resultados obtidos são apresentados na Figura 6.2.10, que traz os volumes médios $V_{\text {plug }}, V_{\text {mix }}$ e $V_{\text {morto }}$ em função do número de passes para arranjo em série ou em função do número de canais para arranjo em paralelo. A Figura 6.2.11 é apresentada para auxiliar a compreensão dos parâmetros volumétricos do modelo de associação PFR+CSTR, no qual a DTR do processo é considerada análoga aquela de uma associação em série de dois reatores ideais com a presença do volume morto. O volume interno total da associação é igual ao volume interno do processo avaliado.

Pode-se observar na Figura 6.2.12 que o aumento nos números de passes ou de canais provoca um aumento quase que proporcional dos parâmetros volumétricos do modelo de associação PFR+CSTR. Correlações foram ajustadas para representar esta tendência. As Equações (6.2.3a) e (6.2.3b) representam a dependência de $V_{p l u g}$ e $V_{\text {mix }}$ com o número de passes para arranjo em série, respectivamente, enquanto a Equação (6.2.3c) foi obtida usando estas correlações, o volume interno do trocador na Equação (5.1.1a) e a Equação (3.3.6b) para expressar $V_{\text {morto }}$.

$$
\begin{array}{lr}
V_{\text {plug }}(\mathrm{mL})=0,0690 \cdot P^{2}+4,65 \cdot P & \left(R^{2}=0.9998\right) \\
V_{\text {mix }}(\mathrm{mL})=-0,0262 \cdot P^{2}+2,16 \cdot P & \left(R^{2}=0.9947\right) \\
V_{\text {morto }}(\mathrm{mL})=V-V_{\text {plug }}-V_{\text {mix }}=-0,0428 \cdot P^{2}+2,39 \cdot P+2,85
\end{array}
$$

Para o arranjo em paralelo do trocador (curvas $d$, e e $f$ na Figura 6.2.12), nota-se que há uma maior dispersão dos pontos, em comparação com os resultados para o arranjo em série. Este comportamento foi também observado por Miura et al. (2008) no estudo do efeito do número de passes e de canais na perda de carga do mesmo trocador de calor. A baixa velocidade nos canais para arranjos em paralelo favorece a má distribuição de fluxo no interior de trocador e a retenção de bolhas de ar nos canais, diminuído a precisão dos dados coletados e prejudicando a reprodutibilidade (Watson et al., 1960). 

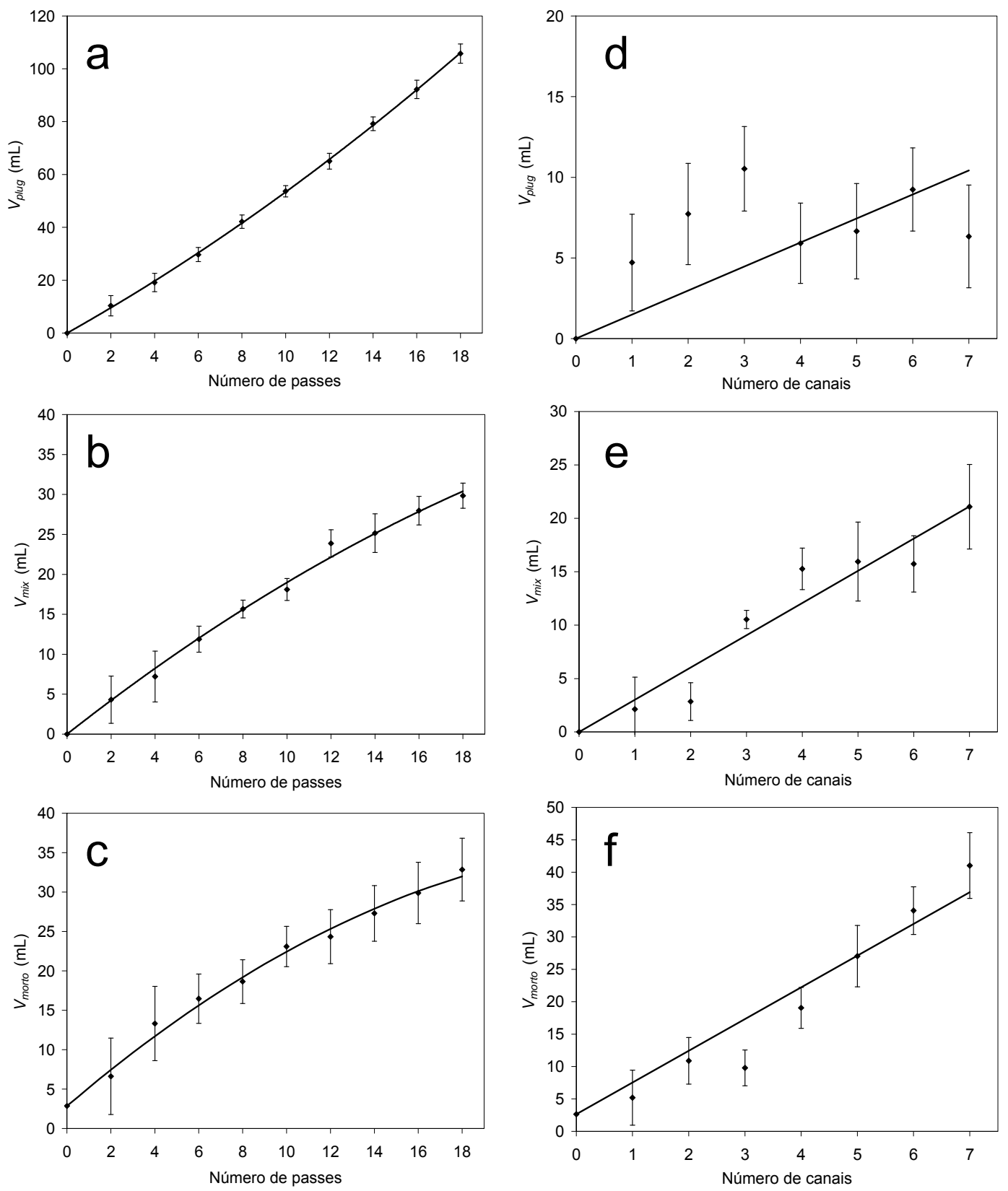

Figura 6.2.10. Parâmetros volumétricos do modelo de associação PFR+CSTR ajustados para o estudo de DTR no trocador de calor com arranjos em série (curvas $a, b$ e $c$ ) e paralelo (curvas $d, e$ e $f$ ) (Gutierrez et al., 2011).
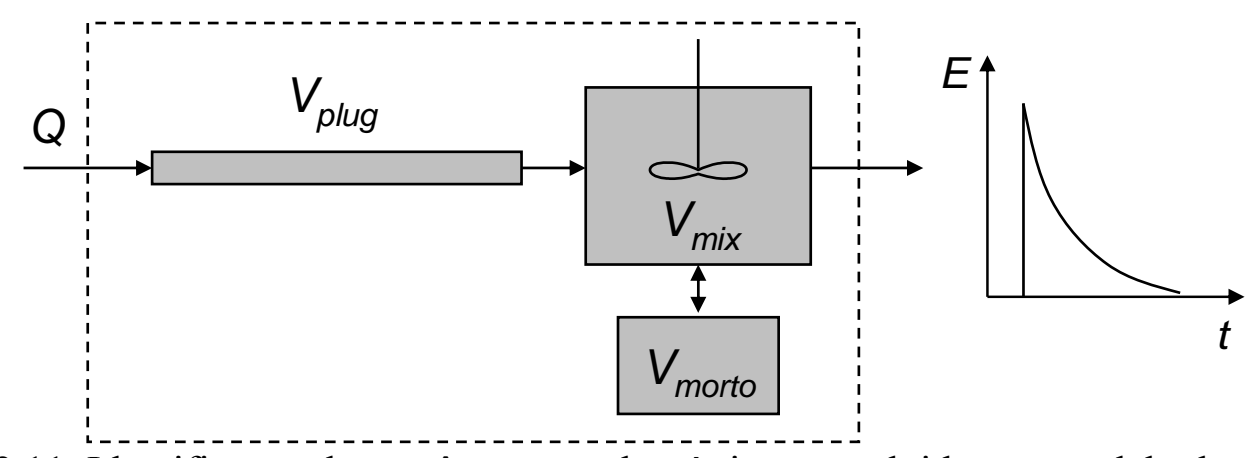

Figura 6.2.11. Identificação dos parâmetros volumétricos envolvidos no modelo de associação PFR+CSTR para representação de curvas de DTR (Gutierrez et al., 2011). 
Os parâmetros de perda de carga obtidos por Miura et al. (2008) para o arranjo em paralelo apontam uma mudança de comportamento quando o número de canais aumenta de $N$ $=3$ para $N=4$. Nas curvas $d$, e e $f$ da Figura 6.2.12 pode-se notar algo semelhante, possivelmente associado à má distribuição de fluxo.

Como o número de pontos é reduzido nas curvas $d$, e e $f$ da Figura 6.2.12, optou-se por ajustar os dados linearmente para todo o intervalo de $N$, obtendo as correlações para $V_{\text {mix }} \mathrm{e}$ $V_{\text {morto }}$ expressas nas Equações (6.2.4a) e (6.2.4b). A Equação (6.2.4c) foi obtida usando estas correlações, o volume interno do trocador na Equação (5.1.1b) e a Equação (3.3.6b) que define o volume morto. Como o erro relativo em $V_{\text {plug }}$ foi alto, foi mais adequado correlacionar $V_{\text {mix }}$ e $V_{\text {morto }}$ com o número de canais, deixando $V_{\text {plug }}$ para ser calculado pela diferença entre volumes.

$$
\begin{array}{ll}
V_{\text {mix }}(\mathrm{mL})=3,02 \cdot N & \left(R^{2}=0,9310\right) \\
V_{\text {morto }}(\mathrm{mL})=4,89 \cdot N+2,65 & \left(R^{2}=0,9307\right) \\
V_{\text {plug }}(\mathrm{mL})=V-V_{\text {mix }}-V_{\text {morto }}=1,49 \cdot N &
\end{array}
$$

A partir das Equações (6.2.3a) a (6.2.4c) é possível avaliar a contribuição de cada parâmetro volumétrico do modelo de associação PFR+CSTR, conforme Figura 6.2.12 que expressa as contribuições como porcentagens do volume interno do equipamento. Para o escoamento em série, o volume do PFR tem a maior contribuição, o que está de acordo com o escoamento sequencial passando por todos os canais, sem derivações de fluxo. As zonas de recirculação existentes nos canais do trocador contribuem para os volumes de mistura e morto do sistema, que somam aproximadamente $40 \%$ do total. Mistura axial no escoamento nos canais é indesejável, pois este fenômeno reduz o potencial térmico que promove a troca de calor entre canais. A presença de volume morto é também indesejável, pois representa uma sub-utilização da área de troca térmica disponível e uma redução do tempo para troca térmica, já que o fluido é acelerado no canal preferencial de escoamento. Como as placas do trocador estudado neste trabalho são lisas e não possuem distribuidores de fluxo, um desempenho hidrodinâmico fraco é justificável. Em todo caso, o procedimento adotado neste trabalho foi útil para diagnosticar problemas de escoamento no trocador de calor a placas e tem potencial para uso em equipamentos de maior escala. 

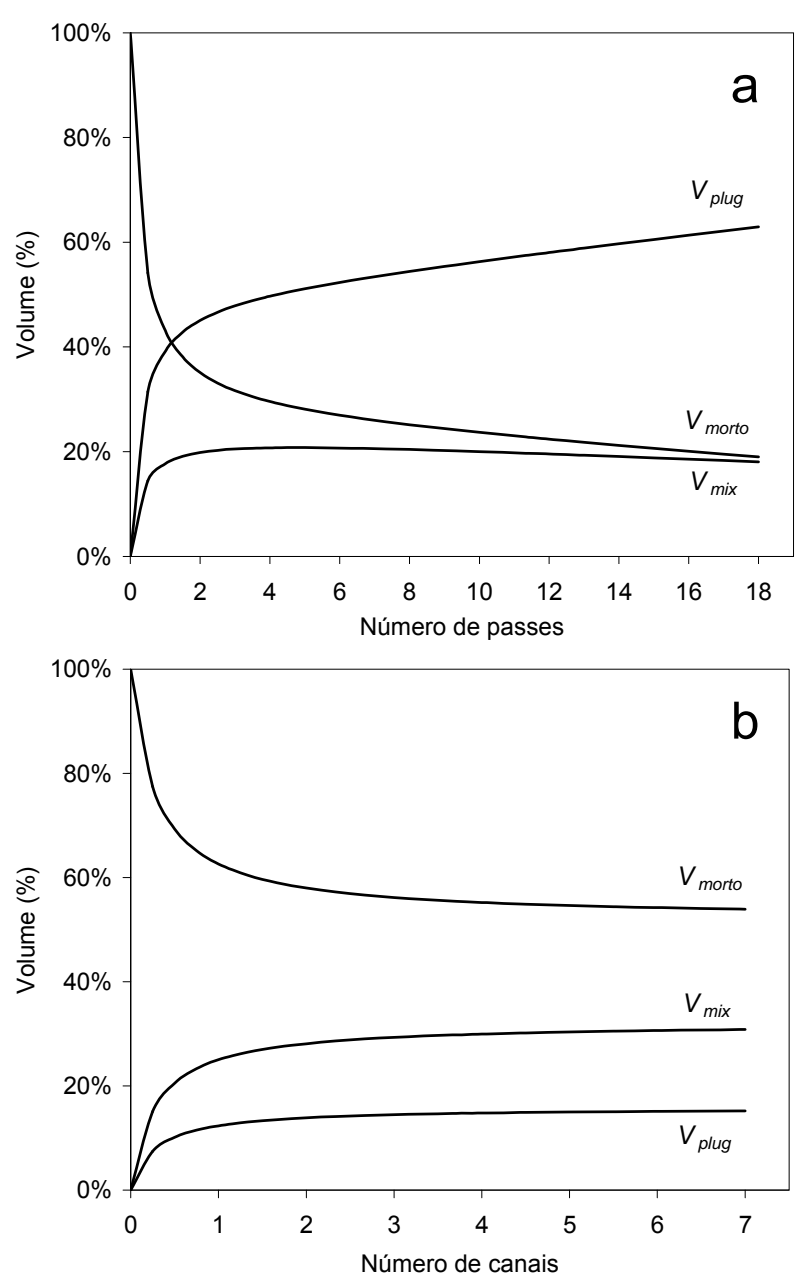

Figura 6.2.12. Contribuição relativa dos parâmetros volumétricos do modelo de associação PFR+CSTR ajustados para o estudo de DTR no trocador de calor com arranjos em série (a) e em paralelo (b) (Gutierrez et al., 2011).

$\mathrm{Na}$ avaliação de trocadores de calor industriais, a turbulência induzida pela corrugação da placa deverá ser melhor representada através do modelo de dispersão axial, mesmo para números de Reynolds baixos, como foi verificado no estudo de DTR de Roetzel e Balzereit (1997). Consequentemente o grau de mistura deverá ser avaliado através do número de Peclet e o volume morto pode ser determinado através das Equações (3.3.6a) e (3.3.6b).

O modelo de associação PFR+CSTR ajustado pode ser usado para previsão da DTR no escoamento através do trocador de calor, em função do arranjo de passes. A Figura 6.2.13 apresenta os resultados obtidos para vazão volumétrica de $20 \mathrm{~L} / \mathrm{h}$. É visível a grande dependência do tempo de residência mínimo com o número de passes em um arranjo em série e o aumento da dispersão ao elevar o número de canais em um arranjo em paralelo. $\mathrm{Na}$ operação do trocador em um processo de pasteurização devem ocorrer diferenças em relação a estes resultados devido ao efeito da temperatura sobre a viscosidade da água (os ensaios de 
DTR foram realizados na temperatura ambiente) ou devido ao uso de um produto alimentício com características hidrodinâmicas muito afastadas daquelas da água.
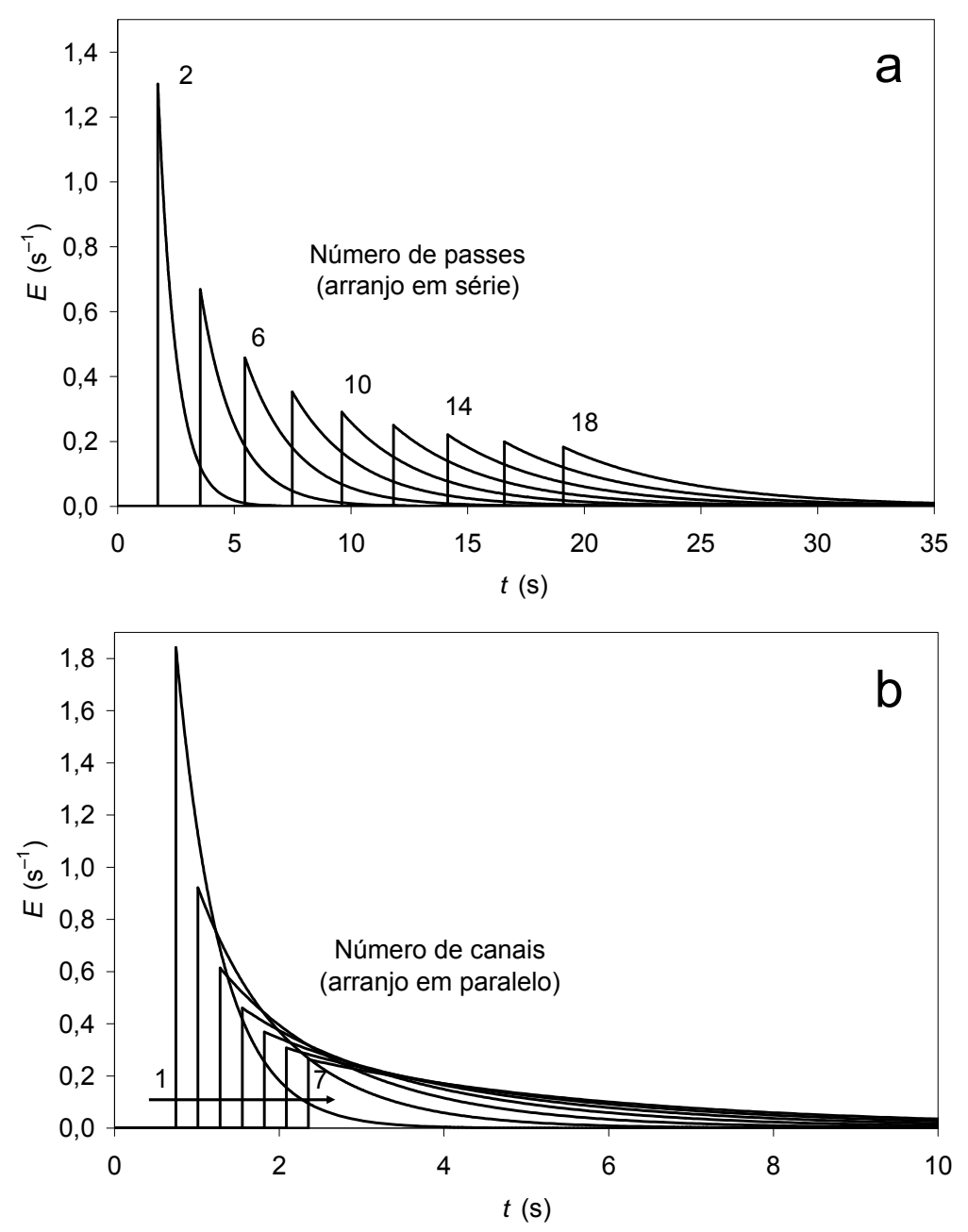

Figura 6.2.13. Curvas $E(t)$ para o trocador de calor a placas, de acordo com o modelo de associação PFR+CSTR ajustado, com arranjo em série (a) ou arranjo em paralelo (b), na vazão de $20 \mathrm{~L} / \mathrm{h}$ (Gutierrez et al., 2011).

O problema de maiores volumes de mistura e morto é evidente para o arranjo em paralelo do trocador de calor a placas, como pode ser visto no gráfico $b$ da Figura 6.2.12. A divisão do fluxo entre vários canais reduz a velocidade de escoamento. Associado a este fato, a geometria plana das placas intensificou a formação de zonas de estagnação. No trabalho de Galeazzo et al. (2006), o escoamento e a troca de calor no mesmo trocador de calor foram estudados usando ferramentas de CFD e zonas de recirculação interna e de baixas velocidades foram identificadas nos canais e também verificou-se que a distribuição do fluxo entre os canais que compõem o passe não é uniforme, como se espera. 
Um parâmetro em comum entre os modelos de DTR testados é o volume ativo do equipamento. Embora o modelo de associação PFR+CSTR tenha fornecido os melhores ajustes, o volume ativo predito pelos três modelos é apresentado na Figura 6.2.14 como função do número de passes em arranjo em série. Pode-se verificar que as tendências são semelhantes, com alguma diferença. Resultados deste tipo não foram localizados na literatura para comparação, mas espera-se que trocadores de calor a placas industriais tenham uma maior porcentagem de volume ativo por causa dos distribuidores de fluxo e da corrugação nas placas.

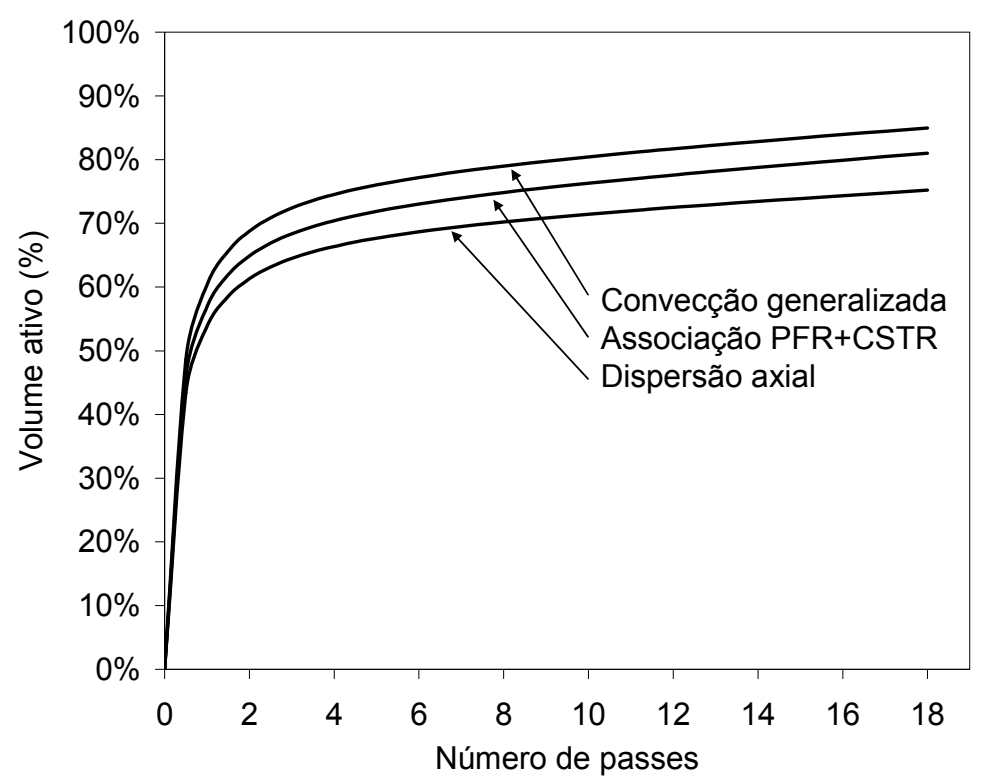

Figura 6.2.14. Volume ativo do trocador calor em função do número de passes para arranjo em série, de acordo com os modelos de DTR ajustados (Gutierrez et al., 2011).

\subsubsection{Distribuição do tempo de residência no processo}

Para avaliar o grau de dispersão ao longo de todo o processo de pasteurização (Figura 5.1.1), foram realizados ensaios de DTR isotérmicos com injeção na entrada da seção de regeneração (lado frio) e detecção na saída da seção de resfriamento (lado quente). Os três trocadores tinham como arranjo de passes a configuração padrão do equipamento $(6 \times 1 / 6 \times 1$ na seção de aquecimento, $10 \times 1 / 10 \times 1$ na seção de regeneração e $4 \times 1 / 4 \times 1$ na seção de resfriamento). As vazões volumétricas avaliadas foram 15, 20 e $25 \mathrm{~L} / \mathrm{h}$ e os ensaios foram realizados em triplicata. A temperatura média da água destilada foi de $23{ }^{\circ} \mathrm{C}$ nos ensaios.

Os modelos de DTR ajustados aos dados coletados foram de dispersão axial (Equação (3.3.8)), de tanques em série estendido (Equação (3.3.9)), de convecção generalizado (Equação (3.3.12)) e de associação PFR+CSTR (Equação (3.3.14)). Os valores médios dos somatórios do erro quadrático minimizados são apresentados na Tabela 6.2.2, na qual 
verifica-se que o melhor ajuste foi proveniente do modelo de dispersão axial, seguido do modelo de tanques em série estendido. Os resultados dos ensaios são apresentados nas Figuras $6.2 .15,6.2 .16$ e 6.2 .17 para as vazões de 15,20 e $25 \mathrm{~L} / \mathrm{h}$, respectivamente.

Tabela 6.2.2. Valores minimizados do somatório do erro quadrático $\left(S E Q \times 10^{3}, \mathrm{~s}^{-2}\right)$ para ajuste dos modelos de DTR aos dados coletados no processo de pasteurização.

\begin{tabular}{lccc}
\hline \multirow{2}{*}{ Modelo } & \multicolumn{3}{c}{ Vazão volumétrica } \\
\cline { 2 - 4 } & $15 \mathrm{~L} / \mathrm{h}$ & $20 \mathrm{~L} / \mathrm{h}$ & $25 \mathrm{~L} / \mathrm{h}$ \\
\hline Conv. generalizado & $2,5 \pm 0,1$ & $2,6 \pm 0,3$ & $3,5 \pm 0,3$ \\
Assoc. PFR+CSTR & $1,9 \pm 0,2$ & $2,1 \pm 0,2$ & $3,0 \pm 0,1$ \\
Dispersão axial & $0,4 \pm 0,0$ & $0,7 \pm 0,1$ & $1,1 \pm 0,3$ \\
Tanques em série & $0,6 \pm 0,0$ & $0,8 \pm 0,1$ & $1,3 \pm 0,4$ \\
\hline
\end{tabular}

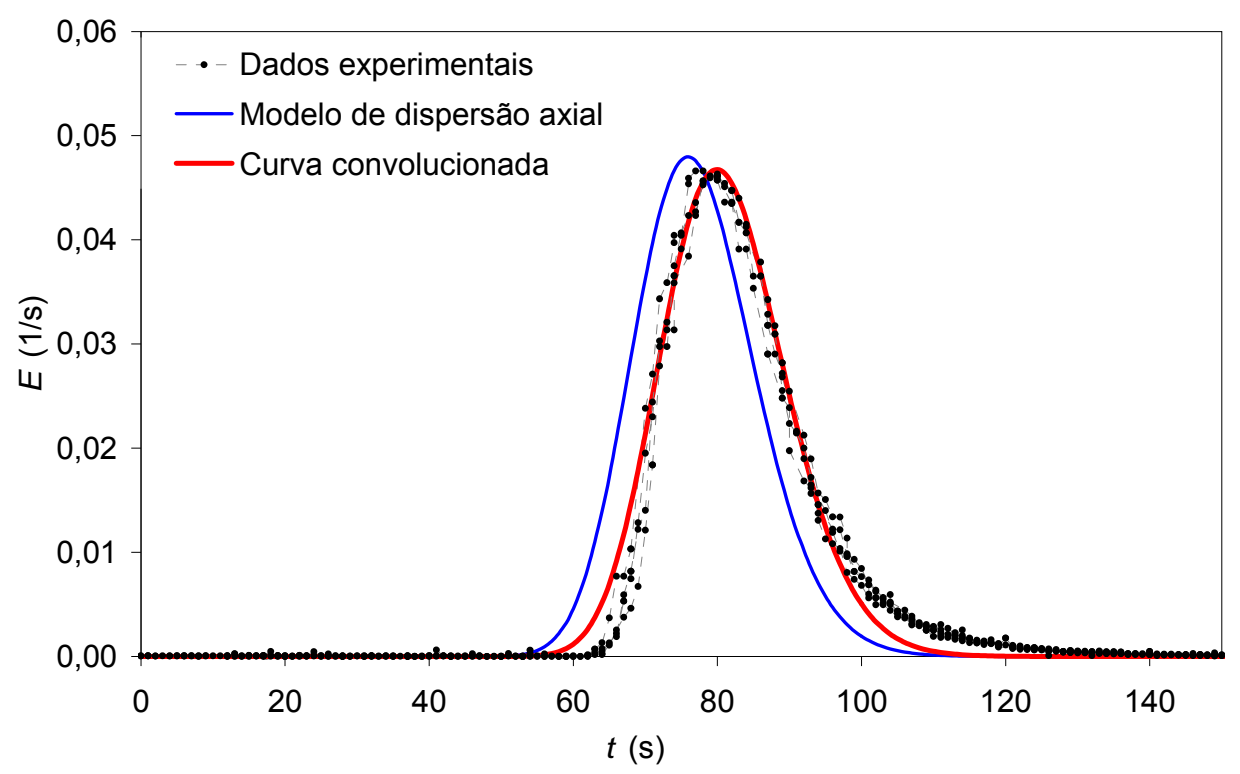

Figura 6.2.15. Dados experimentais de DTR para o processo de pasteurização na vazão de 15 $\mathrm{L} / \mathrm{h}$ com o ajuste pelo modelo de dispersão axial (Gutierrez, 2008). 


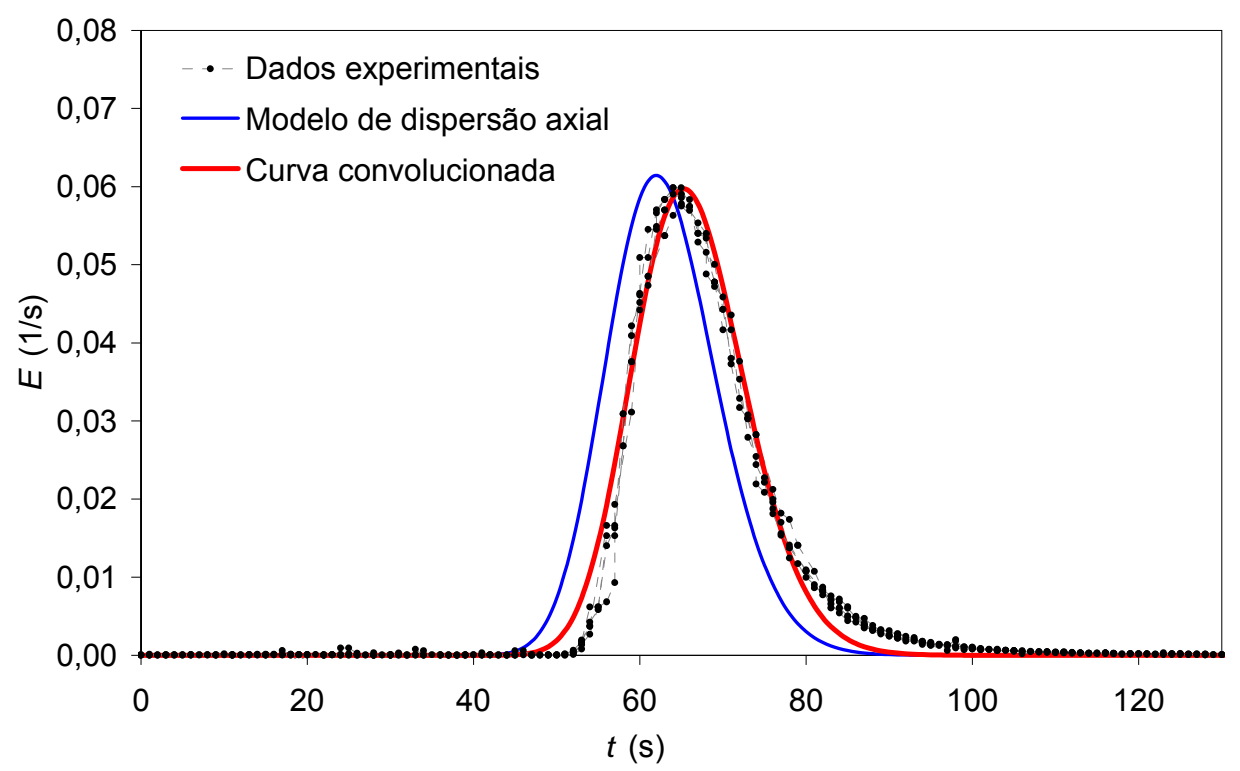

Figura 6.2.16. Dados experimentais de DTR para o processo de pasteurização na vazão de 20 $\mathrm{L} / \mathrm{h}$ com o ajuste pelo modelo de dispersão axial (Gutierrez, 2008).

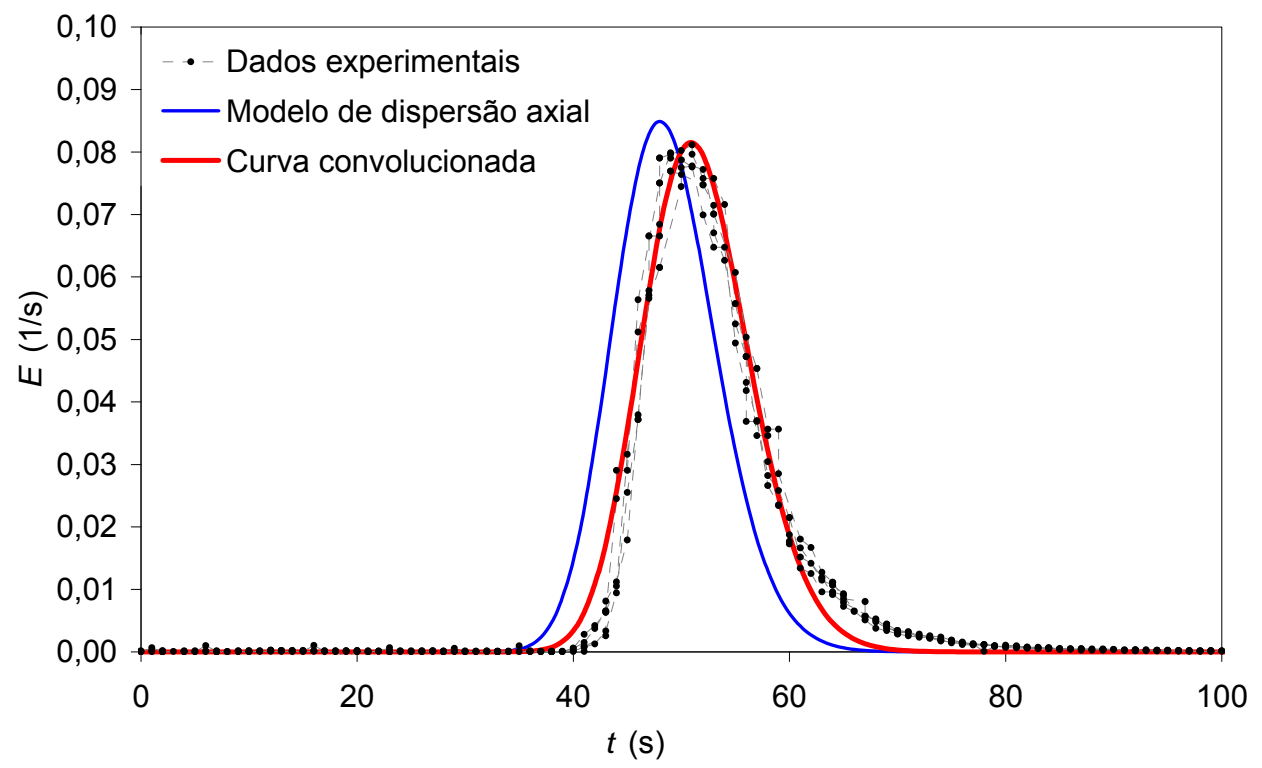

Figura 6.2.17. Dados experimentais de DTR para o processo de pasteurização na vazão de 25 L/h com o ajuste pelo modelo de dispersão axial (Gutierrez, 2008).

Apesar do modelo de dispersão axial ter fornecido o melhor ajuste, nota-se nas Figuras 6.2.15, 6.2.16 e 6.2.17 que a distribuição de pontos experimentais não é totalmente simétrica, havendo um maior erro no início e no fim da curva. Como o volume interno do pasteurizador é superior ao volume da célula do condutivímetro, a distorção na curva de DTR provocada pelo sistema de aquisição de dados de condutividade é pequena, sendo visível nas Figuras 6.2.15, 6.2.16 e 6.2.17 como um atraso de sinal. A reprodutibilidade dos ensaios foi boa, tendo pequena diferença entre as triplicatas. 
Os resultados nas Figuras 6.2.15, 6.2.16 e 6.2.17 são úteis para a etapa de partida na operação do equipamento. Usualmente o pasteurizador é colocado em regime estacionário usando água potável como fluido de processo e em seguida o tanque de alimentação é preenchido com o produto a ser processado. A Figura 6.2.16 indica que, na vazão nominal de $20 \mathrm{~L} / \mathrm{h}$, será necessário aguardar cerca de $100 \mathrm{~s}$ para ter o produto saindo sem interferência da água que estava no equipamento.

As Figuras 6.2.18 e 6.2.19 correlacionam os parâmetros ajustados com a vazão volumétrica. Para a faixa estreita de vazão estudada não foi possível identificar a curvatura esperada no gráfico de tempo médio de residência em função da vazão. O número de Peclet foi correlacionado linearmente com a vazão experimental devido ao reduzido número de pontos experimentais.

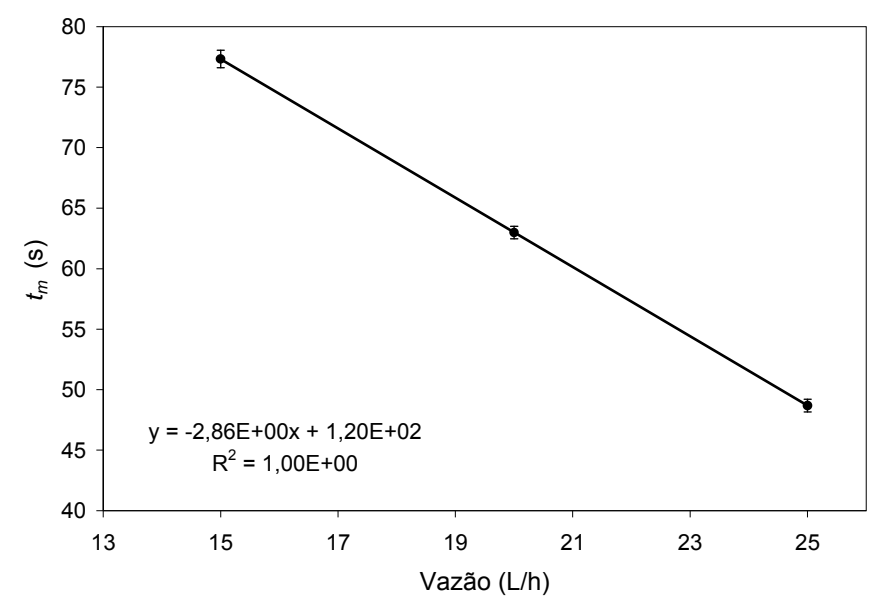

Figura 6.2.18. Tempo médio de residência no processo de pasteurização em função da vazão de processamento de acordo com o modelo de dispersão axial ajustado (Gutierrez, 2008).

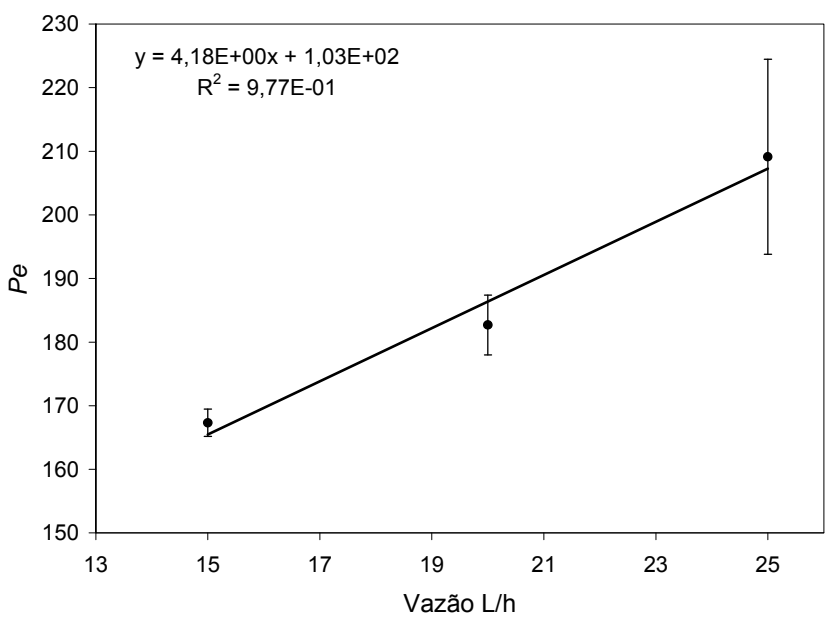

Figura 6.2.19. Número de Peclet no processo de pasteurização em função da vazão de processamento de acordo com o modelo de dispersão axial ajustado (Gutierrez, 2008). 


\subsubsection{Tempos médios de residência nas etapas do processo}

O modelo matemático desenvolvido no Capítulo 4 considera, para o cálculo de letalidade, o tempo médio de residência de cada trecho no percurso do produto alimentício, indicado na Figura 4.1.1 pelo trajeto $\mathrm{p} 1 \rightarrow \mathrm{p} 8$. Inicialmente é possível adotar o tempo espacial como tempo de residência em cada etapa (Equação (3.3.5)). A Tabela 6.2.3 apresenta o volume interno e o tempo espacial de cada trecho, para a vazão nominal de operação do equipamento, $Q=20 \mathrm{~L} / \mathrm{h}$. Já a Tabela 6.2.4 apresenta os volumes ativos e os tempos médios de residência determinados experimentalmente neste trabalho para a mesma vazão, exceto para as conexões de entrada e de saída do tubo de retenção.

Tabela 6.2.3. Volumes internos dos trechos que compõem o percurso do produto alimentício e tempo espacial calculado para vazão volumétrica de $20 \mathrm{~L} / \mathrm{h}$.

\begin{tabular}{llccl}
\hline Trecho & & $V(\mathrm{~mL})$ & $\tau(\mathrm{s})$ & \multicolumn{1}{c}{ Fonte } \\
\hline $\mathrm{p} 1 \rightarrow \mathrm{p} 2$ & Regeneração, lado frio & 94,9 & 17,1 & Equação (5.1.1a) \\
p2 $\rightarrow \mathrm{p} 3$ & Aquecimento, lado frio & 58,1 & 10,4 & Equação (5.1.1a) \\
p3 $\rightarrow \mathrm{p} 4$ & Conexão 1 & 34,0 & 6,1 & Tabela 5.1.4 \\
p4 $\rightarrow \mathrm{p} 5$ & Tubo de retenção & 75,0 & 13,5 & Figura 5.1.2 \\
p5 $\rightarrow \mathrm{p} 6$ & Conexão 2 & 37,3 & 6,7 & Tabela 5.1.4 \\
p6 $\rightarrow \mathrm{p} 7$ & Regeneração, lado quente & 94,9 & 17,1 & Equação (5.1.1a) \\
p7 $\rightarrow$ p8 & Resfriamento, lado quente & 39,7 & 7,1 & Equação (5.1.1a) \\
\hline
\end{tabular}

Tabela 6.2.4. Volumes ativos dos trechos que compõem o percurso do produto alimentício e tempo médio de residência para vazão volumétrica de $20 \mathrm{~L} / \mathrm{h}$.

\begin{tabular}{llccl}
\hline Trecho & & $V_{\text {ativo }}(\mathrm{mL})$ & $t_{m}(\mathrm{~s})$ & \multicolumn{1}{c}{ Fonte } \\
\hline p1 $\rightarrow \mathrm{p} 2$ & Regeneração, lado frio & 72,4 & 13,0 & Eqs. (6.2.3a) e (6.2.3b) \\
p2 $\rightarrow$ p3 & Aquecimento, lado frio & 42,4 & 7,6 & Eqs. (6.2.3a) e (6.2.3b) \\
p3 $\rightarrow$ p4 & Conexão 1 & 34,0 & 6,1 & Tabela 5.1.4* \\
p4 $\rightarrow$ p5 & Tubo de retenção & 65,3 & 11,8 & Figura 6.2.5 \\
p5 $\rightarrow$ p6 & Conexão 2 & 37,3 & 6,7 & Tabela 5.1.4 \\
p6 $\rightarrow$ p7 & Regeneração, lado quente & 72,4 & 13,0 & Eqs. (6.2.3a) e (6.2.3b) \\
p7 $\rightarrow$ p8 & Resfriamento, lado quente & 27,9 & 5,0 & Eqs. (6.2.3a) e (6.2.3b) \\
\hline & Total & 351,8 & 63,3 &
\end{tabular}

* hipótese: $V=V_{\text {ativo }}$ e $t_{m}=\tau$ 
As Tabelas 6.2.3 e 6.2.4 trazem o volume interno total da linha do produto $(433,9 \mathrm{~mL}) \mathrm{e}$ o correspondente volume ativo $(351,8 \mathrm{~mL})$, obtidos pela soma dos volumes individuais dos trechos. Devido à existência de zonas de recirculação e estagnação no equipamento, há uma redução de 19\% no tempo médio total. Com estes volumes é possível calcular o tempo espacial do processo e estimar o tempo médio de residência, como mostra a Figura 6.2.20. Nota-se que há uma boa correspondência entre o valor estimado de $t_{m}$ e o valor obtido através de ensaios de DTR no processo de pasteurização completo (Figura 6.2.18), especialmente para a vazão de $20 \mathrm{~L} / \mathrm{h}$.

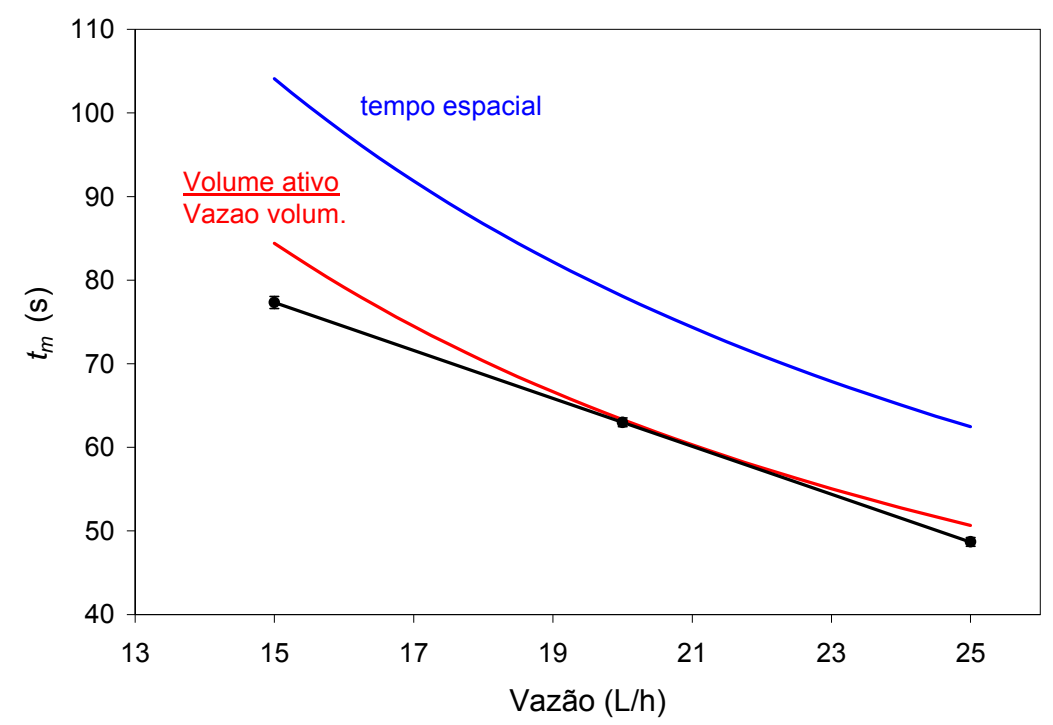

Figura 6.2.20. Tempo médio de residência no processo de pasteurização em função da vazão de processamento de acordo com o modelo de dispersão axial ajustado incluindo curvas de tempo espacial e de tempo médio obtido a partir do volume ativo.

De acordo com o fabricante do equipamento, o tubo de retenção $\mathrm{T} 1$ possui tempo de residência de $15 \mathrm{~s}$ para o processamento HTST de leite a $72{ }^{\circ} \mathrm{C}$. O tempo espacial determinado foi de 13,5 s (Tabela 6.2.3) e o tempo médio de residência foi de 11,8 s (Tabela 6.2.4), devido ao volume morto identificado nos ensaios de DTR.

Normalmente o tempo mínimo de residência é usado nos cálculos de letalidade para garantir que a partícula mais rápida atenda às exigências de segurança ou inocuidade alimentar. O tempo mínimo de residência no trocador de calor está ligado ao parâmetro $V_{\text {plug }}$ do modelo ajustado (Equações (6.2.3a) e (6.2.4c)) e o tempo mínimo no tubo de retenção pode ser obtido através do parâmetro $\theta_{0}$ na Figura 6.2.6. Os valores de tempos mínimos de residência para a vazão volumétrica de 20 L/h estão apresentados na Tabela 6.2.5. 
Tabela 6.2.5. Tempo mínimo de residência dos trechos que compõem o percurso do produto alimentício para vazão volumétrica de $20 \mathrm{~L} / \mathrm{h}$.

\begin{tabular}{llcl}
\hline Trecho & & $t_{i}(\mathrm{~s})$ & \multicolumn{1}{c}{ Fonte } \\
\hline $\mathrm{p} 1 \rightarrow \mathrm{p} 2$ & Regeneração, lado frio & 9,6 & Eqs. (6.2.3a) e (3.3.5) \\
$\mathrm{p} 2 \rightarrow \mathrm{p} 3$ & Aquecimento, lado frio & 5,5 & Eqs. (6.2.3a) e (3.3.5) \\
$\mathrm{p} 3 \rightarrow \mathrm{p} 4$ & Conexão 1 & 6,1 & Tabela 6.2.3* \\
$\mathrm{p} 4 \rightarrow \mathrm{p} 5$ & Tubo de retenção & 8,3 & Eqs. (6.2.2a) e Figura 6.2.5 \\
p5 $\rightarrow \mathrm{p} 6$ & Conexão 2 & 6,7 & Tabela 6.2.3 \\
p6 $\rightarrow \mathrm{p} 7$ & Regeneração, lado quente & 9,6 & Eqs. (6.2.3a) e (3.3.5) \\
p7 $\rightarrow$ p8 & Resfriamento, lado quente & 3,5 & Eqs. (6.2.3a) e (3.3.5) \\
\hline
\end{tabular}

* hipótese: plug flow, $t_{i}=t_{m}=\tau$

\subsection{Determinação da distribuição de temperatura e validação dos modelos}

O ensaio realizado com água nas condições nominais do equipamento, de acordo com procedimento descrito na Seção 5.4, permitiu a determinação da distribuição de temperatura nas condições de processamento HTST do equipamento. Os Modelos 1, 2 e 3 foram simulados para predição das temperaturas e os resultados são apresentados na Tabela 6.3.1, incluindo os desvios em relação aos valores experimentais. Pode-se verificar que no percurso do produto, os erros de predição foram inferiores a $2{ }^{\circ} \mathrm{C}$ e que a diferença entre o Modelo $1 \mathrm{e}$ os Modelos 2 e 3 foi muito pequena. Pontualmente os Modelos 2 e 3 apresentam os mesmos valores de temperatura, já que ambos usam as eficiências calculadas para os trocadores. A diferença está no perfil linear (Modelo 2) ou não-linear (Modelo 3) de temperatura.

A Tabela 6.3.2 apresenta as cargas térmicas calculadas para os lados quente e frio dos três trocadores de calor (Equações (4.2.1a), (4.2.1b) e (4.2.1c)), considerando as temperaturas experimentais, para verificação da conservação de energia através do desvio em relação à média. A seção de regeneração teve o melhor resultado, pois este trocador tem pouca troca térmica com o ambiente por estar isolado entre as grades conectoras (Figura 5.1.1). Já as seções de aquecimento e resfriamento tiveram uma considerável troca com o ambiente. Notase que o erro de predição dos modelos foi inferior ao erro nos balanços de energia dos trocadores. A Tabela 6.3.3 compara os valores experimentais e preditos de carga térmica dos trocadores de calor e os desvios são próximos aos desvios da verificação da conservação de energia. Estes desvios não comprometeram significativamente a determinação das temperaturas na Tabela 6.3.1. 
Tabela 6.3.1. Temperaturas experimentais e preditas pelos modelos matemáticos para as condições de processamento HTST do equipamento.

\begin{tabular}{lccccc}
\hline & $\begin{array}{c}\text { Experimental } \\
\left({ }^{\circ} \mathrm{C}\right)\end{array}$ & $\begin{array}{c}\text { Modelo } 1 \\
\left({ }^{\circ} \mathrm{C}\right)\end{array}$ & $\begin{array}{c}\text { Desvio } \\
\text { absoluto }\left({ }^{\circ} \mathrm{C}\right)\end{array}$ & $\begin{array}{c}\text { Modelos } 2 \text { e 3 } \\
\left({ }^{\circ} \mathrm{C}\right)\end{array}$ & $\begin{array}{c}\text { Desvio } \\
\text { absoluto }\left({ }^{\circ} \mathrm{C}\right)\end{array}$ \\
\hline$T_{p 1}$ & $19,4 \pm 0,1$ & $19,4^{*}$ & - & $19,4^{*}$ & - \\
$T_{p 2}$ & $54,6 \pm 0,3$ & 55,9 & 1,3 & 55,5 & 0,9 \\
$T_{p 3}$ & $73,1 \pm 0,5$ & 73,4 & 0,4 & 73,3 & 0,2 \\
$T_{p 4}$ & - & 73,4 & - & 73,3 & - \\
$T_{p 5}$ & $72,3 \pm 0,3$ & 71,4 & 0,9 & 71,3 & 1,1 \\
$T_{p 6}$ & $71,3 \pm 0,1$ & 71,4 & 0,2 & 71,3 & 0,0 \\
$T_{p 7}$ & $33,4 \pm 0,1$ & 34,9 & 1,5 & 35,1 & 1,7 \\
$T_{p 8}$ & $18,8 \pm 0,3$ & 20,5 & 1,7 & 20,6 & 1,8 \\
\hline$T_{h 1}$ & $76,3 \pm 0,2$ & $76,3^{*}$ & - & 76,3 & - \\
$T_{h 2}$ & $69,0 \pm 0,2$ & 70,4 & 1,4 & 70,3 & 1,3 \\
\hline$T_{c 1}$ & $10,1 \pm 0,4$ & $10,1 *$ & - & $10,1 *$ & - \\
$T_{c 2}$ & $14,3 \pm 0,1$ & 14,8 & 0,5 & 14,8 & 0,5 \\
\hline
\end{tabular}

Tabela 6.3.2. Verificação da conservação de energia nos trocadores de calor no ensaio de pasteurização HTST.

\begin{tabular}{cccc}
\hline \multicolumn{1}{c}{ Seção } & Variável & Calor (W) & Desvio (\%) \\
\hline Aquecimento & $q^{\text {H,quente }}$ & 499 & 16 \\
& $q^{\text {H,frio }}$ & 426 & \\
\hline Regeneração & $q^{R, q u e n t e}$ & 872 & 7 \\
& $q^{\text {R,frio }}$ & 813 & \\
\hline Resfriamento & $q^{\text {Cquente }}$ & 338 & 13 \\
& $q^{\text {C,frio }}$ & 297 & \\
\hline
\end{tabular}

Tabela 6.3.3. Cargas térmicas experimentais e calculadas pelos modelos matemáticos para os trocadores de calor no ensaio de processamento HTST.

\begin{tabular}{cccccc}
\hline & $\begin{array}{c}\text { Experimental } \\
(\mathrm{W})\end{array}$ & $\begin{array}{c}\text { Modelo 1 } \\
(\mathrm{W})\end{array}$ & Desvio (\%) & $\begin{array}{c}\text { Modelos 2 e 3 } \\
(\mathrm{W})\end{array}$ & Desvio (\%) \\
\hline$q^{H}$ & 462 & 405 & 12 & 410 & 11 \\
$q^{R}$ & 843 & 843 & 0 & 834 & 1 \\
$q^{C}$ & 317 & 333 & 5 & 334 & 5 \\
\hline
\end{tabular}


Tabela 6.3.4. Parâmetros do modelo calculados para a simulação do ensaio de pasteurização em condições HTST.

\begin{tabular}{llccccc}
\hline Trecho & & $v(\mathrm{~m} / \mathrm{s})$ & $R e$ & $P r$ & $N u$ & $\begin{array}{c}h \\
\left(\mathrm{~W} / \mathrm{K} \cdot \mathrm{m}^{2}\right)\end{array}$ \\
\hline $\mathrm{p} 1 \rightarrow \mathrm{p} 2$ & Regeneração, lado frio & 0,0617 & 240 & 5,12 & 5,25 & 1094 \\
$\mathrm{p} 2 \rightarrow \mathrm{p} 3$ & Aquecimento, lado frio & 0,0624 & 409 & 2,86 & 6,86 & 1501 \\
$\mathrm{p} 4 \rightarrow \mathrm{p} 5$ & Tubo de retenção & 0,0628 & 1675 & 2,47 & - & - \\
$\mathrm{p} 6 \rightarrow \mathrm{p} 7$ & Regeneração, lado quente & 0,0621 & 321 & 3,72 & 6,07 & 1302 \\
$\mathrm{p} 7 \rightarrow \mathrm{p} 8$ & Resfriamento, lado quente & 0,0615 & 206 & 6,09 & 4,87 & 995 \\
\hline $\mathrm{h} 1 \rightarrow \mathrm{h} 2$ & Aquecimento, lado quente & 0,185 & 1382 & 2,47 & 18,8 & 4160 \\
$\mathrm{c} 1 \rightarrow \mathrm{c} 2$ & Resfriamento, lado frio & 0,185 & 450 & 8,77 & 10,8 & 2132 \\
\hline
\end{tabular}

Tabela 6.3.5. Parâmetros do modelo calculados para os trocadores na simulação do ensaio de pasteurização em condições HTST.

\begin{tabular}{lcccccccc}
\hline & $\begin{array}{c}A \\
\left(\mathrm{~m}^{2}\right)\end{array}$ & $C C^{*}$ & $\begin{array}{c}U \\
\left(\mathrm{~W} / \mathrm{K} \cdot \mathrm{m}^{2}\right)\end{array}$ & & $\begin{array}{c}\varepsilon_{c c} \\
(\%)\end{array}$ & $\begin{array}{c}\varepsilon \\
(\%)\end{array}$ & $\alpha^{I}$ & $\alpha^{I I}$ \\
\hline Aquecimento & 0,0551 & 0,34 & 1019 & 2,44 & 0,858 & 0,852 & 0,2214 & 0,0749 \\
Regeneração & 0,0952 & 1,00 & 569 & 2,35 & 0,701 & 0,697 & 0,1236 & 0,1236 \\
Resfriamento & 0,0351 & 0,33 & 646 & 0,98 & 0,581 & 0,578 & 0,1402 & 0,0462 \\
\hline
\end{tabular}

As Tabelas 6.3.4 e 6.3.5 apresentam parâmetros calculados na resolução dos modelos matemáticos. Os números de Reynolds indicam escoamento preferencialmente laminar no equipamento, comportamento que foi verificado no estudo da distribuição do tempo de residência (Seção 6.2). A eficiência térmica dos trocadores está muito próxima da eficiência calculada para o arranjo puramente contracorrente, o que justifica a pequena diferença entre os resultados de modelos na Tabela 6.3.1. Esta proximidade depende do tipo de arranjo dos trocadores e não pode-se afirmar que os Modelos 1 e 2 sempre terão resultados semelhantes. Como esperado verifica-se que $\varepsilon<\varepsilon_{c c}$.

A Figura 6.3.1 apresenta os históricos de temperatura preditos pelos modelos matemáticos e os pontos experimentais. Como os Modelos 1 e 2 têm resultados muito próximos (Tabela 6.3.1), o gráfico do Modelo 1 foi omitido nesta figura. Os tempos de residência foram obtidos da Tabela 6.2.4. Nota-se que apenas na seção de aquecimento há uma diferença visível entre os resultados dos Modelos 2 e 3, indicando que a hipótese de variação linear de temperatura entre pontos foi válida neste estudo de caso. Segundo Lewis e 
Heppell (2000), a hipótese de variação linear de temperatura é válida para pasteurizadores a placas com alta eficiência de regeneração $(E R)$. Esta variável é calculada através da Equação (6.3.1) considerando a razão entre a carga térmica da regeneração e a carga térmica total de aquecimento. Neste trabalho tem-se $E R=67 \%$, o que pode explicar os bons resultados do Modelo 2.

$$
E R=\frac{q^{R}}{q^{R}+q^{H}}=\frac{C C_{p 1-2} \cdot\left(T_{p 2}-T_{p 1}\right)}{C C_{p 1-2} \cdot\left(T_{p 2}-T_{p 1}\right)+C C_{p 2-3} \cdot\left(T_{p 3}-T_{p 2}\right)} \approx \frac{T_{p 2}-T_{p 1}}{T_{p 3}-T_{p 1}}
$$

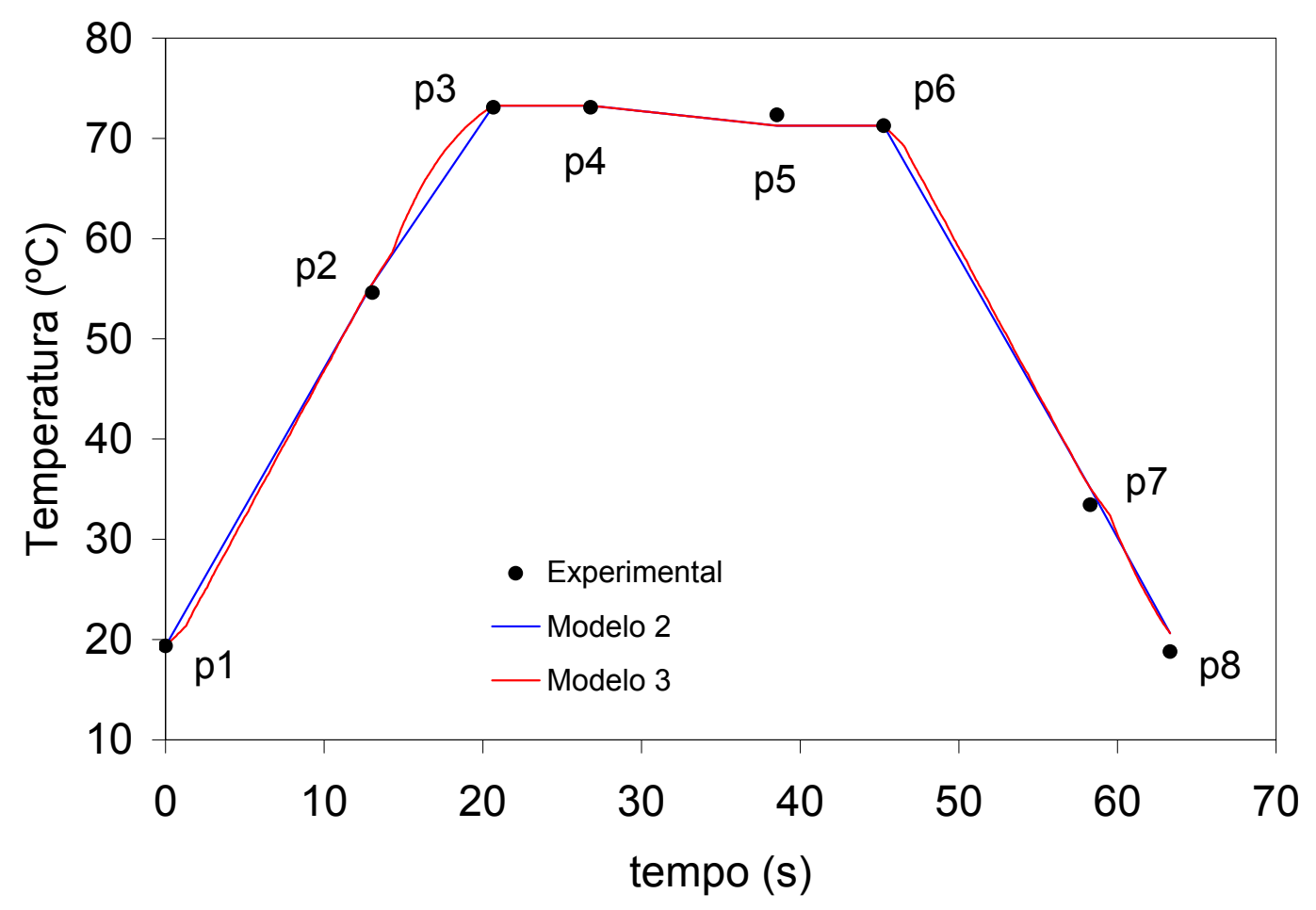

Figura 6.3.1. Comparação entre os históricos de temperatura preditos pelos Modelos 2 e 3 e os pontos experimentais para o ensaio de pasteurização HTST.

A Figura 6.3.2 apresenta as letalidades calculadas sobre os históricos de temperatura dos Modelos 1, 2 (Equações (4.4.8a) e (4.4.8b)) e 3 (Equação (4.4.4)) considerando a temperatura de referência $T_{\text {ref }}=72{ }^{\circ} \mathrm{C}$ e o parâmetro cinético $\mathrm{z}=4,4{ }^{\circ} \mathrm{C}$ referente à bactéria Coxiella burnetti (Cerf e Condron, 2006), de grande importância na pasteurização HTST do leite. Os valores ao final do processo foram 35,9 s, 32,6 s e 33,9 s, respectivamente para os Modelos 1 , 2 e 3. A Figura 6.3.2 traz ainda a lelatidade baseada nas temperaturas experimentais assumindo variação linear entre os pontos. Como a função letalidade envolve uma potência da diferença de temperatura (Equação (4.4.3b)), as pequenas diferenças de temperatura entre as predições dos modelos matemáticos foram amplificadas no resultado de letalidade integrada. 


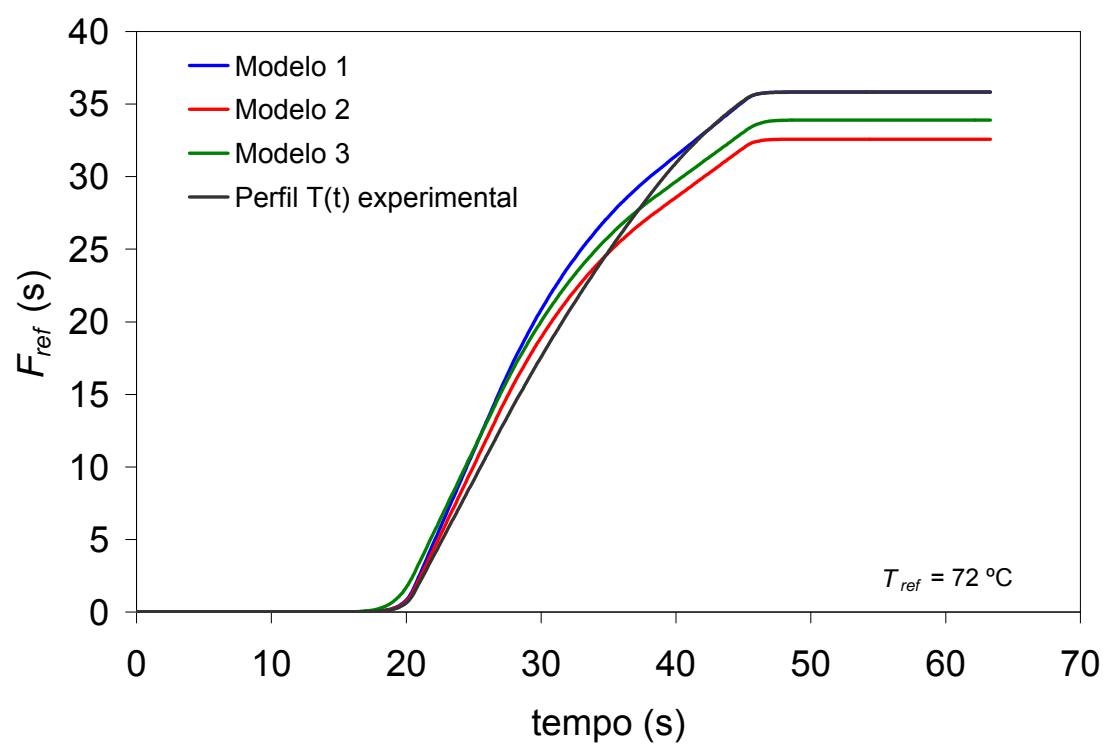

Figura 6.3.2. Comparação entre os perfis de letalidade avaliados sobre os históricos de temperatura preditos pelos Modelos 1, 2 e 3 para as condições de pasteurização HTST.

A Figura 6.3.2 inclui também, para comparação, a curva de letalidade integrada sobre os dados experimentais de temperatura assumindo variação linear entre pontos, atingindo $F_{r e f}=$ $35,8 \mathrm{~s}$. Os valores obtidos estão acima do desejado $\left(F_{r e f}=15 \mathrm{~s}\right)$ devido à maior temperatura na saída da seção de aquecimento e às conexões de entrada e saída do tubo de retenção que prolongam o tempo de residência. A Tabela 6.3.6 traz as contribuições de cada trecho sobre a letalidade integrada, de acordo com o Modelo 2. A maior interferência na letalidade adicional (fora do tubo de retenção) provém da conexão de entrada do tubo de retenção. Os trocadores de calor têm uma participação pequena na letalidade do processo $(6,3 \%)$.

Tabela 6.3.6. Contribuição de cada trecho sobre a letalidade integrada para a simulação do Modelo 2 referente ao estudo de caso de pasteurização HTST.

\begin{tabular}{ccc}
\hline Trecho & $F_{\text {ref }}$ do trecho (s) & $\begin{array}{c}\text { Contribuição } \\
(\%)\end{array}$ \\
\hline $\mathrm{p} 1 \rightarrow \mathrm{p} 2$ & 0,0 & 0,0 \\
$\mathrm{p} 2 \rightarrow \mathrm{p} 3$ & 1,6 & 4,9 \\
$\mathrm{p} 3 \rightarrow \mathrm{p} 4$ & 11,9 & 36,4 \\
$\mathrm{p} 4 \rightarrow \mathrm{p} 5$ & 14,1 & 43,3 \\
$\mathrm{p} 5 \rightarrow \mathrm{p} 6$ & 4,6 & 14,0 \\
$\mathrm{p} 6 \rightarrow \mathrm{p} 7$ & 0,5 & 1,4 \\
$\mathrm{p} 7 \rightarrow \mathrm{p} 8$ & 0,0 & 0,0 \\
\hline Total & 32,6 & 100
\end{tabular}


Para verificar a influência do tempo de residência, a letalidade foi avaliada utilizando os tempos espaciais na Tabela 6.2.3, os tempos médios de residência na Tabela 6.2.4 e os tempos mínimos de residência na Tabela 6.2.5. Para esta comparação foi adotado apenas o Modelo 2 e o resultado pode ser visto na Figura 6.3.3. A letalidade integrada adotando os tempos médios de residência foi de $32,6 \mathrm{~s}$, enquanto que o valor adotando os tempos espaciais foi de 35,4 s (aumento de 9\%). Nesta diferença, o tempo de residência do tubo de retenção tem a maior influência já que é onde a função letalidade é mais alta. Como os tempos de residência experimentais não foram determinados para as conexões de entrada e de saída do tubo de retenção $(\mathrm{p} 3 \rightarrow \mathrm{p} 4$ e p5 $\rightarrow \mathrm{p} 6)$ a diferença entre os resultados não foi elevada. Adotando os tempos mínimos de residência como fator de segurança para o cálculo de letalidade, tem-se $F_{\text {ref }}=27,9$ s (redução de $14 \%$ ).

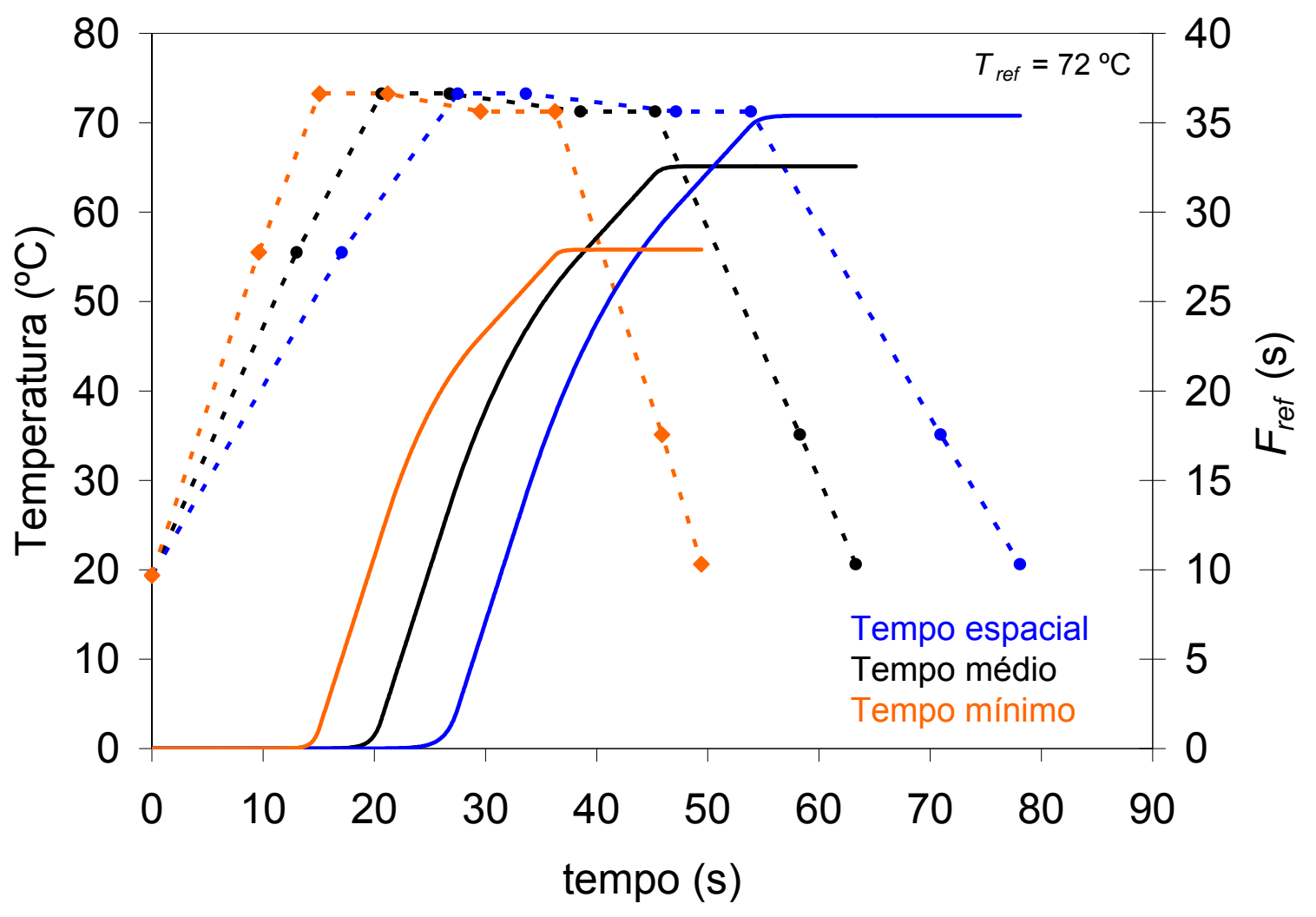

Figura 6.3.3. Históricos de temperatura (linhas pontilhadas) e perfis de letalidade (linhas contínuas) preditos pela simulação do Modelo 2 nas condições de pasteurização HTST considerando: tempo espacial, tempo médios de residência e tempo mínimo de residência.

\subsection{Uso dos indicadores enzimáticos e validação do modelo matemático}

Conforme procedimento descrito na Seção 5.4.2, foram realizados ensaios de pasteurização dos indicadores enzimáticos POD e ALP. As temperaturas de processamento 
foram de $70,75,80$ e $85^{\circ} \mathrm{C}$. O Modelo 2 foi simulado para prever o histórico de temperatura do produto nestes ensaios em função do tempo médio de residência e a Equação (5.2.5) foi usada para determinar a atividade enzimática residual, usando os parâmetros ajustados na Seção 6.1 (Tabela 6.1.1).

A Figura 6.4.1 apresenta as temperaturas experimentais e os históricos de temperatura obtidos da simulação do Modelo 2 para os quatro ensaios realizados com o indicador POD. Nota-se que a linha azul que representa o modelo matemático se aproxima bem dos pontos experimentais. Para comparação, foi introduzido na Figura 6.4.1 o histórico de temperatura "ideal" (linha vermelha) considerando tubo isotérmico no tempo médio de residência com aquecimento e resfriamento instantâneos.
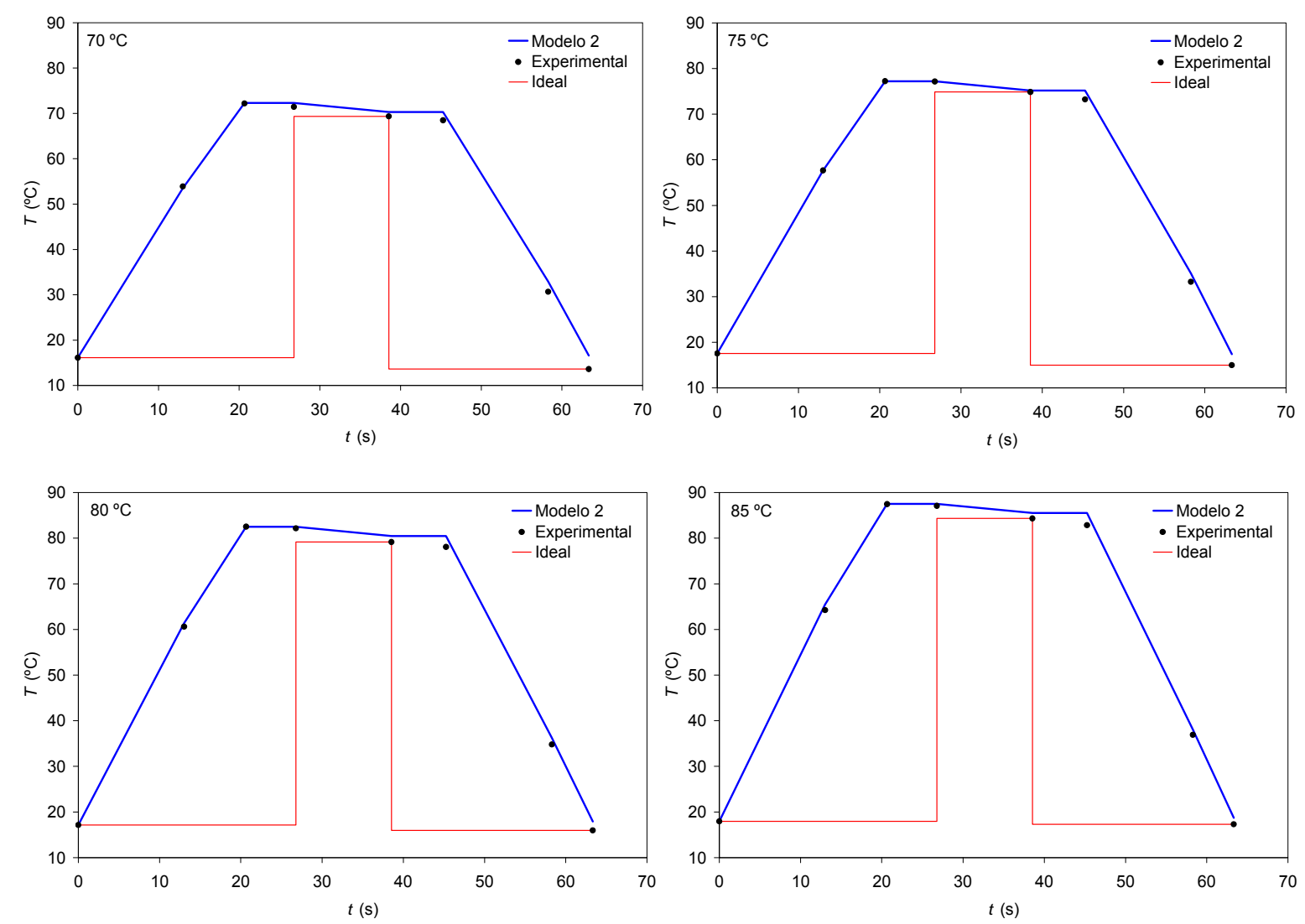

Figura 6.4.1. Históricos de temperatura experimentais e obtidos a partir do Modelo 2 para os ensaios de pasteurização do indicador POD em diferentes temperaturas de processo, incluindo o caso ideal de tubo isotérmico com aquecimento e resfriamento instantâneos.

Sobre os históricos de temperatura na Figura 6.4.1 foi calculada a evolução da atividade residual do indicador POD e o resultado é apresentado na Figura 6.4.2. Nesta figura, a linha azul representa a predição do Modelo 2, a linha preta representa a avaliação sobre o histórico experimental de temperatura (assumindo variações lineares), a linha vermelha corresponde à avaliação feita sobre o histórico ideal e o ponto verde indica o valor experimental da atividade 
enzimática (média de cinco leituras). Os valores de atividade enzimática residual do indicador ao final do processo estão organizados na Tabela 6.4.1.
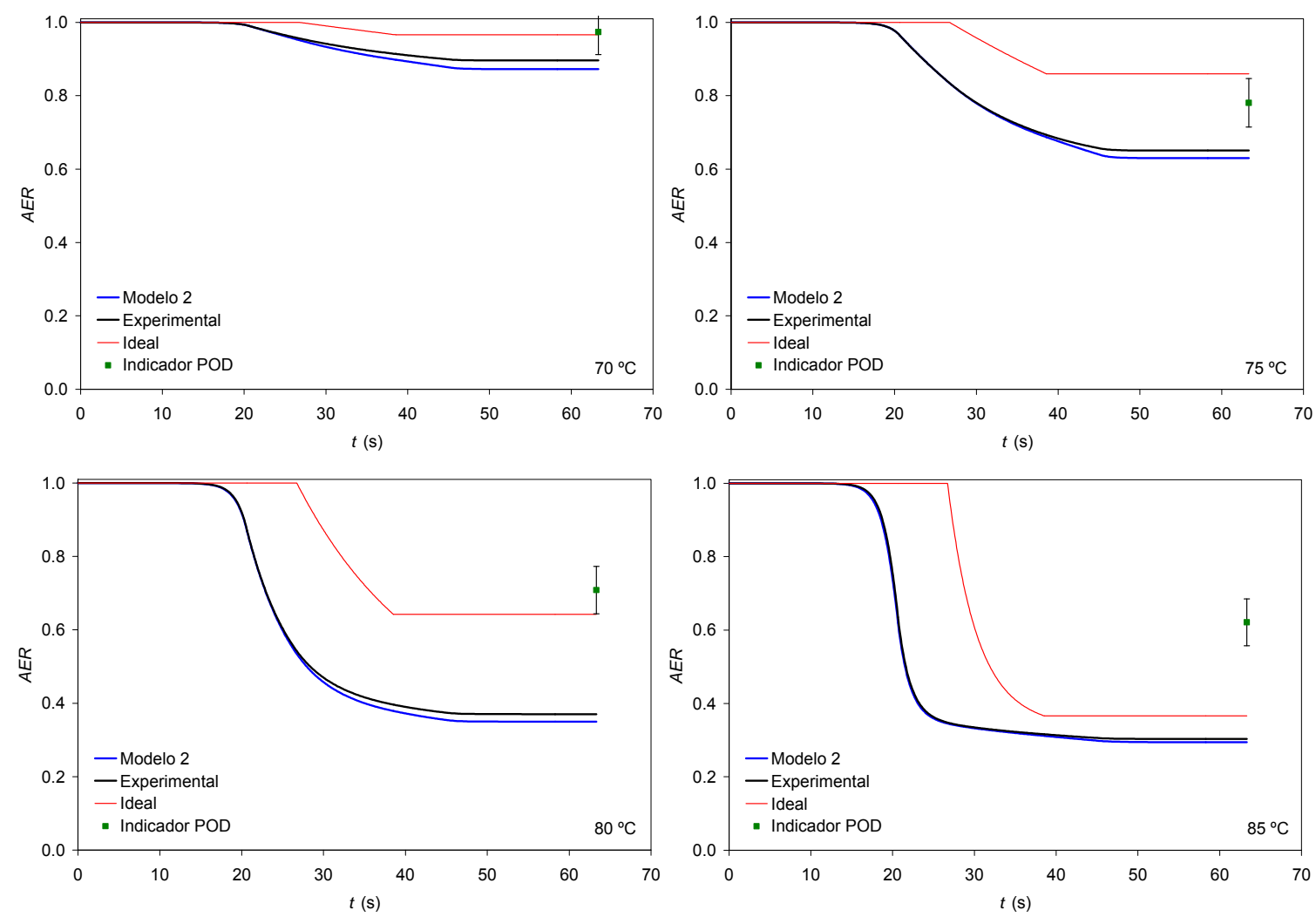

Figura 6.4.2. Evolução da atividade enzimática residual do indicador POD predita para os ensaios de pasteurização em diferentes temperaturas de processamento, incluindo o valor experimental determinado na saída do processo.

Tabela 6.4.1. Atividade enzimática residual do indicador POD predita para os ensaios em diferentes temperaturas de processamento, incluindo o valor experimental.

\begin{tabular}{lcccc}
\hline \multirow{2}{*}{ AER } & \multicolumn{4}{c}{ Condição } \\
\cline { 2 - 5 } & $70{ }^{\circ} \mathrm{C}$ & $75^{\circ} \mathrm{C}$ & $80{ }^{\circ} \mathrm{C}$ & $85^{\circ} \mathrm{C}$ \\
\hline Experimental & $0,97 \pm 0,06$ & $0,78 \pm 0,07$ & $0,71 \pm 0,06$ & $0,62 \pm 0,06$ \\
\hline Modelo 2 & 0,87 & 0,63 & 0,35 & 0,29 \\
Desvio & 0,10 & 0,15 & 0,36 & 0,33 \\
& $10 \%$ & $19 \%$ & $51 \%$ & $53 \%$ \\
\hline Histórico experimental & 0,90 & 0,65 & 0,37 & 0,30 \\
Desvio & 0,08 & 0,13 & 0,34 & 0,32 \\
& $8 \%$ & $17 \%$ & $48 \%$ & $51 \%$ \\
\hline Ideal & 0,97 & 0,86 & 0,64 & 0,37 \\
\hline
\end{tabular}


Os resultados na Tabela 6.4.1 e na Figura 6.4.2 indicam um fraco desempenho do indicador POD em avaliar o efeito letal do processo. A atividade enzimática residual ficou acima do valor previsto pelo modelo cinético ajustado e o histórico de temperatura do processo. Resultado semelhante foi observado nos ensaios de validação realizados com o indicador POD (Seção 6.1.2), confirmando a hipótese de que este indicador apresenta comportamentos distintos para ensaios com aquecimento rápido e com aquecimento lento.

Os ensaios de pasteurização do indicador ALP foram realizados em duplicata (ensaios independentes). Para o primeiro conjunto de ensaios, os resultados são apresentados nas Figuras 6.4.3 e 6.4.4 e na Tabela 6.4.2, em formato análogo ao tratamento de dados realizado para os ensaios com o indicador POD. Os resultados referentes ao segundo conjunto de ensaios são apresentados nas Figuras 6.4.5 e 6.4.6 e na Tabela 6.4.3.
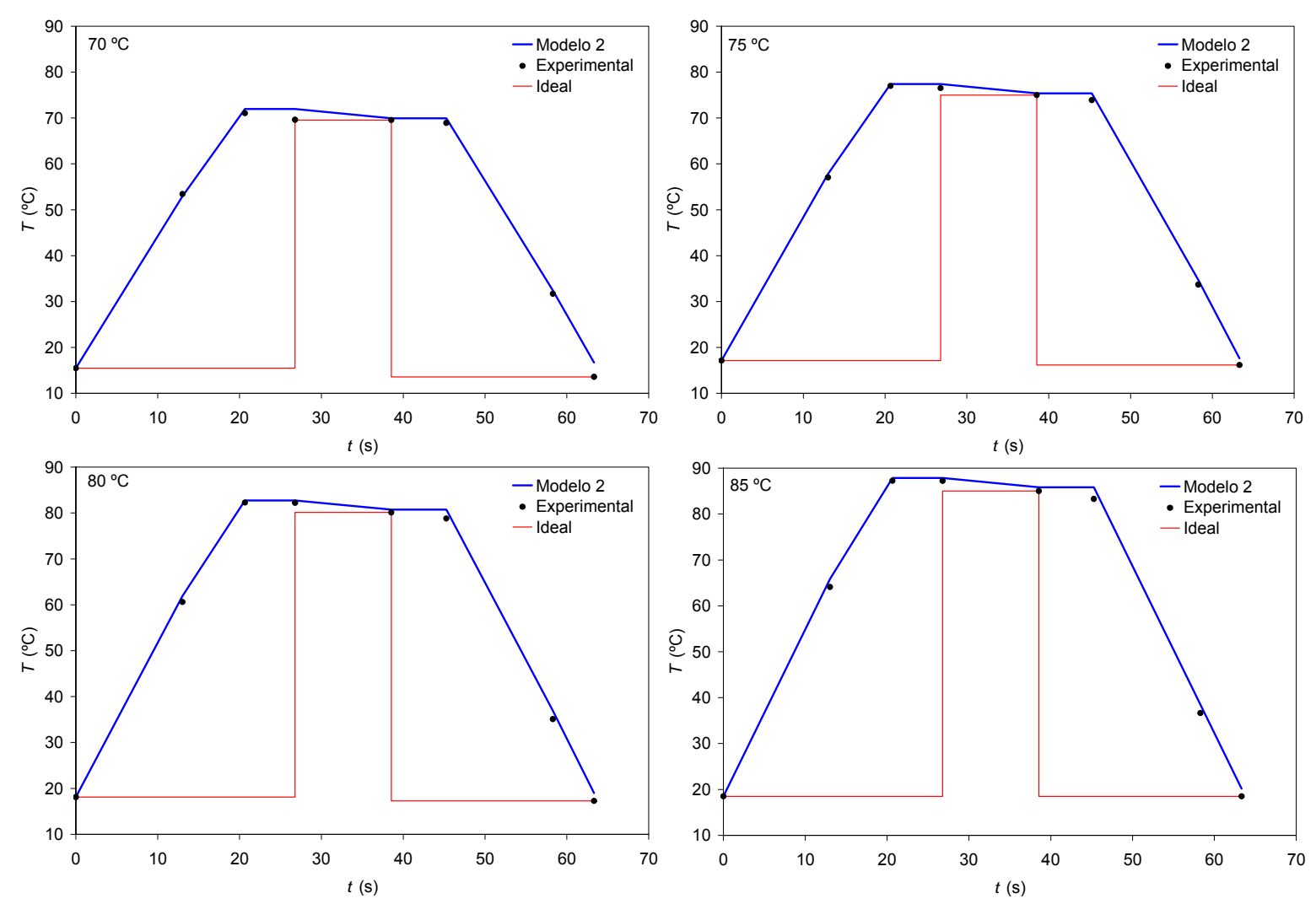

Figura 6.4.3. Históricos de temperatura experimentais e obtidos a partir do Modelo 2 para o primeiro conjunto de ensaios de pasteurização do indicador ALP em diferentes temperaturas de processo, incluindo o caso ideal de tubo isotérmico com aquecimento e resfriamento instantâneos. 
Tabela 6.4.2. Atividade enzimática residual do indicador ALP predita para o primeiro conjunto de ensaios em diferentes temperaturas de processamento, incluindo o valor experimental.

\begin{tabular}{lcccc}
\hline \multirow{2}{*}{ AER } & \multicolumn{4}{c}{ Condição } \\
\cline { 2 - 5 } & $70{ }^{\circ} \mathrm{C}$ & $75{ }^{\circ} \mathrm{C}$ & $80{ }^{\circ} \mathrm{C}$ & $85{ }^{\circ} \mathrm{C}$ \\
\hline Experimental & $0,82 \pm 0,12$ & $0,48 \pm 0,08$ & $0,32 \pm 0,05$ & $0,03 \pm 0,04$ \\
\hline Modelo 2 & 0,57 & 0,48 & 0,21 & 0,00 \\
Desvio & 0,25 & 0,00 & 0,11 & 0,03 \\
& $31 \%$ & $0 \%$ & $33 \%$ & $85 \%$ \\
\hline Histórico experimental & 0,60 & 0,50 & 0,25 & 0,01 \\
Desvio & 0,22 & 0,02 & 0,06 & 0,02 \\
& $27 \%$ & $4 \%$ & $19 \%$ & $54 \%$ \\
\hline Ideal & 0,72 & 0,55 & 0,45 & 0,18 \\
\hline
\end{tabular}
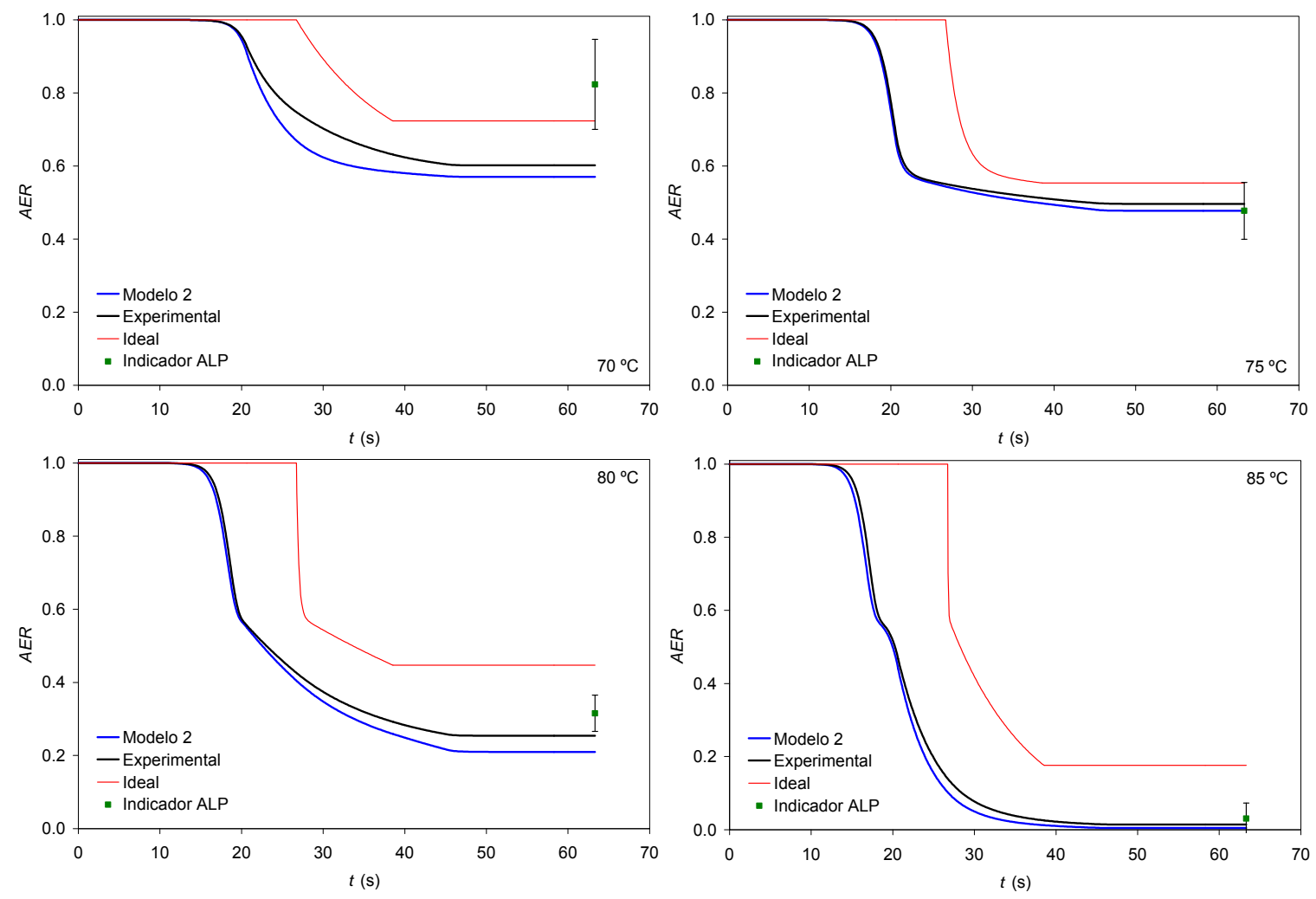

Figura 6.4.4. Evolução da atividade enzimática residual do indicador ALP predita para o primeiro conjunto de ensaios de pasteurização em diferentes temperaturas de processamento, incluindo o valor experimental determinado na saída do processo. 

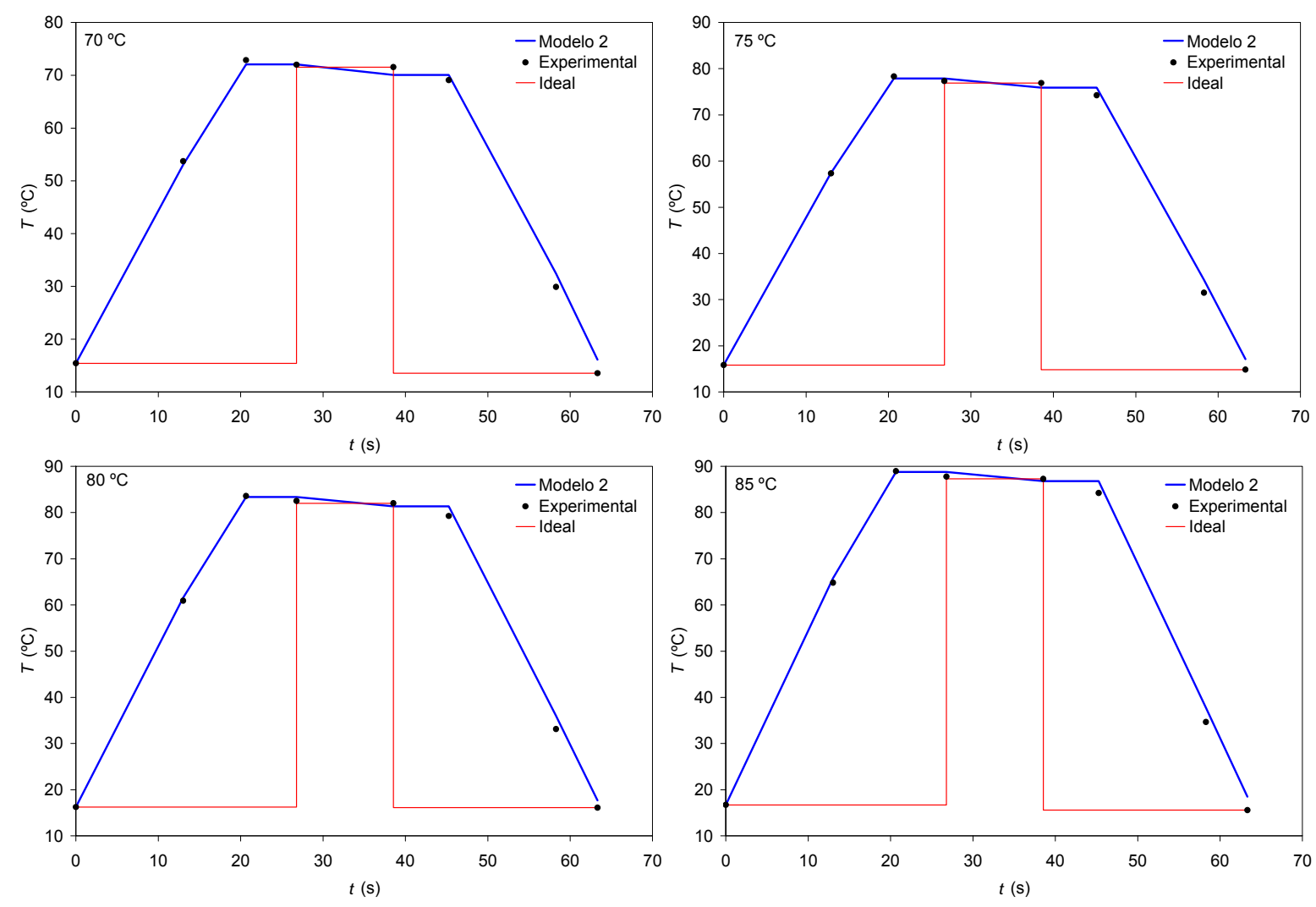

Figura 6.4.5. Históricos de temperatura experimentais e obtidos a partir do Modelo 2 para o segundo conjunto de ensaios de pasteurização do indicador ALP em diferentes temperaturas de processo, incluindo o caso ideal de tubo isotérmico com aquecimento e resfriamento instantâneos.

Tabela 6.4.3. Atividade enzimática residual do indicador ALP predita para o segundo conjunto de ensaios em diferentes temperaturas de processamento, incluindo o valor experimental.

\begin{tabular}{lcccc}
\hline \multirow{2}{*}{ AER } & \multicolumn{4}{c}{ Condição } \\
\cline { 2 - 5 } & $70{ }^{\circ} \mathrm{C}$ & $75^{\circ} \mathrm{C}$ & $80{ }^{\circ} \mathrm{C}$ & $85^{\circ} \mathrm{C}$ \\
\hline Experimental & $0,66 \pm 0,08$ & $0,48 \pm 0,03$ & $0,24 \pm 0,03$ & $0,08 \pm 0,04$ \\
\hline Modelo 2 & 0,57 & 0,46 & 0,17 & 0,00 \\
Desvio & 0,09 & 0,02 & 0,07 & 0,08 \\
& $14 \%$ & $4 \%$ & $29 \%$ & $99 \%$ \\
\hline Histórico experimental & 0,56 & 0,46 & 0,19 & 0,00 \\
Desvio & 0,10 & 0,02 & 0,05 & 0,08 \\
& $15 \%$ & $5 \%$ & $21 \%$ & $97 \%$ \\
\hline Ideal & 0,62 & 0,53 & 0,36 & 0,05 \\
\hline
\end{tabular}



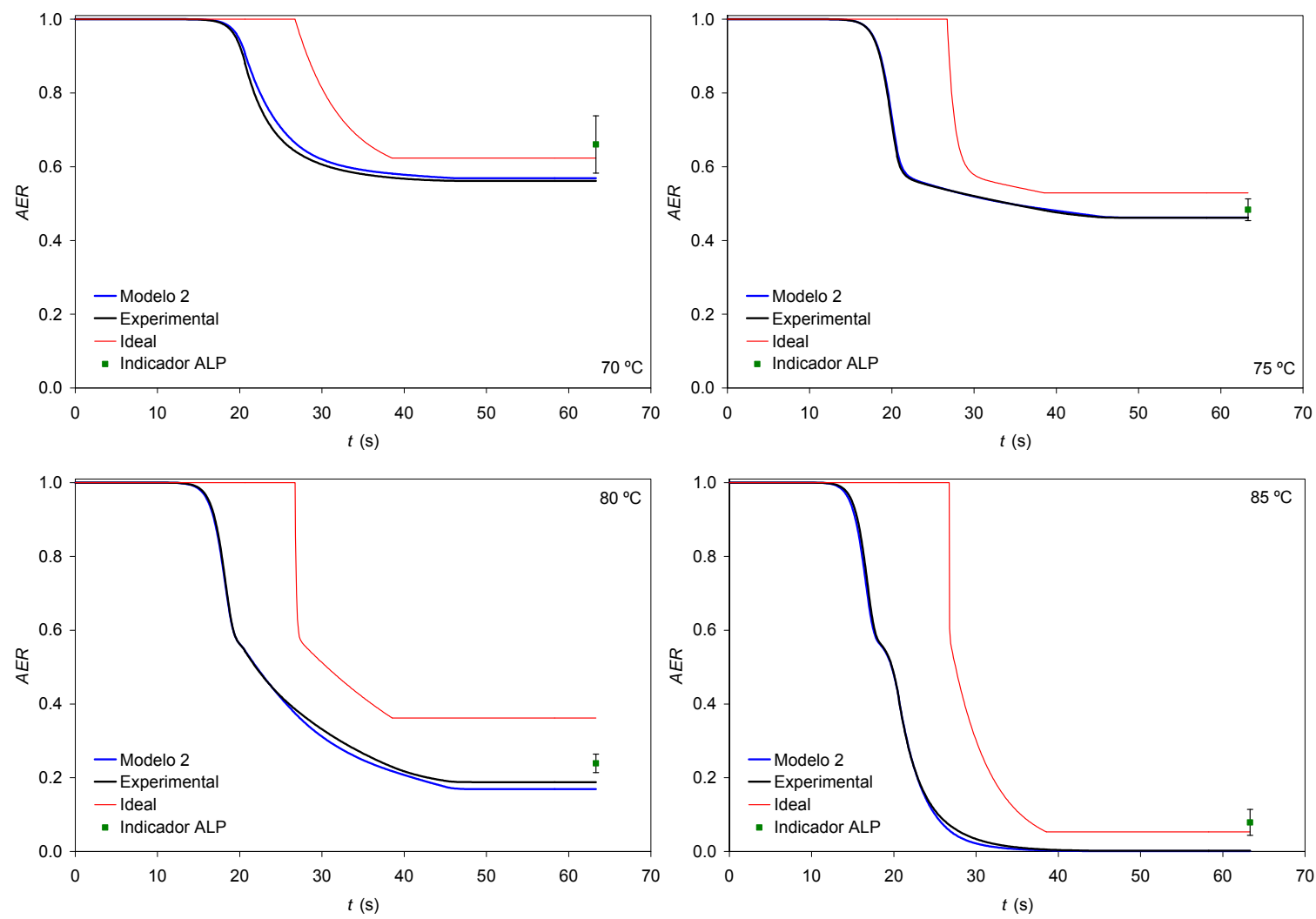

Figura 6.4.6. Evolução da atividade enzimática residual do indicador ALP predita para o segundo conjunto de ensaios de pasteurização em diferentes temperaturas de processamento, incluindo o valor experimental determinado na saída do processo.

Novamente o modelo matemático do processo reproduziu bem a distribuição de temperatura ao longo do processo (Figuras 6.4.3 e 6.4.5). As predições de atividade residual do indicador ALP ficaram muito próximas do valor determinado experimentalmente para a condição de $75^{\circ} \mathrm{C}$. Nas outras temperaturas, a atividade residual ficou ligeiramente acima do valor predito. Levando em conta os erros experimentais envolvidos no ajuste do modelo cinético (Figura 6.1.1), pode-se considerar como satisfatório o desempenho do indicador ALP na avaliação da letalidade do processo.

Assim como nos testes de validação do indicador ALP (Seção 6.1.2), para valores medidos de atividade residual abaixo de 0,2 , o modelo cinético prevê atividade residual quase nula, indicando um maior erro do modelo ajustado para avaliar condições de processo mais severas. Para valores baixos de atividade enzimática o erro relativo de predição é elevado, devido aos valores absolutos muito baixos de $A E R$.

O modelo matemático do processo, assumindo escoamento pistonado com variação linear de temperatura ao longo do tempo médio de residência teve um bom desempenho na predição da letalidade ao longo do processo, considerando o indicador enzimático adotado, como pode-se ver na Figuras 6.4.4 e 6.4.6. 


\section{CONCLUSÕES}

O modelo matemático proposto neste trabalho é capaz de fornecer a distribuição de temperatura média do produto alimentício ao longo de um processo contínuo de pasteurização com trocadores de calor a placas. Combinado aos tempos médios de residência de cada etapa do processo foi possível obter o histórico de temperatura, sobre o qual foi avaliada e integrada a letalidade associada a algum atributo de segurança ou qualidade (Figura 4.4.2). Para testar e validar o modelo, este foi aplicado para simular a operação de um equipamento de escala laboratorial. O modelo previu com sucesso a distribuição de temperatura nas condições nominais de operação (Figura 6.3.1) e as hipóteses de variação linear de temperatura e de uso da eficiência térmica de arranjo contracorrente tiveram pouca influência nos resultados deste estudo de caso.

A avaliação da distribuição do tempo de residência (DTR) no equipamento foi feita de forma abrangente, explorando diferentes vazões e configurações do trocador de calor. Foi possível ajustar um modelo de DTR para representar os dois tubos de retenção e o trocador de calor a placas com arranjo de passes em série ou em paralelo com número variável de canais. Os resultados foram muito úteis para diagnosticar o escoamento ao longo do processo e para fornecer os valores dos tempos mínimos e médios de residência em cada etapa (Tabelas 6.2.4 e 6.2.5).

Para avaliar a previsão de efeito letal fornecida pelo modelo, foram desenvolvidos e testados três indicadores enzimáticos para atuarem como integradores tempo-temperatura (TTI), dos quais apenas o indicador ALP (enzima fosfatase alcalina em tampão fosfato) se apresentou adequado para o uso. Suas vantagens são o reduzido custo específico, a facilidade de medição da atividade enzimática e parâmetros cinéticos adequados para avaliar processos de pasteurização HTST (Tabela 6.1.1).

O modelo cinético ajustado foi atrelado ao histórico de temperatura predito pelo modelo térmico do processo (com os tempos médios de residência) para simular a inativação do indicador ALP no processo de pasteurização. Ensaios de processamento térmico do indicador foram realizados em quatro condições de temperatura e o valor final de atividade residual medido foi comparado com o resultado de simulação. Para a temperatura de $75{ }^{\circ} \mathrm{C}$ o desvio foi pequeno, enquanto que para as condições de 70,80 e $85^{\circ} \mathrm{C}$, o resultado de simulação para a atividade residual ficou ligeiramente abaixo do medido. As diferenças estão associadas principalmente ao erro experimental na determinação da atividade, ao erro no ajuste do 
modelo cinético e à hipótese de escoamento pistonado no tempo médio de residência, já que existem uma clara distribuição no tempo de residência do processo.

As principais contribuições deste trabalho são: o modelo matemático desenvolvido, que pode ser aplicado para a avaliação ou o dimensionamento de processos térmicos (Gut e Pinto, 2009); o indicador enzimático ALP que pode ser usado como TTI para avaliar processos de pasteurização HTST de alimentos líquidos de baixa viscosidade (Aguiar et al., 2012); a metodologia para correção dos dados de DTR eliminando a distorção provocada pelo sistema de detecção do traçador (Gutierrez et al., 2010); e a metodologia para estudo da DTR nas etapas de um processo de pasteurização com trocador a placas (Gutierrez et al., 2011).

Como continuação deste trabalho, sugere-se o estudo da DTR em condições nãoisotérmicas de operação para avaliar o efeito da temperatura sobe a dispersão. Os resultados obtidos indicam que o esforço de caracterização da DTR e da distribuição de temperatura deve se concentrar no tubo de retenção e nas conexões deste tubo. A eliminação da hipótese de escoamento pistonado nestes trechos melhoraria muito a qualidade do modelo. A modelagem do escoamento e da troca térmica no tubo de retenção também seria de grande valia, em vez de assumir apenas uma queda linear de temperatura conhecida. A discretização do espaço de escoamento permitiria acoplar as distribuições de tempo de residência e de temperatura ao longo do tubo.

A análise paramétrica do modelo proposto pode evidenciar problemas de otimização a serem explorados, especialmente em estudos de caso em que atributos de segurança e de qualidade avaliados simultaneamente. Outra possibilidade de continuação seria o desenvolvimento do modelo dinâmico do processo, incluindo a cinética de formação de incrustação e as estratégias de controle. Com relação à exploração experimental, podem ser abordados fluidos mais complexos, como líquidos com viscosidade superior à da água ou com comportamento pseudoplástico, ou ainda alimentos reais. Para o estudo dinâmico, pode-se utilizar um alimento que forme incrustação, como o leite ou o soro de leite. 


\section{REFERÊNCIAS BIBLIOGRÁFICAS}

AGUIAR, H.F. Modelagem matemática e validação experimental da pasteurização de leite pela avaliação do histórico de temperatura e letalidade em trocador a placas. Dissertação (Mestrado). Orientador: Jorge Andrey Wilhelms Gut. Escola Politécnica da Universidade de São Paulo, 2009.

AGUIAR, H.F.; YAMASHITA, A.S.; GUT, J.A.W. Development of enzymic timetemperature integrators with rapid detection for evaluation of continuous HTST pasteurization processes. Lebensmittel-Wissenschaft + Technologie / Food Science + Technology, 47(1), 110-116, 2012.

ALFA LAVAL. Warminster. Processes: Milk and Cream Pasteurization. Disponível em: $<$ http://www.us.thermal.alfalaval.com>. Acesso em: 19 de dez. 2002.

ÁVILA, I.M.L.B.; SILVA, C.L.M. Methodologies to optimize thermal processing conditions: an overview. In: OLIVEIRA, F.A.R.; OLIVEIRA, J.C. (Eds.) Processing Foods: Quality Optimization and Process Assessment. Boca Raton: CRC Press, 1999.

AWUAH, G.B.; RAMASWAMY, H.S.; ECONOMIDES, A. Thermal processing and quality: Principles and overview. Chemical Engineering and Processing, 46, 584-602, 2007.

BANSAL, B.; MÜLLER-STEINHAGEN, H.; CHEN, X.D. Comparison of crystallization fouling in plate and double-pipe heat exchangers. Heat Transfer Engineering, 22, 13-25, 2001.

BENNETT, H.A.E. Aspects of Fouling in dairy processing. PhD. Thesis - Food Engineening. Massey University, New Zeland, 2007.

BENNETT, C.O.; MYERS, J.E. Momentum, Heat and Mass Transfer, 3rd ed., McGrawHill, London, 1982.

CAREZZATO, A.; ALCANTARA, M.R.; TELIS-ROMERO, J.; TADINI, C.C.; GUT, J.A.W. Non-Newtonian heat transfer on a plate heat exchanger with generalized configurations. Chemical Engineering and Technology, 30(1), 21-26, 2007.

CERF, O.; CONDRON, R. For debate: Coxiella burnetti and milk pasteurization: an early application of the precautionary principle? Epidemiology \& Infection, 134, 946-951. 2006.

CHEN, C.S.; WU, M.C. Critical Review: Kinetic models for thermal inactivation of multiple pectinesterases in citrus juices. Journal of Food Science, 63(5), 1-4, 1998.

CHENG, H.; FRIIS, A. Operability and flexibility of a milk production line. Food and Bioproducts Processing, 85(C4), 372-380, 2007.

CLAEYS, W.L.; VAN LOEY, A.M.; HENDRICKX, M.E. Intrinsic time temperature integrators for heat treatment of milk. Trends In Food Science \& Technology 13 (9-10), 293-311, 2002. 
DE JONG, P. Impact and control of fouling in milk processing. Trends in Food Science \& Technology, 8, 401-405, 1997.

DITCHFIELD, C.; TADINI, C.C.; SINGH, R.K.; TOLEDO, R.T. Residence time distribution, heat transfer coefficients, velocity and temperature profiles of banana puree in a tubular heat exchanger. In: International Congress on Engineering and Food iCEF 9, Montpellier. Proceedings of iCEF 9, 2004.

DITCHFIELD, C.; TADINI, C.C.; SINGH, R.K.; TOLEDO, R.T. Velocity and temperature profiles, heat transfer coefficients and residence time distribution of a temperature dependent Herschel-Bulkley fluid in a tubular heat exchanger, Journal of Food Engineering, 76(4), 632-638, 2006.

EFIGÊNIA, M.; POVOA, B.; MORAES-SANTOS, T. Effect of heat treatment on the nutricional quality of milk proteins. International Dairy Journal, 7, 609-6012, 1997.

ELLBORG, A., \& TRÄGÅRDH, Ch. A method for measuring thermal time distributions in continuous flow heat exchangers. Journal of Food Process Engineering, 17(3), 279-298, 1994.

FADILOGLU, S.; ERKMEN, O.; SEKEROGLU, G. Thermal Inactivation kinetics of alkaline phosphatase in buffer and milk. Journal of Food Processing and Preservation 30, 258 268, 2006.

FERNANDES, C.S.; DIAS, R.P.; NÓBREGA, J.M.; AFONSO, I.M.; MELO, L.F.; MAIA, J.M.. Simulation of stirred yoghurt processing in plate heat exchangers. Journal of Food Engineering, 69, 281-290, 2005.

FERNANDES, C.S.; DIAS, R.P.; NÓBREGA, J.M.; AFONSO, I.M.; MELO, L.F.; MAIA, J.M. Thermal behaviour of stirred yoghurt during cooling in plate heat exchangers. Journal of Food Engineering, 76(3), 433-439, 2006.

FILLAUDEAU, L.; LE-NGUYEN, K.; ANDRÉ, C. Influence of low regime and thermal power on residence time distribution in tubular Joule effect heaters. Journal of Food Engineering, 95, 489-498, 2009.

FUJIKAWA, H.; ITOH, T. Characteristics of a multicomponent first-order model for thermal inactivation of microorganisms and enzymes. International Journal of Food Microbiology, 31, 263-271, 1996.

GALEAZZO, F.C.C. ; MIURA, R.Y. ; GUT, J.A.W. ; TADINI, C.C. Experimental and numerical heat transfer in a plate heat exchanger. Chemical Engineering Science, 61(21), 7133-7138, 2006.

GARCIA-SERNA, J.; GARCIA-VERDUGO, E.; HYDE, J.R.; FRAGA-DUBREUIL, J.; YAN, C.; POLIAKOFF, M.; COCERO, M.J. Modelling residence time distribution in chemical reactors: A novel generalised n-laminar model - Application to supercritical CO2 and subcritical water tubular reactors. Journal of Supercritical Fluids, 41(1), 82-91, 2007.

GENTRY, T.S.; ROBERTS, J.S. Formation kinetics and application of 5hydroxymethylfurfural as a time-temperature indicator of lethality for continuous 
pasteurization of apple cider. Innovative Food Science \& Emerging Technologies, 5(3), 327-333, 2004.

GEORGIADIS, M. C.; MACCHIETTO. S. Dynamic modelling and simulation of plate heat exchangers under milk fouling. Chemical Engineering Science, 55, 1605-1619, 2000.

GEORGIADIS, M.C.; ROTSTEIN, G.E.; MACCHIETTO S. Modelling and simulation of complex plate heat exchanger arrangements under milk fouling, Computers \& Chemical Engineering, 22(S), S331-S338, 1998.

GOULD, G.W. Methods for preservation and extension of shelf life. International Journal of Food Microbiology, 33(1), 51-64, 1996.

GOUVÊA, M.T.; PARK, S.W.; GIUDICI, R. Estimação de coeficientes de dispersão axial em leitos fixos. In: Anais do XVIII Encontro sobre Escoamento em Meios Porosos, Nova Friburgo, October 23th-25th, 1990.

GRANDGEORGE, S.; JALLUT, C.; THONON, B. Particulate Fouling of Corrugated Plate Heat Exchangers: Global Kinetic and Equilibrium Studies. Chemical Engineering Science, 53(17), 3051-3071, 1998.

GRIJSPEERDT, K.; HAZARIKA, B.; VUCINIC, D. Application of computational fluid dynamics to model the hydrodynamics of plate heat exchangers for milk processing. Journal of Food Engineering, 57, 237-242, 2003.

GRIJSPEERDT, K.; MORTIER, L.; DE BLOCK, J.; VAN RENTERGHEM, R. Applications of modelling to optimise ultra high temperature milk heat exchangers with respect to fouling. Food Control, 15, 117-130, 2004.

GUIAVARC'H, Y.P.; DELI, V.; VAN LOEY, A.M.; HENDRICKX, M.E. Development of an enzymic time temperature integrator for sterilization processes based on Bacillus licheniformis $\alpha$-amylase at reduced water content. Journal of Food Science, 67(1), 285291, 2002a.

GUIAVARC'H, Y.P.; DINTWA, E.; VAN LOEY, A.M.; ZUBER, F.T.; HENDRICKX, M.E. Validation and use of an enzymic time-temperature integrator to monitor thermal impacts inside a solid/liquid model food. Biotechnology Progress, 18(5), 1087-1094, 2002b.

GUT, J.A.W.; PINTO, J.M. Modeling of Plate Heat Exchangers with Generalized Configurations. International Journal of Heat and Mass Transfer, 46(14), 2571-2585, $2003 \mathrm{a}$.

GUT, J.A.W.; PINTO, J.M. Selecting Optimal Configurations for Multisection Plate Heat Exchangers in Pasteurization Processes. Industrial \& Engineering Chemical Research, 42(24), 6112-6124, 2003b.

GUT, J.A.W.; PINTO, J.M. Optimal design of continuous thermal processing with plate heat exchangers. In: ERDOGDU, F. (Ed.). Optimization in Food Engineering. Boca Raton: CRC Press, 597-631, 2009. 
GUT, J.A.W.; FERNANDES, R.; PINTO, J.M.; TADINI, C.C. Thermal Model Validation of Plate Heat Exchangers with Generalized Configurations. Chemical Engineering Science, 59, 4589-4598, 2004.

GUT, J.A.W.; PINTO, J.M.; GABAS, A.L.; TELIS-ROMERO, J. Continuous pasteurization of egg yolk: thermophysical properties and process simulation. Journal of Food Process Engineering, 28(2), 181-203, 2005.

GUTIERREZ, C.G.C.C. Distribuição do tempo de residência em processo de pasteurização com trocador de calor a placas. Dissertação (Mestrado). Orientador: Jorge Andrey Wilhelms Gut. Escola Politécnica da Universidade de São Paulo, 2008.

GUTIERREZ, C.G.C.C.; DIAS, E.F.T.S.; GUT, J.A.W. Investigation of the residence time distribution in a plate heat exchanger with series and parallel arrangements using a nonideal tracer detection technique. Applied Thermal Engineering, 31(10), 1725-1733, 2011.

GUTIERREZ, C.G.C.C.; DIAS, E.F.T.S.; GUT, J.A.W. Residence time distribution in holding tubes using generalized convection model and numerical convolution for non-ideal tracer detection. Journal of Food Engineering, 98(2), 248-256, 2010.

HEIBEL, A.K.; LEBENS, P.J.M.; MIDDELHOFF, J.W.; KAPTEIJN, F.; MOULIJN, J. Liquid residence time distribution in the film flow monolith reactor. AIChE Journal, 51(1), 122-133, 2005.

HENDRICKX, M.; MAESMANS, G.; DE CORDT, S.; NORONHA, J.; VAN LOEY, A.; TOBBACK, P. Evaluation of the integrated time-temperature effect in thermal processing of foods. Critical Reviews in Food Science and Nutrition, 35(3), 231-262, 1995.

HENDRICKX, M.; WENG, Z.; MAESMANS, G.; TOBBACK, P. Validation of a timetemperature-integrator for thermal processing of food under pasteurization conditions. International Journal of Food Science \& Technology, 27(1), 21-31, 1992.

HEWITT, G.F.; SHIRES, G.L.; BOTT. T.R. Process Heat Transfer. Boca Raton: CRC Press, 1994.

IBARROLA, J.J.; GUILLÉN, J.C.; SANDOVAL, J.M.; GARCÍA-SANZ, M. Modelling of a high temperature short time pasteurization process. Food Control, 9(5), 267-277, 1998.

IBARROLA, J.J.; SANDOVAL, J.M.; GARCÍA-SANZ, M.; PINZOLAS M. Predictive control of a high temperature-short time pasteurization process. Control Engineering Practice, 10(7), 713-725, 2002.

IBARZ, A.; BARBOSA-CÁNOVAS, G.V. Unit Operations in Food Engineering. Boca Raton: CRC Press, 2003.

JACKSON, B.W.; TROUPE, R.A. Plate heat exchnager design by $\varepsilon-N T U$ method. Chemical Engineering Progress Symposium Series, 62(64), 185-190, 1966.

JORDÁN, M.J.; GOODNER, K.L.; LAENCINA, J. Deaeration and pasteurization effects on the orange juice aromatic fraction. Lebensmittel-Wissenschaft und-Technologie, 36(4), 391-396, 2003. 
JUNG, A.; FRYER, P.J. Optimising the quality of safe food: Computational modelling of a continuous sterilisation process. Chemical Engineering Science, 54(6), 717-730, 1999.

KHADIR, M.T.; RINGWOOD, J.V. Linear and nonlinear model predictive control design for a milk pasteurization plant. Control and Intelligent Systems, 31(1), 2003.

KAKAÇ, S.; LIU, H. Heat Exchangers: Selection, Rating and Thermal Design, 2nd ed. Boca Raton: CRC Press, 2002.

KANDLIKAR, S.G.; SHAH, R.K. Asymptotic effectiveness-NTU formulas for multipass plate heat exchangers. Journal of Heat Transfer, 111, 314-321, 1989.

KECHICHIAN, V.; CRIVELLARI, G.P.; GUT, J.A.W.; TADINI, C.C. Modeling of continuous thermal processing of a non-newtonian liquid food under diffusive laminar flow in a tubular system. International Journal of Heat and Mass Transfer, no prelo, 2012.

KHO, T.; MÜLLER-STEINHAGEN, H. An experimental and numerical investigation of heat transfer fouling and fluid flow in flat plate heat exchangers. Chemical Engineering Research and Design, 77A, 124-130, 1999.

LANDFELD, A.; ZITNÝ, R.; HOUSKA, M.; KÝHOS, K.; NOVOTNÁ, P. Residence time distribution during egg yolk pasteurization, Czech Journal of Food Sciences, 20(5), 193 201, 2002.

LEE, H.S.; COATES, G.A. Effect of thermal pasteurization on valencia orange juice color and pigments. Lebensmittel-Wissenschaft und-Technologie, 36(1), 153-156, 2003.

LEVENSPIEL, O. The Chemical Reactor Omnibook, OSU, Corvallis, 1989.

LEVENSPIEL, O. Chemical Reaction Engineering, 3rd ed. John Wiley \& Sons, New York, 1999.

LEVENSPIEL, O.; BISCHOFF, K.B. Patterns of flow in chemical process vessels. In DREW, T.B.; HOOPES, J.W.; VERMEULEN, T. (Eds.). Advances in Chemical Engineering, vol.4. Academic Press, New York, 1963.

LEVIEN K.L.; LEVENSPIEL O. Optimal product distribution from laminar flow reactors: Newtonian and other power-law fluids. Chemical Engineering Science, 54(13-14), 24532458, 1999.

LEWIS, M.J. Heat treatment of milk. In: ROBINSON, R.K. (Ed.) Modern Dairy Technology, v.1. Gaithersburg: Aspen Publishers, 1999.

LEWIS, M.; HEPPELL, N. Continuous Thermal Processing of Foods: Pasteurization and UHT Sterilization. Gaithersburg: Aspen Publishers, 2000.

MABIT, J.; BELHAMRI, R.; FAYOLLE, F.; LEGRAND, J. Development of a time temperature integrator for quantification of thermal treatment in scraped surface heat exchangers, Innovative Food Science \& Emerging Technologies, 9(4), 516-526, 2008. 
MACHADO, M. F. ; SARAIVA, J. Inactivation and reactivation kinetics of horseradish peroxidase in phosphate buffer and buffer-dimethylformamide solutions. Journal of molecular catalysis. B-Enzymatic, 19(SI), 451-457, 2002.

MARRIOTT, J. Where and how to use plate heat exchangers. Chemical Engineering, 5(4), 127-134, 1971.

MARTIN, A.D. Interpretation of residence time distribution data. Chemical Engineering Science, 55(23), 5907-5917, 2000.

MARTIN, D.; LINXWEILER, W.; TANZER, D.; VORMBROCK, R.; OLT, R.; KIESNER, CHR.; MEISEL, H. Use of Reflectoquant ${ }^{\circledR}$ rapid tests for determination of thermal inactivation of the indigenous milk enzymes lipase, alkaline phosphatase and lactoperoxidase. Deutsche Lebensmittel-Rundschau, 101(7), 281-286, 2005.

MERCK. Reflectoquant: Alkalische Phosphatase-Test in Milch. (1.16123.0001). Darmstadt: Merck KGaA, 2005.

MERCK. Reflectoquant: Peroxidase-Test in Milch. (1.16121.0001). Darmstadt: Merck KGaA, 2008.

MILES, J. J., \& SWARTZEL, K. R. Evaluation of continuous thermal processes using thermocouple data and calibrating reactions. Journal of Food Process Engineering, 18(1), 99-113, 1995a.

MILES, J.J.; SWARTZEL, K.R. Development of sucrose inversion kinetics under continuous flow conditions. Journal of Food Quality, 18(5), 369-378, 1995 b.

MIURA, R.Y. Estudo da troca térmica em um trocador de calor a placas com configurações generalizadas. Relatório de iniciação científica FAPESP. Orientador: Jorge Andrey Wilhelms Gut, 2006.

MIURA, R.Y.; GALEAZZO, F.C.C.; TADINI, C.C.; GUT, J.A.W. The effect of flow arrangement on the pressure drop of plate heat exchangers. Chemical Engineering Science, 63, 5386-5393, 2008.

MURASAKI-ALIBERTI, N.C.; SILVA, R.M.S.; GUT, J.A.W.; TADINI, C.C. Thermal inactivation of polyphenoloxidase and peroxidase in green coconut (Cocos nucifera) water. International Journal of Food Science \& Technology, 44, 2662-2668, 2009.

NARATARUKSA, P.; TRIRATANA, P.; PANA-SUPPAMASSADU, K.; HEGGS, P.J.; TIA, $S$. Dynamic simulation of plate and frame heat exchanger undergoing food fouling: coconut milk fouling case study. ScienceAsia, 34(2), 229-237, 2008.

NAUMAN, E.B. The residence time distribution for laminar-flow in helically coiled tubes. Chemical Engineering Science, 32(3), 287-293, 1977.

NAUMAN, E.B. Flow patterns and residence time distributions. In: BISIO, A.; KABEL, R.L. (Eds.) Scaleup of Chemical Processes, John Wiley \& Sons, New York, 1985. 
NEGIZ, A.; ÇINAR, A.; SCHLESSER, J.E.; RAMANAUSKAS, P.; ARMSTRONG, D.J.; STROUP, W. Automated control of high temperature short time pasteurization. Food Control, 7(6), 309-315, 1996.

NEGIZ, A.; RAMANAUSKAS, P.; ÇINAR, A.; SCHLESSER, J.E.; ARMSTRONG, D.J. Modeling, monitoring and control strategies for high temperature short time pasteurization systems - 1. Empirical model development. Food Control, 9(1), 1-15, 1998a.

NEGIZ, A.; RAMANAUSKAS, P.; ÇINAR, A.; SCHLESSER, J.E.; ARMSTRONG, D.J. Modeling, monitoring and control strategies for high temperature short time pasteurization systems - 2. Lethality-based control. Food Control, 9(1), 17-28, 1998 b.

NEGIZ, A.; RAMANAUSKAS, P.; ÇINAR, A.; SCHLESSER, J.E.; ARMSTRONG, D.J. Modeling, monitoring and control strategies for high temperature short time pasteurization systems - 3. Statistical monitoring of product lethality and process sensor reliability. Food Control, 9(1), 29-47, 1998c.

NOTT, K.P.; HALL, L.D. Advances in temperature validation of foods. Trends in Food Science \& Technology, 10(11), 366-374, 1999.

OLSZEWSKI, E.; REUTER, H. The inactivation and reactivation behavior of lactoperoxidase in milk at temperatures between 50 and $135{ }^{\circ} \mathrm{C}$. Zeitschrift für LebensmittelUntersuchung und-Forschung, 194(3), 235-239, 1992.

PÁTKAI, Gy.; BARTA, J.; VARSÁNYI, I. Decomposition of anticarcinogen factors of the beetroot during juice and nectar production. Cancer Letters, 114(1-2), 105-106, 1997.

PERRY, R.H.; GREEN, D.W.; MALONEY, J.O. Perry's Chemical Engineers' Handbook, 7th ed., McGraw-Hill, New York, 1997.

PIGNOTTI, A.; TAMBORENEA, P.I. Thermal effectiveness of multipass plate exchangers. International Journal of Heat and Mass Transfer, 31(10), 1983-1991, 1988.

POLAKOVIČ, M.; VRÁBEL, P. Analysis of the mechanism and kinetics of thermal inactivation of enzymes: Critical assessment of isothermal inactivation experiments. Process Biochemistry, 31(8), 787-800, 1996.

RAJU, K.S.N.; BANSAL, J.C. Design of plate heat exchangers. In: KAKAÇ, S.; SHAH, R.K.; BERGLES, A.E. Low Reynolds Number Flow Heat Exchangers. New York: Hemisphere, 1983.

RAO, M.A.; LONCIN, M. Residence time distribution and its role in continuous pasteurization (Part I). Lebensmittel-Wissenschaft and Technologie 7, 5-13, 1974a.

RAO, M.A.; LONCIN, M. Residence time distribution and its role in continuous pasteurization (Part II). Lebensmittel-Wissenschaft and Technologie 7, 14-17, 1974b.

ROETZEL, W.; BALZEREIT, F. Determination of axial dispersion coefficients in plate heat exchangers using residence time measurements. Revue Generale de Thermique, 36(8), 635-644, 1997. 
RUTHVEN, D.M. The residence time distribution for ideal laminar flow in a helical tube. Chemical Engineering Science, 26, 1113-1121, 1971.

SARAIVA, J.; OLIVEIRA, J.C.; LEMOS, A.; HENDRICKX, M. Analysis of the kinetic patterns of horseradish peroxidase thermal inactivation in sodium phosphate buffer solutions of different ionic strength. International Journal of Food Science and Technology, 31(3), 223-231, 1996.

SCHWIER, K. Properties of liquid water. In: HEWITT G.F. (Ed.) Handbook of Heat Exchanger Design. Begell House, New York, s.5.5.3, 1992.

SHAH, R.K.; FOCKE, W.W. Plate heat exchangers and their design theory. In SHAH, R.K.; SUBBARAO, E.C.; MASHELKAR, R.A. Heat Transfer Equipment Design. New York: Hemisphere, 1988.

SHAH, R.K.; SEKULIC, D. P. Heat exchangers. In ROHSENOW, W.M.; HARTNETT, J.P.; CHO, Y.I. Handbook of Heat Transfer, 3rd ed. New York: McGraw-Hill, 1998.

SHARMA, S.K.; SEHGAL, N.; KUMAR A. Dry-reagent strips for testing milk pasteurization. LWT - Food Science and Technology, 36(6), 567-571, 2003.

SKOGLUND, T.; DEJMEK, P. A dynamic object-oriented model for efficient simulation of microbial reduction in dispersed turbulent flow. Journal of Food Engineering, 86(3), 358-369, 2008.

STRELOW, O. A general calculation method for plate heat exchangers. International Journal of Thermal Sciences, 39(6), 645-658, 2000.

SUNG, N.; COLLINS, M.T. Thermal tolerance of Mycobacterium paratuberculosis. Applied and Environmental Microbiology, 64(3), 999-1005, 1998.

TOLEDO, R.T. Fundamentals of Food Process Engineering. 3.ed. New York: Springer, 2007.

TOMASULA, P.M.; KOZEMPEL, M.F. Flow characteristics of a pilot-scale high temperature, short time pasteurizer. Journal of Dairy Science, 87(9), 2761-2768, 2004.

TORRES, A.P.; OLIVEIRA, F.A.R. Application of the acid hydrolysis of sucrose as a temperature indicator in continuous thermal processes. Journal of Food Engineering, 40(3), 181-188, 1999.

TORRES, A.P.; OLIVEIRA, F.A.R., Residence Time distribution studies in continuous thermal processing of liquid foods: a Review. Journal of Food Engineering, 36(1), 1-30, 1998a.

TORRES, A.P.; OLIVEIRA, F.A.R. Residence Time distribution of liquids in a continuous tubular thermal processing system - Part II: Relating hold tube efficiency to processing conditions. Journal of Food Engineering, 35(2), 165-175, 1998 b.

TORRES, A.P.; OLIVEIRA, F.A.R.; FORTUNA, S.P. Residence time distribution of liquids in a continuous tubular thermal processing system - Part I: Relating RTD to processing conditions. Journal of Food Engineering 35(2), 147-163, 1998. 
TRIBESS, T.B.; TADINI, C.C. Inactivation kinetics of pectin methylesterase in orange juice as a function of $\mathrm{pH}$ and temperature/time process conditions. Journal of the Science of Food and Agriculture, 86, 1328-1335, 2006.

TRIVEDI, R.N.; VASUDEVA, K. RTD for diffusion free laminar-flow in helical coils. Chemical Engineering Science, 29(12), 2291-2295, 1974.

TUCKER, G.; HANBY, E.; BROWN, H. Development and application of a new timetemperature integrator for the measurement of P-values in mild pasteurization processes. Food and Bioproducts Processing, 87, 23-33, 2009.

TUCKER, G.S.; LAMBOURNE, T.; ADAMS, J.B.; LACH, A. Application of a biochemical time-temperature integrator to estimate pasteurization values in continuous food processes. Innovative Food Science \& Emerging Technologies, 3, 165-174, 2002.

VALERO, E.; VILLAMIEL, M.; SANZ, J.; MARTÍNEZ-CASTRO, I. Chemical and sensorial changes in milk pasteurised by microwave and conventional systems during cold storage. Food Chemistry, 70(1), 77-81, 2000.

VAN BOEKEL, M.A.J.S.; JONGEN, W.M.F. Product quality and food processing: how to quantify the healthiness of a product. Cancer Letters, 114(1-2), 65-69, 1997.

VAN LOEY, A.; HENDRICKX, M.; DE CORDT, S.; HAENTJENS, T.; TOBBACK, P. Quantitative evaluation of thermal processes using time-temperature integrators. Trends in Food Science \& Technology, 7(1), 16-26, 1996.

WATSON, E.L.; MCKILLOP, A.A.; DUNKLEY, W.L.; PERRY, R.L. Plate heat exchangers: flow characteristics. Industrial and Engineering Chemistry, 52(9), 733-740, 1960.

WILIŃSKA, A.; BRYJAK, J.; ILLEOVÁ, V.; POLAKOVIČ, M. Kinetics of thermal inactivation of alkaline phosphatase in bovine and caprine milk and buffer. International Dairy Journal, 17(6), 579-586, 2007.

ZALESKI, T. A general mathematical-model of parallel-flow, multichannel heat-exchangers and analysis of its properties. Chemical Engineering Science, 39(7/8), 1251-1260, 1984.

ZALESKI, T.; KLEPACKA, K. Approximate methods of solving equations for plate heatexchangers. International Journal of Heat and Mass Transfer, 35, 1125-1130, 1992. 


\section{APÊNDICE A - Instruções para medição da atividade enzimática}

O sistema Reflectoquant ${ }^{\circledR}$ (Merck, EUA) foi adaptado para medição da atividade enzimática dos indicadores POD, LPO e ALP apresentados no Capítulo 5. As instruções do fabricante para os testes de peroxidase e fosfatase em leite (Merck, 2005, 2008) foram adaptados para este trabalho e os procedimentos são descritos na sequencia.

\section{A.1 Instruções para teste de peroxidase usando Reflectoquant}

\section{Material:}

- Reflectoquant

- Recipiente de teste

- Reagente POD-1

- Tiras analíticas

- Microcubeta

- $\operatorname{Amostra~(>1\mathrm {mL})}$
- Água destilada (> $4 \mathrm{~mL})$

- Banho a $23 \pm 1{ }^{\circ} \mathrm{C}$

- Pipeta $1 \mathrm{~mL}$

- Pipeta $4 \mathrm{~mL}$

- Bastão de vidro

- Papel absorvente

Temperatura ambiente: $20-25^{\circ} \mathrm{C}$

\section{Instruções:}

1) Preparar banho termostático para manter a microcubeta a $23^{\circ} \mathrm{C}$.

2) Adicionar ao recipiente de teste: $1,0 \mathrm{~mL}$ da amostra e 4,0 mL de água destilada. Agitar com o bastão de vidro.

3) Aguardar temperatura de $23 \pm 1{ }^{\circ} \mathrm{C}$.

4) Ligar Reflectoquant (ON/OFF), selecionar o teste (TEST) e pressionar START. O mostrador indica $180 \mathrm{~s}$.

5) Rapidamente, em seqüência: pingar 5 gotas de POD-1 no recipiente, agitar com o bastão, inclinar o recipiente, mergulhar a tira e neste instante apertar o botão START (contagem regressiva de 180 s começa). Após 2 s, retirar a tira do recipiente e agitar (6x) para remover o excesso de líquido. Deixar a tira dentro da microcubeta a $23{ }^{\circ} \mathrm{C}$. Confirmar temperatura com um sensor termopar. 
6) Quando faltar $10 \mathrm{~s}$ para o térmico do tempo de reação, inserir a tira no adaptador com a face voltada para o mostrador. Quando faltar 5 s o aparelho emite um beep e no instante 0 s faz a leitura da tira. O valor é apresentado em U/L.

\section{Notas:}

- Faixa de leitura: 5 - 200 U/L

- Fechar reagentes e tubo de tiras imediatamente após o uso.

- Ao final, remover o adaptador de tiras do Reflectoquant, lavá-lo com água destilada e secar.

- Guardar o kit em geladeira $\left(2-8^{\circ} \mathrm{C}\right)$.

\section{A.2 Instruções para teste de fosfatase alcalina usando Reflectoquant}

\section{Material:}

- Reflectoquant

- $\quad$ Amostra (> $3 \mathrm{~mL})$

- Recipiente de teste

- Banho a $37 \pm 1{ }^{\circ} \mathrm{C}$

- Microcubeta

- Pipeta $2 \mathrm{~mL}$

- Reagente ALP-1 preparado

- Bastão de vidro

- $\quad$ Reagente ALP-3

- Papel absorvente

- Tiras analíticas

Temperatura ambiente: $20-25^{\circ} \mathrm{C}$

\section{Preparação do reagente ALP-1:}

Despejar conteúdo de ALP-2 em ALP-1, encaixar o gotejador, tampar e agitar.

ALP-1 tem agora validade de 6 semanas.

\section{Instruções:}

1) Colocar 15 gotas $(0,9 \mathrm{~mL})$ de ALP-1 na microcubeta e deixar no banho a $37^{\circ} \mathrm{C}$.

2) Trazer o frasco do reagente ALP-3 a temperatura ambiente $\left(20-25^{\circ} \mathrm{C}\right)$.

3) Colocar $2,0 \mathrm{~mL}$ da amostra no recipiente, a temperatura ambiente $\left(20-25^{\circ} \mathrm{C}\right)$.

4) Adicionar 4 gotas de ALP-3 ao recipiente e agitar com o bastão de vidro.

5) Inclinar o recipiente e mergulhar a tira para molhar as zonas de reação. 
6) Após 2 s retirar a tira do recipiente, agitá-la (6x) para remover o excesso de líquido, inseri-la na microcubeta e ativar o cronômetro.

7) No instante 19,5 min, ligar o Reflectoquant (ON/OFF), selecionar o teste (TEST) e pressionar START. O mostrador indica $5 \mathrm{~s}$.

8) Exatamente no instante $20 \mathrm{~min}$, retirar a tira da microcubeta, agitá-la (6x), inseri-la no adaptador com a face voltada para o mostrador e pressionar START.

9) Após a contagem de $5 \mathrm{~s}$, ler o resultado em U/L.

\section{Notas:}

- Para medidas em série, esvaziar microcubeta e refazer o procedimento.

- Faixa de leitura: 0,8 - 12,0 U/L

- Fechar reagentes e tubo de tiras imediatamente após o uso.

- Ao final, remover o adaptador de tiras do Reflectoquant, lavá-lo com água destilada e secar.

- Guardar o kit em geladeira $\left(2-8^{\circ} \mathrm{C}\right)$. 